\title{
Actinide Removal Process Sample Analysis, Chemical Modeling, and Filtration Evaluation
}

C.J. Martino

D.T. Herman

J.A. Pike

T.B. Peters

June 2014

SRNL-STI-2013-00700, Revision 0 
SRNL-STI-2013-00700

Revision 0

\section{DISCLAIMER}

This work was prepared under an agreement with and funded by the U.S. Government. Neither the U.S. Government or its employees, nor any of its contractors, subcontractors or their employees, makes any express or implied:

1. warranty or assumes any legal liability for the accuracy, completeness, or for the use or results of such use of any information, product, or process disclosed; or

2. representation that such use or results of such use would not infringe privately owned rights; or

3. endorsement or recommendation of any specifically identified commercial product, process, or service.

Any views and opinions of authors expressed in this work do not necessarily state or reflect those of the United States Government, or its contractors, or subcontractors.

\section{Printed in the United States of America \\ Prepared for \\ U.S. Department of Energy}


Keywords: Monosodium Titanate, 512-S, Crossflow Filtration

Retention: Permanent

\title{
Actinide Removal Process Sample Analysis, Chemical Modeling, and Filtration Evaluation
}

\author{
C.J. Martino \\ D.T. Herman \\ J.A. Pike \\ T.B. Peters
}

June 2014

Prepared for the U.S. Department of Energy under contract number DE-AC09-08SR22470.

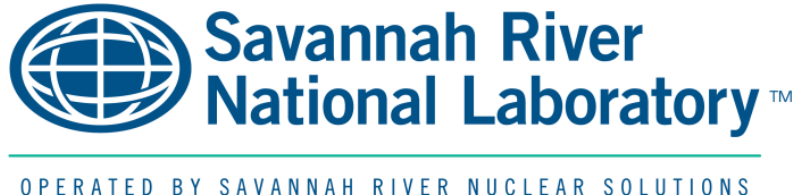




\section{REVIEWS AND APPROVALS}

\section{AUTHORS:}

\begin{tabular}{lc}
\hline C.J. Martino, Advanced Characterization and Processing & Date
\end{tabular}

D.T. Herman, Advanced Characterization and Processing Date

J.A. Pike, Process Modeling and Computational Chemistry $\quad$ Date

T.B. Peters, Advanced Characterization and Processing Date

TECHNICAL REVIEW:

S.H. Reboul, Advanced Characterization and Processing, Reviewed per E7 2.60 Date

D.J. McCabe, Advanced Characterization and Processing, Reviewed Sections 2.3 and 3.3 per E7 2.60

Date

APPROVAL:

F.M. Pennebaker, Manager

Date

Advanced Characterization and Processing

S.L. Marra, Manager

Date

Environmental \& Chemical Process Technology Research Programs

\begin{tabular}{l}
\hline E.J. Freed, Manager \\
SRR DWPF Facility Engineering
\end{tabular}

Date

D.J. Martin, Manager

Date

SRR Treatment Process Engineering

J.S. Contardi, Manager

Date

SRR Tank Farm Facility Engineering 


\section{ACKNOWLEDGEMENTS}

Suspended solids and isolated solids analyses were performed by David Missimer, Henry Ajo, Ken Imrich, and John Pareizs. Chuck Coleman provided support for sample digestions. Chemical analyses were overseen by Tom White, John Young, and Amy Ekechukwu. The authors acknowledge the assistance of Rita Sullivan, Monica Jenkins, and the rest of the staff of the SRNL Shielded Cells for sample receipt and preparation.

The authors acknowledge the helpful reviews and technical input from Michael Poirier, Mark Duignan, Charles Nash, Bill Wilmarth, and Sam Fink regarding crossflow filter performance, including operational improvements and cleaning options. The authors also thank Kathryn Taylor-Pashow and David Hobbs for helpful information on monosodium titanate and Charles Crawford and Chris Bannochie for discussion of the Precipitate Reactor Feed Tank sample results.

Stephen Smith of SRR Engineering provided much of the filtration data and recent process history, and provided valuable insights into ARP processing. Additionally, Azadeh Samadi-Dezfouli and Ryan McNew provided valuable filtration, processing, and sampling insights specific to ARP. 


\section{EXECUTIVE SUMMARY}

Filtration within the Actinide Removal Process (ARP) currently limits the throughput in interim salt processing at the Savannah River Site. In this process, batches of salt solution with Monosodium Titanate (MST) sorbent are concentrated by crossflow filtration. The filtrate is subsequently processed to remove cesium in the Modular Caustic Side Solvent Extraction Unit (MCU) followed by disposal in saltstone grout. The concentrated MST slurry is washed and sent to the Defense Waste Processing Facility (DWPF) for vitrification.

During recent ARP processing, there has been a degradation of filter performance manifested as the inability to maintain high filtrate flux throughout a multi-batch cycle. The objectives of this effort were to characterize the feed streams, to determine if solids (in addition to MST) are precipitating and causing the degraded performance of the filters, and to assess the particle size and rheological data to address potential filtration impacts. Equilibrium modelling with OLI Analyzer ${ }^{\mathrm{TM}}$ and OLI ESP ${ }^{\mathrm{TM}}$ was performed to determine chemical components at risk of precipitation and to simulate the ARP process. The performance of ARP filtration was evaluated to review potential causes of the observed filter behavior.

Task activities for this study included extensive physical and chemical analysis of samples from the Late Wash Pump Tank (LWPT) and the Late Wash Hold Tank (LWHT) within ARP as well as samples of the tank farm feed from Tank $49 \mathrm{H}$. The samples from the LWPT and LWHT were obtained from several stages of processing of Salt Batch 6D, Cycle 6, Batch 16.

The following are the key results for sample analysis from the ARP process tanks and the salt feed tank, and from the subsequent modelling effort.

- At the time of sampling, the slurries in the ARP 512-S LWPT and LWHT are $6.6 \mathrm{M} \mathrm{Na}^{+}, 2.2 \mathrm{M}$ $\mathrm{OH}^{-}$, and $2.7 \mathrm{M} \mathrm{NO}_{3}^{-}$salt solutions with less than $1 \mathrm{wt} \%$ of insoluble solids. The soluble content in the pre-filtration slurry sample (LWPT-1), the post-filtration slurry sample (LWPT-2), the filtrate sample (LWHT-1), and the Salt Bach feed tank (Tank 49H) matched for most analytes with the exception of oxalate.

- The insoluble solids contain primarily titanium and are consistent with the MST added during processing. Based on slurry analysis, the LWPT-1 and LWPT-2 samples have $0.19 \mathrm{wt} \%$ and 0.65 $\mathrm{wt} \%$ MST, respectively.

- Sample analysis showed a reduction in the amount of soluble oxalate between Tank $49 \mathrm{H}$ and the ARP 512-S tanks. Sodium oxalate solids were identified in the precipitate tank samples LWPT-1 and LWPT-2. OLI modelling confirmed that sodium oxalate is significantly supersaturated in Tank $49 \mathrm{H}$ and throughout the ARP. There is a risk of precipitating sodium oxalate within ARP and in the downstream MCU process.

- Based on the quantity of iron in the solids, High-Level Waste sludge also appears to be present as a minor fraction of the solids in the ARP slurries, with sludge present at roughly $1 / 24^{\text {th }}$ the mass of MST present.

- Due to a high concentration of soluble aluminum in the samples causing analytical interference, there is no direct evidence of precipitated aluminum compounds from sample analysis. OLI modeling showed that aluminum is practically at saturation in Tank $49 \mathrm{H}$ and in ARP during filtration. With minor fluctuations in temperature or hydroxide concentration, there is a risk of precipitating aluminum hydroxide (gibbsite) solids during processing. 
- A small quantity of sodium aluminosilicate may also be present in the insoluble solids. OLI modeling showed that silicon is supersaturated in Tank $49 \mathrm{H}$ relative to sodium aluminosilicate (cancrinite). Silicon was present in the unwashed solids isolated from all LWPT samples.

- There is little difference between the chemical results for the samples taken at three different levels in Tank 49H. This good agreement in composition confirms the homogeneity of the soluble components within the feed to the ARP.

- Sample LWPT-3, pH adjusted material from after cleaning of the crossflow filter with oxalic acid, differed significantly from the other ARP 512-S samples. Hydroxide concentration remained high, but most other salt components were diluted approximately 20-times from the process values. The total salt content of LWPT-3 is consistent with the corresponding simulation stream results, but the sample salt to hydroxide ratio is several times higher than the simulation results. This suggests that more salt is retained in the cross-flow filter/tanks than expected.

- The ARP 512-S slurries exhibited Newtonian flow behavior, with a filtrate viscosity of $3.9 \mathrm{cP}$ and a post-filtration slurry viscosity of $5.5 \mathrm{cP}$ at $25^{\circ} \mathrm{C}$. Flow behavior observed for the samples would not appear to challenge the filtration system outside of the expected salt feeds.

Filter performance over the last several Salt Batches has been relatively constant, producing an average of approximately $6.1 \mathrm{gpm}$ over the last 4 Salt Batches. However, starting in Salt Batch 5 and continuing through the most recent batch (Salt Batch 6D), filter performance has shown a more rapid decline and more frequent cleaning of the filters was performed. A review of the filtration performance data resulted in the following observations.

- There have been multiple changes to the operation of the filtration system. Many of these changes occurred at the same time or in close succession, making it difficult to determine the impact to the filtration system of the individual events. Most of the changes that were expected to increase filtration performance did not have the desired impact. Many of the parameters are interdependent and may have counteracting results.

- It is important to maintain a high axial velocity. A drop in the axial velocity appears to corellate with the inability to sustain an acceptable filtration rate through at least 40 batches. Due to system limitations, reduced axial velocity is encountered when the transmembrane pressure (TMP) is raised. This reduced axial velocity may counteract the short-term beneficial effect on filter performance of increasing the TMP.

- The current behavior of the filtration system is consistent with the behavior expected while filtering fines. The amount of fines in the MST varies batch to batch, ranging from $1.7 \mathrm{wt} \%$ to $7.8 \mathrm{wt} \%$. No data has been found to correlate the amount of fines per batch of MST with the filtration performance of the 512-S system.

- The secondary filter has limited the performance of the overall filtration system on many occasions. Ideally, the secondary filter would be transparent to the system. However, data has shown that the secondary filter has often become fouled and limits the overall filtration system performance, requiring either cleaning or replacement of the secondary filter. While the secondary filter has limited performance, it has not typically been the cause of the decline in the number of filter batches per cycle. 
The analysis of the filtration data, in concert with sample analysis, indicates multiple factors impacting filtration. Several steps can be taken that may provide a consistent improvement to filtration rate.

- Limit the amount of fines sent to the crossflow filter. Use the previous specification for MST, with less than $1 \mathrm{vol} \%$ of fines less than $1 \mu \mathrm{m}$. Minimization of fines would reduce the amount of deep pore fouling. The definition of what would be considered as fines is a function of the pore size. Collect data on the MST batches to determine if there is a relationship between the amount of fines in the MST and the filter performance.

- Investigate the removal, redesign, or relocation of the secondary filter. The secondary filter should act as a guard filter and should ideally be transparent to the process (i.e., have small to no pressure drop across secondary filter). Filtration within ARP has had periods where the secondary filter limited the overall filtration performance. In absence of removal of the secondary filter, consider redesign of the filter, including potential changes to configuration (pleated filter instead of tubes), media pore size, and media area.

- Given the shift in the salt processing flowsheet (e.g., increased free hydroxide, more concentrated salt solutions, and lower MST concentrations), lab scale tests are needed to define a reliable baseline for filter performance expectations. Tests should be performed with small scale filters (such as the cells unit filter, CUF) to duplicate the current method of operation and to understand filter performance more fully. This testing should show relative effect of changes in parameters, including the following:

o MST (percent fines, solids concentration, inclusion of sludge, etc)

o Sludge (presence and absence)

o Filter pore size $(0.1 \mu \mathrm{m}$ and $0.5 \mu \mathrm{m})$

o Soluble phase composition (sodium concentration, hydroxide concentration)

o Start-up process filtration impacts (TMP, axial velocity, etc. during filter start-up)

o Methods for restoring filter performance during processing (scouring and backpulsing)

0 Agitation in the feed tank (with and without)

o Filter cleaning optimization (acid, time, heel mixing, returning to feed)

o Investigate impact of precipitates (sodium oxalate)

o Other operational parameters

- Filtration rates should be limited at the startup to 8 or $9 \mathrm{gpm}$ at the lowest required TMP. The process of running initial batches at very high filtration rates may have a significant impact on sustained filter production.

- Recent testing has demonstrated axial velocity can have a significant impact on filtering MST. From the ARP data, the axial velocity appears to have a greater impact on extending the number of batches processed per cycle than the short-term benefit obtained in filtration rate by increasing the TMP. Test and develop a redesigned system to increase routine operations at axial velocities up to $15 \mathrm{ft} / \mathrm{s}$.

- Additional benefit may be realized by scouring the filter membranes through maximizing the axial velocity with minimal TMP. This may best be applied by scouring the filter at the end of the batch to prepare the filter for the following batch.

- Adjustments to the filter cleaning process should be investigated. Assure that the filter is adequately flushed after cleaning with oxalic acid to avoid precipitation of sodium oxalate. Nitric 
acid cleaning should be considered as a replacement cleaning method if testing shows significant advantages.

- Currently, no testing is performed during qualification of a salt batch that evaluates operation of the feed during filtration. Since 512-S filtering often limits salt processing, filtration testing should be performed in the salt batch preparation process. Filtration testing may provide indications of potential filtration issues before they are experienced in the 512-S facility. The testing may also assist in developing more effective cleaning strategies. 


\section{TABLE OF CONTENTS}

LIST OF TABLES xii

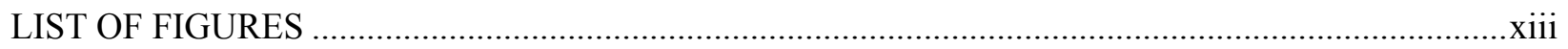

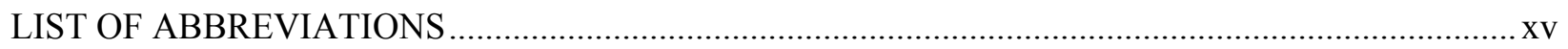

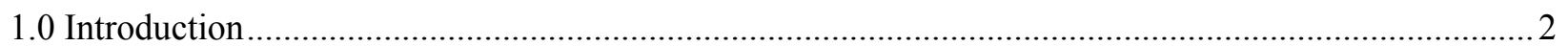

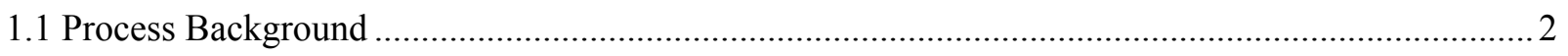

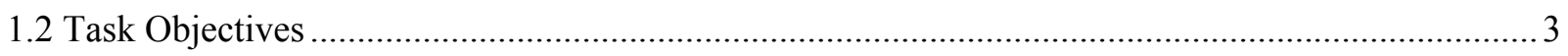

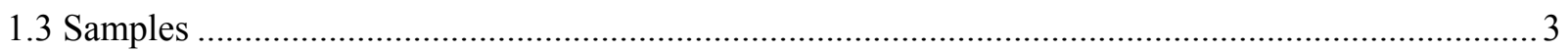

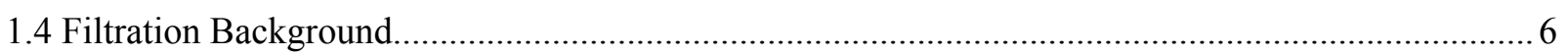

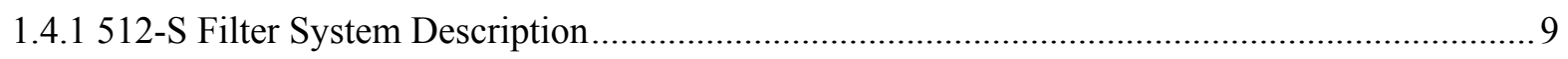

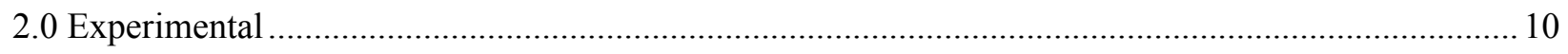

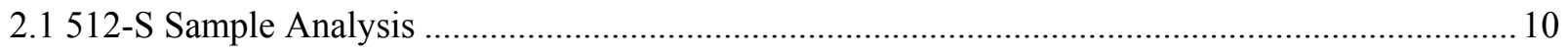

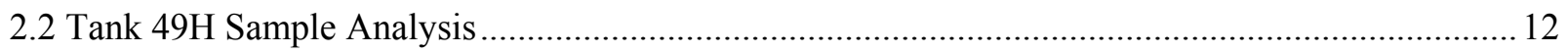

2.3 Electrolyte Thermodynamic Modelling Details ....................................................................... 12

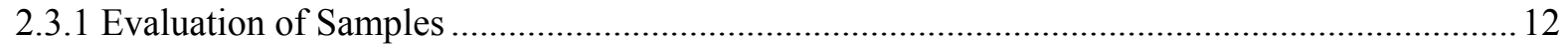

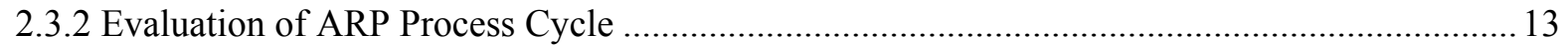

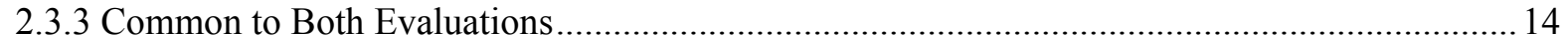

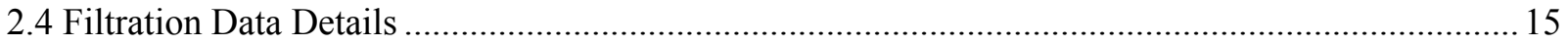

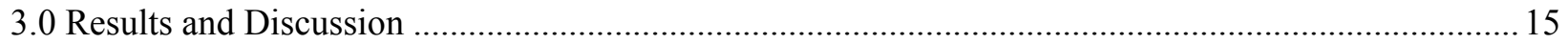

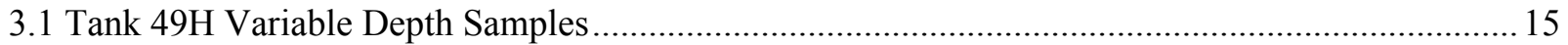

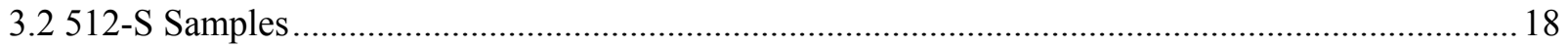

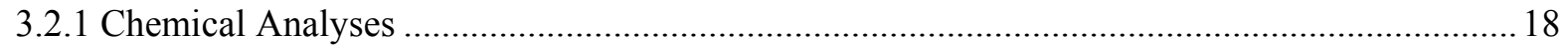

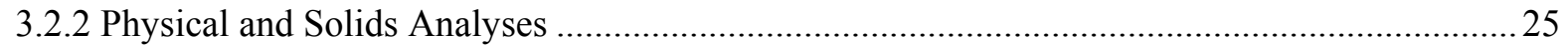

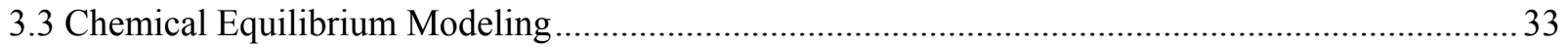

3.3.1 Evaluation of Chemical Saturation of Samples from Tank 49H and 512-S Facilities............... 33

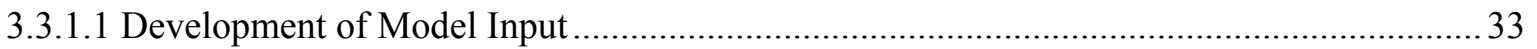

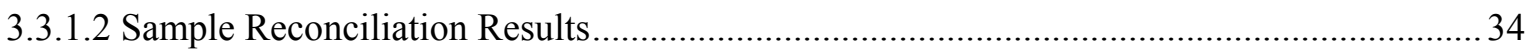

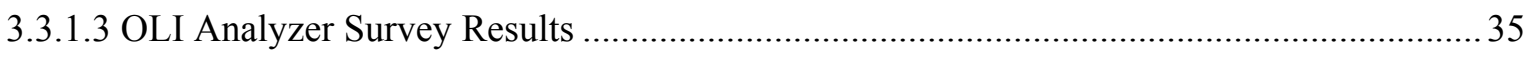

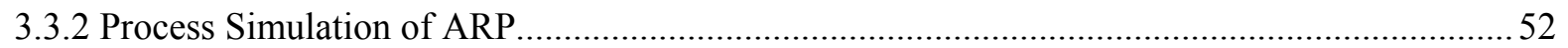

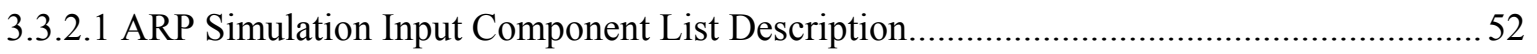

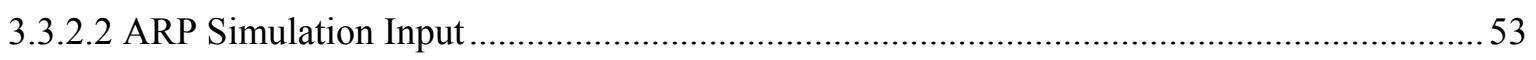

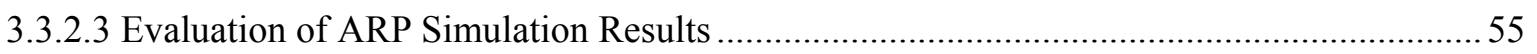

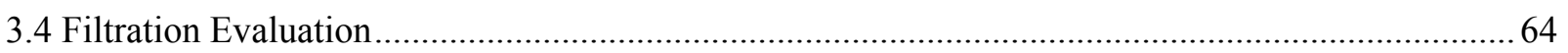

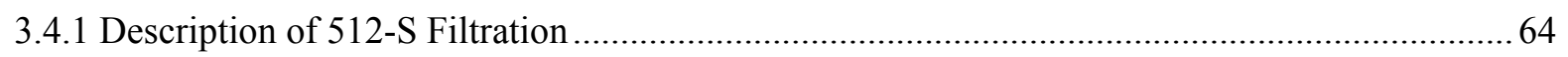




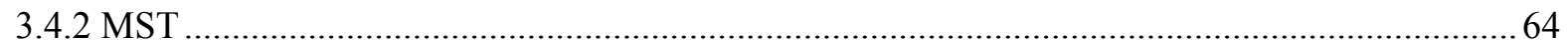

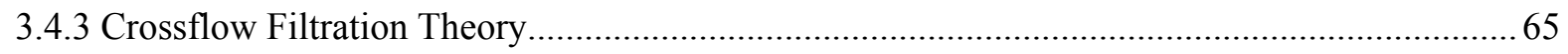

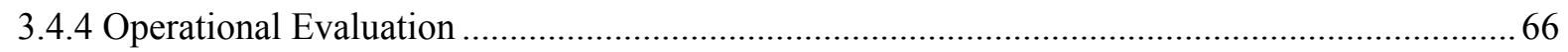

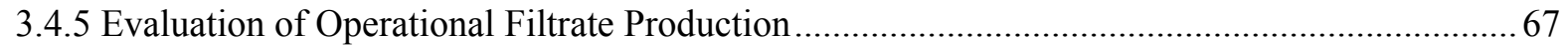

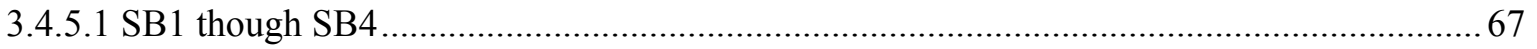

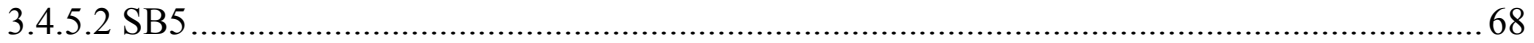

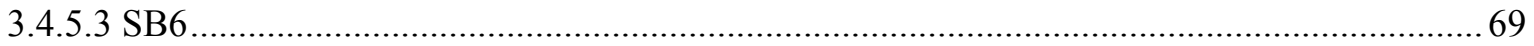

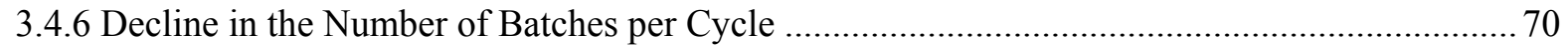

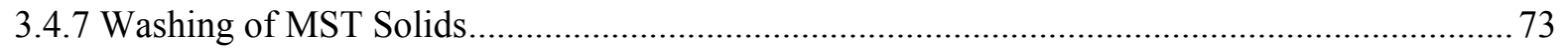

3.4.8 Evaluation of Parameters Impacting Filter Performance ........................................................ 74

3.4.8.1 Contribution of Fines to Filter Performance Degradation.................................................. 75

3.4.8.2 Impact of Transmembrane Pressure on Filtration Rate....................................................... 76

3.4.8.3 Contribution of Axial Velocity to Filter Performance Degradation..................................... 77

3.4.8.4 Contribution of Secondary Filter Fouling to Filter Performance Degradation .................... 78

3.4.8.5 Contribution of Abnormal Operational Events to Filter Performance Degradation ............ 80

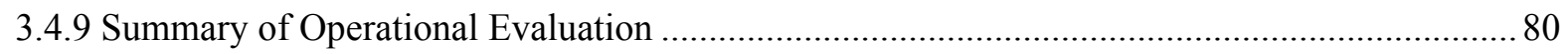

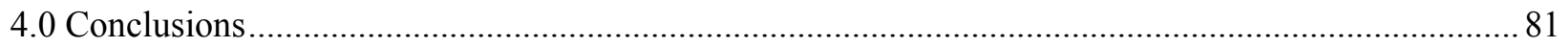

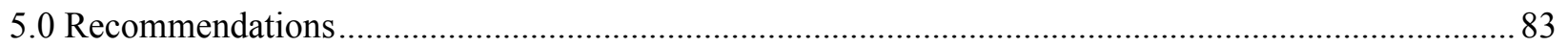

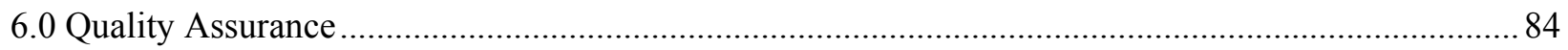

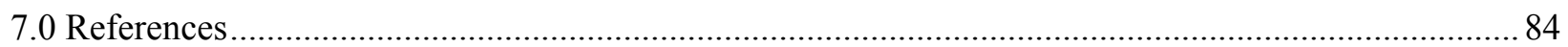

Appendix A . Rheology Measurements of 512-S Samples.................................................................

Appendix B . Particle Size Distribution Measurements of LWPT Samples .......................................... B-90

Appendix C . SEM of Solids Isolated from LWPT Samples ............................................................. C-96

Appendix D . Detailed Step-by-Step Process Description of ARP Process Cycle ............................ D-108

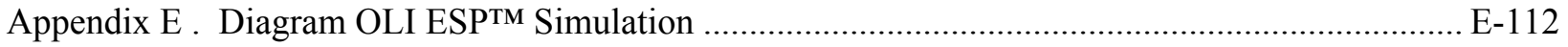




\section{LIST OF TABLES}

Table 1-1. ARP 512-S sample set description ........................................................................... 4

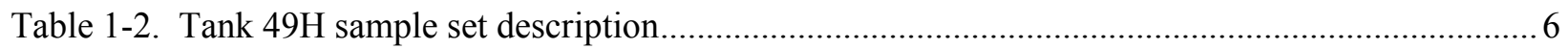

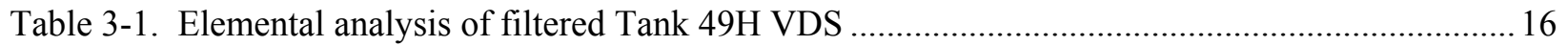

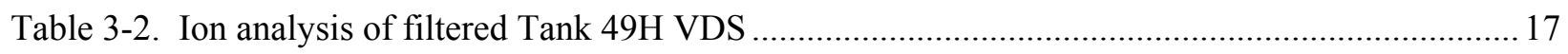

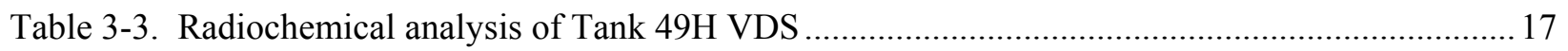

Table 3-4. Solids quantitative analysis and density measurements of Tank 49H VDS .......................... 17

Table 3-5. Elemental analysis of filtered LWPT samples and as-received LWHT sample...................... 19

Table 3-6. Elemental analysis of as-received samples from LWPT and LWHT ...................................20

Table 3-7. Ion analysis of filtered LWPT samples and as-received LWHT sample ..............................2 21

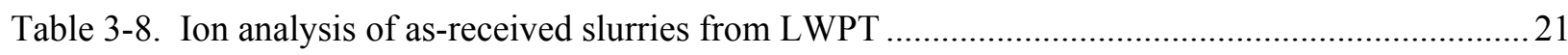

Table 3-9. Elemental analysis of dried unwashed solids isolated from LWPT samples..........................22

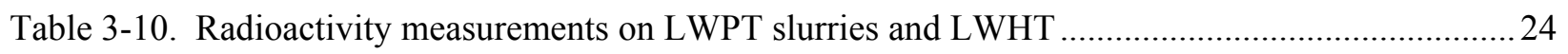

Table 3-11. Radioactivity measurements on solids isolated from LWPT samples..................................24

Table 3-12. Solids quantitative analysis and density measurement of ARP 512-S samples....................25

Table 3-13. Viscosity measurements of ARP 512-S samples (at approx. $25^{\circ} \mathrm{C}$ ) .................................. 27

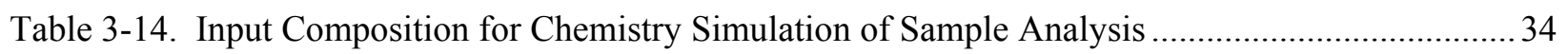

Table 3-15. Results of Reconciliation Calculation - Apparent Species .................................................. 35

Table 3-16. Summary of Predicted Solids in Each Sample …............................................................. 47

Table 3-17. Molecular Component List for the ARP Simulation ..........................................................53

Table 3-18. Molecular Component Composition of Chemical Input Streams for the ARP Simulation .... 54

Table 3-19. Molecular Composition of Predicted Solids in LWPT at the End of 40 Batches.................. 56

Table 3-20. OLI ESP Simulation of LWPT at the End of Filter Cleaning and Adjustment, Compared with

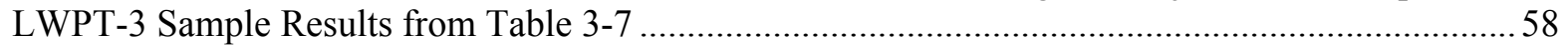

Table 3-21. Simulation of LWHT at the end of batch 16, compared with LWHT-1 sample results.........61

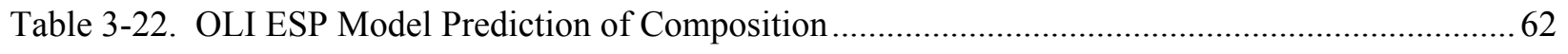

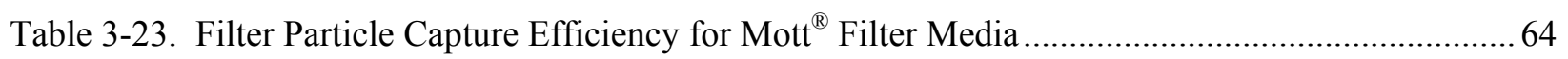

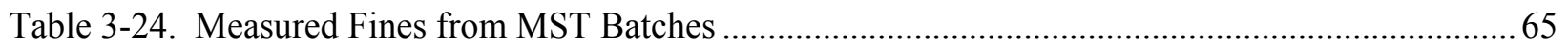




\section{LIST OF FIGURES}

Figure 1-1. Simplified diagram of the 512-S portion of ARP .......................................................... 2

Figure 1-2. APR 512-S samples photographed in SRNL Shielded Cells A-Block Cell 6 ......................... 5

Figure 1-3. Portions of the Tank 49H VDS photographed in SRNL Shielded Cells B-Block Cell 11. Comparatively, HTF-49-13-165 is very clear and HTF-49-13-166 and HTF-49-13-167/8/9 have a slight haze.

Figure 1-4. End of batch filtrate flow for ARP processing of SB5 .................................................... 7

Figure 1-5. Comparison of Filtration Rate from SB-4 and SB-6 ..................................................... 8

Figure 1-6. ARP 512-S Performance for SB-3 through SB-6, Batches per Cycle ................................... 8

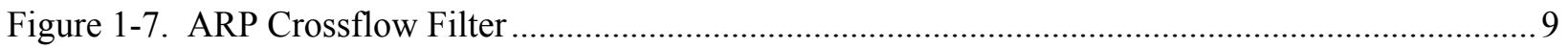

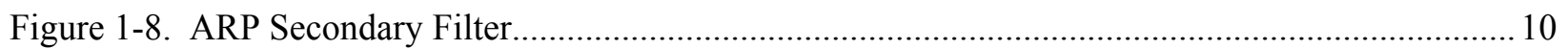

Figure 3-1. Example flow curve (rheology measurement) of LWPT-2 slurry ....................................... 27

Figure 3-2. Particle size volume distributions of LWPT samples .......................................................28

Figure 3-3. XRD analysis of unwashed solids isolated from LWPT-1 ...............................................29

Figure 3-4. XRD analysis of unwashed solids isolated from LWPT-2 ...............................................29

Figure 3-5. XRD analysis of unwashed solids isolated from LWPT-3 ................................................ 30

Figure 3-6. Example SEM image of dried unwashed solids from LWPT-2 .......................................... 31

Figure 3-7. TGA of unwashed solids isolated from LWPT samples.................................................. 32

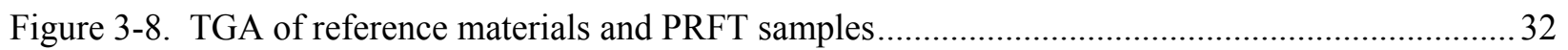

Figure 3-9. Predicted Solids Precipitated from Analytical Results of Tank 49H Sample ........................38

Figure 3-10. Predicted Solids Precipitated from Analytical Results of LWPT-1 Sample ....................... 41

Figure 3-11. Predicted Solids Precipitated from Analytical Results of LWPT-2 Sample ....................... 43

Figure 3-12. Predicted Solids Precipitated from Analytical Results of LWPT-3 Sample ....................... 45

Figure 3-13. Predicted Solids Precipitated from Analytical Results of LWHT-1 Sample....................... 46

Figure 3-14. Scaling Tendencies for Carbonate Compounds above 0.10 in Sample LWPT-1 .................49

Figure 3-15. Scaling Tendencies for Carbonate Compounds above 0.10 in Sample LWPT-2 .................50

Figure 3-16. Predicted Solids Concentration in LWPT during One Complete ARP Cycle with Predicted Effect on Filtration Rate 
Figure 3-17. Predicted Solids Concentration in LWHT during One Complete ARP Cycle with Secondary Filter Cleaning

Figure 3-18. The $\mathrm{pH}$ in the Surge Tank Throughout the Filter Cleaning Process 63

Figure 3-19. Filtration Rate and Significant Events during Processing ................................................ 67

Figure 3-20. Filtration Rate as a Function of Batch for Salt Batch 4 Cycles.......................................... 71

Figure 3-21. Filtration Rate as a Function of Batch for Salt Batch 5 Cycles............................................ 72

Figure 3-22. Filtration Rate as a Function of Batch for Salt Batch 6 Cycles.......................................... 73

Figure 3-23. Batch Washing of MST at the End of SB6D Cycle 5 .................................................... 74

Figure 3-24. Relative Change in Pressure Drop, Filter Feed Flow, and Filtrate Flow for SB-6 Cycles... 75

Figure 3-25. Filtration Flow Rate and Filter Pressures as a Function of Batch ..................................... 76

Figure 3-26. Filtration Rate as a Function of Transmembrane Pressure ................................................. 77

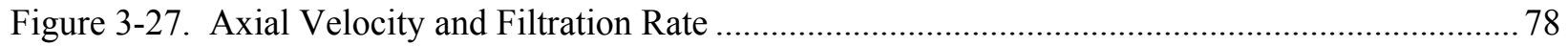

Figure 3-28. Permeability of the Crossflow Filter, Secondary Filter and Total Filter System ..................79 


\section{LIST OF ABBREVIATIONS}

\begin{tabular}{|c|c|}
\hline ARP & Actinide Removal Process \\
\hline $\mathrm{C}$ & Cycle \\
\hline $\mathrm{CFF}$ & Crossflow Filter \\
\hline $\mathrm{CI}$ & Confidence Interval \\
\hline CUF & Cells Unit Filter \\
\hline CVAA & Cold Vapor Atomic Absorption \\
\hline DWPF & Defense Waste Processing Facility \\
\hline HLW & High-Level Waste \\
\hline IC & Ion Chromatography \\
\hline ICP-ES & Inductively Coupled Plasma - Emission Spectroscopy \\
\hline IW & Inhibited Water \\
\hline LPPP & Low Point Pump Pit \\
\hline LWHT & Late Wash Hold Tank (in ARP 512-S) \\
\hline LWPT & Late Wash Pump Tank (in ARP 512-S) \\
\hline MCU & Modular Caustic Side Solvent Extraction Unit \\
\hline MSE & Mixed Solvent Electrolyte \\
\hline MST & Monosodium Titanate \\
\hline MW & Molecular Weight \\
\hline $\mathrm{n}$ & Number of replicate measurements \\
\hline $\mathrm{N} / \mathrm{A}$ & Not applicable \\
\hline PRFT & Precipitate Reactor Feed Tank \\
\hline PuTTA & Plutonium separation by thenoyltrifluoracetone \\
\hline SB & Salt Batch \\
\hline SEM & Scanning Electron Microscopy \\
\hline SRNL & Savannah River National Laboratory \\
\hline SRR & Savannah River Remediation \\
\hline TGA & Thermogravimetric Analysis \\
\hline TIC & Total Inorganic Carbon \\
\hline TOC & Total Organic Carbon \\
\hline TTQAP & Task Technical and Quality Assurance Plan \\
\hline TTR & Task Technical Request \\
\hline VDS & Variable Depth Samples \\
\hline WAC & Waste Acceptance Criteria \\
\hline XRD & X-ray Diffraction \\
\hline
\end{tabular}




\subsection{Introduction}

\subsection{Process Background}

Savannah River Remediation (SRR) operates a set of closely coupled facilities that process salt waste, removing strontium, actinides, and cesium prior to disposal of decontaminated salt solution in saltstone. One facility that limits operating rates due to processing difficulties is the filtration portion of the Actinide Removal Process (ARP), located in 512-S. In this portion of the process, batches of salt solution containing Monosodium Titanate (MST) sorbent are received in the Late Wash Precipitate Tank (LWPT) and are concentrated by crossflow filtration, with the filtrate going to the Late Wash Hold Tank (LWHT) and the concentrated slurry remaining in the LWPT, where it is subsequently washed. These filtration steps in 512-S have been the limiting factor for obtaining the desired salt processing throughput in spite of recent changes to process timing and filter cleaning steps. ${ }^{1}$ After LWPT and LWHT contents are sent to downstream facilities, the filter is washed with oxalic acid which is $\mathrm{pH}$ adjusted and mixed with the LWPT heel and sent to Defense Waste Processing Facility (DWPF).

The ARP is housed within two separate facilities, with the MST addition performed in 241-96H and the filtration of MST solids in 512-S. Batches of salt waste are contacted with MST at a dose of 0.2 grams of MST per liter of waste. For each cycle, the solids from a series of batches (up to 50) are combined in the LWPT. The filtrate from the process is sent to the Modular Caustic Side Solvent Extraction Unit (MCU) for cesium removal. The solids are washed to a sodium molarity of nearly $0.5 \mathrm{M}$, after which they are concentrated and sent to DWPF via the Low Point Pump Pit (LPPP).

The simplified process diagram of Figure 1-1 highlights the connectivity of the sampling locations for this study. During crossflow filtration, slurry is recirculated through the tube side of the filter from the LWPT. Filtrate emerges on the shells side of the crossflow filter, is forced through a secondary filter, and enters the LWHT. The surge tank is utilized during filter cleaning.

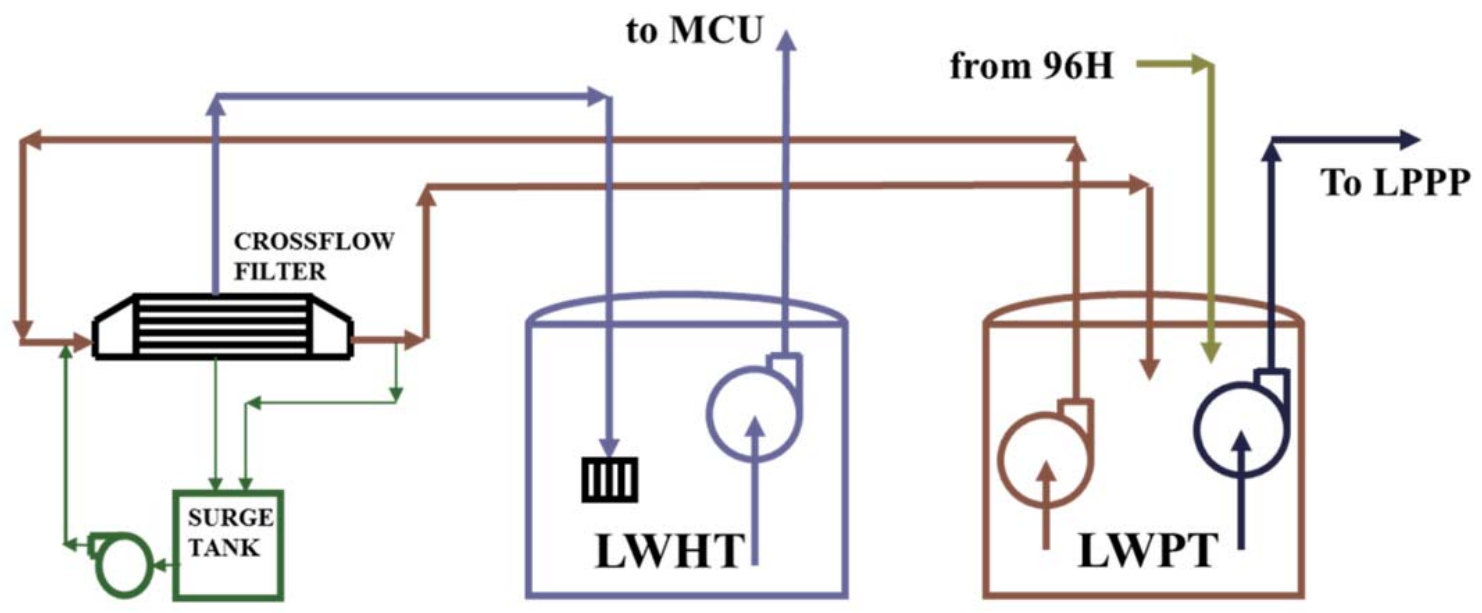

Figure 1-1. Simplified diagram of the 512-S portion of ARP 


\subsection{Task Objectives}

A series of samples were taken from the LWPT and LWHT to improve understanding of the process chemistry and physical properties of the material being filtered. Additionally, samples were collected from several depths within Tank $49 \mathrm{H}$, the $1.3 \mathrm{Mgal}$ capacity waste tank that feeds the ARP, to investigate the degree of feed heterogeneity of the process feed.

The goals of this effort are to characterize the feed streams, to determine if solids (in addition to MST) are precipitating and causing the degraded performance of the filters, and to apply the particle size and rheological data to confirm the applicability of the filtration process. Solubility is calculated based on electrolyte thermodynamic modeling with OLI Systems software in order to evaluate the risk of precipitation. Filtration performance is reviewed with consideration of the chemical analysis and modelling data to identify potential causes of the observed filter behavior.

Task activities include extensive physical and chemical analysis of the LWPT, LWHT, and Tank $49 \mathrm{H}$ samples, followed by completion of evaluations utilizing the data collected from the samples. SRR DWPF Engineering issued two Task Technical Requests (TTR) for this task. ${ }^{2,3}$ A Task Technical and Quality Assurance Plan (TTQAP) contains the work scope for ARP sample characterization, filtration evaluation, and modelling, ${ }^{4}$ while a separate TTQAP contains the work scope for Tank $49 \mathrm{H}$ sample characterization. ${ }^{5}$

\section{$1.3 \underline{\text { Samples }}$}

SRR collected four sets of samples from the ARP 512-S facility tanks and sent them to SRNL for analysis. Samples were collected during the processing of Salt Batch 6D, Cycle 6, Batch 16 . Table 1-1 describes the naming convention of the samples, describes the stage of processing at which the samples were collected, and lists the tank volume and temperature at the time of sampling. Vessels were under continuous agitation just prior to sampling. Three of the sets were from the LWPT and were slurries containing MST and potentially other undissolved solids. The fourth set was from the LWHT and did not contain visible indication of undissolved solids. The volume of each set of samples was nominally $600 \mathrm{~mL}$ in total (i.e., three individual $200 \mathrm{~mL}$ samples). The following is a description and the naming convention for the four sample sets:

Sample set LWPT-1 arrived at SRNL on August 29, 2013 and was placed into A-Block of the Shielded Cells. Sample set LWPT-2 arrived on September 3 and sample sets LWPT-3 and LWHT-1 arrived on September 4, and were all placed in the cells on September 4.

Upon receipt by SRNL, ARP samples from a set were combined into a single bottle for each set. The cell temperature as ARP samples were unpackaged was $25^{\circ} \mathrm{C}$. The $\mathrm{pH}$ as determined by $\mathrm{pH}$ test strips was roughly 14 for all samples.

Figure 1-2 contains photographs of the individual samples within each sample set. While visual differences were noted between the different sample sets, no visual differences were noted between samples within each sample set. All of the LWPT samples were turbid with nearly white solids, consistent with the presence of MST as the major solid phase. The whiteness of the solids indicates that the LWPT samples contain no more than a minor fraction of HLW sludge, which tends to contain dark brown or black solids. Among the LWPT samples and assuming that any difference in the appearance of the was due to the solids concentration, the post-filtration sample LWPT-2 appears to have the highest concentration of solids and the post-cleaning sample LWPT- 
3 appears to have the lowest concentration of solids. The LWHT samples were clear and thus did not have visual indication of insoluble solids. The same camera settings and lighting conditions were used for the photographs of all four sample sets, and these did not prove to be optimal for the LWHT samples. Sample photographs taken through the Cell 6 window exhibit an overall haze due to the cell window and splash guard. This haze is more evident for the LWHT sample photograph due to reflections of the cell lighting off of the metal tray and through the relatively clear sample.

Table 1-1. ARP 512-S sample set description

\begin{tabular}{c|l|c}
\hline $\begin{array}{c}\text { Sample } \\
\text { Name }\end{array}$ & \multicolumn{1}{|c}{ Sample Set Description } & \multicolumn{1}{|c}{$\begin{array}{c}\text { Tank } \\
\text { Conditions }\end{array}$} \\
\hline LWPT-1 & $\begin{array}{l}\text { Samples collected from the LWPT after receiving the last batch of } \\
\text { material from 241-96H (SB 6D Cycle 6 Batch 16), but before } \\
\text { filtration of the last batch has taken place. These samples also } \\
\text { contain the solids concentrated from the first 15 batches of SB 6D } \\
\text { Cycle 6. }\end{array}$ & $\begin{array}{r}5504 \text { gal } \\
28^{\circ} \mathrm{C}\end{array}$ \\
\hline LWPT-2 & $\begin{array}{l}\text { Samples collected from the LWPT after filtration has been } \\
\text { performed for the batch mentioned above. }\end{array}$ & $\begin{array}{r}1641 \text { gal } \\
28^{\circ} \mathrm{C}\end{array}$ \\
\hline LWHT-1 & $\begin{array}{l}\text { Samples collected from the LWHT at the time that the last batch of } \\
\text { material had been processed through the filter. Sample timing } \\
\text { corresponds to LWPT-2. }\end{array}$ & $\begin{array}{r}4989 \text { gal } \\
29^{\circ} \mathrm{C}\end{array}$ \\
\hline LWPT-3 & $\begin{array}{l}\text { Samples collected from the LWPT after filter cleaning had been } \\
\text { performed and the material had undergone pH adjustment with } \\
\text { sodium hydroxide (as described in Reference 1 Table 3). These } \\
\text { samples correspond to the heel remaining in the LWPT at the time } \\
\text { when the first batch of feed in a new cycle would be sent from 241- } \\
\text { 96H to 512-S. }\end{array}$ & $\begin{array}{r}1509 \text { gal } \\
38^{\circ} \mathrm{C}\end{array}$ \\
\hline
\end{tabular}

A similar task recently has looked at the slurry within the DWPF Precipitate Reactor Feed Tank (PRFT). ${ }^{7}$ The PRFT materials are washed and concentrated MST slurries downstream of the LWPT and LPPP. From the preliminary results prior to chemical and radiological analysis, the PRFT material was seen to be primarily MST with no indication of HLW sludge. 

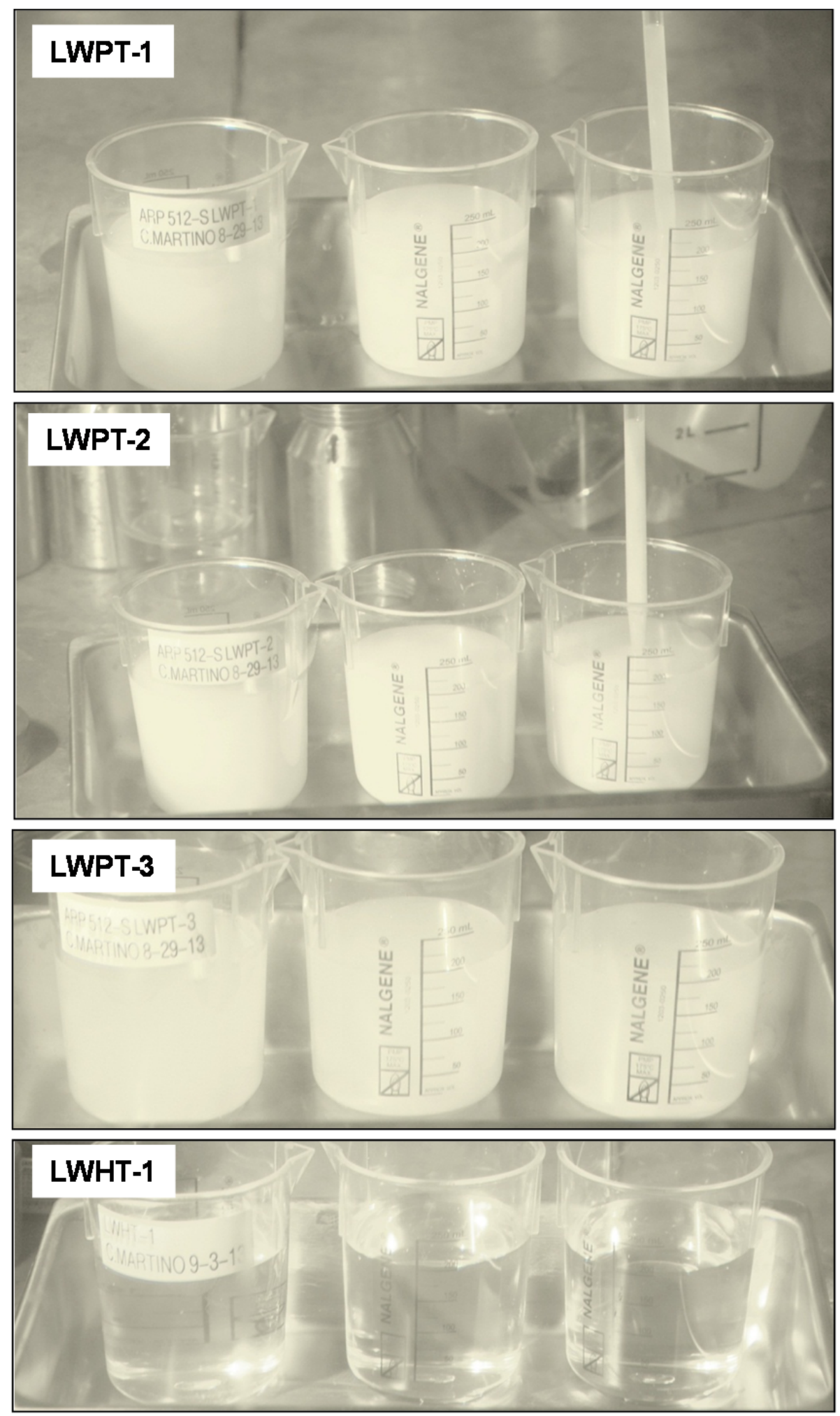

Figure 1-2. APR 512-S samples photographed in SRNL Shielded Cells A-Block Cell 6 
Table 1-2 contains descriptions of the sampling locations and the quantity received of the Tank 49H Variable Depth samples (VDS). The three samples from the lowest tank height (8 inches from the bottom of Tank 49H) were combined prior to analysis. Figure 1-3 contains photographs of portions of samples HTF-49-13-165, 166, and the composite of 167 through 169. The supernate surface sample HTF-49-13-165 appeared very clear while the other samples appeared to have a very slight haze.

Table 1-2. Tank 49H sample set description

\begin{tabular}{c|c|c|c}
\hline Sample Name & Tank Location & Volume & Mass \\
\hline HTF-49-13-165 & $\begin{array}{c}\text { Supernate sub-surface } \\
(146 \text { inches from tank bottom })\end{array}$ & $\sim 200 \mathrm{~mL}$ & $\sim 260 \mathrm{~g}$ \\
\hline $\begin{array}{c}\text { Supernate sub-surface } \\
\text { HTF-49-13-166 }\end{array}$ & $\sim 200 \mathrm{~mL}$ inch from tank bottom $)$ & $\sim 260 \mathrm{~g}$ \\
\hline $\begin{array}{c}\text { HTF-49-13-167, } \\
\text { HTF-49-13-168, } \\
\text { HTF-49-13-169 }\end{array}$ & \begin{tabular}{c} 
(8 inches from tank bottom $)$ \\
\hline
\end{tabular} & $\sim 600 \mathrm{~mL}$ & $\sim 780 \mathrm{~g}$ \\
\hline
\end{tabular}

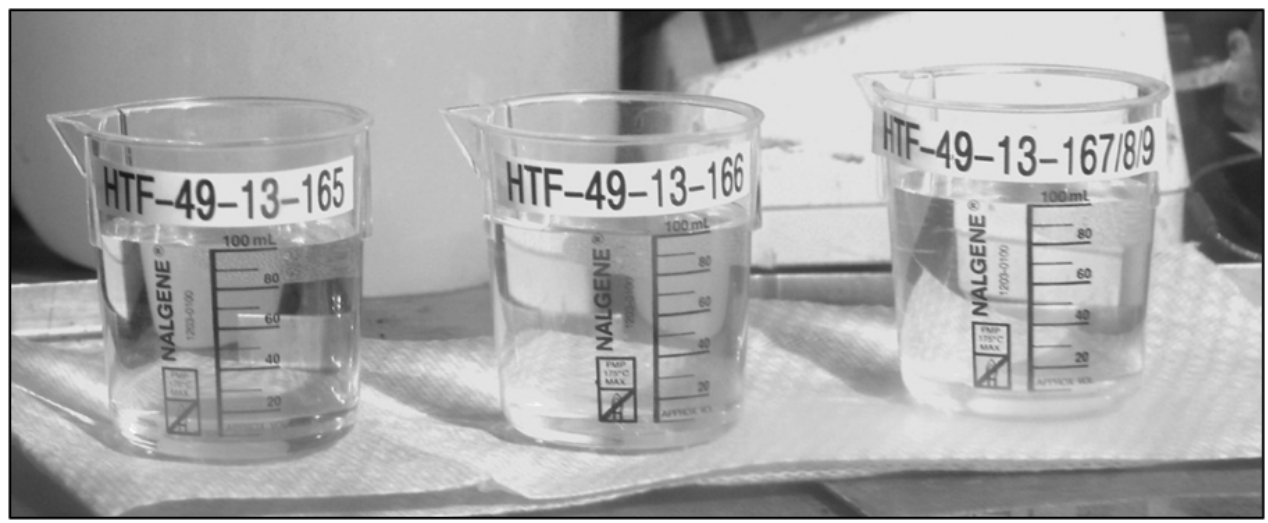

Figure 1-3. Portions of the Tank 49H VDS photographed in SRNL Shielded Cells B-Block Cell 11. Comparatively, HTF-49-13-165 is very clear and HTF-49-13-166 and HTF-49-13$167 / 8 / 9$ have a slight haze.

\subsection{Filtration Background}

In recent reviews, recommendations have been made for improvements to crossflow filtration within ARP 512-S. ${ }^{1,8}$ Previously, SRNL made initial recommendations on the ARP crossflow filter cleaning process based on the heel volume in the surge tank and filter. ${ }^{9}$

A filtration batch is a single 241-96H strike tank batch that has been filtered through the crossflow filter. The processing of multiple batches, up to 50 batches, with accumulation of the solids, is referred to as a cycle. Once a cycle is complete, the slurry from the multiple batches in 
the cycle in the LWPT is washed to lower the sodium concentration. Cleaning of the crossflow filter with oxalic acid takes place at the end of each cycle. Feed to the ARP is staged in Tank 49H. When material is added to Tank $49 \mathrm{H}$, it is considered a new Salt Batch (SB). A typical SB requires several cycles to be processed through ARP. Figure 1-4 contains an example of filtrate flow during processing of several cycles of a SB.

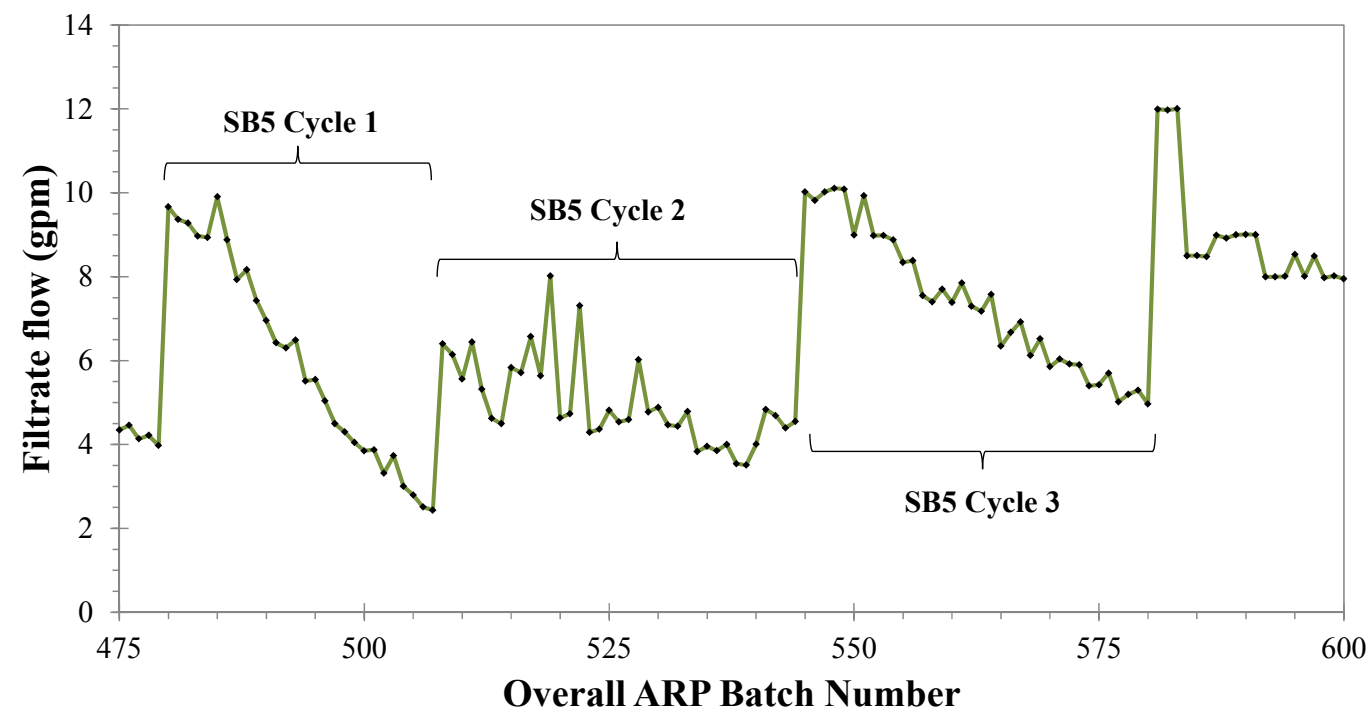

Figure 1-4. End of batch filtrate flow for ARP processing of SB5

The cleaning is typically performed by recirculating nominally $0.5 \mathrm{M}$ oxalic acid through the tube side of the crossflow filter and backpulsing $0.5 \mathrm{M}$ oxalic acid into the system. In general, filter flux is highest during the initial batches of a cycle and deteriorates with subsequent batches later in the cycle. It is unclear whether this reduction in flux is due to fouling within the filter or with deficiencies in the formation in the filter cake. Because the ARP filter is not able to be backpulsed efficiently during operation, filter cleaning has been the only remedy to restore filter flux.

Figure 1-5 shows a comparison of the filtration rate from two Cycles SB4 and SB6. The Cycles from SB6 were unable to sustain the filtration rate and fewer batches were completed before filter cleaning was required. The chart illustrates that the batch-to-batch performance for the SB6 cycles declined at a faster rate when compared with the SB4 cycles. This translates into fewer batches run prior to the filter requiring cleaning. 


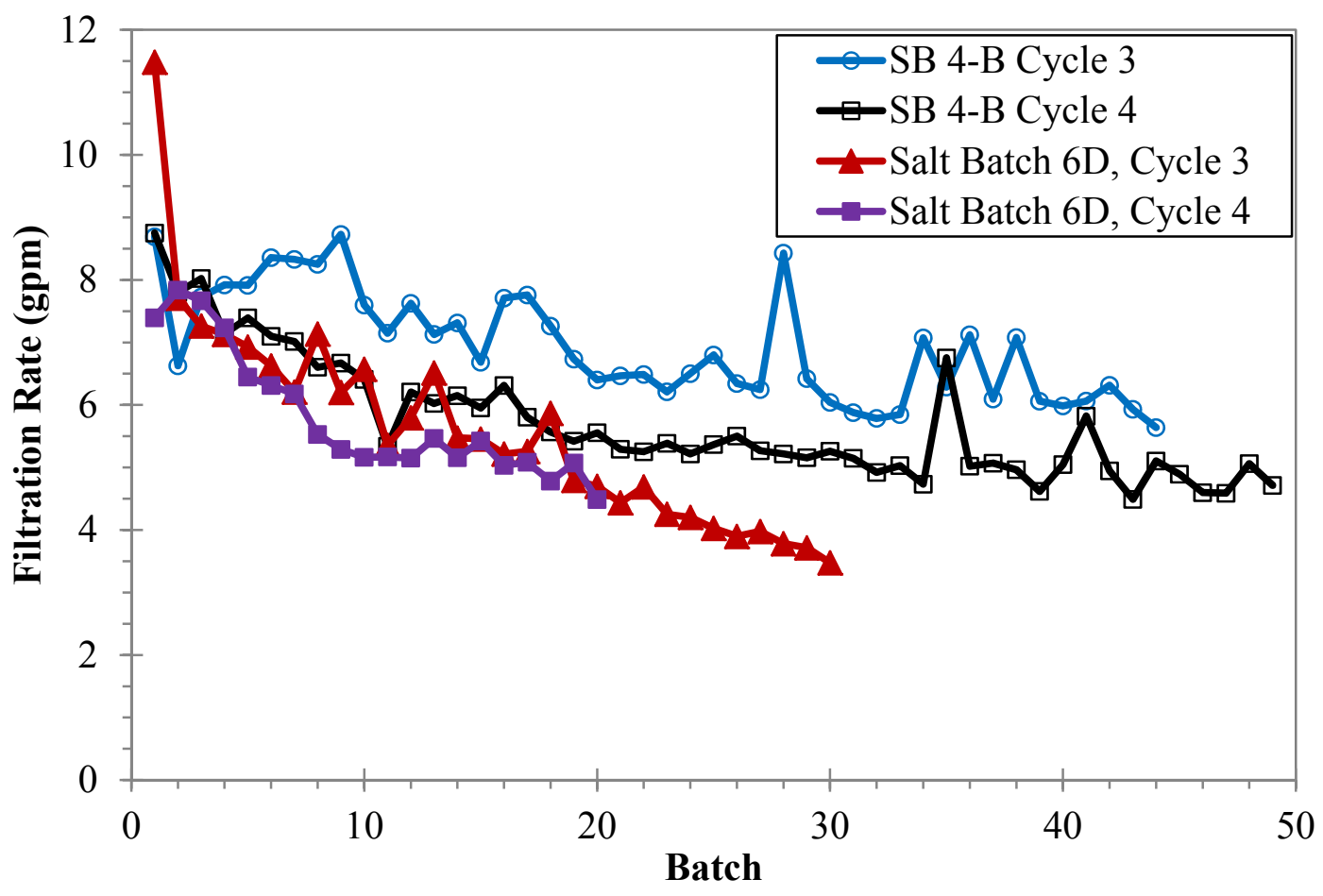

Figure 1-5. Comparison of Filtration Rate from SB-4 and SB-6

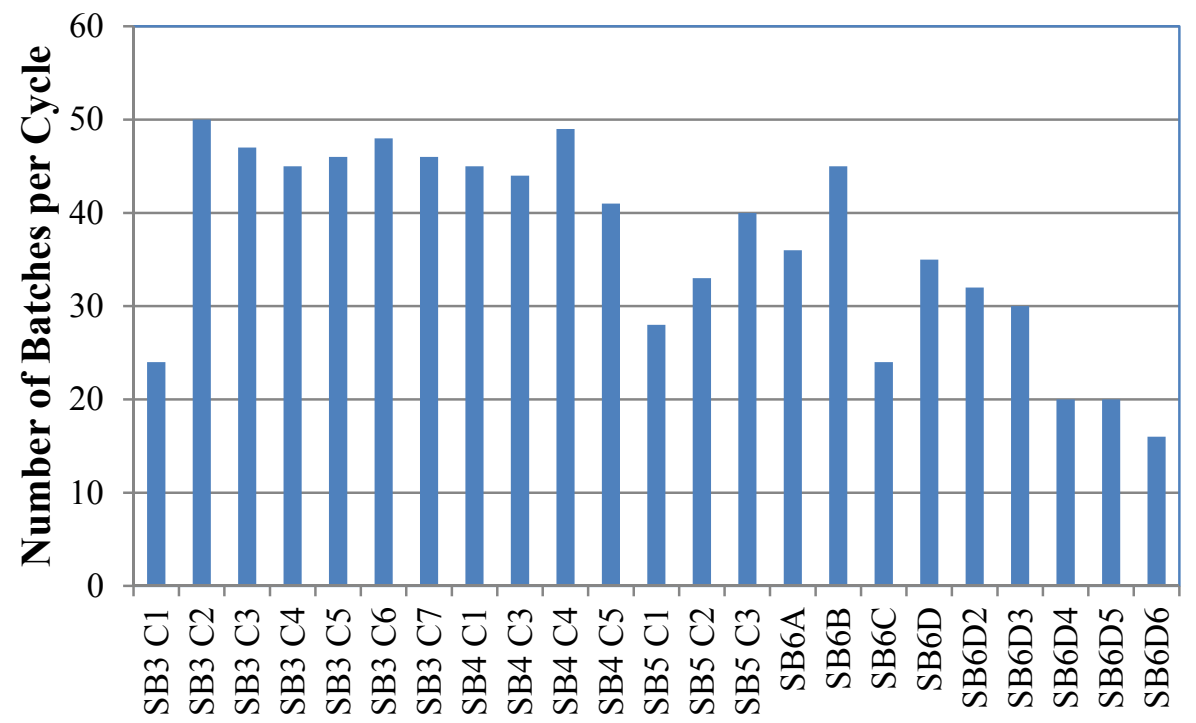

Figure 1-6. ARP 512-S Performance for SB-3 through SB-6, Batches per Cycle

Figure 1-6 shows a chart of the number of batches completed per cycle starting with SB3. The chart shows the number of batches per cycle typically above 40 for SB4. SB5 shows a drop in the number of cycles for the first two cycles. SB6 shows a steady decline in the number of batches as the salt batch continues to be processed. 


\subsubsection{2-S Filter System Description}

The crossflow filter unit in ARP contains $144 \mathrm{Mott}^{\circledR}$ sintered metal filter tube elements with nominal pore size of $0.1 \mu \mathrm{m}$ and a total filter area of $230 \mathrm{ft}^{2}$. The filter tubes are made of 316 stainless steel with an inner diameter of $0.625 "$ and are 120" long. Figure 1-7 contains a drawing and a picture of the primary filter.
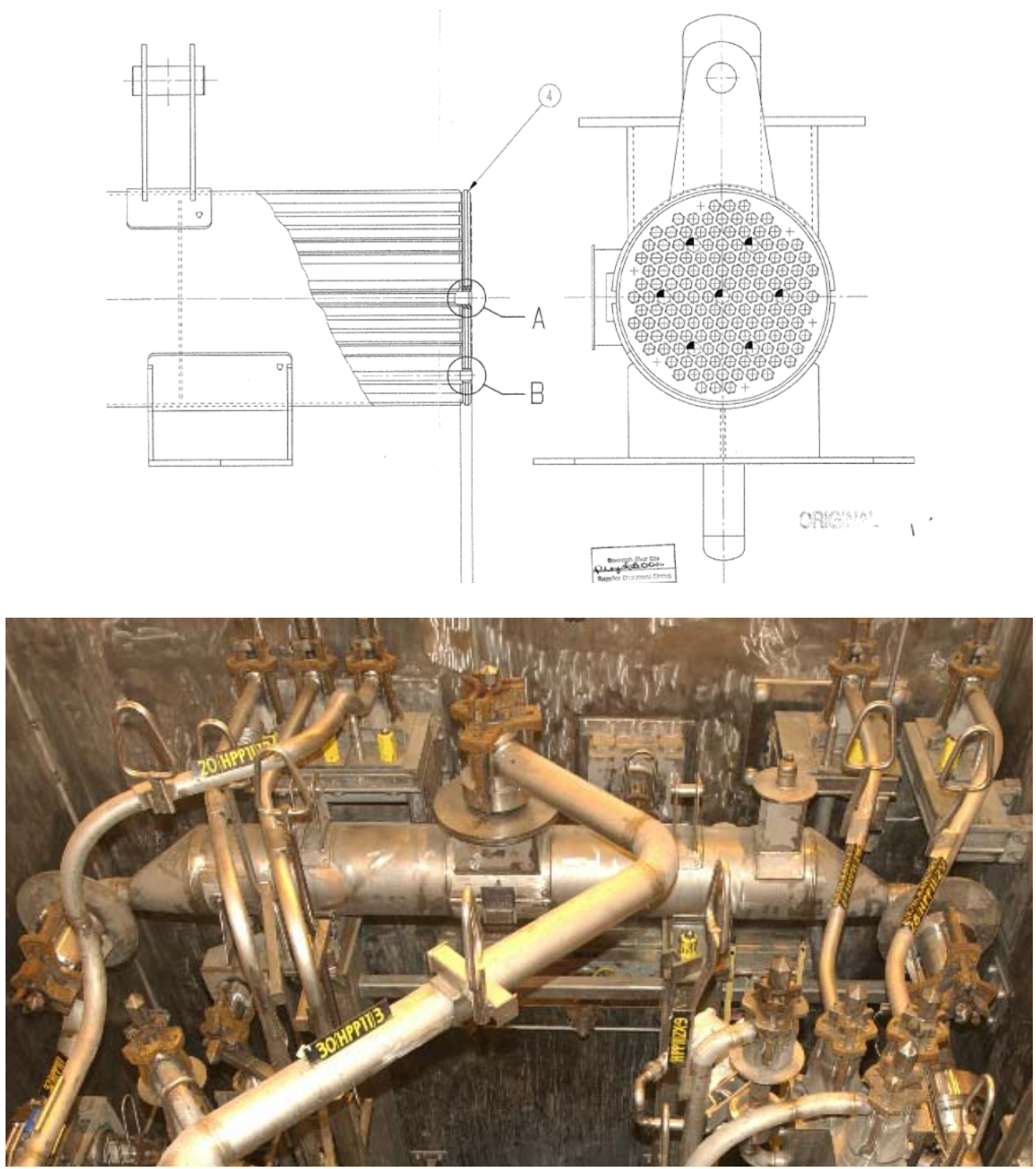

Figure 1-7. ARP Crossflow Filter

Downstream of the crossflow filter, there is a secondary filter. The secondary filter is a dead-end filter constructed of 21 sintered metal filter tubes with a $0.5 \mu \mathrm{m}$ nominal rating, with a total surface area of $16.5 \mathrm{ft}^{2}$. The tubes are made from 316 stainless steel and are also manufactured by Mott ${ }^{\circledR}$. The filter elements sit inside the LWHT. Figure 1-8 contains a drawing of the current secondary filter. 
SRNL-STI-2013-00700

Revision 0

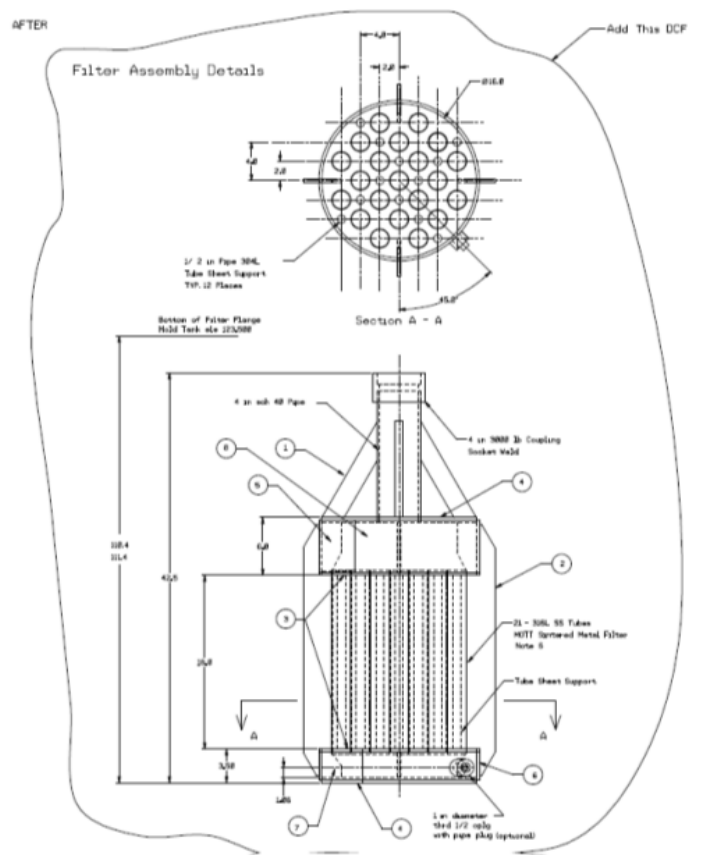

Figure 1-8. ARP Secondary Filter

In ARP, the filtrate from the crossflow filter is passed through a secondary filter prior to entering the LWHT. The secondary filter has a history of becoming fouled even though it has a larger pore size than the primary filter. ${ }^{10}$

\subsection{Experimental}

\subsection{2-S Sample Analysis}

The samples were visually observed and photographed in the SRNL shielded cells.

For the mixed samples (slurries), the following measurements and analyses were performed: $\mathrm{pH}$, solids content (total, soluble and insoluble), density, rheology, particle size analysis, Inductively Coupled Plasma - Emission Spectroscopy (ICP-ES) for metals, including axial detection for sulfur; Ion Chromatography (IC) for anions; and Total Inorganic Carbon/Total Organic Carbon (TIC/TOC).

For filtrate obtained from the slurries, the following measurements and analyses were performed: ICP-ES for metals, including axial detection for sulfur; IC for anions; TIC/TOC; and Free Hydroxide.

For solids isolated from the slurries, the following measurements and analyses were performed: X-ray Diffraction (XRD), Thermogravimetric Analysis (TGA), Scanning Electron Microscopy (SEM), Particle Size Distribution (PSD) analysis, ICP-ES for metals, including axial detection for sulfur; and Cold Vapor Atomic Absorption (CVAA) for mercury. 
Material for filtrate analysis was obtained from LWPT samples via filtration of the slurries through cup filters with $0.45 \mu \mathrm{m}$ nylon membranes. Preparations of the filtrate samples of LWPT and the unfiltered LWHT was by two methods. Preparation for ICP-ES was by dilution with $2 \mathrm{M}$ nitric acid. Preparation for IC anions and wet chemical methods was by dilution with water.

Preparation of slurries for analyses that require dissolution (ICP-ES) was performed by a mixed acid dissolution method. This method uses a combination of nitric and hydrofluoric acids for heated digestion and boric acid for dilution.

Preparation of slurries for analysis by IC for anions was accomplished by a 100-times weighted dilution with water. The liquid phase was analyzed by IC and would include anions that dissolved during the contact of the slurry with water.

Solids were isolated from the slurries by filtering through $0.45 \mu \mathrm{m}$ nylon filters and allowing additional air to pass through the filter cake to minimize interstitial liquid inclusion. The solids were not washed (i.e., rinsed with water) prior to any analysis so that salts that were insoluble at process conditions would not be dissolved. The solids were air dried in the cells. As a result, the isolated insoluble solids contain a contribution from the soluble solids for XRD, SEM and TGA analyses. Prior to the chemical analysis of solids, the material was dried for approximately 12 hours at $120^{\circ} \mathrm{C}$ so that the results would be on a dry unwashed solids basis.

Preparation of isolated solids for analyses that require dissolution (ICP-ES, CVAA Hg) were performed by a mixed acid dissolution method. This method uses a combination of nitric and hydrofluoric acids for heated digestion and boric acid for dilution. For sample LWPT-2, the method needed to be altered to add additional hydrofluoric acid and the dissolution time increased to attain full dissolution of the solids in the sample.

Preparation of solids for PSD analysis involved the settling of solids for removal of high Cs-137 supernate and the addition of nonradioactive simulated supernate for the re-suspension of the solids. Particle size analysis was performed on a Microtrac 100 using scattering mode. LWPT slurry materials were analyzed in nonradioactive simulants of sample supernate (based on the results in Section 3.2.1) that were made from laboratory grade chemicals and filtered with a 0.45 $\mu \mathrm{m}$ nylon filter. The simulated supernate for LWPT-1 and LWPT-2 was $2.2 \mathrm{M} \mathrm{NaOH}, 2.6 \mathrm{M}$ $\mathrm{NaNO}_{3}$, and $0.61 \mathrm{M} \mathrm{NaNO}_{2}$; and the simulated supernate for LWPT-3 was $1.7 \mathrm{M} \mathrm{NaOH}, 0.13 \mathrm{M}$ $\mathrm{NaNO}_{3}$, and $0.029 \mathrm{M} \mathrm{NaNO}_{2}$. Samples were agitated vigorously prior to analysis but samples were not sonicated. Results were obtained for both number and volume distributions. The minimum particle size that the instrument can quantify is $0.7 \mu \mathrm{m}$.

TGA was conducted with a ramp $20{ }^{\circ} \mathrm{C} / \mathrm{min}$ to $900{ }^{\circ} \mathrm{C}$ and with a purge of argon. In addition to the samples, TGA was performed on a separate instrument for various standards important to our system, including MST and sodium oxalate.

The rheological properties of the samples were determined using a Haake M5/RV30 rotoviscometer. The M5/RV30 is a Searle sensor system, where the bob rotates and the cup is fixed. The torque and rotational speed of the bob are measured. The shear stress is determined from the torque measurement and is independent of the rheological properties. Based on the expected particle size of the materials in this investigation, the MV 1 rotor was considered most appropriate. Additional details on this instrument and the measurement technique, including calibration, is reported elsewhere. ${ }^{11}$ 
SRNL-STI-2013-00700

Revision 0

\subsection{Tank 49H Sample Analysis}

Samples HTF-49-13-165 and HTF-49-13-166 were kept separate and samples HTF-49-13-167, HTF-49-13-168, and HTF-49-13-169 were combined into a composite. All samples were filtered with cup filters with $0.45 \mu \mathrm{m}$ nylon membranes and the filtrate was used in the analysis. Small portions of the undiluted samples were removed from the cells for the various chemical (ICP-ES, IC anions, titration) and radiochemical methods (gamma scan, PuTTA, and Sr-90). Carbonate was not analyzed directly, but was estimated from the titration results.

\subsection{Electrolyte Thermodynamic Modelling Details}

Risk of precipitation is evaluated using electrolyte thermodynamic modeling with OLI Systems software for the specific sample results as well as a thorough evaluation of a complete ARP cycle, including cross flow and secondary filter cleaning.

\subsubsection{Evaluation of Samples}

The first of these two evaluations investigates the propensity of each sample to form precipitates. Analytical results from the filtered sample as well as the sample slurry are examined in detail and the calculated solids are compared to the analytical results from the solids filtered from the sample. The calculations are performed in two parts:

- Sample reconciliation

- Survey of isothermal, thermodynamic equilibrium determinations

Reconciliation converts the analytical results into input for the solubility calculations. Analytical results provide elemental concentrations, ion concentrations, and some other data that must all be converted into a charge balanced composition of chemical compounds in order to begin calculating solubility. OLI AnalyzerTM 9.0.12.1 reconciliation function is used to develop this input composition. The reconciliation function accepts ionic components, elemental components, and any compounds found in the databases. The user selects criteria to direct how the input is charge balanced. For these calculations, charge balance is achieved by allowing the sodium concentration to be adjusted up or down. In addition, some judgment is applied to reported elemental concentrations from ICP-ES to determine the most likely oxidation state and a compatible ionic species such that the input includes each elemental result. The output of the calculation provides the likely composition of the solution in terms of ionic species, e.g. true composition, as well as an equivalent chemical compound composition, e.g. apparent composition. The apparent composition contains chemical forms that are the least hydrated and sometimes will appear arbitrary, but will be mass, charge, and oxidation state balanced. The software readily recreates the true composition from the apparent composition. Since the apparent composition list is substantially shorter than the true composition list, the calculated apparent composition is the input for all further calculations.

Several types of calculations may be performed using OLI AnalyzerTM. Each type calculates thermodynamic equilibrium conditions for the given inputs. An isothermal calculation restrains the conditions of the calculation to maintain temperature to a specified value and is used here. A survey of isothermal calculations where one variable is changed will trace an isotherm for that variable. By making a series of calculations over a range of temperatures, multiple isotherms will 
be traced. The survey calculation provides the information needed to evaluate the analytical sample results relative the propensity or risk to form solid precipitates.

In addition to identifying formation of solid precipitates, OLI software calculates relative saturation as a scaling tendency. A scaling tendency value of 1.0 indicates saturation, values less than 1.0 indicate calculated equilibrium concentration relative to the calculated saturation concentration, and values above 1.0 would indicate a supersaturated concentration. However, the calculated results are at equilibrium which means all of the calculated compositions are at or below saturation so none of the results include scaling tendencies above 1.0 unless the user identifies solids to exclude from the calculation.

For each sample, a survey relative to temperature and hydroxide ion concentration provides information to determine the relative risk to form solids as the temperature changes as well as provides information to evaluate the potential risk of solids formation based on variance of in-situ solution from analytical results. In other words, the calculation determines the solids precipitation if the analytically determined hydroxide concentration is in error by up to $20 \%$. Hydroxide is selected as the component most likely to affect solubility in this solution. Since sodium is used to reconcile charge balance, the survey actually varies the $\mathrm{NaOH}$ over a range $20 \%$ above and below the calculated component composition from the reconciliation calculation. The temperature ranged from 15 to $50{ }^{\circ} \mathrm{C}$ in $5{ }^{\circ} \mathrm{C}$ increments, which represents temperature range observed in the Tank $49 \mathrm{H}$ and the ARP tanks.

\subsubsection{Evaluation of ARP Process Cycle}

The results of the first modeling evaluation provide information about the samples. The second evaluation provides comprehensive information of the propensity to precipitate solids in the ARP process by simulating the ARP process cycle. The simulation traces an entire process cycle for each batch feed from Tank $49 \mathrm{H}$ to $241-96 \mathrm{H}$ and through $512-\mathrm{S}$ including cross-flow filter cleaning and secondary filter cleaning. The evaluation identifies where in the process precipitation is likely to occur as well as the process step likely to cause precipitation.

The approach taken here to simulate the ARP process expanded on previous work. The Salt Integrated Project Chemistry Team created a detailed description of the filter cleaning procedure for the purpose of simulating the same. ${ }^{1}$ The ARP process is broken down into a detailed sequential series of steps or operations on each of the main process vessels. The sequence is used to simulate the changing chemical conditions that occur during the cross-flow filter cleaning and the secondary filter cleaning. The description is expanded here in order to capture a complete ARP cycle.

The step-by-step process description is then translated to a chain of OLI ESPTM version 9.1.2 model blocks to simulate the process. Each block calculates the energy and material balance and the equilibrium composition of each resulting stream. The calculated stream compositions are evaluated for predicted solids compositions. At the equivalent process step, simulation results are compared to the results of samples LWPT-1, LWPT-2, LWPT-3, and LWHT-1.

Appendix D contains the detailed step-by-step process description of the ARP process cycle with the assumption of 40 batch transfers from Tank $49 \mathrm{H}$ per cycle. The table shows the effect of each step on a nominal volume balance between each of the tanks as well as holdup volume in the filter. Each initial heel as well as chemical/water addition has a short description. OLI ESPTM 
allows only short descriptors for each model block and stream. The left most column on the table identifies suffix designators used for cross referencing the model blocks and streams in the simulation. For example, the first batch of feed to $241-96 \mathrm{H}$ has a suffix of c01, the second has $\mathrm{c} 02$, and so on. The model descriptors can then be distinguished between batches as "tank 49 out c01", "tank 49 out c02", "tank 49 out c03", etc.

Appendix E shows a diagram of the complete ARP cycle simulation. This diagram has several parts. Each square represents a process step as identified in the table Appendix D. The blocks are labeled with two lines. The top line is the unique identifier in the simulation and the second line identifies the OLI ESPTM simulation process block selected to represent the step. Each connecting arrow represents a simulation stream to connect the blocks. This does not necessarily represent a physical stream in the facility, but will represent a solution that does exist at some point in the process, either as a solution/slurry in a tank or as an actual stream transferred from one tank to another. Every stream has a unique identifier. In addition, some streams, especially input streams have addition information describing the nature, composition and/or quantity. Streams that exit the ARP process to MCU, Tank 50, or the low point pump pit are highlighted in red boxes.

Tank $49 \mathrm{H}$ feed composition input is taken from the apparent composition determined for the Tank $49 \mathrm{H}$ samples in the first evaluation for the analytical sample results. The molecular component composition is used for stream compositions for convenience. The true component list is several times larger than the apparent component list which would increase the possibility of input data entry errors when manipulating the true component list.

The ARP process cycle simulation includes secondary filter cleaning. Secondary filter cleaning is no longer routinely performed since the completion of the Salt Batch $6 \mathrm{~B}$ cycle.

\subsubsection{Common to Both Evaluations}

Earlier work indicated that all HLW calculations should include the public database for the Mixed Solvent Electrolyte (MSE) model/database with default redox chemistry active. ${ }^{1}$ The effect of active redox allows inclusion of reactions in the database that change oxidation state. Allowing default selection identifies the following metals for the inputs used in this analysis: $\mathrm{Al}, \mathrm{Cd}, \mathrm{Cr}$, $\mathrm{Cu}, \mathrm{Fe}, \mathrm{Mn}, \mathrm{Mo}, \mathrm{U}, \mathrm{V}, \mathrm{Zn}$, and $\mathrm{Zr}$.

ARP process should note that the OLI database does not have any information on MST. As such, the risk of titanium solids formation is not simulated. Assessing the risk of titanium solids requires evaluation of results of a specific stream. MST is the dominant solid in the 512-S feed and MST dissolves very slowly in caustic waste solutions. There is no information on the amount of MST that would be in the filter or piping at the start of cleaning, but the OA solution has a significant capacity to dissolve the MST. One method of assessing the risk of titanium oxalate formation is approximating the MST chemistry with one of the sodium titanate compounds in the database. At the least, when MST dissolves, it likely decomposes to its component parts, which would then be expected to behave the same as a dissolved sodium titanate. Effectively, this defines a dissolved titanium capacity for a stream, and then an evaluation of the change in capacity at different points in the process would indicate potential for titanium-containing solid species to precipitate. This approach was demonstrated in earlier work. ${ }^{1}$ Without substantial ancillary analysis, an alternative approach takes advantage of the propensity of the titanium solids to precipitate at the time and location as of sodium oxalate formation because the mixing of the 
OA with $\mathrm{NaOH}$ will cause metal oxalate solid formation including titanium oxalate, assuming the species are above their solubility limits.

Details of the sample calculations are contained along with the results in Section 3.3.1 whereas details of the ARP process cycle simulation are in Section 3.3.2.

\subsection{Filtration Data Details}

Data for the performance of the 512-S filtration system was provided by SRR. The data provided included crossflow transmembrane pressure (TMP), secondary filter TMP, filtrate flow rate, average filter pressure, filter feed flow and system temperature. The data provided for evaluation in this study begins with SB3 which started in June of 2010. Detailed data for SB1 and SB2 were not provided as part of this evaluation. In addition SRR provided the timing of events that would have an impact of the filtration system performance including filter cleaning, filter replacement, system upsets, etc. In the data that was provided, a single data point represents the performance of an individual batch. That data point was taken near the end of the batch when the system was relatively steady. Therefore, the individual data point represents the filter performance at the near steady state and the end of the batch and not the average performance of the batch. As this study progressed, SRNL gained access to PI (the operational data acquisition system) which allowed investigation of the individual batches.

\subsection{Results and Discussion}

Results of the characterization of the Tank $49 \mathrm{H}$ and ARP samples are contained in the first two subsections below. OLI modelling results are contained in the subsequent subsection, followed by the filtration evaluation subsection. The final subsection contains an overall review of the observations and modelling along with an interpretation as applicable to the 512-S facility.

\subsection{Tank 49H Variable Depth Samples}

Table 3-1 and Table 3-2 contain the results for the chemical analysis of the Tank 49H VDS. ICPES results for components at detectable levels are contained in Table 3-1 and results for anions measured by various methods are reported in Table 3-2. The anion/cation balance reveals that the sodium measurement is approximately $90 \%$ of the sum of the anions, with no other major cation present. There is little difference between the chemical results for the samples taken at the different tank levels. This good agreement supports the homogeneity of the soluble components within Tank 49H.

Table 3-3 contains several radioactive components measured in the filtered Tank $49 \mathrm{H}$ samples. As expected, Cs-137 was the primary radioactive component of these samples. The good agreement in the radiochemical results from the three different tank levels also support that the tank supernate is homogenous. These show generally good agreement with the Salt Batch 6 qualification report results although some differences are expected due to the changes in the feed from transfers after the Salt Batch 6 document was written. ${ }^{12}$ 
Table 3-4 contains the weight percent solids measurements and density measurements of the Tank $49 \mathrm{H}$ samples. The insoluble solids contents were calculated as slightly negative values. The uncertainty in the insoluble solids measurements encompasses $0 \mathrm{wt} \%$ insoluble solids. Visual observation is consistent with very low insoluble solids content of the samples. Dissolved and total solids content of the Tank $49 \mathrm{H}$ samples are approximately $34 \mathrm{wt} \%$, which is consistent with the analogous dissolved solids content of LWPT-1 and LWPT-2 and the total solids content of LWHT-1. A single density measurement was performed at each Tank $49 \mathrm{H}$ tank level, and the results ranged from 1.28 to $1.30 \mathrm{~g} / \mathrm{mL}$. It is likely that these density measurements are the same within the uncertainty in the measurement. The wt \% solids and density measurements from the Tank $49 \mathrm{H}$ samples at different tank levels also confirm that the Tank $49 \mathrm{H}$ supernate appears nearly homogeneous.

Carbonate was estimated through the titration results rather than through a TIC measurement. Carbonate in Tank $49 \mathrm{H}$ estimated through the titration results match the TIC values reported for LWPT-1, LWPT-2, and LWHT-1 reported in Section 3.2.

Table 3-1. Elemental analysis of filtered Tank 49H VDS

\begin{tabular}{c|c|c|c|cc}
\hline $\begin{array}{c}\text { element } \\
(\mathrm{mg} / \mathrm{L})\end{array}$ & HTF-49-13-165 & HTF-49-13-166 & HTF-49-13-167/8/9 & \multicolumn{2}{|c}{ Tank 49H Overall } \\
\hline $\mathrm{Al}$ & $5.23 \mathrm{E}+03$ & $5.41 \mathrm{E}+03$ & $5.39 \mathrm{E}+03$ & $5.34 \mathrm{E}+03$ & $1.8 \%$ \\
\hline $\mathrm{B}$ & $5.10 \mathrm{E}+01$ & $5.14 \mathrm{E}+01$ & $5.27 \mathrm{E}+01$ & $5.17 \mathrm{E}+01$ & $1.7 \%$ \\
\hline $\mathrm{Cr}$ & $4.60 \mathrm{E}+01$ & $4.58 \mathrm{E}+01$ & $4.58 \mathrm{E}+01$ & $4.59 \mathrm{E}+01$ & $0.3 \%$ \\
\hline $\mathrm{Cu}$ & $2.05 \mathrm{E}+01$ & $1.95 \mathrm{E}+01$ & $1.92 \mathrm{E}+01$ & $1.97 \mathrm{E}+01$ & $3.4 \%$ \\
\hline $\mathrm{Fe}$ & $4.26 \mathrm{E}+00$ & $5.31 \mathrm{E}+00$ & $5.36 \mathrm{E}+00$ & $4.98 \mathrm{E}+00$ & $12.5 \%$ \\
\hline $\mathrm{K}$ & $3.47 \mathrm{E}+02$ & $4.01 \mathrm{E}+02$ & $4.16 \mathrm{E}+02$ & $3.88 \mathrm{E}+02$ & $9.4 \%$ \\
\hline $\mathrm{Li}$ & $2.13 \mathrm{E}+01$ & $2.21 \mathrm{E}+01$ & $2.39 \mathrm{E}+01$ & $2.24 \mathrm{E}+01$ & $5.9 \%$ \\
\hline $\mathrm{Na}$ & $1.38 \mathrm{E}+05$ & $1.39 \mathrm{E}+05$ & $1.39 \mathrm{E}+05$ & $1.39 \mathrm{E}+05$ & $0.4 \%$ \\
\hline $\mathrm{P}$ & $1.83 \mathrm{E}+02$ & $1.84 \mathrm{E}+02$ & $1.73 \mathrm{E}+02$ & $1.80 \mathrm{E}+02$ & $3.4 \%$ \\
\hline $\mathrm{S}$ & $3.12 \mathrm{E}+03$ & $3.15 \mathrm{E}+03$ & $3.20 \mathrm{E}+03$ & $3.16 \mathrm{E}+03$ & $1.3 \%$ \\
\hline $\mathrm{Si}$ & $3.71 \mathrm{E}+01$ & $3.76 \mathrm{E}+01$ & $3.93 \mathrm{E}+01$ & $3.80 \mathrm{E}+01$ & $3.0 \%$ \\
\hline $\mathrm{Zn}$ & $5.30 \mathrm{E}+00$ & $5.27 \mathrm{E}+00$ & $5.16 \mathrm{E}+00$ & $5.24 \mathrm{E}+00$ & $1.4 \%$ \\
\hline
\end{tabular}


Table 3-2. Ion analysis of filtered Tank 49H VDS

\begin{tabular}{c|c|c|c|cc}
\hline analyte & HTF-49-13-165 & HTF-49-13-166 & HTF-49-13-167/8/9 & \multicolumn{2}{c}{ Tank 49H Overall } \\
Average & RSD \\
\hline $\mathrm{OH}^{-}$ & $2.38 \mathrm{E}+00$ & $2.36 \mathrm{E}+00$ & $2.37 \mathrm{E}+00$ & $2.37 \mathrm{E}+00$ & $0.4 \%$ \\
\hline $\mathrm{NO}_{3}{ }^{-}$ & $2.71 \mathrm{E}+00$ & $2.61 \mathrm{E}+00$ & $2.71 \mathrm{E}+00$ & $2.68 \mathrm{E}+00$ & $2.1 \%$ \\
\hline $\mathrm{NO}_{2}{ }^{-}$ & $5.87 \mathrm{E}-01$ & $5.67 \mathrm{E}-01$ & $5.98 \mathrm{E}-01$ & $5.84 \mathrm{E}-01$ & $2.6 \%$ \\
\hline $\mathrm{CO}_{3}{ }^{2-}$ & $3.40 \mathrm{E}-01$ & $3.60 \mathrm{E}-01$ & $3.00 \mathrm{E}-01$ & $3.33 \mathrm{E}-01$ & $9.2 \%$ \\
\hline $\mathrm{SO}_{4}{ }^{2-}$ & $7.40 \mathrm{E}-02$ & $6.88 \mathrm{E}-02$ & $7.05 \mathrm{E}-02$ & $7.11 \mathrm{E}-02$ & $3.7 \%$ \\
\hline $\mathrm{C}_{2} \mathrm{O}_{4}{ }^{2-}$ & $3.06 \mathrm{E}-03$ & $2.86 \mathrm{E}-03$ & $2.94 \mathrm{E}-03$ & $2.95 \mathrm{E}-03$ & $3.3 \%$ \\
\hline $\mathrm{PO}_{4}{ }^{3-}$ & $4.55 \mathrm{E}-03$ & $4.34 \mathrm{E}-03$ & $4.49 \mathrm{E}-03$ & $4.46 \mathrm{E}-03$ & $2.5 \%$ \\
\hline $\mathrm{CHO}_{2}{ }^{-}$ & $8.36 \mathrm{E}-03$ & $6.91 \mathrm{E}-03$ & $8.33 \mathrm{E}-03$ & $7.87 \mathrm{E}-03$ & $10.5 \%$ \\
\hline $\mathrm{Cl}^{-}$ & $3.44 \mathrm{E}-03$ & $2.11 \mathrm{E}-03$ & $3.69 \mathrm{E}-03$ & $3.08 \mathrm{E}-03$ & $27.5 \%$ \\
\hline $\mathrm{AlO}_{2}{ }^{-}$ & $1.94 \mathrm{E}-01$ & $2.00 \mathrm{E}-01$ & $2.00 \mathrm{E}-01$ & $1.98 \mathrm{E}-01$ & $1.8 \%$ \\
\hline anions & $6.73 \mathrm{E}+00$ & $6.63 \mathrm{E}+00$ & $6.65 \mathrm{E}+00$ & $6.67 \mathrm{E}+00$ & $0.8 \%$ \\
\hline $\mathrm{Na}^{+}$ & $6.00 \mathrm{E}+00$ & $6.04 \mathrm{E}+00$ & $6.04 \mathrm{E}+00$ & $6.03 \mathrm{E}+00$ & $0.4 \%$ \\
\hline cation/anion & $89 \%$ & $91 \%$ & $91 \%$ & $90 \%$ & $1.2 \%$ \\
\hline
\end{tabular}

Table 3-3. Radiochemical analysis of Tank 49H VDS

\begin{tabular}{c|c|c|c|cc}
\hline analyte & \multirow{2}{*}{ HTF-49-13-165 } & HTF-49-13-166 & \multirow{2}{*}{ HTF-49-13-167/8/9 } & \multicolumn{2}{|c}{ Tank 49H Overall } \\
(dpm/mL) & & & & Average & RSD \\
\hline $\mathrm{Sr}-90$ & $4.26 \mathrm{E}+05$ & $3.33 \mathrm{E}+05$ & $4.27 \mathrm{E}+05$ & $3.95 \mathrm{E}+05$ & $13.7 \%$ \\
\hline $\mathrm{Cs}-137$ & $1.33 \mathrm{E}+08$ & $1.35 \mathrm{E}+08$ & $1.36 \mathrm{E}+08$ & $1.35 \mathrm{E}+08$ & $1.1 \%$ \\
\hline $\mathrm{Pu}-238$ & $3.07 \mathrm{E}+04$ & $2.81 \mathrm{E}+04$ & $3.07 \mathrm{E}+04$ & $2.98 \mathrm{E}+04$ & $5.0 \%$ \\
\hline $\mathrm{Pu}-239 / 240$ & $3.68 \mathrm{E}+03$ & $3.14 \mathrm{E}+03$ & $3.36 \mathrm{E}+03$ & $3.39 \mathrm{E}+03$ & $8.0 \%$ \\
\hline
\end{tabular}

Table 3-4. Solids quantitative analysis and density measurements of Tank 49H VDS

\begin{tabular}{l|c|c|c|c|c|c|c|c|c}
\hline \multirow{2}{*}{ Sample } & \multicolumn{3}{|c|}{$\begin{array}{c}\text { Total Solids } \\
\text { (wt\% in slurry) }\end{array}$} & \multicolumn{2}{c|}{$\begin{array}{c}\text { Dissolved Solids } \\
\text { (wt\% in filtrate) }\end{array}$} & \multicolumn{2}{|c|}{$\begin{array}{c}\text { Insoluble Solids } \\
\text { (wt\% in slurry) }\end{array}$} & \multirow{2}{*}{$\begin{array}{c}\text { Density } \\
\text { (g/mL) }\end{array}$} \\
& avg. & st.dev. & $\mathrm{n}$ & avg. & st.dev. & $\mathrm{n}$ & avg. & 95\% C.I. & \\
\hline HTF-49-13-165 & 33.7 & 0.3 & 2 & 34.1 & 0.5 & 4 & -0.6 & 1.5 & 1.28 \\
HTF-49-13-166 & 33.7 & 0.2 & 2 & 33.9 & 0.2 & 4 & -0.4 & 0.8 & 1.30 \\
HTF-49-13-167/8/9 & 33.8 & 0.2 & 2 & 33.9 & 0.4 & 4 & -0.04 & 1.2 & 1.29 \\
\hline
\end{tabular}




\subsection{2-S Samples}

\subsubsection{Chemical Analyses}

Chemical analysis of the various preparations of the LWPT and LWHT samples are reported in Table 3-5 through Table 3-9. Table 3-5 and Table 3-7 contain the analytical results for the portions of the LWPT samples passed through a $0.45 \mu \mathrm{m}$ nylon filter and the relatively solids free LWHT sample without filtration. Results are reported on a liquid basis. Table 3-6 and Table 3-8 contain analysis of the LWPT samples including suspended solids, and an additional analysis of the LWHT sample without filtration. Results are reported on a wet slurry volume basis. Table 3-9 contains the analysis of the solids that were isolated from the slurry by filtration and dried unwashed. Results are on a dried unwashed solids mass basis.

The average values and the relative standard deviations (RSD) are reported where replicate preparations and measurements were performed. Average values are preceded by " $<$ " when the analyte is below the limits of quantification. The RSD values are not reported when all measurements are below the limits of quantification. Average values are preceded by " $<=$ " (meaning "less than or equal to") when values above the limits of quantification are combined with other values taken at the limits of quantification.

From Table 3-5 and Table 3-7, the filtrate from LWPT-1 and LWPT-2 matches LWHT-1 very well for all analytes with the exception of titanium. This agreement is expected, as in the absence of dissolution or precipitation, supernate components are not thought to change during the filtration process. Comparable with the expected SB 6D feed, LWPT-1, LWPT-2, and LWHT-1 were high in sodium nitrate and sodium hydroxide with significant amounts of nitrite, aluminate and carbonate and smaller amounts of sulfate, phosphate and oxalate. The titanium ranged from $7.1 \mathrm{mg} / \mathrm{L}$ in the acid dilution of the as-received LWHT-1 sample, to $13.9 \mathrm{mg} / \mathrm{L}$ and $23.8 \mathrm{mg} / \mathrm{L}$ in the laboratory filtered and acid diluted LWPT-1 and LWPT-2 samples, respectively.

Comparing the liquid portions of ARP samples LWPT-1, LWPT-2, and LWHT-1 reported in Table 3-7 with the filtered Tank $49 \mathrm{H}$ samples reported in Table 3-2, one key difference is the lower concentration of oxalate in the ARP samples. The liquid portion of the ARP feed in Tank $49 \mathrm{H}$ had $3.0 \mathrm{mM}$ oxalate while the liquid portion of the ARP samples had $1.1 \mathrm{mM}$ oxalate, indicating that oxalate may have subsequently precipitated in Tank $49 \mathrm{H}$ or in the ARP process. As will be seen in the chemical equilibrium modeling in Section 3.3, both the Tank 49H samples and the ARP samples LWPT-1, LWPT-2, and LWHT-1 appear to be supersaturated with respect to sodium oxalate.

Filtrate from LWPT-3 differs significantly from the other materials; however, as LWPT-3 is heel material after cleaning of the crossflow filter with oxalic acid and $\mathrm{pH}$ adjustment with sodium hydroxide. Hydroxide concentration remained high at $1.7 \mathrm{M}$, but most other salt components were significantly diluted in LWPT-3, approximately 20-times diluted (based on Al) from the process values. This dilution does not hold true for oxalate and carbonate. Oxalate is added during the cleaning process so its increased representation in LWPT-3 is expected. Carbonate is not intentionally added to the process and shows a dilution of approximately 6-times versus the expected 20-times dilution for inert components. This may indicate either that filter cleaning is solubilizing carbonates or that some other process is introducing carbonates to LWPT-3 (such as the decomposition of oxalate). 
Table 3-5. Elemental analysis of filtered LWPT samples and as-received LWHT sample

\begin{tabular}{|c|c|c|c|c|c|c|c|c|}
\hline \multirow{2}{*}{$\begin{array}{c}\text { element } \\
(\mathrm{mg} / \mathrm{L})\end{array}$} & \multicolumn{2}{|c|}{ LWPT-1 filtrate } & \multicolumn{2}{|c|}{ LWPT-2 filtrate } & \multicolumn{2}{|c|}{ LWHT-1 } & \multicolumn{2}{|c|}{ LWPT-3 filtrate } \\
\hline & average & RSD & average & RSD & average & RSD & average & RSD \\
\hline $\mathrm{Ag}$ & $<2.43 E+00$ & -- & $<2.57 E+00$ & -- & $<2.52 E+00$ & -- & $<2.52 E+00$ & -- \\
\hline $\mathrm{Al}$ & $5.30 \mathrm{E}+03$ & $0.2 \%$ & $5.32 \mathrm{E}+03$ & $0.8 \%$ & $5.34 \mathrm{E}+03$ & $0.4 \%$ & $2.45 \mathrm{E}+02$ & $0.4 \%$ \\
\hline $\mathrm{B}$ & $5.32 \mathrm{E}+01$ & $0.4 \%$ & $5.33 \mathrm{E}+01$ & $0.8 \%$ & $5.34 \mathrm{E}+01$ & $0.4 \%$ & $<=9.99 E-01$ & $1.1 \%$ \\
\hline $\mathrm{Ba}$ & $<1.60 E+00$ & -- & $<1.69 E+00$ & -- & $<1.66 E+00$ & -- & $<1.66 E+00$ & -- \\
\hline $\mathrm{Be}$ & $<2.29 E-01$ & -- & $<2.42 E-01$ & -- & $<2.38 E-01$ & -- & $<2.38 E-01$ & -- \\
\hline $\mathrm{Ca}$ & $<3.90 E+00$ & -- & $<4.12 E+00$ & -- & $<4.04 E+00$ & -- & $<=5.56 E+00$ & $47 \%$ \\
\hline $\mathrm{Cd}$ & $<3.21 E+00$ & -- & $<3.39 E+00$ & -- & $<3.33 E+00$ & -- & $<3.33 E+00$ & -- \\
\hline $\mathrm{Ce}$ & $<2.00 E+01$ & -- & $<2.12 E+01$ & -- & $<2.08 E+01$ & -- & $<2.08 E+01$ & -- \\
\hline $\mathrm{Co}$ & $<4.86 E+00$ & -- & $<5.13 E+00$ & -- & $<5.04 E+00$ & -- & $<5.04 E+00$ & -- \\
\hline $\mathrm{Cr}$ & $4.55 \mathrm{E}+01$ & $1.3 \%$ & $4.54 \mathrm{E}+01$ & $0.8 \%$ & $4.58 \mathrm{E}+01$ & $0.2 \%$ & $<3.90 E+00$ & -- \\
\hline $\mathrm{Cu}$ & $<2.06 E+00$ & -- & $<2.18 E+00$ & -- & $<2.14 E+00$ & -- & $<2.14 E+00$ & -- \\
\hline $\mathrm{Fe}$ & $<=5.99 E+00$ & $38 \%$ & $<=6.82 E+00$ & $47 \%$ & $<4.85 E+00$ & -- & $<4.85 E+00$ & -- \\
\hline $\mathrm{Gd}$ & $<4.40 E+00$ & -- & $<4.65 E+00$ & -- & $<4.56 E+00$ & -- & $<4.57 E+00$ & -- \\
\hline $\mathrm{K}$ & $3.74 \mathrm{E}+02$ & $5.2 \%$ & $3.91 \mathrm{E}+02$ & $2.0 \%$ & $3.96 \mathrm{E}+02$ & $2.0 \%$ & $<9.37 E+01$ & -- \\
\hline $\mathrm{La}$ & $<1.79 E+00$ & -- & $<1.89 E+00$ & -- & $<1.85 E+00$ & -- & $<1.85 E+00$ & -- \\
\hline $\mathrm{Li}$ & $4.65 \mathrm{E}+00$ & $4.0 \%$ & $4.86 \mathrm{E}+00$ & $3.7 \%$ & $4.57 \mathrm{E}+00$ & $11 \%$ & $<2.28 E+00$ & -- \\
\hline $\mathrm{Mg}$ & $<=2.64 E-01$ & $17 \%$ & $<=2.50 E-01$ & $8.1 \%$ & $<2.38 E-01$ & -- & $<2.38 E-01$ & -- \\
\hline $\mathrm{Mn}$ & $<5.50 E-01$ & -- & $<5.81 E-01$ & -- & $<5.71 E-01$ & -- & $<5.71 E-01$ & -- \\
\hline Mo & $<9.81 E+00$ & -- & $<1.04 E+01$ & -- & $<=1.07 E+01$ & $8.3 \%$ & $<1.02 E+01$ & -- \\
\hline $\mathrm{Na}$ & $1.51 \mathrm{E}+05$ & $0.3 \%$ & $1.51 \mathrm{E}+05$ & $0.1 \%$ & $1.51 \mathrm{E}+05$ & $0.5 \%$ & $5.15 \mathrm{E}+04$ & $0.5 \%$ \\
\hline $\mathrm{Ni}$ & $<6.19 E+00$ & -- & $<6.54 E+00$ & -- & $<6.42 E+00$ & -- & $<6.42 E+00$ & -- \\
\hline $\mathrm{P}$ & $1.84 \mathrm{E}+02$ & $4.3 \%$ & $<1.88 E+02$ & -- & $<=1.89 E+02$ & $6.2 \%$ & $<1.85 E+02$ & -- \\
\hline $\mathrm{Pb}$ & $<2.25 E+01$ & -- & $<2.37 E+01$ & -- & $<2.33 E+01$ & -- & $<2.33 E+01$ & -- \\
\hline $\mathrm{S}$ & $2.93 \mathrm{E}+03$ & $0.1 \%$ & $2.93 \mathrm{E}+03$ & $0.9 \%$ & $2.97 \mathrm{E}+03$ & $1.4 \%$ & $<3.35 E+02$ & -- \\
\hline $\mathrm{Sb}$ & $<6.65 E+01$ & -- & $<7.02 E+01$ & -- & $<6.89 E+01$ & -- & $<6.90 E+01$ & -- \\
\hline $\mathrm{Si}$ & $<4.43 E+01$ & -- & $<4.68 E+01$ & -- & $<4.60 E+01$ & -- & $<4.60 E+01$ & -- \\
\hline $\mathrm{Sn}$ & $<4.09 E+01$ & -- & $<4.32 E+01$ & -- & $<4.24 E+01$ & -- & $<4.24 E+01$ & -- \\
\hline $\mathrm{Sr}$ & $<2.29 E-01$ & -- & $<2.42 E-01$ & -- & $<2.38 E-01$ & -- & $<2.38 E-01$ & -- \\
\hline Th & $<2.19 E+01$ & -- & $<2.31 E+01$ & -- & $<2.27 E+01$ & -- & $<2.27 E+01$ & -- \\
\hline $\mathrm{Ti}$ & $1.39 \mathrm{E}+01$ & $0.5 \%$ & $2.38 \mathrm{E}+01$ & $0.4 \%$ & $7.09 \mathrm{E}+00$ & $0.1 \%$ & $<1.66 E+00$ & -- \\
\hline $\mathrm{U}$ & $<1.01 E+02$ & -- & $<1.07 E+02$ & -- & $<1.05 E+02$ & -- & $<1.05 E+02$ & -- \\
\hline $\mathrm{V}$ & $<1.65 E+00$ & -- & $<1.74 E+00$ & -- & $<1.71 E+00$ & -- & $<1.71 E+00$ & -- \\
\hline $\mathrm{Zn}$ & $5.03 \mathrm{E}+00$ & $0.9 \%$ & $<=4.87 E+00$ & $2.5 \%$ & $5.15 \mathrm{E}+00$ & $3.9 \%$ & $<4.71 E+00$ & -- \\
\hline $\mathrm{Zr}$ & $<1.42 E+00$ & -- & $<1.50 E+00$ & -- & $<1.47 E+00$ & -- & $<1.47 E+00$ & -- \\
\hline
\end{tabular}


SRNL-STI-2013-00700

Revision 0

Table 3-6. Elemental analysis of as-received samples from LWPT and LWHT

\begin{tabular}{|c|c|c|c|c|c|c|c|}
\hline \multirow{2}{*}{$(\mathrm{mg} / \mathrm{L})$} & \multicolumn{2}{|c|}{ LWPT-1 } & \multicolumn{2}{|c|}{ LWPT-2 } & \multirow{2}{*}{ LWHT-1 } & \multicolumn{2}{|c|}{ LWPT-3 } \\
\hline & average & RSD & average & RSD & & average & RSD \\
\hline $\mathrm{Ag}$ & $<6.79 E+01$ & -- & $<6.68 E+01$ & -- & $<6.72 E+01$ & $<5.64 E+01$ & -- \\
\hline $\mathrm{Al}$ & $4.32 \mathrm{E}+03$ & $16 \%$ & $5.19 \mathrm{E}+03$ & $2.8 \%$ & $5.32 \mathrm{E}+03$ & $<=1.98 E+02$ & $9 \%$ \\
\hline $\mathrm{Ba}$ & $<8.97 E+00$ & -- & $<8.83 E+00$ & -- & $<8.87 E+00$ & $<7.45 E+00$ & -- \\
\hline $\mathrm{Be}$ & $<6.41 E+00$ & -- & $<6.31 E+00$ & -- & $<6.33 E+00$ & $<5.32 E+00$ & -- \\
\hline $\mathrm{Ca}$ & $<1.08 E+02$ & -- & $<1.07 E+02$ & -- & $<1.07 E+02$ & $<8.99 E+01$ & -- \\
\hline $\mathrm{Cd}$ & $<7.82 E+01$ & -- & $<7.69 E+01$ & -- & $<7.73 E+01$ & $<6.49 E+01$ & -- \\
\hline $\mathrm{Ce}$ & $<5.60 E+02$ & -- & $<5.51 E+02$ & -- & $<5.54 E+02$ & $<4.65 E+02$ & -- \\
\hline $\mathrm{Co}$ & $<1.36 E+02$ & -- & $<1.33 E+02$ & -- & $<1.34 E+02$ & $<1.12 E+02$ & -- \\
\hline $\mathrm{Cr}$ & $<8.65 E+01$ & -- & $<8.51 E+01$ & -- & $<8.55 E+01$ & $<7.18 E+01$ & -- \\
\hline $\mathrm{Cu}$ & $<5.77 E+01$ & -- & $<5.68 E+01$ & -- & $<5.69 E+01$ & $<4.79 E+01$ & -- \\
\hline $\mathrm{Fe}$ & $<1.30 E+02$ & -- & $<=1.94 E+02$ & $59 \%$ & $<1.29 E+02$ & $<1.09 E+02$ & -- \\
\hline Gd & $<1.50 E+02$ & -- & $<1.48 E+02$ & -- & $<1.49 E+02$ & $<1.25 E+02$ & -- \\
\hline $\mathrm{K}$ & $<3.33 E+03$ & -- & $<3.28 E+03$ & -- & $<3.29 E+03$ & $<2.76 E+03$ & -- \\
\hline $\mathrm{La}$ & $<5.00 E+01$ & -- & $<4.92 E+01$ & -- & $<4.94 E+01$ & $<4.15 E+01$ & -- \\
\hline $\mathrm{Li}$ & $<6.09 E+01$ & -- & $<5.99 E+01$ & -- & $<6.02 E+01$ & $<5.05 E+01$ & -- \\
\hline $\mathrm{Mg}$ & $<6.41 E+00$ & -- & $<6.31 E+00$ & -- & $<6.33 E+00$ & $<5.32 E+00$ & -- \\
\hline $\mathrm{Mn}$ & $<5.83 E+01$ & -- & $<5.74 E+01$ & -- & $<5.76 E+01$ & $<4.84 E+01$ & -- \\
\hline Mo & $<5.31 E+02$ & -- & $<5.23 E+02$ & -- & $<5.25 E+02$ & $<4.42 E+02$ & -- \\
\hline $\mathrm{Na}$ & $1.51 \mathrm{E}+05$ & $2.3 \%$ & $1.51 \mathrm{E}+05$ & $1.3 \%$ & $1.56 \mathrm{E}+05$ & $5.26 \mathrm{E}+04$ & $3 \%$ \\
\hline $\mathrm{Ni}$ & $<1.72 E+02$ & -- & $<1.70 E+02$ & -- & $<1.70 E+02$ & $<1.43 E+02$ & -- \\
\hline $\mathrm{P}$ & $<1.17 E+03$ & -- & $<1.15 E+03$ & -- & $<1.15 E+03$ & $<9.69 E+02$ & -- \\
\hline $\mathrm{Pb}$ & $<6.28 E+02$ & -- & $<6.18 E+02$ & -- & $<6.21 E+02$ & $<5.22 E+02$ & -- \\
\hline $\mathrm{S}$ & $2.90 \mathrm{E}+03$ & $2.3 \%$ & $2.92 \mathrm{E}+03$ & $1.9 \%$ & $2.89 \mathrm{E}+03$ & $<7.63 E+02$ & -- \\
\hline $\mathrm{Sb}$ & $<1.86 E+03$ & -- & $<1.83 E+03$ & -- & $<1.83 E+03$ & $<1.54 E+03$ & -- \\
\hline $\mathrm{Sn}$ & $<7.44 E+02$ & -- & $<7.32 E+02$ & -- & $<7.35 E+02$ & $<6.18 E+02$ & -- \\
\hline $\mathrm{Sr}$ & $<6.41 E+00$ & -- & $<6.31 E+00$ & -- & $<6.33 E+00$ & $<5.32 E+00$ & -- \\
\hline Th & $<3.62 E+02$ & -- & $<3.56 E+02$ & -- & $<3.58 E+02$ & $<3.01 E+02$ & -- \\
\hline $\mathrm{Ti}$ & $9.04 \mathrm{E}+02$ & $0.6 \%$ & $3.11 \mathrm{E}+03$ & $1.7 \%$ & $<4.37 E+01$ & $3.24 \mathrm{E}+02$ & $2 \%$ \\
\hline $\mathrm{U}$ & $<2.50 E+03$ & -- & $<2.46 E+03$ & -- & $<2.48 E+03$ & $<2.08 E+03$ & -- \\
\hline $\mathrm{V}$ & $<4.55 E+01$ & -- & $<4.48 E+01$ & -- & $<4.50 E+01$ & $<3.78 E+01$ & -- \\
\hline $\mathrm{Zn}$ & $<5.13 E+01$ & -- & $<5.05 E+01$ & -- & $<5.07 E+01$ & $<4.26 E+01$ & -- \\
\hline $\mathrm{Zr}$ & $<3.97 E+01$ & -- & $<3.91 E+01$ & -- & $<3.93 E+01$ & $<3.30 E+01$ & -- \\
\hline
\end{tabular}


Table 3-7. Ion analysis of filtered LWPT samples and as-received LWHT sample

\begin{tabular}{c|c|c|c|c|c|c|c|c}
\hline \multirow{2}{*}{$\begin{array}{c}\text { analyte } \\
(\mathrm{M})\end{array}$} & \multicolumn{2}{|c|}{ LWPT-1 filtrate } & \multicolumn{2}{c|}{ LWPT-2 filtrate } & \multicolumn{2}{c}{ LWHT-1 } & \multicolumn{2}{c}{ LWPT-3 filtrate } \\
\hline $\mathrm{OH}^{-}$ & $2.22 \mathrm{E}+00$ & $2.6 \%$ & $2.16 \mathrm{E}+00$ & $2.4 \%$ & $2.23 \mathrm{E}+00$ & $1.1 \%$ & $1.70 \mathrm{E}+00$ & $6.5 \%$ \\
\hline $\mathrm{NO}_{3}{ }^{-}$ & $2.54 \mathrm{E}+00$ & $1.0 \%$ & $2.61 \mathrm{E}+00$ & $1.3 \%$ & $2.57 \mathrm{E}+00$ & $1.3 \%$ & $1.25 \mathrm{E}-01$ & $1.3 \%$ \\
\hline $\mathrm{NO}_{2}{ }^{-}$ & $5.87 \mathrm{E}-01$ & $1.2 \%$ & $6.16 \mathrm{E}-01$ & $0.4 \%$ & $6.10 \mathrm{E}-01$ & $1.2 \%$ & $2.90 \mathrm{E}-02$ & $1.7 \%$ \\
\hline $\mathrm{CO}_{3}{ }^{2-}$ & $2.83 \mathrm{E}-01$ & $2.3 \%$ & $2.88 \mathrm{E}-01$ & $2.5 \%$ & $2.84 \mathrm{E}-01$ & $0.9 \%$ & $4.90 \mathrm{E}-02$ & $5.4 \%$ \\
\hline $\mathrm{SO}_{4}{ }^{2-}$ & $6.38 \mathrm{E}-02$ & $1.2 \%$ & $6.96 \mathrm{E}-02$ & $1.5 \%$ & $6.75 \mathrm{E}-02$ & $3.4 \%$ & $3.30 \mathrm{E}-03$ & $3.1 \%$ \\
\hline $\mathrm{C}_{2} \mathrm{O}_{4}{ }^{2-}$ & $1.11 \mathrm{E}-03$ & $1.8 \%$ & $1.19 \mathrm{E}-03$ & $1.2 \%$ & $1.17 \mathrm{E}-03$ & $0.7 \%$ & $3.43 \mathrm{E}-02$ & $2.0 \%$ \\
\hline $\mathrm{PO}_{4}{ }^{3-}$ & $2.30 \mathrm{E}-03$ & $0.3 \%$ & $2.49 \mathrm{E}-03$ & $1.9 \%$ & $2.49 \mathrm{E}-03$ & $1.3 \%$ & $<5.47 \mathrm{E}-04$ & -- \\
\hline $\mathrm{CHO}_{2}{ }^{-}$ & $<1.09 \mathrm{E}-02$ & -- & $<1.13 \mathrm{E}-02$ & -- & $<1.16 \mathrm{E}-02$ & -- & $<1.15 \mathrm{E}-02$ & -- \\
\hline $\mathrm{F}^{-}$ & $<2.58 \mathrm{E}-02$ & -- & $<2.69 \mathrm{E}-02$ & -- & $<2.75 \mathrm{E}-02$ & -- & $<2.74 \mathrm{E}-02$ & -- \\
\hline $\mathrm{Cl}^{-}$ & $<1.38 \mathrm{E}-02$ & -- & $<1.44 \mathrm{E}-02$ & -- & $<1.47 \mathrm{E}-02$ & -- & $<1.47 \mathrm{E}-02$ & -- \\
\hline $\mathrm{Br}^{-}$ & $<6.13 \mathrm{E}-02$ & -- & $<6.39 \mathrm{E}-02$ & -- & $<6.53 \mathrm{E}-02$ & -- & $<6.51 \mathrm{E}-02$ & - \\
\hline $\mathrm{AlO}_{2}{ }^{-}$ & $1.97 \mathrm{E}-01$ & $0.2 \%$ & $1.97 \mathrm{E}-01$ & $0.8 \%$ & $1.98 \mathrm{E}-01$ & $0.4 \%$ & $9.07 \mathrm{E}-03$ & $0.4 \%$ \\
\hline sum anions & $6.25 \mathrm{E}+00$ & -- & $6.31 \mathrm{E}+00$ & -- & $6.12 \mathrm{E}+00$ & -- & $2.02 \mathrm{E}+00$ & -- \\
\hline $\mathrm{Na}^{+}$ & $6.57 \mathrm{E}+00$ & $0.3 \%$ & $6.57 \mathrm{E}+00$ & $0.1 \%$ & $6.57 \mathrm{E}+00$ & $0.5 \%$ & $2.24 \mathrm{E}+00$ & $0.5 \%$ \\
\hline cation/anion & $105 \%$ & -- & $104 \%$ & -- & $107 \%$ & -- & $111 \%$ & -- \\
\hline
\end{tabular}

Table 3-8. Ion analysis of as-received slurries from LWPT

\begin{tabular}{c|c|c|c|c|c|c}
\hline \multirow{2}{*}{$(\mathrm{M})$} & \multicolumn{2}{|c|}{ LWPT-1 } & \multicolumn{2}{c|}{ LWPT-2 } & \multicolumn{2}{c}{ LWPT-3 } \\
& average & RSD & average & RSD & average & RSD \\
\hline $\mathrm{NO}_{3}{ }^{-}$ & $2.63 \mathrm{E}+00$ & $0.9 \%$ & $2.66 \mathrm{E}+00$ & $2.5 \%$ & $1.26 \mathrm{E}-01$ & $0.4 \%$ \\
\hline $\mathrm{NO}_{2}{ }^{-}$ & $6.19 \mathrm{E}-01$ & $1.7 \%$ & $6.25 \mathrm{E}-01$ & $0.7 \%$ & $2.91 \mathrm{E}-02$ & $0.5 \%$ \\
\hline $\mathrm{CO}_{3}{ }^{2-}$ & $2.80 \mathrm{E}-01$ & $1.0 \%$ & $2.81 \mathrm{E}-01$ & $1.0 \%$ & $4.56 \mathrm{E}-02$ & $4.5 \%$ \\
\hline $\mathrm{SO}_{4}{ }^{2-}$ & $6.82 \mathrm{E}-02$ & $0.7 \%$ & $6.90 \mathrm{E}-02$ & $0.4 \%$ & $3.31 \mathrm{E}-03$ & $6.1 \%$ \\
\hline $\mathrm{C}_{2} \mathrm{O}_{4}{ }^{2-}$ & $1.17 \mathrm{E}-03$ & $1.0 \%$ & $1.25 \mathrm{E}-03$ & $0.9 \%$ & $3.34 \mathrm{E}-02$ & $2.3 \%$ \\
\hline $\mathrm{F}^{-}$ & $<2.64 \mathrm{E}-02$ & -- & $<2.73 \mathrm{E}-02$ & -- & $<2.94 \mathrm{E}-02$ & - \\
\hline $\mathrm{CHO}_{2}{ }^{-}$ & $<1.11 \mathrm{E}-02$ & -- & $<1.15 \mathrm{E}-02$ & -- & $<1.24 \mathrm{E}-02$ & -- \\
\hline $\mathrm{Cl}^{-}$ & $<1.42 \mathrm{E}-02$ & -- & $<1.46 \mathrm{E}-02$ & -- & $<1.57 \mathrm{E}-02$ & -- \\
\hline $\mathrm{PO}_{4}{ }^{3-}$ & $2.34 \mathrm{E}-03$ & $1.3 \%$ & $2.41 \mathrm{E}-03$ & $1.2 \%$ & $<5.88 \mathrm{E}-04$ & -- \\
\hline $\mathrm{Br}^{-}$ & $<6.28 \mathrm{E}-02$ & -- & $<6.50 \mathrm{E}-02$ & -- & $<6.99 \mathrm{E}-02$ & -- \\
\hline
\end{tabular}


Table 3-9. Elemental analysis of dried unwashed solids isolated from LWPT samples

\begin{tabular}{|c|c|c|c|c|c|}
\hline \multirow{2}{*}{$(w t \%)$} & \multicolumn{2}{|c|}{ LWPT-1 solids } & \multicolumn{2}{|c|}{ LWPT-2 solids } & \multirow{2}{*}{ LWPT-3 solids } \\
\hline & average & RSD & average & RSD & \\
\hline $\mathrm{Ag}$ & $<1.13 E-02$ & -- & $<1.07 E-02$ & -- & $<2.16 E-02$ \\
\hline $\mathrm{Al}$ & $5.50 \mathrm{E}-01$ & $9.1 \%$ & $6.26 \mathrm{E}-01$ & $4.5 \%$ & $1.21 \mathrm{E}-01$ \\
\hline $\mathrm{Ba}$ & $1.21 \mathrm{E}-02$ & $5.1 \%$ & $1.16 \mathrm{E}-02$ & $12.1 \%$ & $2.69 \mathrm{E}-02$ \\
\hline $\mathrm{Be}$ & $<8.35 E-04$ & -- & $<7.91 E-04$ & -- & $<1.60 E-03$ \\
\hline $\mathrm{Ca}$ & $1.72 \mathrm{E}-01$ & $4.4 \%$ & $1.66 \mathrm{E}-01$ & $6.6 \%$ & $3.26 \mathrm{E}-01$ \\
\hline $\mathrm{Cd}$ & $8.55 \mathrm{E}-02$ & $2.1 \%$ & 7.84E-02 & $9.1 \%$ & $1.27 \mathrm{E}-01$ \\
\hline $\mathrm{Ce}$ & $<4.81 E-02$ & -- & $<4.57 E-02$ & -- & $<9.23 E-02$ \\
\hline Co & $<1.76 E-02$ & -- & $<1.67 E-02$ & -- & $<3.38 E-02$ \\
\hline $\mathrm{Cr}$ & 2.39E-02 & $4.2 \%$ & $9.65 \mathrm{E}-03$ & $12.8 \%$ & $8.10 \mathrm{E}-02$ \\
\hline $\mathrm{Cu}$ & $<7.51 E-03$ & -- & $<7.13 E-03$ & -- & $<1.44 E-02$ \\
\hline $\mathrm{Fe}$ & $3.48 \mathrm{E}-01$ & $8.2 \%$ & 2.72E-01 & $30.7 \%$ & 7.02E-01 \\
\hline $\mathrm{Gd}$ & $<1.96 E-02$ & -- & $<1.86 E-02$ & -- & $<3.76 E-02$ \\
\hline $\mathrm{Hg}$ & 4.87E-03 & $8.3 \%$ & 4.79E-03 & $8.4 \%$ & $3.48 \mathrm{E}-02$ \\
\hline $\mathrm{K}$ & $<4.34 E-01$ & -- & $<4.12 E-01$ & -- & $<8.32 E-01$ \\
\hline $\mathrm{La}$ & $<6.51 E-03$ & -- & $<6.17 E-03$ & -- & $<1.25 E-02$ \\
\hline $\mathrm{Li}$ & $1.00 \mathrm{E}-01$ & $2.6 \%$ & $9.43 \mathrm{E}-02$ & $7.3 \%$ & $7.36 \mathrm{E}-02$ \\
\hline $\mathrm{Mg}$ & $<8.35 E-04$ & -- & $<7.91 E-04$ & -- & $2.56 \mathrm{E}-02$ \\
\hline $\mathrm{Mn}$ & $<7.59 E-03$ & -- & $<7.21 E-03$ & -- & $1.38 \mathrm{E}-02$ \\
\hline Mo & $<1.25 E-01$ & -- & $<1.18 E-01$ & -- & $<2.39 E-01$ \\
\hline $\mathrm{Na}$ & $1.93 \mathrm{E}+01$ & $6.5 \%$ & $2.06 \mathrm{E}+01$ & $6.6 \%$ & $1.76 \mathrm{E}+01$ \\
\hline $\mathrm{Ni}$ & $<9.98 E-02$ & -- & $<9.46 E-02$ & -- & $<1.91 E-01$ \\
\hline $\mathrm{P}$ & 7.19E-01 & $7.4 \%$ & 7.37E-01 & $7.8 \%$ & $9.83 \mathrm{E}-01$ \\
\hline $\mathrm{Pb}$ & $<1.22 E+00$ & -- & $<1.17 E+00$ & -- & $<2.35 E+00$ \\
\hline $\mathrm{S}$ & 3.19E-01 & $3.7 \%$ & $3.30 \mathrm{E}-01$ & $0.6 \%$ & $<1.95 E-01$ \\
\hline $\mathrm{Sb}$ & $<2.42 E-01$ & -- & $<2.29 E-01$ & -- & $<4.63 E-01$ \\
\hline $\mathrm{Si}$ & $1.83 \mathrm{E}-01$ & $11.9 \%$ & 2.33E-01 & $21.6 \%$ & $3.56 \mathrm{E}-01$ \\
\hline $\mathrm{Sn}$ & $<8.46 E-01$ & -- & $<8.03 E-01$ & -- & $<1.62 E+00$ \\
\hline $\mathrm{Sr}$ & $3.58 \mathrm{E}-03$ & $3.9 \%$ & $3.55 \mathrm{E}-03$ & $6.8 \%$ & $5.76 \mathrm{E}-03$ \\
\hline Th & $<7.96 E-02$ & -- & $<7.55 E-02$ & -- & $<1.53 E-01$ \\
\hline $\mathrm{Ti}$ & $1.96 \mathrm{E}+01$ & $6.1 \%$ & $1.92 \mathrm{E}+01$ & $9.8 \%$ & $2.78 \mathrm{E}+01$ \\
\hline $\mathrm{U}$ & 4.22E-01 & $10.3 \%$ & 4.26E-01 & $24.3 \%$ & $<6.25 E-01$ \\
\hline $\mathrm{V}$ & $1.16 \mathrm{E}-02$ & $13.0 \%$ & $1.13 \mathrm{E}-02$ & $14.6 \%$ & $1.50 \mathrm{E}-02$ \\
\hline $\mathrm{Zn}$ & $<1.65 E-02$ & -- & $<=3.01 E-02$ & $82.6 \%$ & $<3.17 E-02$ \\
\hline $\mathrm{Zr}$ & $1.42 \mathrm{E}-02$ & $8.1 \%$ & $1.36 \mathrm{E}-02$ & $5.3 \%$ & $2.07 \mathrm{E}-02$ \\
\hline
\end{tabular}


Table 3-6 and Table 3-8 contain the analysis of the as-received ARP samples (including solids when present). Because LWHT-1 was relatively free of solids and was already analyzed without filtration (see Table 3-5 and Table 3-7), only a single replicate was processed for LWHT-1 with the slurry analysis preparation. Slurry results, which include the dissolution of solids, are reported on a volume basis for easier comparison with the filtrate results. Due to the higher dilution factor used for the slurry preparation method, many of the components measured by ICPES were below detection limits. For the acid dissolution preparation of LWPT-3, only two of the three replicate analyses were used, while one result was ignored because it was inconsistent with all other LWPT-3 data. Hydroxide was not analyzed on the slurry preparations, so the filtrate data should be used for slurry free hydroxide. From the comparison of the sodium and anion results between the slurry and the filtrate, good agreement was seen. This indicates that the majority of the analytes are primarily present in the soluble phase and there is little or no contribution from the solids for most analytes.

As expected, the primary difference between the slurry results and the filtrate results is the much higher titanium content in the slurry due to the inclusion of MST. The average titanium concentrations in LWPT-1 and LWPT-2 are $904 \mathrm{mg} / \mathrm{L}$ and $3110 \mathrm{mg} / \mathrm{L}$, respectively. The higher titanium concentration in LWPT-2 reflects the concentration of the MST solids by the crossflow filter within the ARP process. Making an assumption that all of the titanium is in the form of MST, the LWPT-1 and LWPT-2 samples have $0.19 \mathrm{wt} \%$ and $0.65 \mathrm{wt} \%$ MST, respectively. These are $22 \%$ and $27 \%$ lower than the expected MST slurry levels of $0.24 \mathrm{wt} \%$ in LWPT- 1 and $0.89 \mathrm{wt} \%$ in LWPT-2 based on 16 batches of processing. These differences may reflect the solids that are part of the filter cake and are thus not available for sampling. Alternately, these differences may indicate that the LWPT was not fully mixed at the time of sampling or that some MST is dissolved after addition and transferred out of the ARP via the LWHT.

The contribution of sodium in MST to the overall slurry sodium concentration appears trivial. It is not possible to quantify the presence of small amounts of most sludge components from the slurry analysis due to the higher detection limits and the isolated solids analysis must be used for this purpose instead. Within the experimental uncertainty, the aluminum in the slurry is consistent with aluminum in the filtrate, indicating that the LWPT solids do not contribute significantly to the overall aluminum in the slurries.

The anion results in the supernate are inconclusive as to whether minor quantities of sodium oxalate solids are present. The slurry results for oxalate anion match the filtrate results for oxalate anion within the experimental uncertainty. Likewise, the carbonate results for the slurry do not support the presence of insoluble carbonates in the slurries, contradicting the previous observation comparing LWPT-3 filtrate with LWPT-1 and LWPT-2 filtrates.

Table 3-9 contains the chemical analysis of the dried unwashed solids isolated from the LWPT samples. Note that mercury analysis may reflect a low bias because the solids were dried at $120^{\circ} \mathrm{C}$ prior to analysis, potentially volatilizing a portion of the mercury. LWPT-1 and LWPT-2 contained primarily sodium and titanium, but did contain significant amounts of aluminum, iron, calcium and silicon. By comparison with the filtrate and slurry analyses, the iron, calcium and silicon components are likely from the solids portion rather than the supernate portion of the original slurries. Due to the low quantity of solids from LWPT-3 available for analysis, a single analysis was performed for LWPT-3 solids. For LWPT-3, the lower concentration of soluble salts in the interstitial liquid resulted in higher percentage concentrations for many MST and sludge components in LWPT-3 than in LWPT-1 and LWPT-2. The increased iron concentration 
in LWPT-3 may be partially attributable to the performance of filter cleaning with oxalic acid. The presence of iron, magnesium, and manganese in LWPT-3 solids suggests the presence of a small amount of sludge as a possible filter foulant. Since MST solids are a heel component, it is uncertain how much titanium in LWPT-3 is from the MST heel and how much titanium is from filter cleaning and precipitation of another titanium form. The presence of aluminum and silicon in the solids from all LWPT samples suggest the presence of sodium aluminosilicates. Sample LWPT-3 contains aluminum and silicon in a ratio deficient in aluminum with respect to the most typical forms of sodium aluminosilicate identified in the tank farm (nitrated sodalite and cancrinite).

The data in Table 3-9 for dried unwashed solids isolated from the samples LWPT-1 and LWPT-2 can be used to form a rough estimate of the relative amount of sludge present in the ARP slurries. From LWPT-1, the unwashed dried solids contained $0.348 \mathrm{wt} \%$ iron and $19.6 \mathrm{wt} \%$ titanium, respectively. Approximating that typical HLW sludge is $20 \mathrm{wt} \%$ iron (assuming mostly PUREX), the unwashed dried solids from LWPT-1 contained roughly $41 \mathrm{wt} \%$ MST and $1.7 \mathrm{wt} \%$ sludge. Thus, the solids in the ARP slurries being filtered contained roughly a 24:1 ratio of MST:sludge. Comparatively, the majority of the crossflow filtration testing in support of SRS salt processing was performed at a ratio of 0.9:1 of MST:sludge, with the extremes of 0.5:1 and 2:1 MST:sludge also investigaged. ${ }^{13}$ Clearly, there is a difference in the bulk solids composition from what ARP is processing now and what was used in most testing.

Table 3-10 and Table 3-11 contain gross radiochemical analysis of the LWPT and LWHT samples. These measurements were not called for by the TTR but were required for sample processing purposes. As seen in Table 3-10, Cs-137 overwhelms the other radioactive components in the slurry, contributing to a large beta result and a high detection limit for alpha. Data for the solids isolated from the slurry, as seen in Table 3-11, provides a more useful value for beta holdup in the MST solids and a significantly lower detection limit for alpha in the solids.

Table 3-10. Radioactivity measurements on LWPT slurries and LWHT

\begin{tabular}{c|c|c|c|c|c|c|c}
\hline \multirow{2}{*}{$(\mathrm{dpm} / \mathrm{mL})$} & \multicolumn{2}{|c|}{ LWPT-1 } & \multicolumn{2}{c|}{ LWPT-2 } & \multirow{2}{*}{ LWHT-1 } & \multicolumn{2}{c}{ LWPT-3 } \\
& average & RSD & average & RSD & & average & RSD \\
\hline alpha & $<1.59 E+06$ & -- & $<1.54 E+06$ & -- & $<1.53 E+06$ & $<1.32 E+06$ & -- \\
\hline beta & $1.56 \mathrm{E}+08$ & $2.2 \%$ & $1.78 \mathrm{E}+08$ & $3.3 \%$ & $1.52 \mathrm{E}+08$ & $1.16 \mathrm{E}+07$ & $17 \%$ \\
\hline Cs-137 & $1.23 \mathrm{E}+08$ & $2.3 \%$ & $1.26 \mathrm{E}+08$ & $4.2 \%$ & $1.32 \mathrm{E}+08$ & $5.85 \mathrm{E}+06$ & $6.5 \%$ \\
\hline
\end{tabular}

Table 3-11. Radioactivity measurements on solids isolated from LWPT samples

\begin{tabular}{c|cc|c|c|c}
\hline \multirow{2}{*}{ (dpm/g) } & \multicolumn{2}{|c|}{ LWPT-1 solids } & \multicolumn{2}{c|}{ LWPT-2 solids } & LWPT-3 solids \\
& average & RSD & average & RSD & average \\
\hline alpha* & $<7.36 E+03$ & $26.2 \%$ & $<1.07 E+04$ & $24.5 \%$ & $<1.28 E+04$ \\
\hline beta & $2.36 \mathrm{E}+05$ & $5.2 \%$ & $2.27 \mathrm{E}+05$ & $6.7 \%$ & $3.10 \mathrm{E}+05$ \\
\hline
\end{tabular}

$*$ alpha results are upper limit values due to potential interferences 


\subsubsection{Physical and Solids Analyses}

Table 3-12 contains the results for the weight percent solids and density analyses for the LWPT and LWHT samples. For most data, the averages are reported along with the standard deviations (st. dev.) and the number of measurements (n). Two sided 95\% confidence intervals (CI) are reported for the insoluble solids because it is a calculated value that requires propagation of uncertainty.

Table 3-12. Solids quantitative analysis and density measurement of ARP 512-S samples

\begin{tabular}{|c|c|c|c|c|c|c|c|c|c|c|}
\hline \multirow[t]{2}{*}{ Sample } & \multicolumn{3}{|c|}{$\begin{array}{c}\text { Total Solids } \\
\text { (wt\% in slurry) }\end{array}$} & \multicolumn{3}{|c|}{$\begin{array}{l}\text { Dissolved Solids } \\
\text { (wt } \% \text { in filtrate) }\end{array}$} & \multicolumn{2}{|c|}{$\begin{array}{l}\text { Insoluble Solids } \\
\text { (wt } \% \text { in slurry) }\end{array}$} & \multicolumn{2}{|c|}{ Density $(\mathrm{g} / \mathrm{mL})$} \\
\hline & avg. & st.dev. & $\mathrm{n}$ & avg. & st.dev. & $\mathrm{n}$ & avg. & 95\% C.I. & avg. & st.dev. \\
\hline LWPT-1 & 33.2 & 0.1 & 4 & 33.0 & 0.2 & 4 & 0.42 & 0.61 & 1.300 & 0.006 \\
\hline LWPT-2 & 33.4 & 0.1 & 4 & 33.0 & 0.4 & 4 & 0.49 & 1.08 & 1.301 & 0.004 \\
\hline LWPT-3 & 9.9 & 0.1 & 4 & 9.9 & 0.1 & 4 & 0.06 & 0.25 & 1.095 & 0.001 \\
\hline LWHT-1 & 32.5 & 0.5 & 3 & \multicolumn{3}{|c|}{ see Total Solids } & N/A & $\mathrm{N} / \mathrm{A}$ & 1.297 & 0.010 \\
\hline
\end{tabular}

Together, the dissolved solids in LWPT-1 and LWPT-2 and the total solids in LWHT-1 averaged $32.9 \mathrm{wt} \%$ in the liquid (st. dev. $=0.4 \mathrm{wt} \%, \mathrm{n}=11$ ). Measurement of insoluble solids in the LWPT solids proved problematic. The high salt and hydroxide content of the liquid leads to scatter in the total and dissolved solids measurements. In this case, the scatter in the measurements was large enough that it obscured the insoluble solids results. Based on the relatively low insoluble solids content of the slurries and the large uncertainties, the insoluble solids results have limited value for this set of samples. By qualitative comparisons of the sample appearance and the relative amounts of filter cake obtained during sample preparation, LWPT-2 had considerably larger quantities of insoluble solids than did LWPT-1. However, this difference is not reflected in the quantitative results for insoluble solids content. Based on the titanium results in Table 3-6, the insoluble MST solids in samples LWPT-1 and LWPT-2 are $0.19 \mathrm{wt} \%$ and $0.65 \mathrm{wt} \%$, respectively. These fall within the ranges encompassed by the insoluble solids measurements reported in Table 3-12. While sample LWPT-3 has a calculated insoluble MST concentration of $0.07 \mathrm{wt} \%$ (assuming all titanium is MST), it is difficult to know the expected form of titanium in the post-cleaning sample. Additionally, from Table 3-9 the insoluble solids in post-cleaning sample LWPT-3 appear to have a slightly larger fraction of sludge (Fe, Mn), some of which may be newly precipitated as a result of $\mathrm{pH}$ adjustment.

The densities for LWPT-1 and LWPT-2 were measured on the slurries and thus include the influence of the MST solids. The density result for the solids-free LWHT-1 closely matches those of LWPT-1 and LWPT-2. The combined density of LWPT-1, LWPT-2 and LWHT-1 averaged $1.30 \mathrm{~g} / \mathrm{mL}$ (st. dev. $=0.01 \mathrm{~g} / \mathrm{mL}, \mathrm{n}=9$ ). 
LWPT-3 had considerably lower density, total solids, and soluble solids than the other three samples. This is consistent with the chemical results of Section 3.2.1. Insoluble solids measurement was indistinguishable from zero even though visual indication showed LWPT-3 to be hazy and translucent. Filtration of LTPT-3 resulted in a small amount of filter cake.

Figure 3-1 shows an example of the flow curves obtained during rheology measurements. The complete set of flow curves is contained in Appendix A. No yield stress (positive intercept in the flow curve slope) was noted for these samples. Newtonian viscosities (with units of $\mathrm{cP}$ ) can be estimated from 1000-times the slope of the plot of the shear stress (in Pa) versus the shear rate (in $1 / \mathrm{s}$ ). Table 3-13 contains a compilation of the viscosities of the samples measured at the nominal cell temperature of approximately $25{ }^{\circ} \mathrm{C}$. Despite the very small differences in sample density and weight percent total solids between LWPT-1, LWPT-2 and LWHT-3, the presence of different amounts of insoluble solids contributed to notable differences in slurry viscosity, with LWPT-2 having a viscosity of about $5.5 \mathrm{cP}$, which is $45 \%$ higher than that of the insoluble solids free LWHT-1, which is about $3.8 \mathrm{cP}$. 


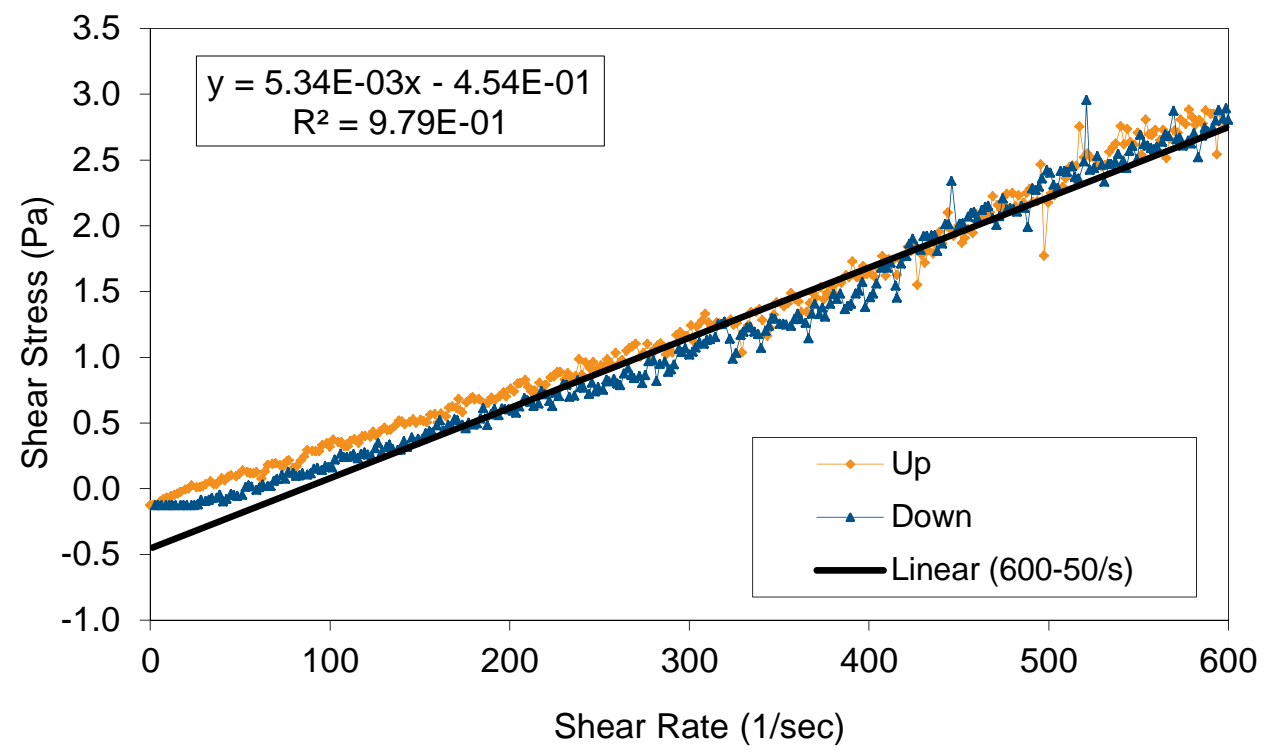

Figure 3-1. Example flow curve (rheology measurement) of LWPT-2 slurry

Table 3-13. Viscosity measurements of ARP 512-S samples (at approx. $25^{\circ} \mathrm{C}$ )

\begin{tabular}{c|cc|cc}
\hline sample & $\begin{array}{c}\text { first meas. } \\
(\mathrm{cP})\end{array}$ & $\begin{array}{c}\text { second meas. } \\
(\mathrm{cP})\end{array}$ & $\begin{array}{c}\text { average } \\
(\mathrm{cP})\end{array}$ & RSD \\
\hline LWPT-1 & 4.7 & 4.1 & 4.4 & $10 \%$ \\
\hline LWPT-2 & 5.7 & 5.3 & 5.5 & $5 \%$ \\
\hline LWPT-3 & 2.5 & 2.7 & 2.6 & $4 \%$ \\
\hline LWHT-1 & 3.8 & 4.0 & 3.9 & $4 \%$ \\
\hline
\end{tabular}

Figure 3-2 contains a plot of the particle size volume distributions of the three LWPT samples. Appendix B contains the instrument results for the particle size measurements, including both the volume and the number distributions. All three samples were similar, with LWPT-1 and LWPT-2 being almost identical. The post filter cleaning sample LWPT-3 contained a small amount of large particles (possibly due to aggregation or another phenomenon) and had slight elongations of the distributions on low end of the small particles and on the high end of the larger particles. It is difficult to determine whether the differences between the LWPT-3 particle size distribution and those of the other samples are a real change in particle characteristics or only a function of the different suspension solution. The volume distributions were bimodal with the major fraction centered around 6 to $7 \mu \mathrm{m}$ and the minor fraction centered around 1.2 to $1.4 \mu \mathrm{m}$. The particle size measurement is consistent with the measurements made on the Harrel Industries MST feed materials, which are characterized upon receipt. ${ }^{7}$ Differences can be attributed to the different instruments used for the measurements of the MST feeds. 
SRNL-STI-2013-00700

Revision 0

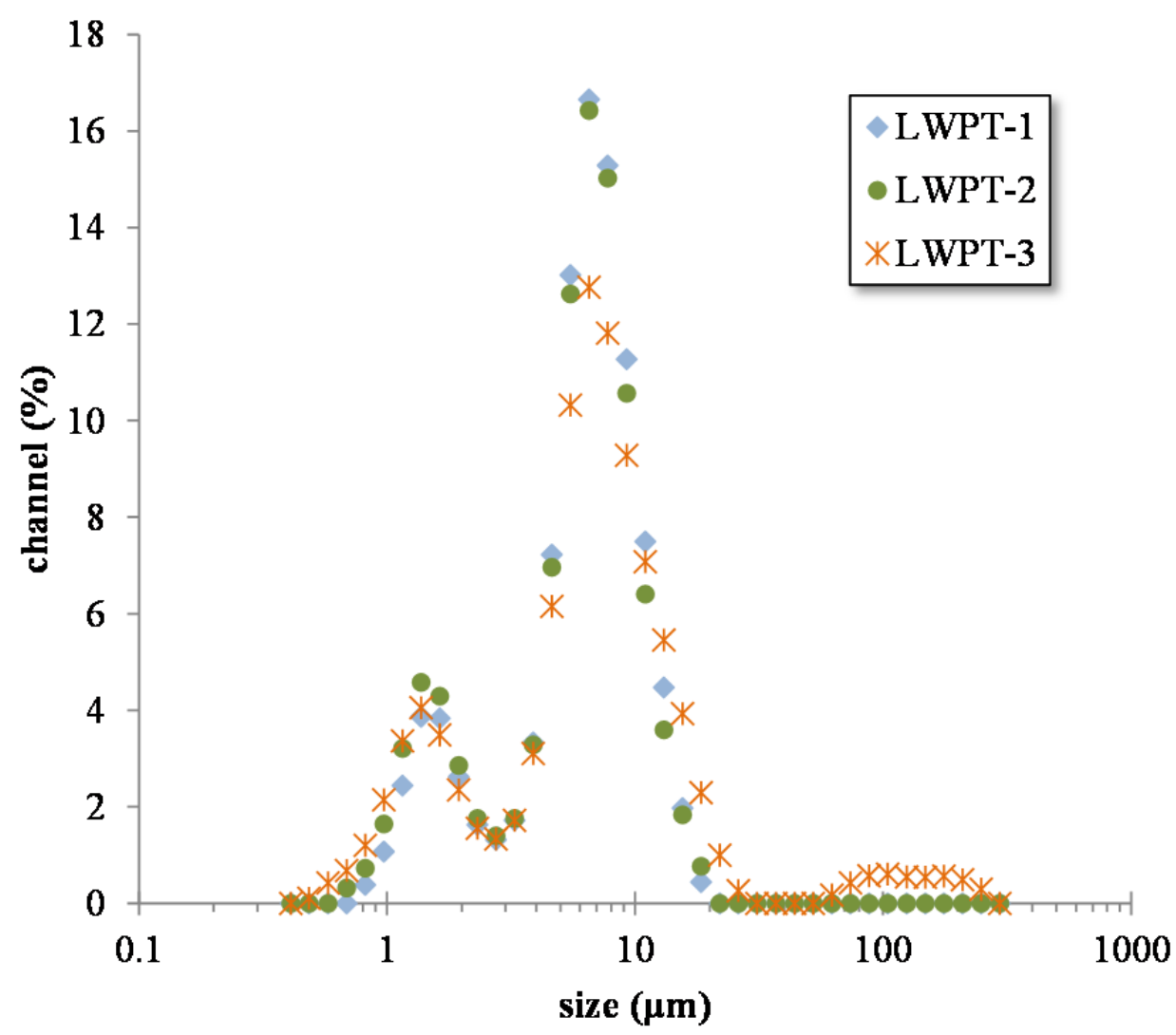

Figure 3-2. Particle size volume distributions of LWPT samples

Figure 3-3, Figure 3-4 and Figure 3-5 contain the XRD results for the unwashed solids isolated from LWPT-1, LWPT-2 and LWPT-3, respectively. All three samples matched a sodium titanium oxide hydroxide compound $\left(\mathrm{Na}_{2} \mathrm{Ti}_{2} \mathrm{O}_{4}(\mathrm{OH})_{2}\right)$. The peaks are somewhat broad and poorly defined and weak, consistent with the XRD results from the PRFT sample analysis. ${ }^{7}$ This compound is the XRD instrument library match that is seen when analyzing "as-received" MST $\left(\mathrm{NaHTi}_{2} \mathrm{O}_{5}\right)$. The origin of the XRD peak profile assignment is not from MST, but is from another related material. The presence of these solids indicate that there is MST present in the samples. Differing from the PRFT analysis results, which had been obtained for materials that were washed with water, the three LWPT samples all have several peaks corresponding to salts. LWPT-1 and LWPT-2 had peaks corresponding to $\mathrm{NaNO}_{3}$, which is expected based on the large concentration of nitrate in the slurry interstitial liquid. 


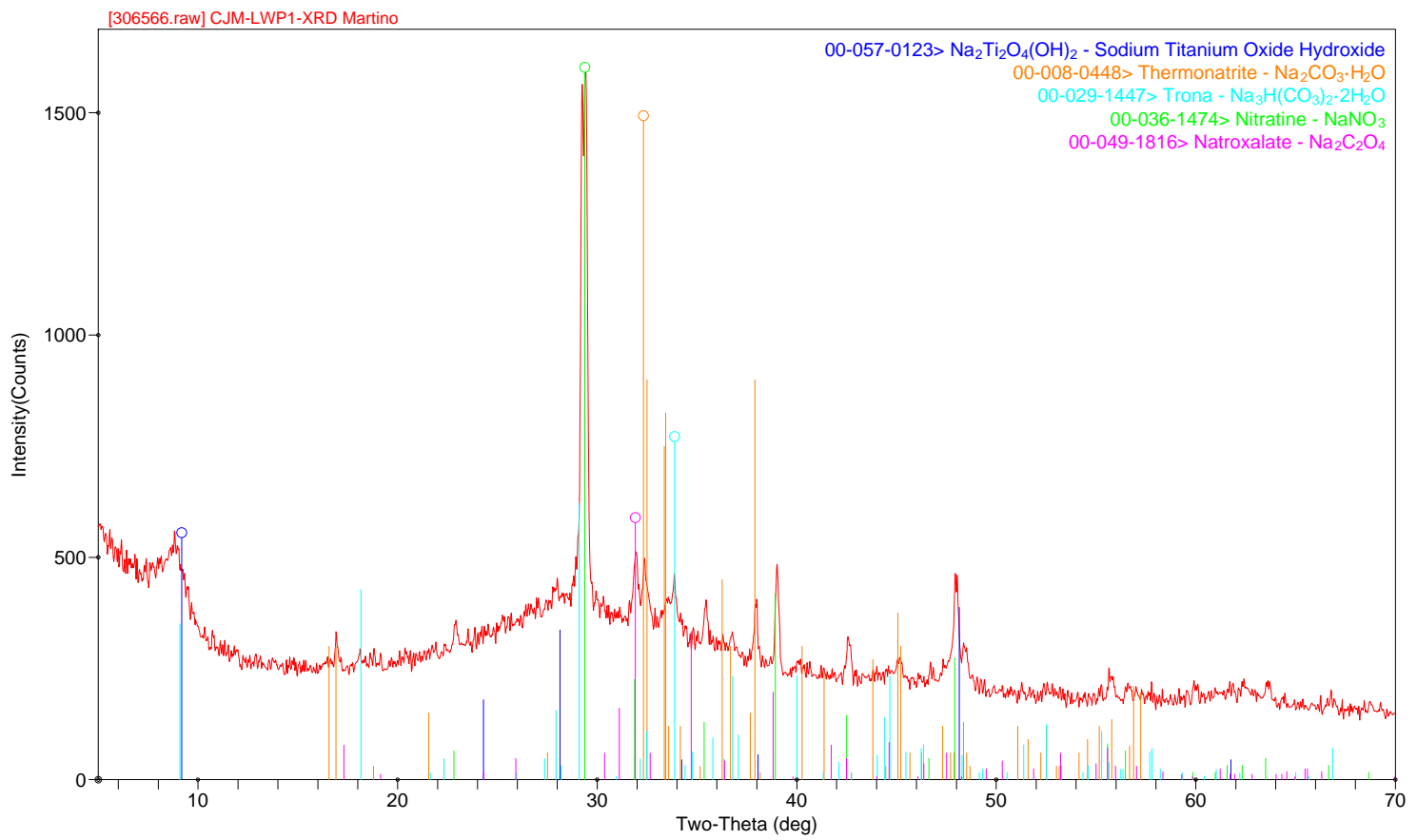

Figure 3-3. XRD analysis of unwashed solids isolated from LWPT-1

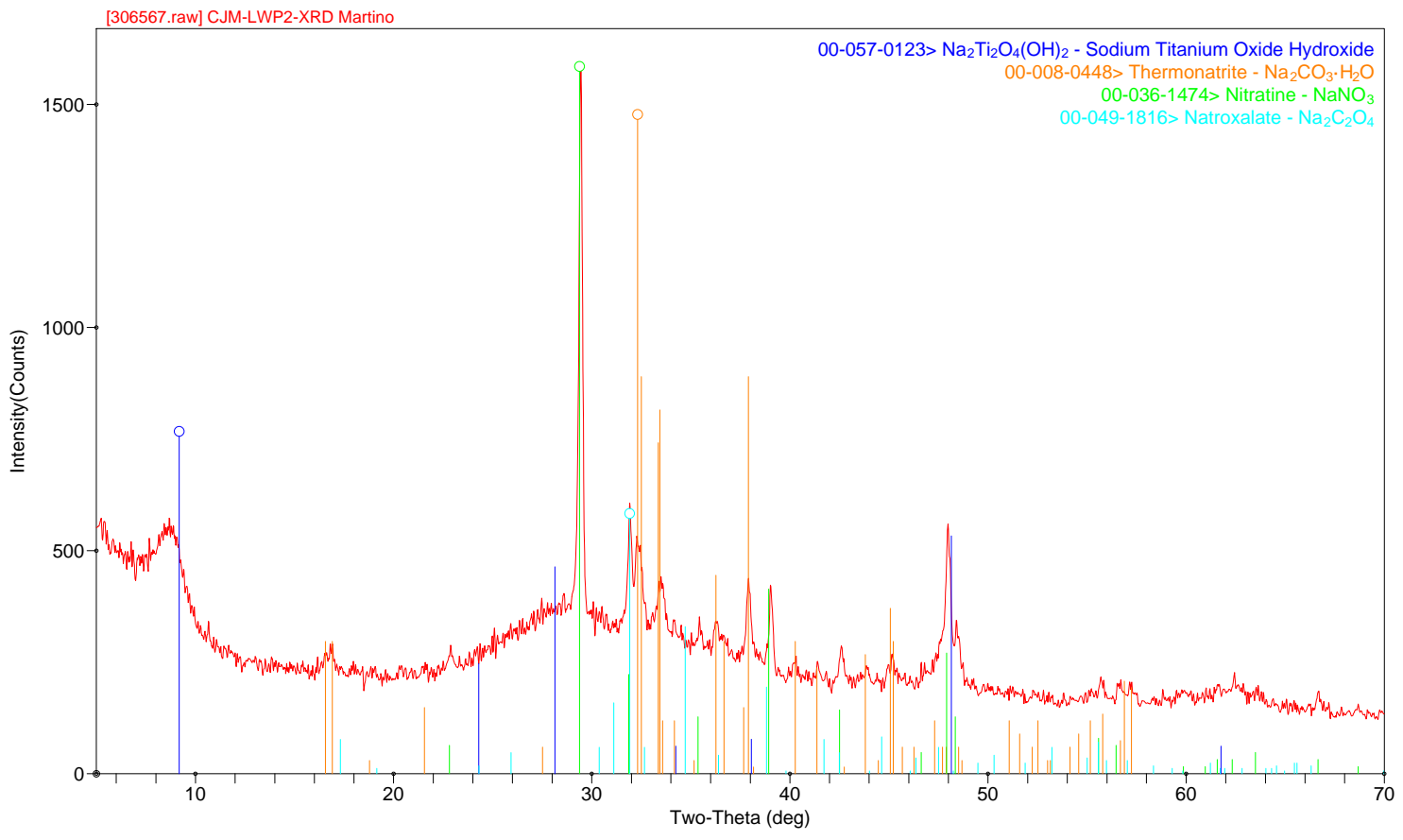

Figure 3-4. XRD analysis of unwashed solids isolated from LWPT-2 


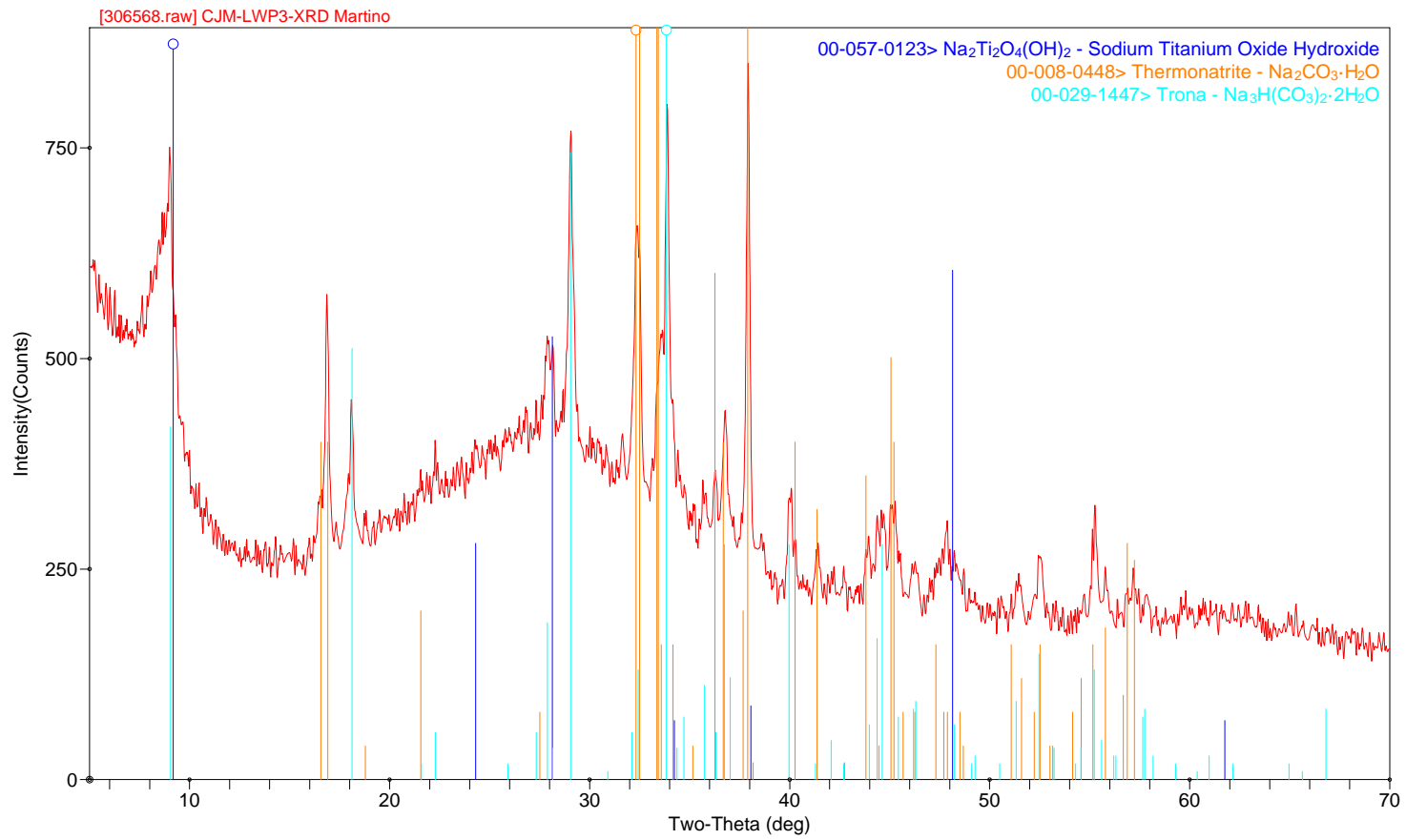

Figure 3-5. XRD analysis of unwashed solids isolated from LWPT-3

The three LWPT samples also showed varying quantities of the carbonate-containing salts thermonatrile $\left(\mathrm{Na}_{2} \mathrm{CO}_{3} * \mathrm{H}_{2} \mathrm{O}\right)$ and trona $\left(\mathrm{Na}_{3} \mathrm{H}\left(\mathrm{CO}_{3}\right)_{2} * 2 \mathrm{H}_{2} \mathrm{O}\right)$. However, the comparison of the carbonate results for the filtrates and slurries (from Table 3-7 and Table 3-8) shows no indication that the solids contain carbonate. Thus, it is most likely that the carbonates seen in the XRD are due to the absorption of $\mathrm{CO}_{2}$ from the air during sample drying due to the high concentration of hydroxide in the interstitial liquid.

Additionally, LWPT-1 and LWPT-2 had identifiable amounts of sodium oxalate $\left(\mathrm{Na}_{2} \mathrm{C}_{2} \mathrm{O}_{4}\right)$. Unidentified peaks in LWPT-3 are also consistent with small amounts of sodium oxalate. For LWPT-1 and LWPT-2, presence of sodium oxalate peaks in the XRD results in spite of the low relative concentration of oxalate in the liquid suggests that the sodium oxalate is present as a solid in the LWPT slurries. This is consistent with the chemical analysis data for oxalate in Tank $49 \mathrm{H}$ and the LWPT samples, which suggests that sodium oxalate may be precipitating within ARP.

Figure 3-6 contains an example SEM image from solids isolated from one of the samples (LWPT-2). Appendix C contains additional SEM images for the LWPT samples along with Energy Dispersive Spectroscopy (EDS) elemental analysis for several locations within each image. Images showed roughly spherical MST solids, which are often bound together by dried salts (a result of sample preparation of the unwashed solids). The MST particle size appeared consistent with the particle size analysis. For unwashed solids from LWPT-1 and LWPT-2, the major elements identified were $\mathrm{Na}, \mathrm{Ti}, \mathrm{C}$, and $\mathrm{O}$ with smaller peaks from $\mathrm{Al}, \mathrm{Fe}$, and $\mathrm{S}$. For LWPT-3, the solids were more consistently $\mathrm{Na}$ and $\mathrm{Ti}$ with smaller amounts of $\mathrm{Fe}$ and $\mathrm{Ni}$. Carbon and aluminum containing compounds appeared to not be prominent in LWPT-3. 


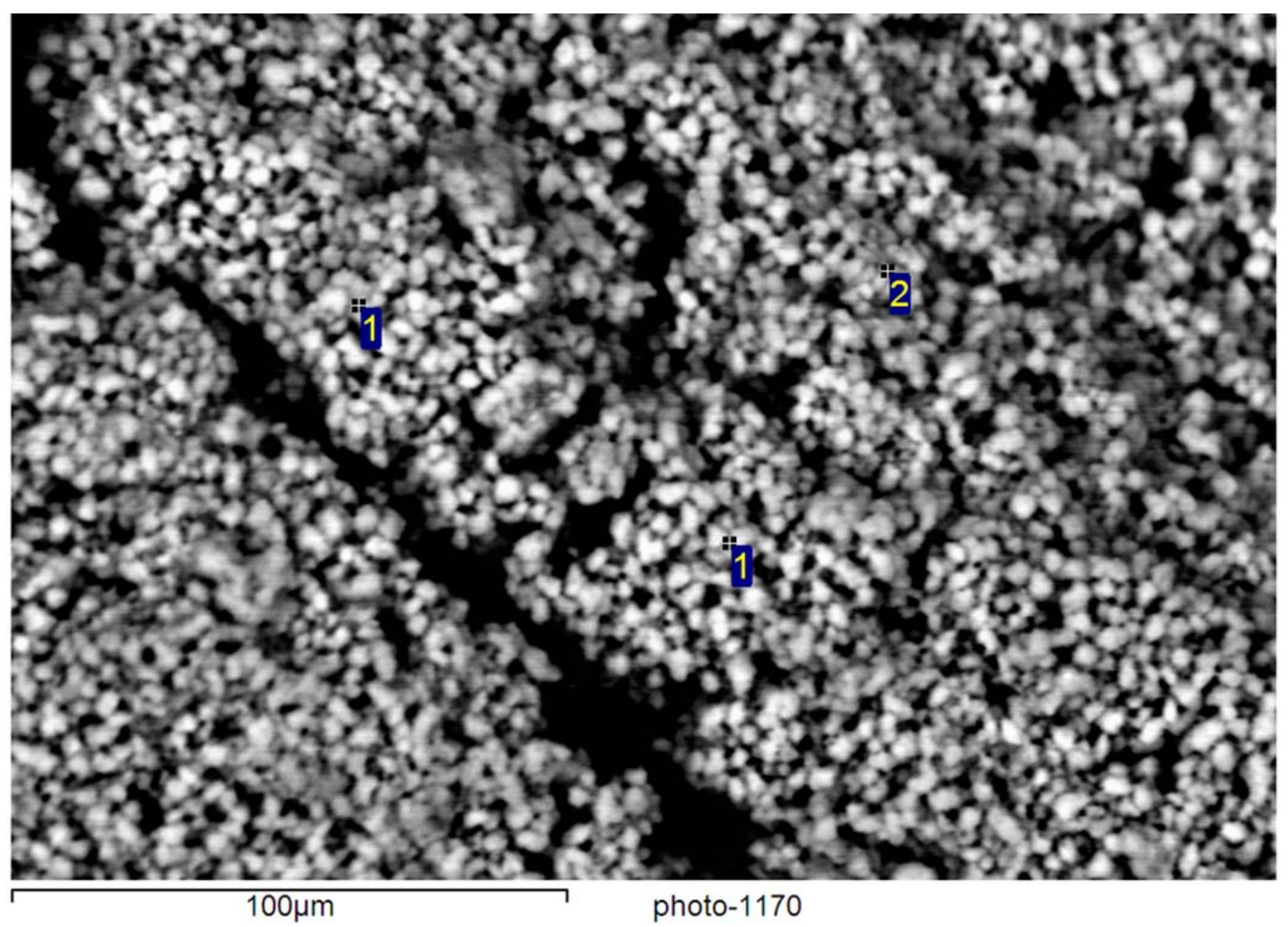

Figure 3-6. Example SEM image of dried unwashed solids from LWPT-2

Figure 3-7 contains the TGA results for the air-dried unwashed solids that were isolated from the three LWPT samples. Figure 3-8 contains results for the similar washed PRFT solids and two reference materials, MST and sodium oxalate. The three LWPT showed similar behavior in the low temperature weight loss region and is consistent with water loss from MST for that region. At higher temperatures, LWPT-1 and LWPT-2 show additional weight loss, likely due to the decomposition or water loss from some of the salts. With the limited sensitivity of this analysis, there is not a significant loss of mass that is seen to be directly attributable to the presence of sodium oxalates in the solids. 
SRNL-STI-2013-00700

Revision 0

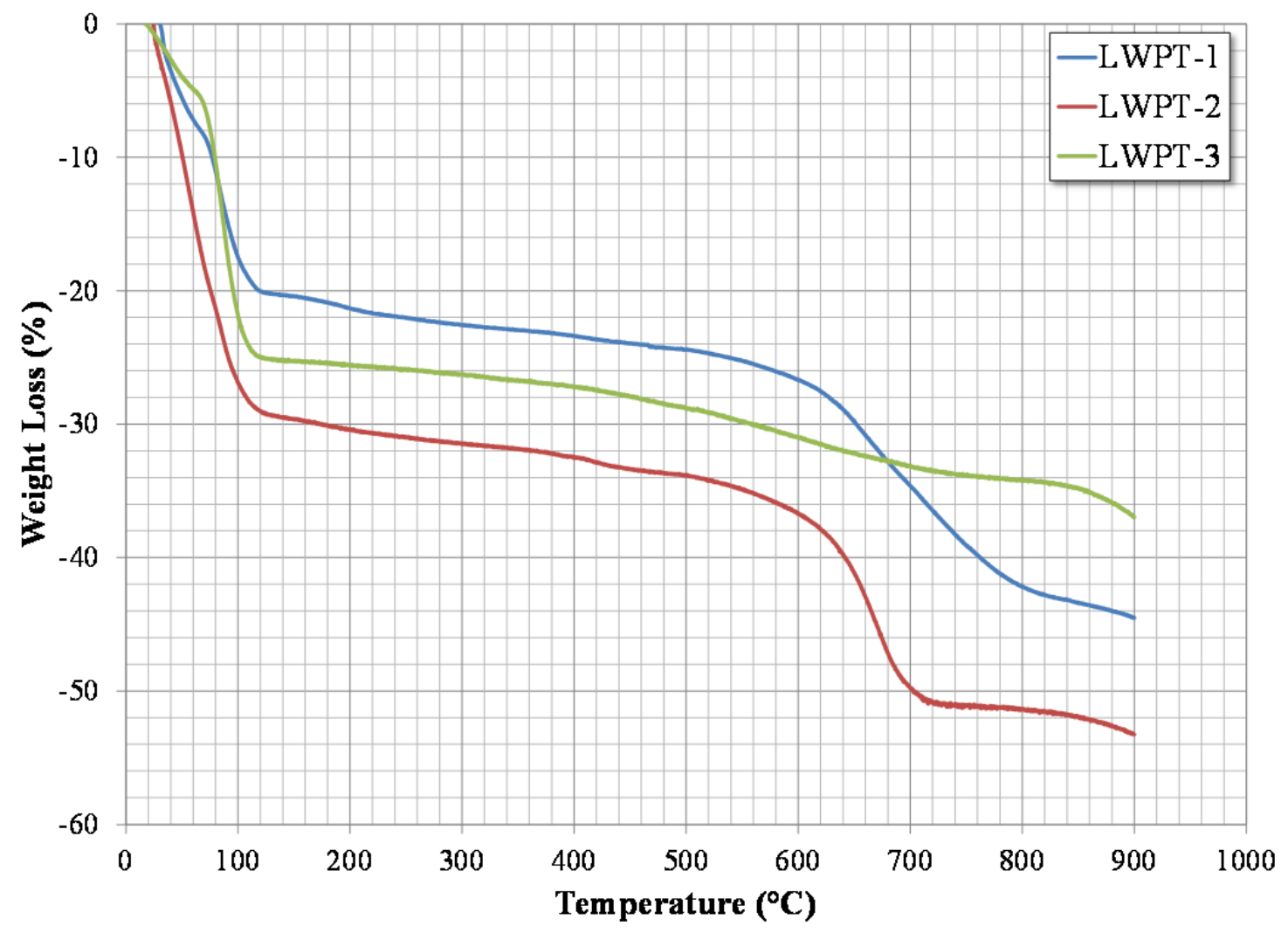

Figure 3-7. TGA of unwashed solids isolated from LWPT samples.

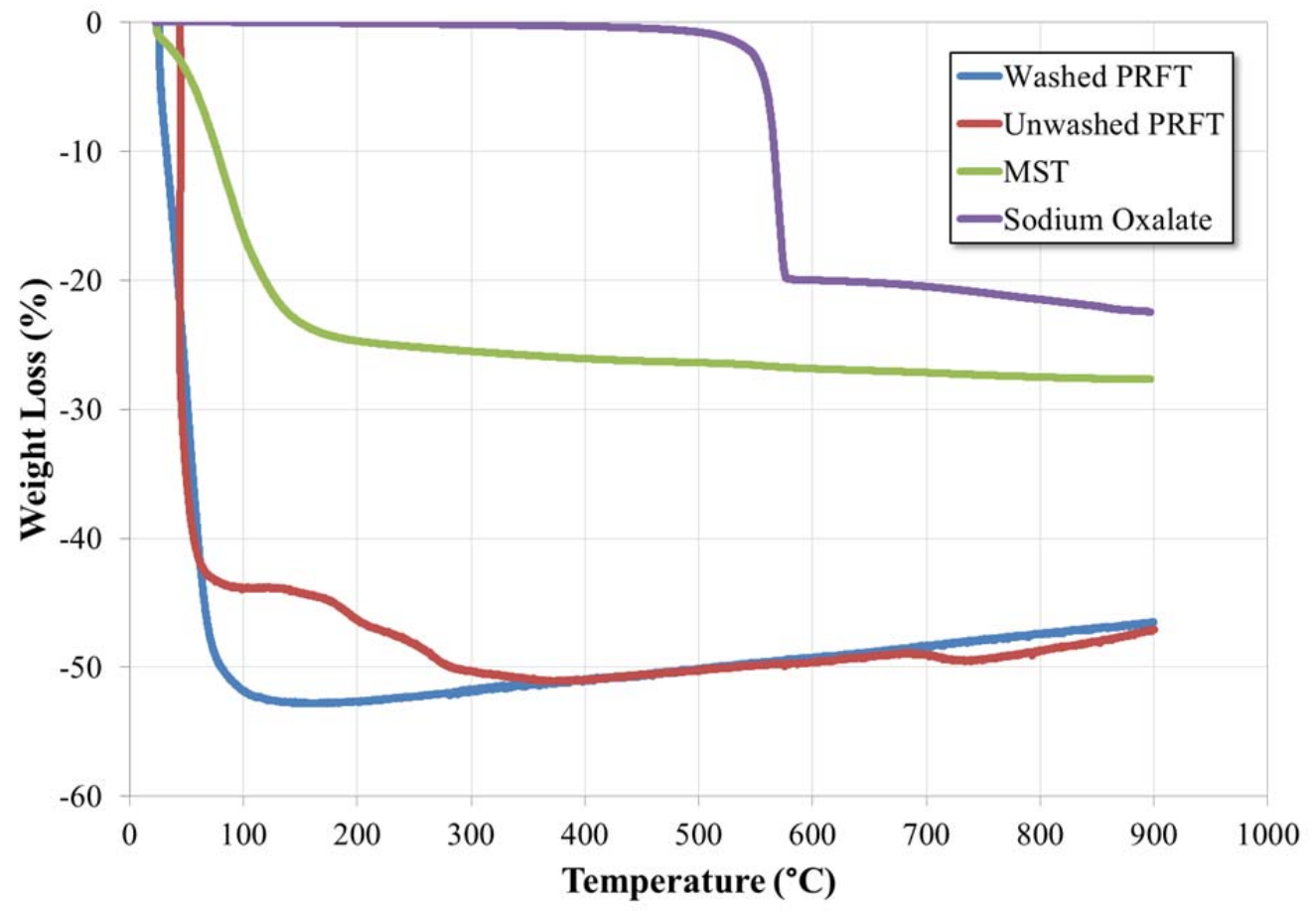

Figure 3-8. TGA of reference materials and PRFT samples 
SRNL-STI-2013-00700

Revision 0

\subsection{Chemical Equilibrium Modeling}

\subsubsection{Evaluation of Chemical Saturation of Samples from Tank 49H and 512-S Facilities}

This section describes the details of the electrolyte thermodynamic modelling of the analytical sample results in order to evaluate the propensity of these samples to form solid precipitates. The discussion is divided into subsections and starts with the initial details about the conversion of the analytical results from the samples into input for the reconciliation calculation. The next subsection presents the reconciliation calculations as an intermediate result that is used as inputs for subsequent calculations. The last subsection presents a summation of the results of the survey calculations.

\subsubsection{Development of Model Input}

The analytical results were converted to ionic species concentrations in the aqueous phase as shown in Table 3-14. For metal analysis, column 2 in Table 3-14 shows the original reported metal and column 1 shows the assumed species as it exists in the solution. Mass was calculated to account for molecular weight (MW) differences between assumed species and the metal. For a given sample, the analytical results were parsed to eliminate all "less than" values, retaining actual measured values and "less than or equal to" values. Values reported as "less than or equal to" are presumed near the detection limits and were used in this evaluation even though the analytical uncertainty on these values is substantially greater than the other results. Note that the following elements are presumed to form anions: Al, B, Cr, Mo, V, P, S, and Ti. Since there is anion analysis for phosphate and sulfate, the P and S ICP-ES results were ignored. Since the OLI database does not have MST solids, the Ti chemistry was not simulated.

Two analytical components, silicon and bromine, are included as to be neutral compounds, $\mathrm{Na}_{2} \mathrm{SiO}_{3}$ and $\mathrm{NaBr}$, because they do not have corresponding ionic species available in the OLI chemistry database. Including these elements as neutral species allows simulation of the corresponding chemistries. These sodium salts were picked because sodium is used to reconcile the charge balance, thus, the metal choice does not affect the analysis. Identifying the elements silicon and bromine in neutral compounds does not constrain OLI Analyzer ${ }^{\mathrm{TM}}$ from calculating the thermodynamically favored species for these elements.

Slurry compositions do not have results for hydroxide ion which is a major component and has a substantial effect on the solution chemistry. The hydroxide results from the filtrate analysis was used to supplement the results for the slurry as there is minimal risk in alteration of liquid phase hydroxide concentration upon filtration. 
Table 3-14. Input Composition for Chemistry Simulation of Sample Analysis

\begin{tabular}{|c|c|c|c|c|c|c|c|c|c|c|}
\hline \multirow{3}{*}{$\begin{array}{c}\text { Presumed } \\
\text { Species }\end{array}$} & \multirow{3}{*}{ Analyte } & \multicolumn{3}{|c|}{ Slurry Mass Concentration (mg/L) } & \multirow{2}{*}{ LWHT-1 } & \multicolumn{3}{|c|}{ Filtrate Mass Concentration (mg/L) } & \multirow[b]{2}{*}{ LWPT-3 } & \multirow[b]{2}{*}{ LWHT-1 } \\
\hline & & LWPT-1 & LWPT-2 & LWPT-3 & & Tank 49 & LWPT-1 & LWPT-2 & & \\
\hline & & average & average & average & average & Average & average & average & average & average \\
\hline \multicolumn{11}{|l|}{ Cations } \\
\hline $\mathrm{Ba}^{+2}$ & $\mathrm{Ba}$ & - & - & - & - & - & - & - & - & - \\
\hline $\mathrm{Ca}^{+2}$ & $\mathrm{Ca}$ & - & - & - & - & - & - & - & $<=5.56 E+00$ & - \\
\hline $\mathrm{Cd}^{+2}$ & $\mathrm{Cd}$ & - & - & - & - & - & - & - & - & - \\
\hline $\mathrm{Cu}^{+2}$ & $\mathrm{Cu}$ & - & - & - & - & $1.97 \mathrm{E}+01$ & - & - & - & - \\
\hline $\mathrm{Fe}^{+3}$ & $\mathrm{Fe}$ & - & - & - & - & $4.98 \mathrm{E}+00$ & $<=5.99 E+00$ & $<=6.82 E+00$ & - & - \\
\hline $\mathrm{K}^{+1}$ & $\mathrm{~K}$ & - & - & - & - & $3.88 \mathrm{E}+02$ & $3.74 \mathrm{E}+02$ & $3.91 \mathrm{E}+02$ & - & $3.96 \mathrm{E}+02$ \\
\hline $\mathrm{Li}^{+1}$ & $\mathrm{Li}$ & - & - & - & - & $2.24 \mathrm{E}+01$ & $4.65 \mathrm{E}+00$ & $4.86 \mathrm{E}+00$ & - & $4.57 \mathrm{E}+00$ \\
\hline $\mathrm{Mg}^{+2}$ & $\mathrm{Mg}$ & - & - & - & - & - & $<=2.64 E-01$ & $<=2.50 E-01$ & - & - \\
\hline $\mathrm{Mn}^{+2}$ & $\mathrm{Mn}$ & - & - & - & - & - & - & - & - & - \\
\hline $\mathrm{Na}^{+1}$ & $\mathrm{Na}$ & $1.51 \mathrm{E}+05$ & $1.51 \mathrm{E}+05$ & $5.26 \mathrm{E}+04$ & $1.56 \mathrm{E}+05$ & $1.39 \mathrm{E}+05$ & $1.51 \mathrm{E}+05$ & $1.51 \mathrm{E}+05$ & $5.15 \mathrm{E}+04$ & $1.51 \mathrm{E}+05$ \\
\hline $\mathrm{Sr}^{+2}$ & $\mathrm{Sr}$ & - & - & - & - & - & - & - & - & - \\
\hline $\mathrm{UO}_{2}^{+2}$ & $\mathrm{U}$ & - & - & - & - & - & - & - & - & - \\
\hline $\mathrm{Zn}^{+2}$ & $\mathrm{Zn}$ & - & - & - & - & $5.24 \mathrm{E}+00$ & $5.03 \mathrm{E}+00$ & $<=4.87 E+00$ & - & $5.15 \mathrm{E}+00$ \\
\hline $\mathrm{Zr}^{+4}$ & $\mathrm{Zr}$ & - & - & - & - & - & - & - & - & - \\
\hline \multicolumn{11}{|l|}{ Neutral } \\
\hline $\mathrm{Na}_{2} \mathrm{SiO}_{3}$ & $\mathrm{Si}$ & - & - & - & - & $1.65 \mathrm{E}+02$ & - & - & - & - \\
\hline $\mathrm{NaBr}$ & $\mathrm{Br}-$ & - & - & - & - & - & - & - & - & - \\
\hline \multicolumn{11}{|l|}{ Anions } \\
\hline $\mathrm{OH}^{-1}$ & $\mathrm{OH}^{-}$ & - & - & - & - & $4.03 E+04$ & $3.78 \mathrm{E}+04$ & $3.68 \mathrm{E}+04$ & $2.89 \mathrm{E}+04$ & $3.78 \mathrm{E}+04$ \\
\hline $\mathrm{NO}_{3}{ }^{-1}$ & $\mathrm{NO}_{3}^{-}$ & $1.63 \mathrm{E}+05$ & $1.65 \mathrm{E}+05$ & $7.79 \mathrm{E}+03$ & - & $1.66 \mathrm{E}+05$ & $1.58 \mathrm{E}+05$ & $1.62 \mathrm{E}+05$ & $7.76 \mathrm{E}+03$ & $1.59 \mathrm{E}+05$ \\
\hline $\mathrm{NO}_{2}^{-1}$ & $\mathrm{NO}_{2}^{-}$ & $2.85 \mathrm{E}+04$ & $2.88 \mathrm{E}+04$ & $1.34 \mathrm{E}+03$ & - & $2.69 \mathrm{E}+04$ & $2.70 \mathrm{E}+04$ & $2.84 \mathrm{E}+04$ & $1.33 \mathrm{E}+03$ & $2.81 \mathrm{E}+04$ \\
\hline $\mathrm{CO}_{3}^{-2}$ & $\mathrm{CO}_{3}^{-2}$ & $1.68 \mathrm{E}+04$ & $1.69 \mathrm{E}+04$ & $2.74 \mathrm{E}+03$ & - & $2.00 \mathrm{E}+04$ & $1.70 \mathrm{E}+04$ & $1.73 E+04$ & $2.94 \mathrm{E}+03$ & $1.70 \mathrm{E}+04$ \\
\hline $\mathrm{SO}_{4}^{-2}$ & $\mathrm{SO}_{4}^{-2}$ & $6.55 \mathrm{E}+03$ & $6.62 \mathrm{E}+03$ & $3.18 \mathrm{E}+02$ & - & $6.82 \mathrm{E}+03$ & $6.13 \mathrm{E}+03$ & $6.69 \mathrm{E}+03$ & $3.17 \mathrm{E}+02$ & $6.48 \mathrm{E}+03$ \\
\hline $\mathrm{C}_{2} \mathrm{O}_{4}^{-2}$ & $\mathrm{C}_{2} \mathrm{O}_{4}{ }^{-2}$ & $1.03 \mathrm{E}+02$ & $1.10 \mathrm{E}+02$ & $2.94 \mathrm{E}+03$ & - & $2.60 \mathrm{E}+02$ & $9.77 \mathrm{E}+01$ & $1.04 \mathrm{E}+02$ & $3.01 \mathrm{E}+03$ & $1.03 \mathrm{E}+02$ \\
\hline $\mathrm{F}^{-1}$ & $\mathrm{~F}^{-}$ & - & - & - & - & - & - & - & - & - \\
\hline $\mathrm{HCOO}^{-1}$ & $\mathrm{HCOO}^{-}$ & - & - & - & - & $3.54 \mathrm{E}+02$ & - & - & - & - \\
\hline $\mathrm{Cl}^{-1}$ & $\mathrm{Cl}^{-}$ & - & - & - & - & $1.09 \mathrm{E}+02$ & - & - & - & - \\
\hline $\mathrm{PO}_{4}^{-3}$ & $\mathrm{PO}_{4}^{-3}$ & $2.22 \mathrm{E}+02$ & $2.29 \mathrm{E}+02$ & - & - & $4.24 \mathrm{E}+02$ & $2.19 \mathrm{E}+02$ & $2.37 \mathrm{E}+02$ & - & $2.36 \mathrm{E}+02$ \\
\hline $\mathrm{Al}(\mathrm{OH})_{4}{ }^{-1}$ & $\mathrm{Al}$ & $1.52 \mathrm{E}+04$ & $1.83 \mathrm{E}+04$ & $<=6.97 E+02$ & $1.87 \mathrm{E}+04$ & $1.88 \mathrm{E}+04$ & $1.87 \mathrm{E}+04$ & $1.87 \mathrm{E}+04$ & $8.61 \mathrm{E}+02$ & $1.88 \mathrm{E}+04$ \\
\hline $\mathrm{B}(\mathrm{OH})_{4}^{-1}$ & $\mathrm{~B}$ & - & - & - & - & $3.77 \mathrm{E}+02$ & $3.88 \mathrm{E}+02$ & $3.88 \mathrm{E}+02$ & $7.28 \mathrm{E}+00$ & $3.89 \mathrm{E}+02$ \\
\hline $\mathrm{CrO}_{4}^{-2}$ & $\mathrm{Cr}$ & - & - & - & - & $1.02 \mathrm{E}+02$ & $1.02 \mathrm{E}+02$ & $1.01 \mathrm{E}+02$ & - & $1.02 \mathrm{E}+02$ \\
\hline $\mathrm{MoO}_{4}^{-2}$ & Mo & - & - & - & - & - & - & - & - & $<=1.78 E+01$ \\
\hline $\mathrm{VO}_{4}^{-3}$ & $\mathrm{~V}$ & - & - & - & - & - & - & - & - & - \\
\hline
\end{tabular}

\subsubsection{Sample Reconciliation Results}

Table 3-15 shows the apparent composition calculated from each of the sample inputs. These are interim calculated values that are used in all subsequent calculations and are included here for information. The Tank $49 \mathrm{H}$ results are also shown as mole fraction as this is the form needed for the OLI ESPTM calculations in Section 3.3.2. A description of how these calculations were performed is included in Section 2.3. 
SRNL-STI-2013-00700

Revision 0

Table 3-15. Results of Reconciliation Calculation - Apparent Species

\begin{tabular}{|c|c|c|c|c|c|c|c|c|c|}
\hline \multirow[b]{2}{*}{ Apparent Species } & \multirow{2}{*}{$\begin{array}{l}\text { lwht-1 } \\
\mathrm{mg} / \mathrm{L}\end{array}$} & \multicolumn{2}{|c|}{ lwpt-1 } & \multicolumn{2}{|c|}{ lwpt-2 } & \multicolumn{2}{|c|}{ lwpt-3 } & \multicolumn{2}{|c|}{ Tank 49} \\
\hline & & $\begin{array}{c}\text { filtrate } \\
\mathrm{mg} / \mathrm{L}\end{array}$ & $\begin{array}{c}\text { as-received } \\
\mathrm{mg} / \mathrm{L}\end{array}$ & $\begin{array}{c}\text { filtrate } \\
\mathrm{mg} / \mathrm{L}\end{array}$ & $\begin{array}{c}\text { as-received } \\
\mathrm{mg} / \mathrm{L}\end{array}$ & $\begin{array}{c}\text { filtrate } \\
\mathrm{mg} / \mathrm{L}\end{array}$ & $\begin{array}{c}\text { as-received } \\
\mathrm{mg} / \mathrm{L}\end{array}$ & $\mathrm{mg} / \mathrm{L}$ & mole fraction \\
\hline $\mathrm{Al}_{2} \mathrm{O}_{3}$ & $1.01 \mathrm{E}+04$ & $1.00 \mathrm{E}+04$ & $8.16 \mathrm{E}+03$ & $1.00 \mathrm{E}+04$ & $9.82 \mathrm{E}+03$ & $4.62 \mathrm{E}+02$ & $3.74 \mathrm{E}+02$ & $1.00 \mathrm{E}+04$ & $1.79956 \mathrm{E}-03$ \\
\hline $\mathrm{B}_{2} \mathrm{O}_{3}$ & $1.72 \mathrm{E}+02$ & $1.71 \mathrm{E}+02$ & & $1.71 \mathrm{E}+02$ & & $3.21 \mathrm{E}+00$ & & $1.66 \mathrm{E}+02$ & $4.37306 \mathrm{E}-05$ \\
\hline $\mathrm{Na}_{8} \mathrm{Al}_{6} \mathrm{Si}_{6} \mathrm{O}_{24} \mathrm{CO}_{3} \cdot 1 \mathrm{H}_{2} \mathrm{O}$ & & & & & & & & $2.03 \mathrm{E}+02$ & $3.80469 \mathrm{E}-06$ \\
\hline $\mathrm{CaCO}_{3}$ & & & & & & $4.07 \mathrm{E}+00$ & & & \\
\hline $\mathrm{CaO}$ & & & & & & $5.49 \mathrm{E}+00$ & & & \\
\hline $\mathrm{CO}_{2}$ & $1.25 \mathrm{E}+04$ & $1.25 \mathrm{E}+04$ & $1.23 \mathrm{E}+04$ & $1.27 \mathrm{E}+04$ & $1.24 \mathrm{E}+04$ & $2.15 \mathrm{E}+03$ & $2.00 \mathrm{E}+03$ & $1.47 \mathrm{E}+04$ & $6.09331 \mathrm{E}-03$ \\
\hline $\mathrm{CrO}_{3}$ & $8.79 \mathrm{E}+01$ & $8.79 \mathrm{E}+01$ & & $8.71 \mathrm{E}+01$ & & & & $8.82 \mathrm{E}+01$ & $1.61376 \mathrm{E}-05$ \\
\hline $\mathrm{CuO}$ & & & & & & & & $2.47 \mathrm{E}+01$ & $5.68005 \mathrm{E}-06$ \\
\hline $\mathrm{Fe}_{2} \mathrm{O}_{3}$ & & $8.56 \mathrm{E}+00$ & & $9.75 \mathrm{E}+00$ & & & & $7.11 \mathrm{E}+00$ & $8.15667 \mathrm{E}-07$ \\
\hline $\mathrm{H}_{2} \mathrm{O}$ & $8.92 \mathrm{E}+05$ & $8.93 \mathrm{E}+05$ & $8.90 \mathrm{E}+05$ & $8.89 \mathrm{E}+05$ & $8.79 \mathrm{E}+05$ & $1.01 \mathrm{E}+06$ & $1.01 \mathrm{E}+06$ & $8.86 \mathrm{E}+05$ & 8.99721E-01 \\
\hline $\mathrm{K}_{2} \mathrm{O}$ & $4.77 \mathrm{E}+02$ & $4.51 \mathrm{E}+02$ & & $4.71 \mathrm{E}+02$ & & & & $4.67 \mathrm{E}+02$ & $9.07730 \mathrm{E}-05$ \\
\hline \multicolumn{10}{|l|}{$\mathrm{KCl}$} \\
\hline $\mathrm{Li}_{2} \mathrm{O}$ & $9.84 \mathrm{E}+00$ & $1.00 \mathrm{E}+01$ & & $1.05 \mathrm{E}+01$ & & & & & \\
\hline $\mathrm{Li}[\mathrm{HCOO}]$ & & & & & & & & $1.68 \mathrm{E}+02$ & $5.91190 \mathrm{E}-05$ \\
\hline $\mathrm{MoO}_{3}$ & $1.60 \mathrm{E}+01$ & & & & & & & & \\
\hline $\mathrm{MgO}$ & & $4.58 \mathrm{E}-05$ & & 4.70E-05 & & & & & \\
\hline $\mathrm{Mg}(\mathrm{OH})_{2}$ & & 6.33E-01 & & $6.00 \mathrm{E}-01$ & & & & & \\
\hline $\mathrm{N}_{2} \mathrm{O}_{5}$ & $1.39 \mathrm{E}+05$ & $1.37 \mathrm{E}+05$ & $1.42 \mathrm{E}+05$ & $1.41 \mathrm{E}+05$ & $1.56 \mathrm{E}+05$ & $6.75 \mathrm{E}+03$ & $6.77 \mathrm{E}+03$ & $1.45 \mathrm{E}+05$ & $2.44887 \mathrm{E}-02$ \\
\hline $\mathrm{NA}_{2}[\mathrm{COO}]_{2}$ & $1.57 \mathrm{E}+02$ & $1.49 \mathrm{E}+02$ & $1.57 \mathrm{E}+02$ & $1.58 \mathrm{E}+02$ & $1.67 \mathrm{E}+02$ & $4.59 \mathrm{E}+03$ & $4.47 \mathrm{E}+03$ & $3.96 \mathrm{E}+02$ & $5.40389 \mathrm{E}-05$ \\
\hline $\mathrm{Na}_{2} \mathrm{O}$ & $1.76 \mathrm{E}+05$ & $1.75 \mathrm{E}+05$ & $1.77 \mathrm{E}+05$ & $1.76 \mathrm{E}+05$ & $1.84 \mathrm{E}+05$ & $5.99 \mathrm{E}+04$ & $6.79 \mathrm{E}+04$ & $1.88 \mathrm{E}+05$ & $5.54550 \mathrm{E}-02$ \\
\hline $\mathrm{Na}_{2} \mathrm{SiO}_{3}$ & & & & & & & & $1.28 \mathrm{E}+01$ & $1.92143 \mathrm{E}-06$ \\
\hline $\mathrm{NaCl}$ & & & & & & & & $1.80 \mathrm{E}+02$ & $5.64156 \mathrm{E}-05$ \\
\hline $\mathrm{Na}[\mathrm{HCOO}]$ & & & & & & & & $3.15 \mathrm{E}+02$ & $8.47380 \mathrm{E}-05$ \\
\hline $\mathrm{NaNO}_{2}$ & $4.21 \mathrm{E}+04$ & $4.05 \mathrm{E}+04$ & $4.27 \mathrm{E}+04$ & $4.26 \mathrm{E}+04$ & $4.31 \mathrm{E}+04$ & $2.00 \mathrm{E}+03$ & $2.00 \mathrm{E}+03$ & $4.03 \mathrm{E}+04$ & $1.06836 \mathrm{E}-02$ \\
\hline $\mathrm{P}_{2} \mathrm{O}_{5}$ & $1.76 \mathrm{E}+02$ & $1.64 \mathrm{E}+02$ & $1.66 \mathrm{E}+02$ & $1.77 \mathrm{E}+02$ & $1.71 \mathrm{E}+02$ & & & $3.17 \mathrm{E}+02$ & 4.08055E-05 \\
\hline $\mathrm{SO}_{3}$ & $5.40 \mathrm{E}+03$ & $5.11 \mathrm{E}+03$ & $5.46 \mathrm{E}+03$ & $5.58 \mathrm{E}+03$ & $5.52 \mathrm{E}+03$ & $2.64 \mathrm{E}+02$ & $2.65 \mathrm{E}+02$ & $5.69 \mathrm{E}+03$ & $1.29942 \mathrm{E}-03$ \\
\hline $\mathrm{ZnO}$ & $6.41 \mathrm{E}+00$ & $6.26 \mathrm{E}+00$ & & $6.06 \mathrm{E}+00$ & & & & $6.53 \mathrm{E}+00$ & $1.46600 \mathrm{E}-06$ \\
\hline
\end{tabular}

\subsubsection{OLI Analyzer Survey Results}

This section presents results of calculation surveys performed for each sample. Only summary information related to predicted solids is presented as the volume of calculated results is quite large. This is followed by a comparison of solids identified in the solids analysis and the thermodynamic model results.

\section{Predicted Solids}

Figure 3-9 through Figure 3-13 graphically depict the predicted propensity of each of the samples to precipitate solids as well as the amount of solids formed. Each line represents the amount of solids calculated to precipitate versus calculated free hydroxide ion. Effectively, these isotherms represent the amount of excess above saturation or quantized super-saturation. The black line at the top of each graph indicates the measured total of the limiting element for each of the solids (i.e., the maximum amount of solids possible for each compound). Solids precipitated are shown in quantity units of moles. The calculations simulated $1 \mathrm{~L}$ of sample so the reported results can very easily be interpreted as moles precipitated per liter of input solution. 
One needs to be careful when interpreting the information presented in the graphs as the calculated results shown represent several chemical changes other than just a change in hydroxide concentration. For example, the total ion strength changes from the changing input conditions as well as from the amount of solids precipitating. These graphs are intended to provide an indication of saturation level for each sample. Variation of sodium hydroxide concentration is picked because of the following two reasons: the anion is known to have a strong effect on aluminum solubility and other metals, thus, maximizing the effect on the solution from the changing anion concentration; and the sodium cation is used to reconcile charge, thus, does not represent the analytically determined sodium content thereby minimizing the difference between the analytically determined composition and the simulated composition. The reconciled sodium concentration is within $12 \%$ of the measured concentration for all samples. The overall variation examined is narrow enough to minimize unintended effects, yet encompass the range of analytical uncertainty.

Several observations may be drawn based on these OLI simulation results:

- Aluminum concentration is practically at saturation in Tank $49 \mathrm{H}$ and in ARP during filtering.

- Sodium oxalate is significantly supersaturated in Tank $49 \mathrm{H}$ and throughout the ARP.

- Silicon is supersaturated in Tank $49 \mathrm{H}$ relative to sodium aluminosilicate (cancrinite). Silicon was present in the solids isolated from all LWPT samples. From these observations, a small quantity of sodium aluminosilicate solids are expected in the ARP strike tanks and the LWPT.

- Measured iron, magnesium, and copper are well above saturation.

- One of the three replicates for LWPT-3 showed calcium at or above saturation. Calcium solubility is a strong function of hydroxide concentration in this salt matrix. As only one of the three sample analyses resulted in a calcium concentration above the detection limit, it is equally likely to be a spurious result.

Analytical results from samples LWPT-1, LWPT-2, and LWPT-3 included as-received slurry results as well as filtered results. The survey results for the slurry as well as the filtered solution are shown for these samples. The differences in the isotherms shown in graphs between the filtrate and slurry are directly indicative of the difference in the analytical results used as inputs and does not reflect any significant difference in solubility. Presumably, the slurry results would indicate higher concentrations of precipitated components than in the filtrate result, but this is not consistently true. For example, the aluminum results are consistently higher in the filtrate results than in the slurry results, whereas, oxalate ion results vary from sample to sample. The aluminum results from the LWPT-1 sample exhibits the largest measured difference and clearly illustrate the effect in Figure 3-10. Though this appears to be a significant difference, the measured values are generally in the range expected for measurement variation and have no effect on any conclusions.

The analytical solids data suggests that the observations listed above relative to iron, magnesium, calcium, silicon, and aluminum are reasonable. The supersaturating of copper cannot be confirmed by the solids analysis. For oxalate solids, particularly for the quantity of oxalate solids, the sample analysis contradicts the simulated results. 
$\mathrm{Ba}, \mathrm{Cd}, \mathrm{Hg}, \mathrm{Li}, \mathrm{Mn}, \mathrm{Sr}, \mathrm{U}, \mathrm{V}, \mathrm{Zn}$, and $\mathrm{Zr}$ are not simulated since these metals were not detected in the filtrate or slurry although they are detected in the solids.

One should note that lithium and chromium were measured in the aqueous phase, included in the OLI simulation, and although the model results indicated sub-saturation levels, these elements were present in the solids.

Note that in figures below, NAS refers to carbonated sodium aluminosilicate monohydrate, $\mathrm{Na}[\mathrm{COO}] 2$ refers to sodium oxalate, and $\mathrm{Al}(\mathrm{OH}) 3$ is in the gibbsite form. 


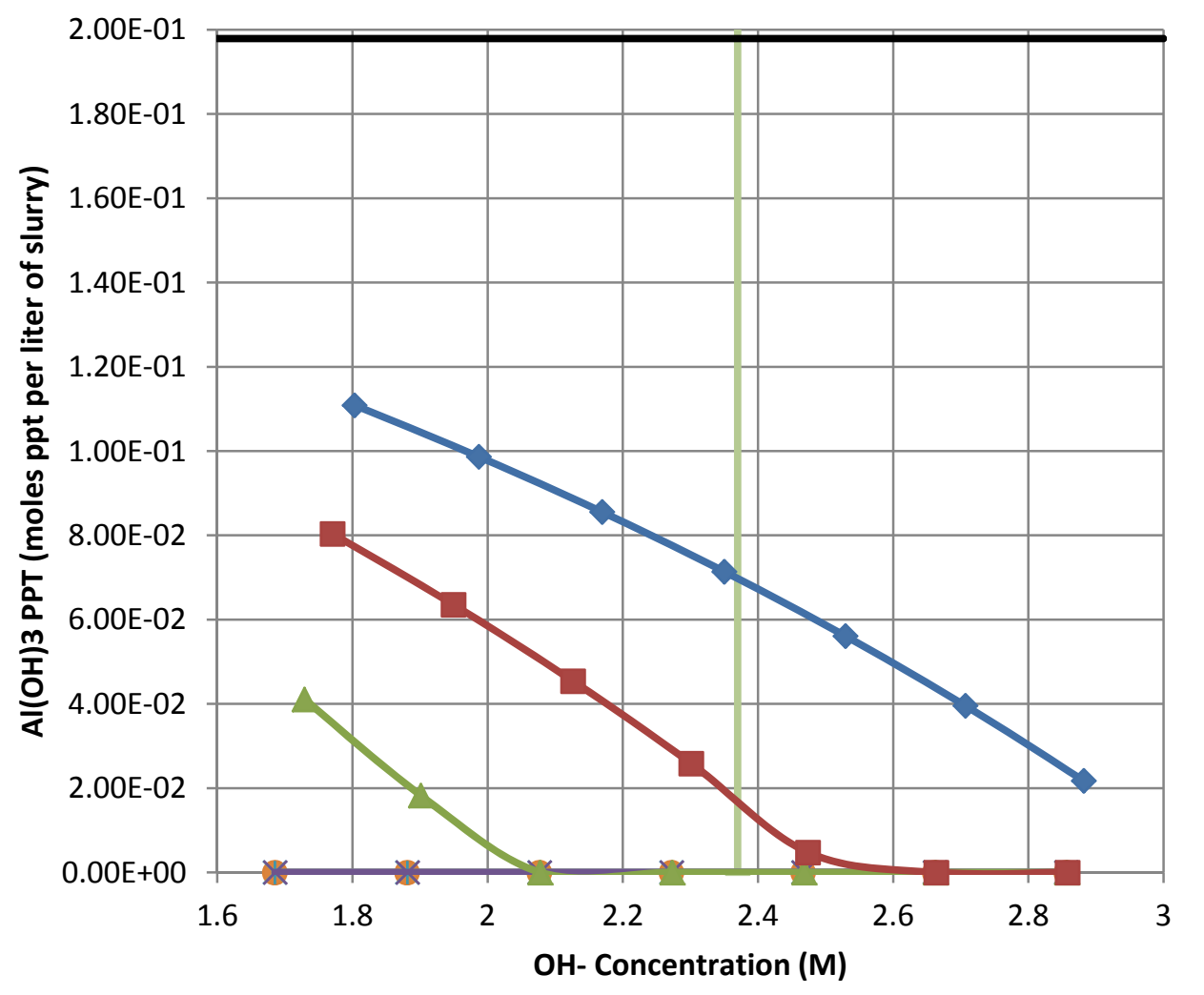

OH- Measured

Total

$-50^{\circ} \mathrm{C}$

$+45^{\circ} \mathrm{C}$

$-40^{\circ} \mathrm{C}$

$35^{\circ} \mathrm{C}$

$\leftarrow 30^{\circ} \mathrm{C}$

$-25^{\circ} \mathrm{C}$

$-15^{\circ} \mathrm{C}$

$-20^{\circ} \mathrm{C}$

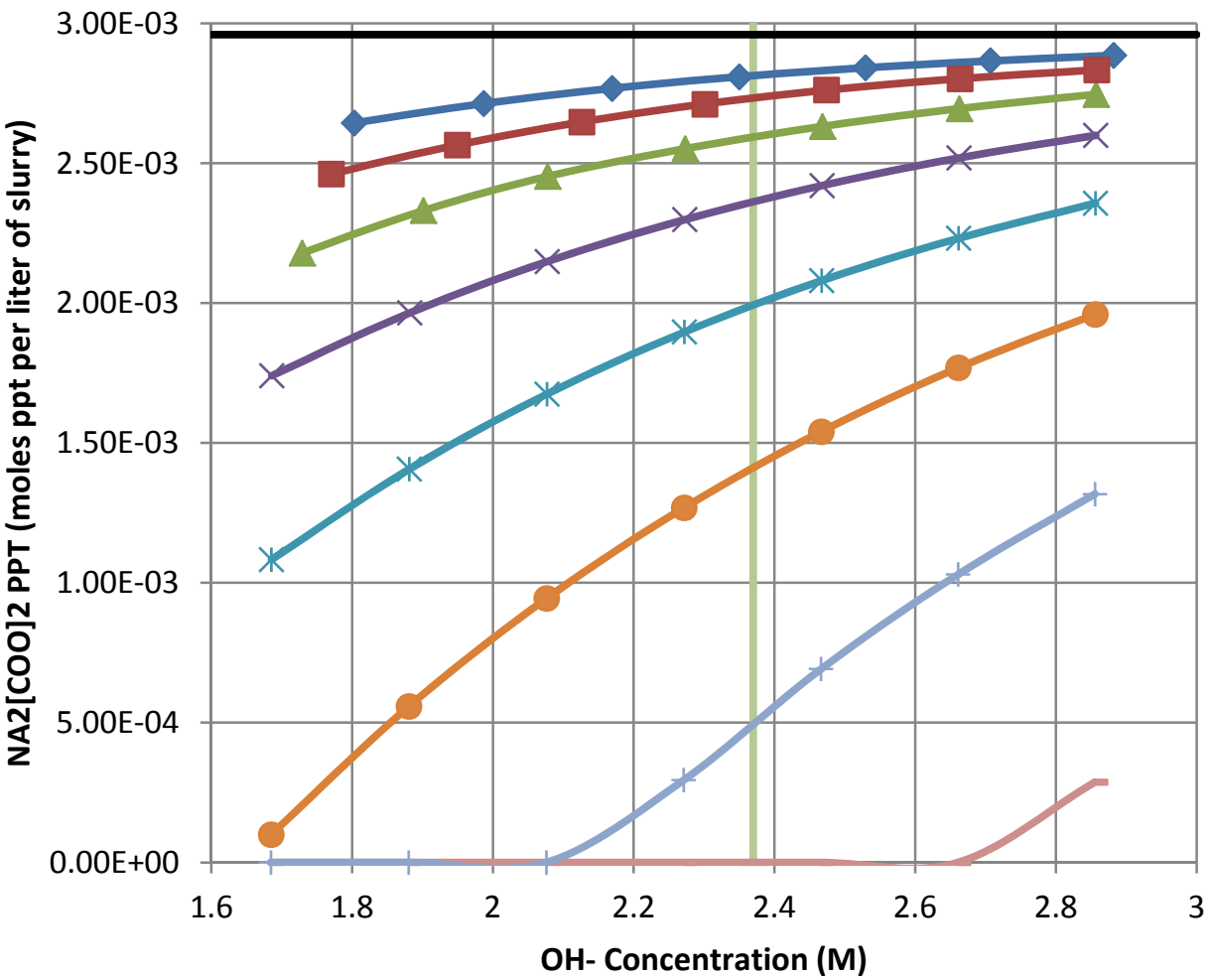

OH- Measured

Total

$-50^{\circ} \mathrm{C}$

$+45^{\circ} \mathrm{C}$

$-40^{\circ} \mathrm{C}$

* $35^{\circ} \mathrm{C}$

$\leftarrow 30^{\circ} \mathrm{C}$

$-25^{\circ} \mathrm{C}$

$-15^{\circ} \mathrm{C}$

$-20^{\circ} \mathrm{C}$

Figure 3-9. Predicted Solids Precipitated from Analytical Results of Tank 49H Sample 


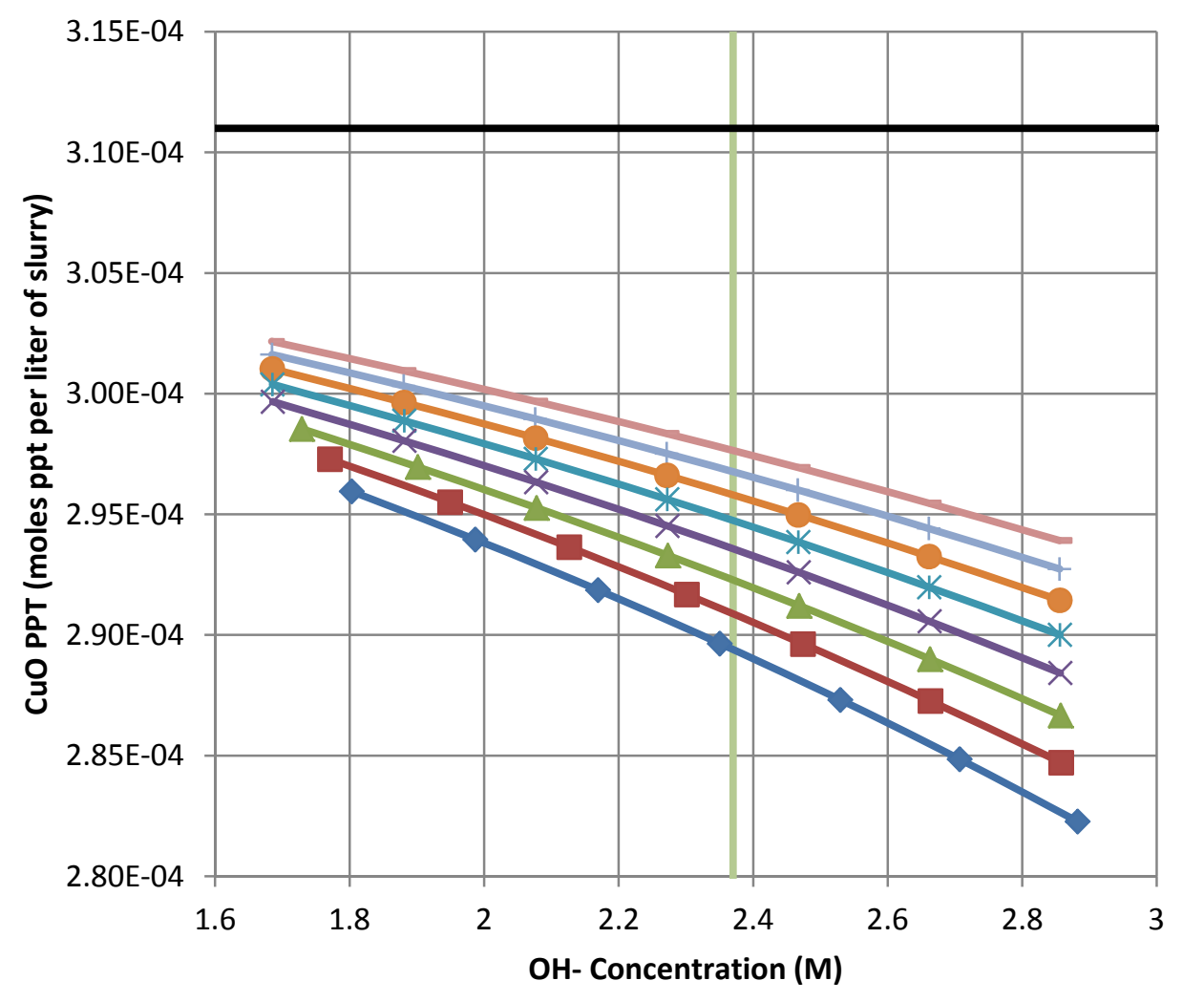

OH- Measured

-Total

$-50^{\circ} \mathrm{C}$

$+45^{\circ} \mathrm{C}$

$-40^{\circ} \mathrm{C}$

$\sim 35^{\circ} \mathrm{C}$

$\leftarrow 30^{\circ} \mathrm{C}$

$-25^{\circ} \mathrm{C}$

$\sim 15^{\circ} \mathrm{C}$

$-20^{\circ} \mathrm{C}$

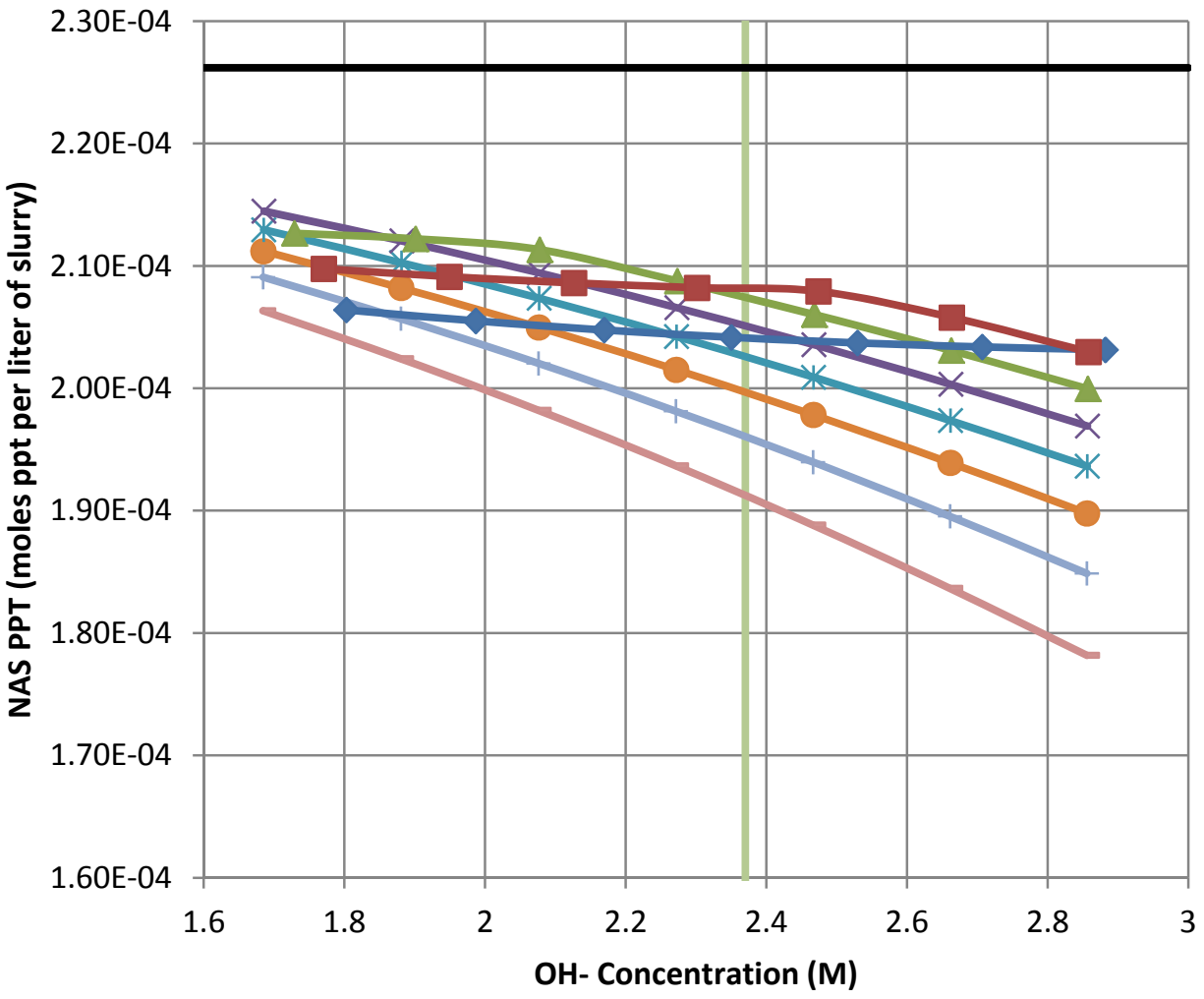

OH- Measured

-Total

$-50^{\circ} \mathrm{C}$

$+45^{\circ} \mathrm{C}$

$-40^{\circ} \mathrm{C}$

* $35^{\circ} \mathrm{C}$

$\leftarrow 30^{\circ} \mathrm{C}$

$-25^{\circ} \mathrm{C}$

$-15^{\circ} \mathrm{C}$

$-20^{\circ} \mathrm{C}$

Figure 3-9. Predicted Solids Precipitated from Analytical Results of Tank 49H Sample (continued) 


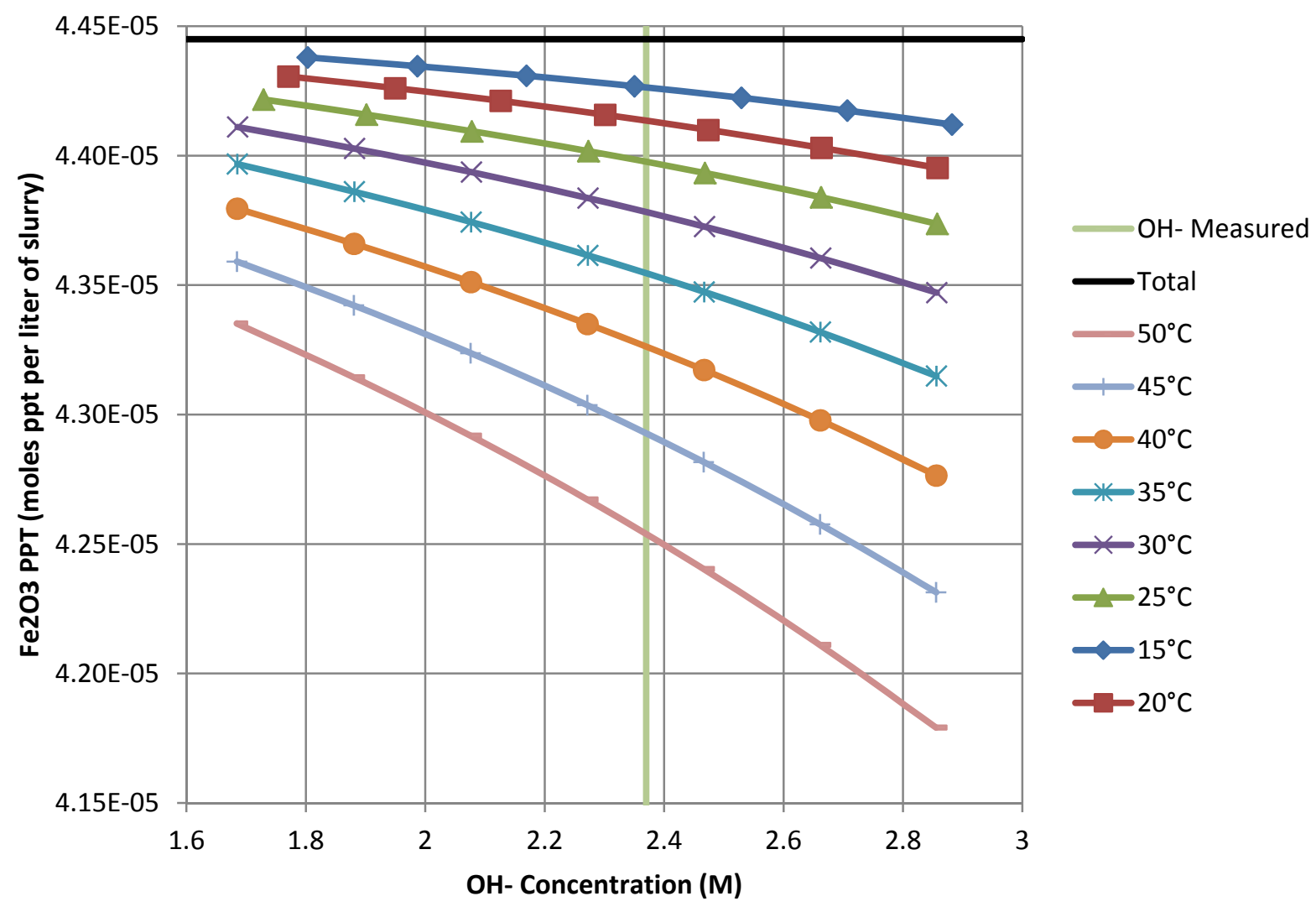

Figure 3-9. Predicted Solids Precipitated from Analytical Results of Tank 49H Sample (continued) 

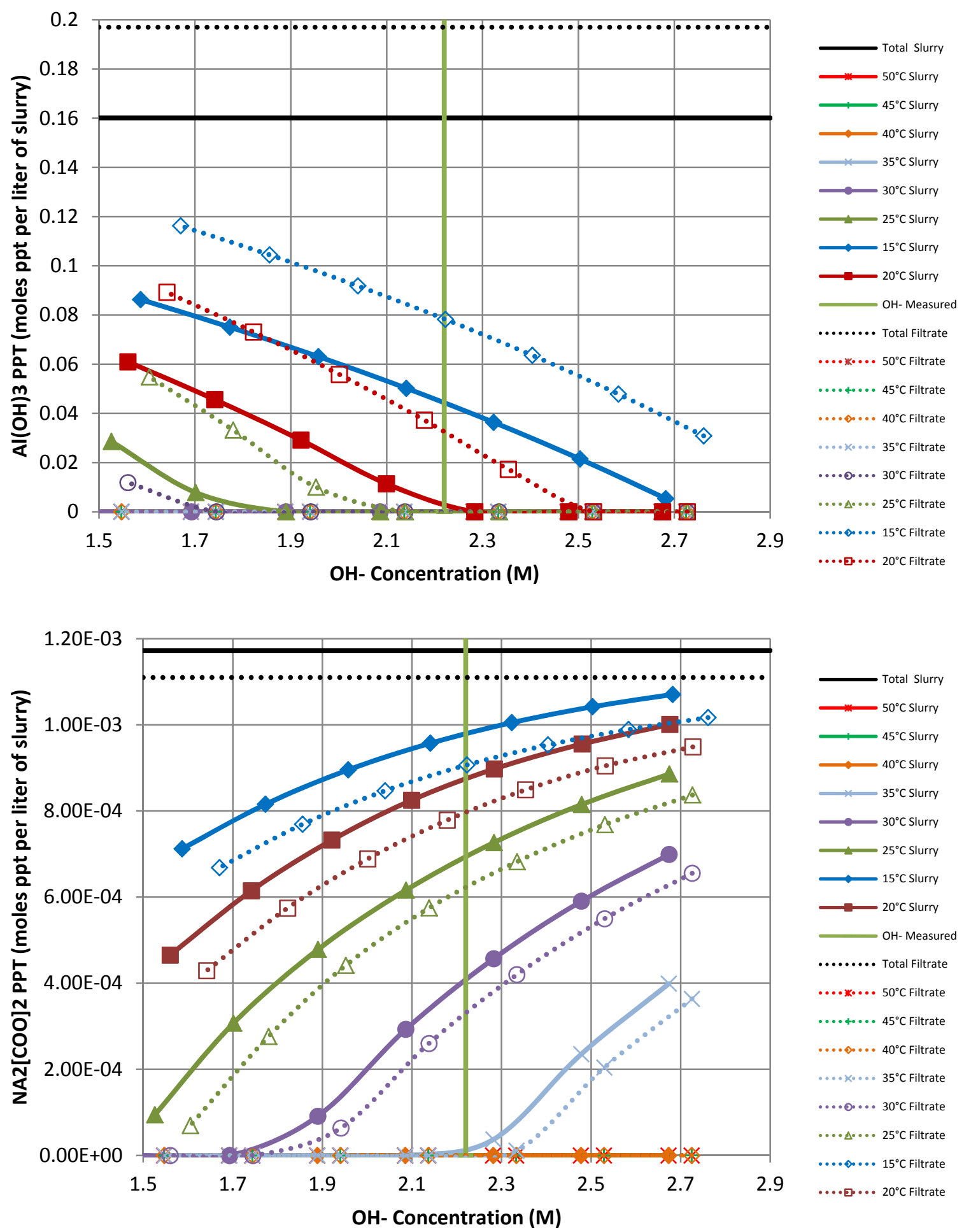

Figure 3-10. Predicted Solids Precipitated from Analytical Results of LWPT-1 Sample 
SRNL-STI-2013-00700

Revision 0
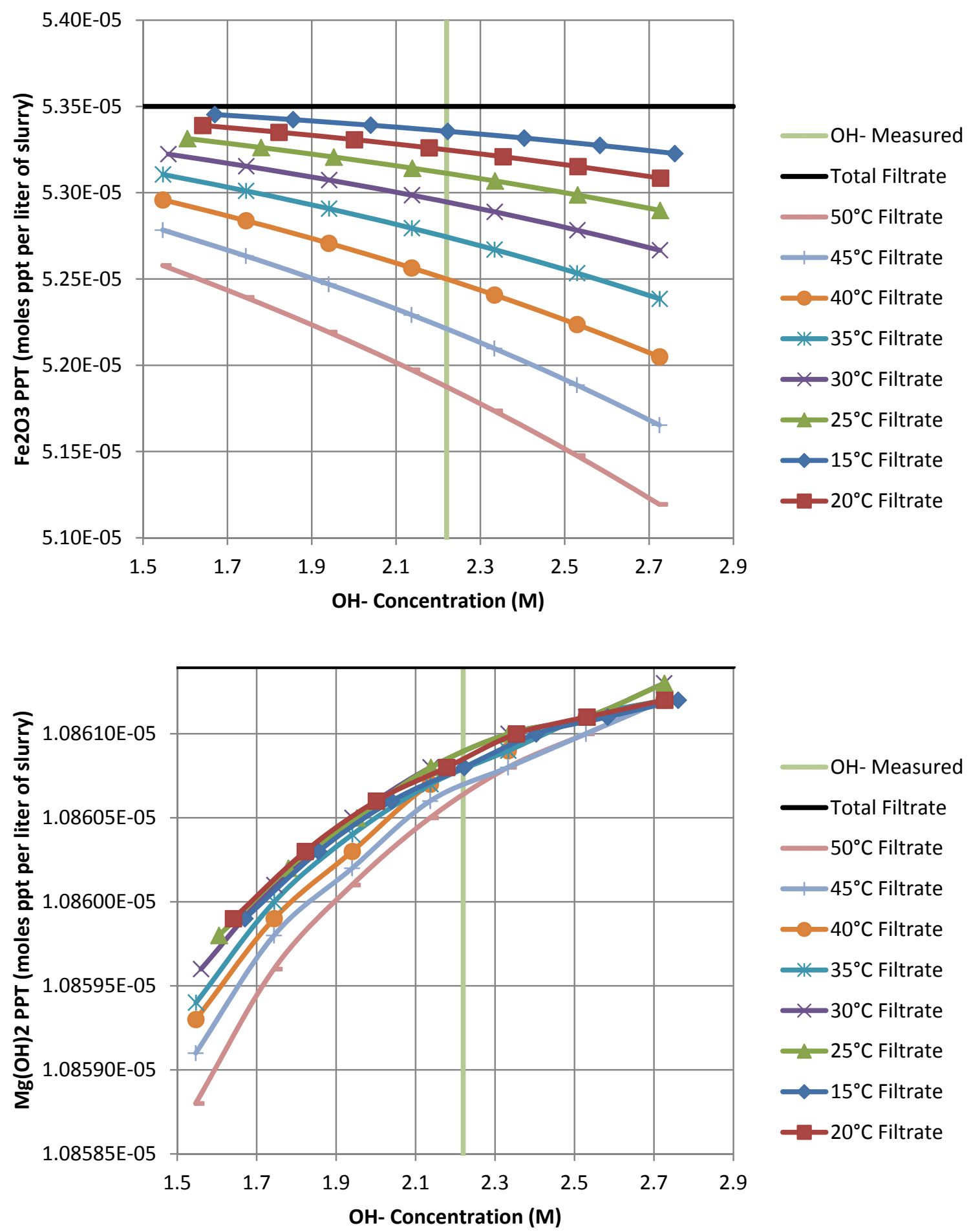

Figure 3-10. Predicted Solids Precipitated from Analytical Results of LWPT-1 Sample (continued) 

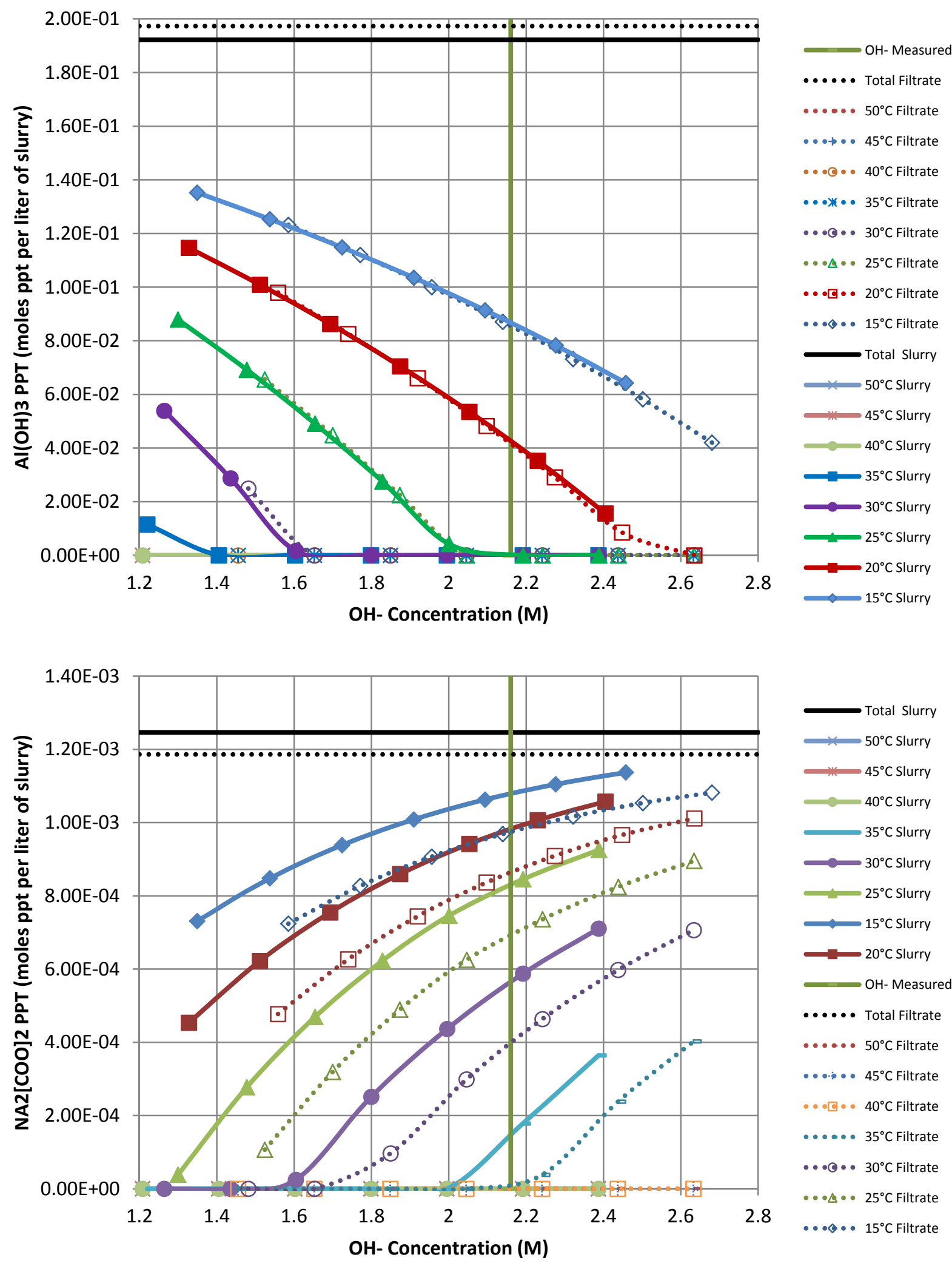

Figure 3-11. Predicted Solids Precipitated from Analytical Results of LWPT-2 Sample 

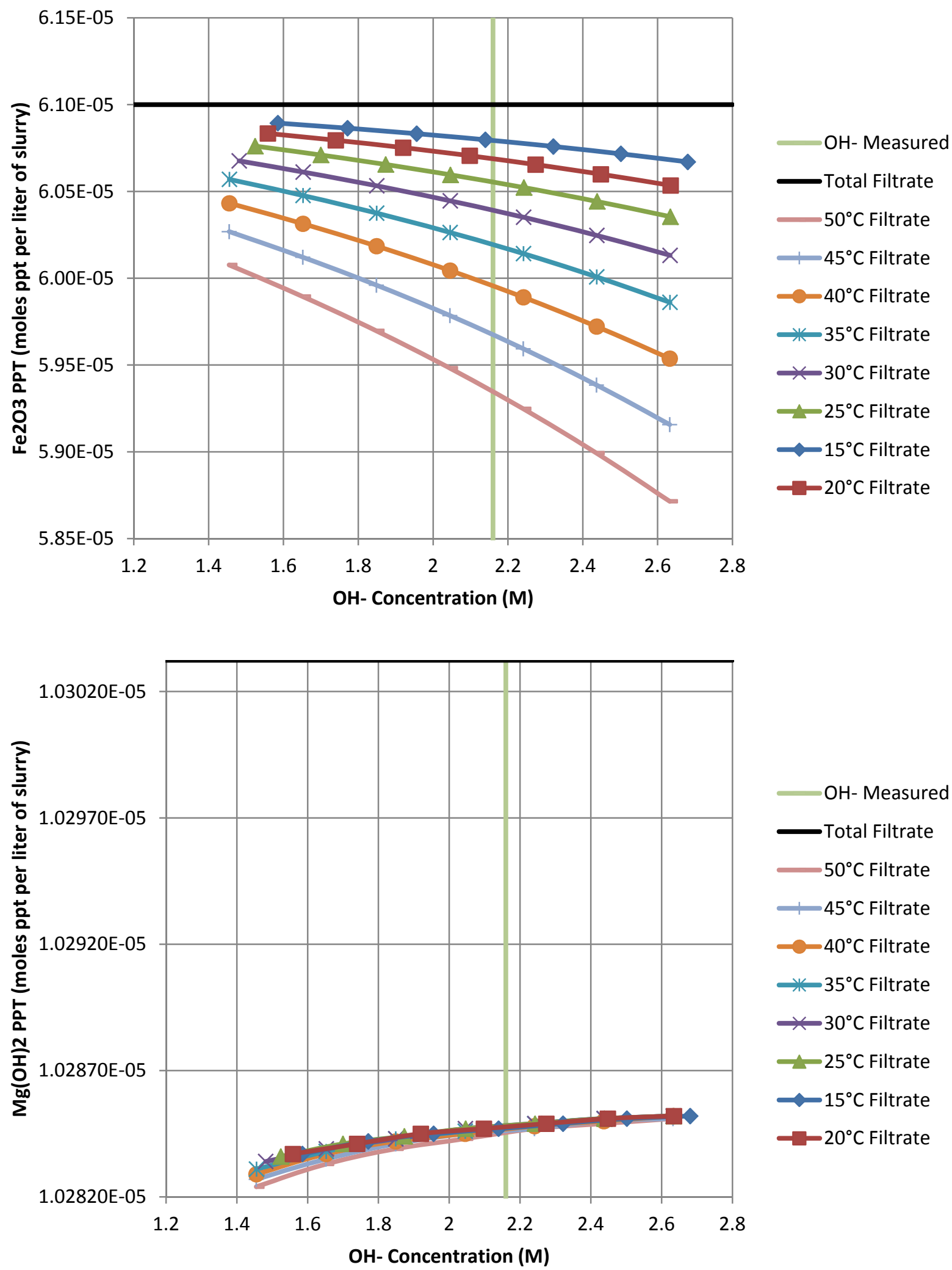

Figure 3-11. Predicted Solids Precipitated from Analytical Results of LWPT-2 Sample (continued) 

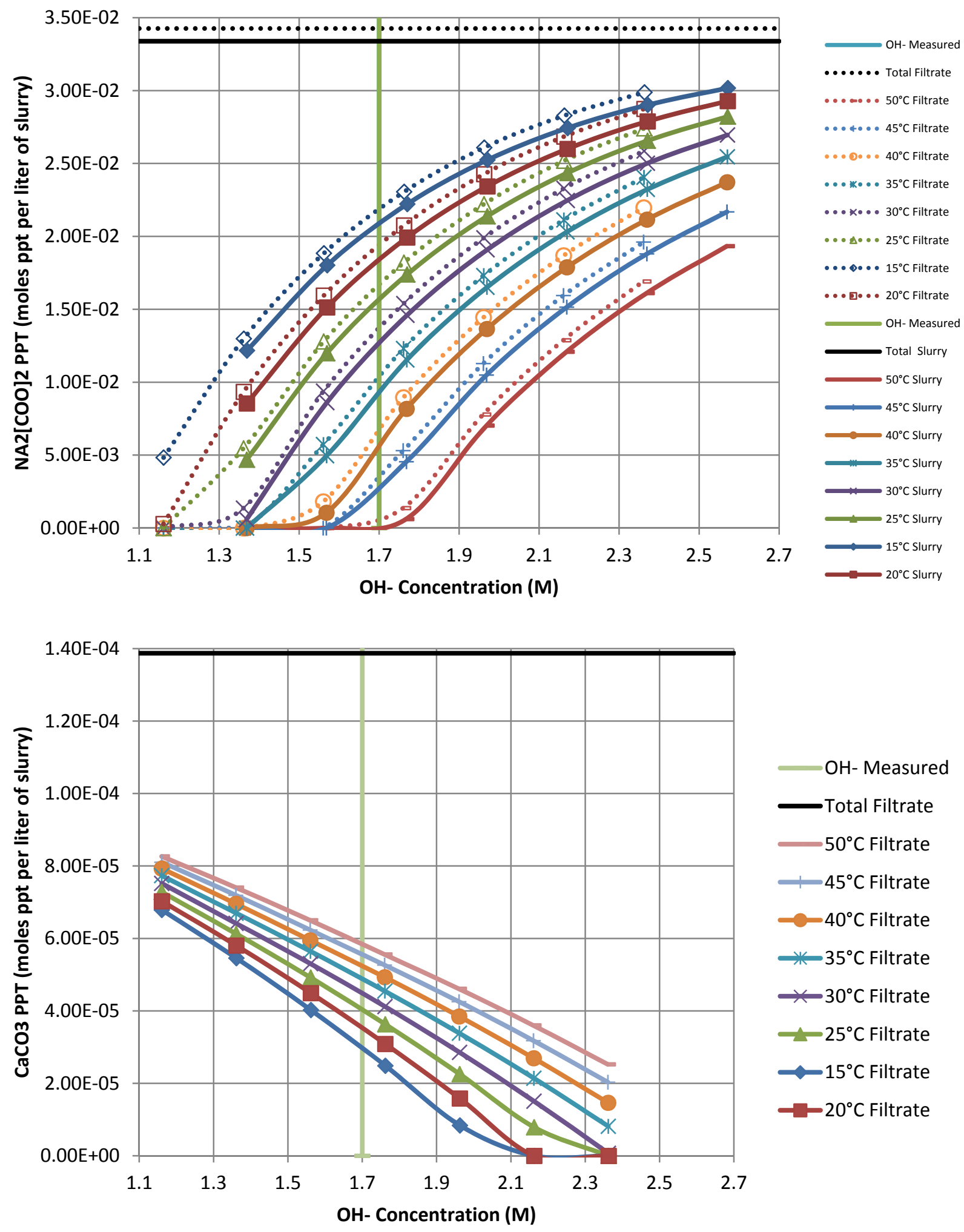

Figure 3-12. Predicted Solids Precipitated from Analytical Results of LWPT-3 Sample 
SRNL-STI-2013-00700

Revision 0

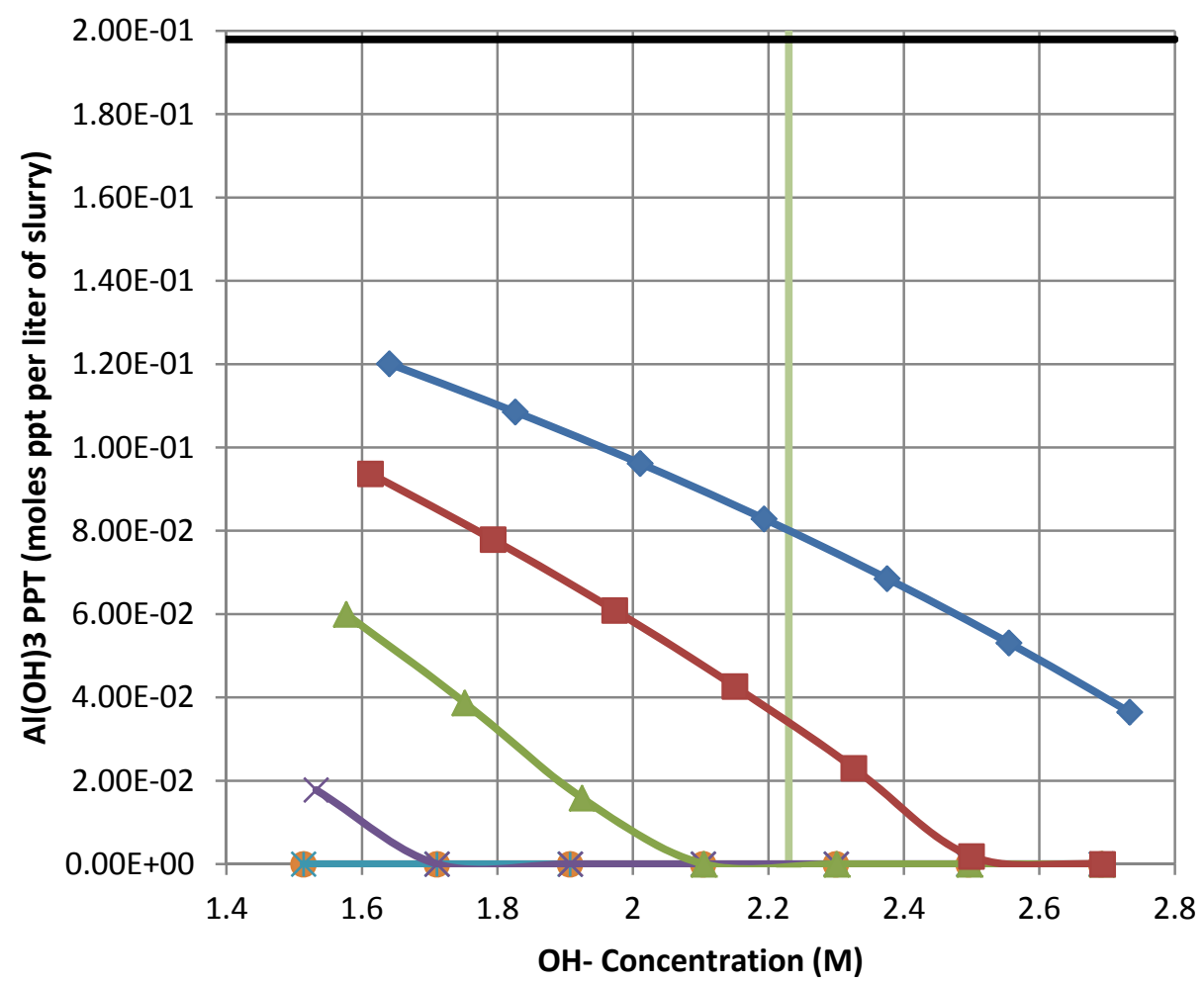

$\mathrm{OH}-$ Measured

Total Filtrate

$50^{\circ} \mathrm{C}$ Filtrate

$-45^{\circ} \mathrm{C}$ Filtrate

$-40^{\circ} \mathrm{C}$ Filtrate

* $35^{\circ} \mathrm{C}$ Filtrate

$\leftarrow 30^{\circ} \mathrm{C}$ Filtrate

$-25^{\circ} \mathrm{C}$ Filtrate

$-15^{\circ} \mathrm{C}$ Filtrate

$-20^{\circ} \mathrm{C}$ Filtrate

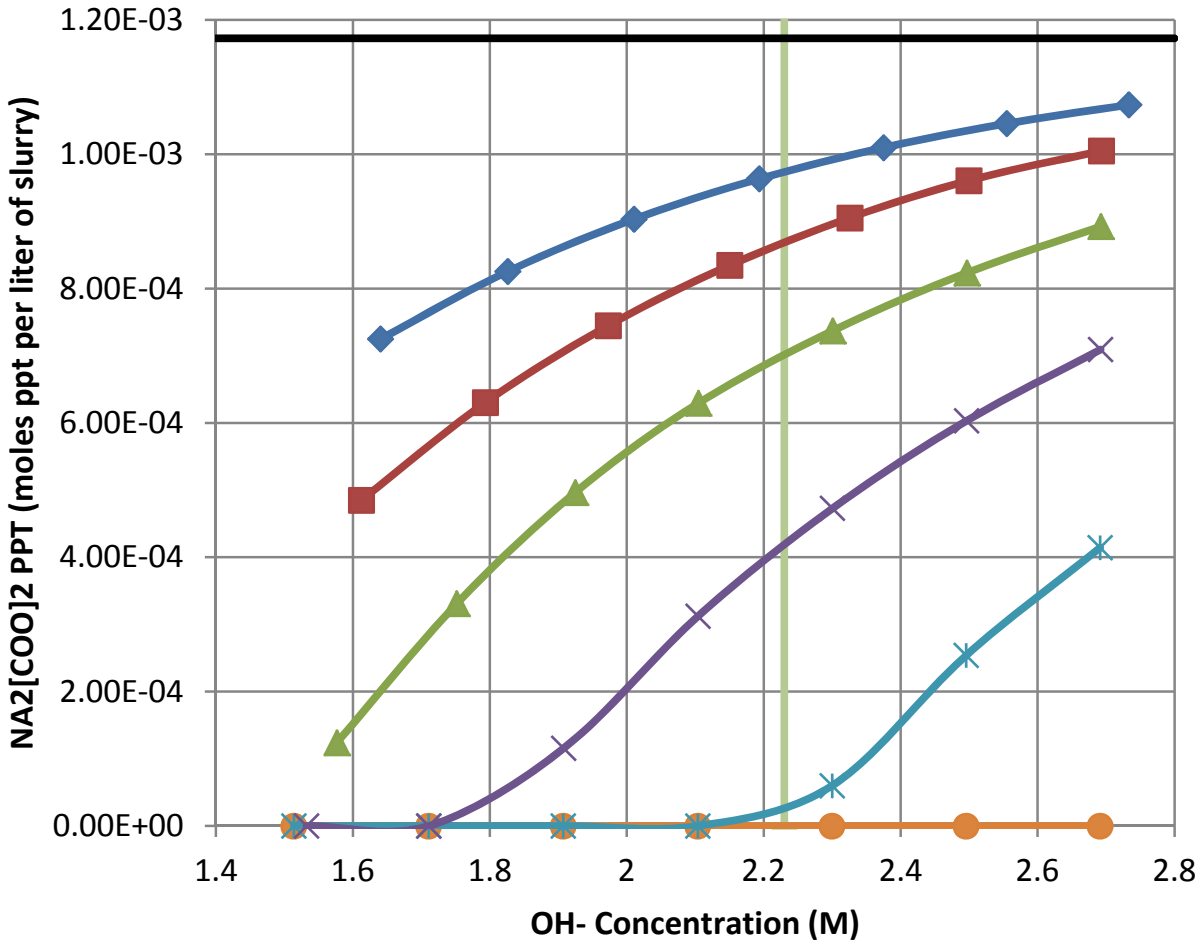

$\mathrm{OH}-$ Measured

Total Filtrate

$50^{\circ} \mathrm{C}$ Filtrate

$-45^{\circ} \mathrm{C}$ Filtrate

$-40^{\circ} \mathrm{C}$ Filtrate

* $35^{\circ} \mathrm{C}$ Filtrate

$\leftarrow 30^{\circ} \mathrm{C}$ Filtrate

$-25^{\circ} \mathrm{C}$ Filtrate

$-15^{\circ} \mathrm{C}$ Filtrate

$-20^{\circ} \mathrm{C}$ Filtrate

Figure 3-13. Predicted Solids Precipitated from Analytical Results of LWHT-1 Sample 


\section{Predicted Solids Composition Compared to Analytically Identified Solids}

The elemental analysis for the unwashed solids from LWPT-1, LWPT-2, and LWPT-3 are dominated by $\mathrm{Ti}$ and $\mathrm{Na}$, but also contained measurable amounts of other metals including $\mathrm{Al}, \mathrm{Ba}$, $\mathrm{Ca}, \mathrm{Cd}, \mathrm{Cr}, \mathrm{Fe}, \mathrm{Hg}, \mathrm{Li}, \mathrm{P}, \mathrm{S}, \mathrm{Si}, \mathrm{Sr}, \mathrm{U}, \mathrm{V}$, and Zr. Several of these metals are not detected in the liquid phase or slurry analysis so that they were not included in the thermodynamic simulation. As already noted, Ti is not simulated. The thermodynamic model did include $\mathrm{Al}, \mathrm{Fe}, \mathrm{Li}, \mathrm{Mg}$, and $\mathrm{Na}$ for simulated LWPT-1 and LWPT-2 samples. LWPT-3 included only Al, $\mathrm{Ca}$ and $\mathrm{Na}$. Table 3-16 presents a summary of predicted precipitated solids for each sample. Comparison to the concentration in the solids is not practical when all the detected metals in the solids are not detected in the liquid, thus, not included in the thermodynamic simulation. For the metals that are included, the qualitative expectations of metal content in the predicted solids are similar to the analytically detected metals.

Table 3-16. Summary of Predicted Solids in Each Sample

\begin{tabular}{l|c|c|c|c|c}
\hline & Tank 49H & LWPT-1 & LWPT-2 & LWPT-3 & LWHT-1 \\
\hline $\mathrm{Na}_{8} \mathrm{Al}_{6} \mathrm{Si}_{6} \mathrm{O}_{24} \mathrm{CO}_{3} \cdot 1 \mathrm{H}_{2} \mathrm{O}$ & $\mathrm{X}$ & & & & \\
\hline $\mathrm{Na}_{2} \mathrm{C}_{2} \mathrm{O}_{4}$ & $\mathrm{X}$ & $\mathrm{X}$ & $\mathrm{X}$ & $\mathrm{X}$ & $\mathrm{X}$ \\
\hline $\mathrm{CaCO}_{3}$ & & & & $\mathrm{X}$ & \\
\hline $\mathrm{Mg}(\mathrm{OH})_{2}$ & & $\mathrm{X}$ & $\mathrm{X}$ & & \\
\hline $\mathrm{Fe}_{2} \mathrm{O}_{3}$ & $\mathrm{X}$ & $\mathrm{X}$ & $\mathrm{X}$ & & \\
\hline $\mathrm{CuO}$ & $\mathrm{X}$ & $\mathrm{X}$ & $\mathrm{X}$ & & \\
\hline $\mathrm{Al}(\mathrm{OH})_{3}$ & & & & \\
\hline
\end{tabular}

XRD results in Figure 3-3 Figure 3-4 and Figure 3-5 for samples LWPT-1, LWPT-2, and LWPT3, identify the following solids: $\mathrm{Na}_{2} \mathrm{Ti}_{2} \mathrm{O}_{4}(\mathrm{OH})_{2}, \mathrm{NaNO}_{3}, \mathrm{Na}_{2} \mathrm{C}_{2} \mathrm{O}_{4}, \mathrm{Na}_{2} \mathrm{CO}_{3}{ }^{*} \mathrm{H}_{2} \mathrm{O}$, and $\mathrm{Na}_{3} \mathrm{H}\left(\mathrm{CO}_{3}\right)_{2} * 2 \mathrm{H}_{2} \mathrm{O}$. The origin of the XRD reflectance pattern assigned to $\mathrm{Na}_{2} \mathrm{Ti}_{2} \mathrm{O}_{4}(\mathrm{OH})_{2}$ is attributed to MST, indicating some MST is in the sample. The presence of solid $\mathrm{NaNO}_{3}$ is attributed to crystallization of the liquid phase clinging to the unwashed solids. The origin of the $\mathrm{Na}_{2} \mathrm{C}_{2} \mathrm{O}_{4}$ is likely due to both precipitated solids in the sample (as the thermodynamic simulation identifies that $\mathrm{Na}_{2} \mathrm{C}_{2} \mathrm{O}_{4}$ exceeds the solubility in all of the samples) and to crystallization of the liquid phase clinging to the unwashed solids. The presence of solid carbonate compounds are attributed to absorption of carbon dioxide from the air by the $\mathrm{NaOH}$ content of the liquid phase during sample preparation. However, since the carbonate solids may also result from precipitated solids in the sample, the following discussion examines the carbonate saturation level calculated by the thermodynamic model.

Relative saturation in OLI Analyzer ${ }^{\mathrm{TM}}$ is represented by the calculated scaling factor as described in Section 2.3, and is an indication of the tendency to form solids (scale). OLI Analyzer ${ }^{\mathrm{TM}}$ calculates a scaling factor for all the solids identified as possible for the given solution, but most of the values are very small, indicating they are far from saturation. This evaluation first determines all the possible carbonate containing solids that OLI AnalyzerTM identified in its database to assure that it includes the solids identified in the XRD as well as all other compounds commonly expected. Note that some variations exist in how the XRD results report identified compounds and the form identified in the OLI Analyzer ${ }^{\mathrm{TM}}$ database. The OLI Analyzer ${ }^{\mathrm{TM}}$ database identifies $\mathrm{Na}_{3} \mathrm{H}\left(\mathrm{CO}_{3}\right)_{2} * 2 \mathrm{H}_{2} \mathrm{O}$ as the double salt: $\mathrm{NaHCO}_{3} \cdot \mathrm{Na}_{2} \mathrm{CO}_{3} \cdot 2 \mathrm{H}_{2} \mathrm{O}$. The chemistry simulation identified the following carbonate compounds: 
SRNL-STI-2013-00700

Revision 0
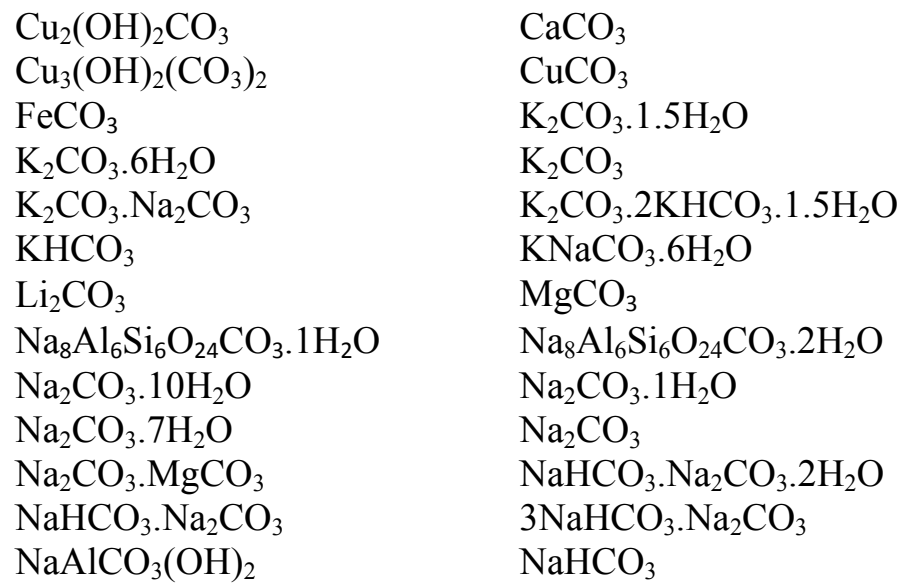

The chemistry simulation identified carbonate solids only in the LWPT-3 sample as shown in Figure 3-12. In this case the results show $\mathrm{CaCO}_{3}$ super-saturation, but this result is based on a single calcium analysis near detection limits. Although this result could be accurate, it also suggest a potential spurious analytical result.

The simulation results are parsed to only the compounds that exhibit scaling tendencies above 0.01 which corresponds to approximately at or above $1 \%$ of saturation. The following are above $1 \%$ in the LWPT-1 and LWPT-2 samples

$\begin{array}{ll}\mathrm{Na}_{2} \mathrm{CO}_{3} \cdot 10 \mathrm{H}_{2} \mathrm{O} & \mathrm{Na}_{2} \mathrm{CO}_{3} \cdot 1 \mathrm{H}_{2} \mathrm{O} \\ \mathrm{Na}_{2} \mathrm{CO}_{3} \cdot 7 \mathrm{H}_{2} \mathrm{O} & \mathrm{Na}_{2} \mathrm{CO}_{3} \\ \mathrm{NaAlCO}_{3}(\mathrm{OH})_{2} & \end{array}$

whereas, LWPT-3 includes

$$
\begin{aligned}
& \mathrm{Na}_{2} \mathrm{CO}_{3} \cdot 10 \mathrm{H}_{2} \mathrm{O} \\
& \mathrm{Na}_{2} \mathrm{CO}_{3} \cdot 7 \mathrm{H}_{2} \mathrm{O} \\
& \mathrm{CaCO}_{3}
\end{aligned}
$$

Figure 3-14 and Figure 3-15 show scaling tendency variation only for the carbonate compounds closest to saturation in LWPT-1 and LWPT-2. Only $\mathrm{CaCO}_{3}$ is above 0.10 (or $10 \%$ ) of the saturation concentration in LWPT-3 and is already shown as a precipitate in Figure 3-12 (i.e., scaling tendency equals 1.0). Note that the carbonate compounds closest to saturation are the most hydrated forms of sodium carbonate though none of the sodium carbonates are close to precipitating. As the water in the sample is evaporated in preparation for the XRD analysis, the compounds closest to saturation are expected to precipitate first. When these solutions are dried, the water is driven off, favoring the more dehydrated forms identified in the XRD. This would be expected regardless of the reaction of atmospheric carbon dioxide with sodium hydroxide in the liquid to form additional sodium carbonate. The simulation indicates only $\mathrm{CaCO}_{3}$ above saturation in LWPT-3, thus, none of the solids identified in the XRD analysis likely resulted from precipitated solids in the sample, but likely resulted from crystallization of the liquid phase clinging to the unwashed solids and probably formation of additional carbonate solids by reaction of sodium hydroxide with carbon dioxide in the air. XRD analysis for LWPT-3 does not indicate the presence of $\mathrm{CaCO}_{3}$, which supports the notion that the single calcium result near detection limits may be spurious. 

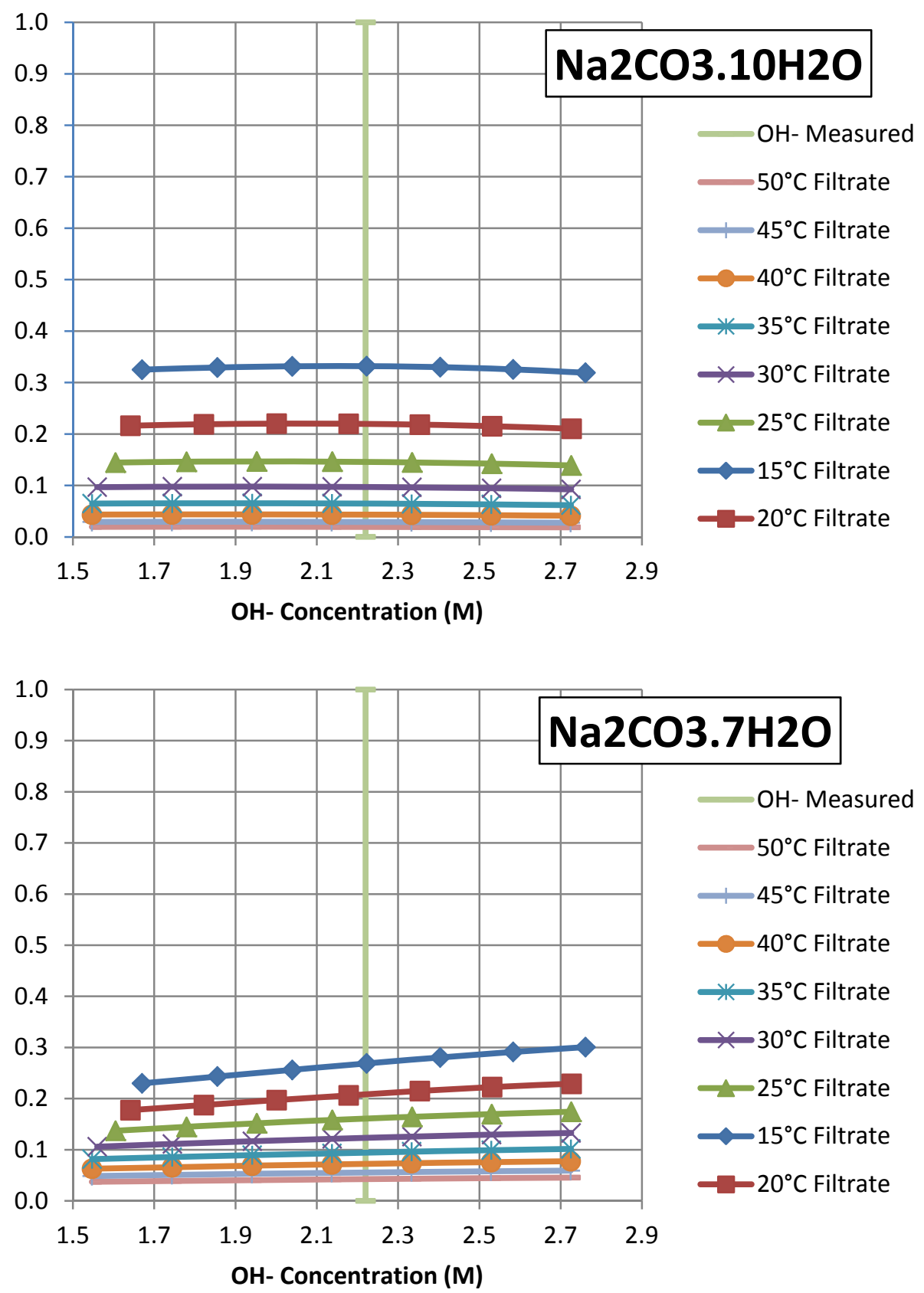

Figure 3-14. Scaling Tendencies for Carbonate Compounds above 0.10 in Sample LWPT-1 

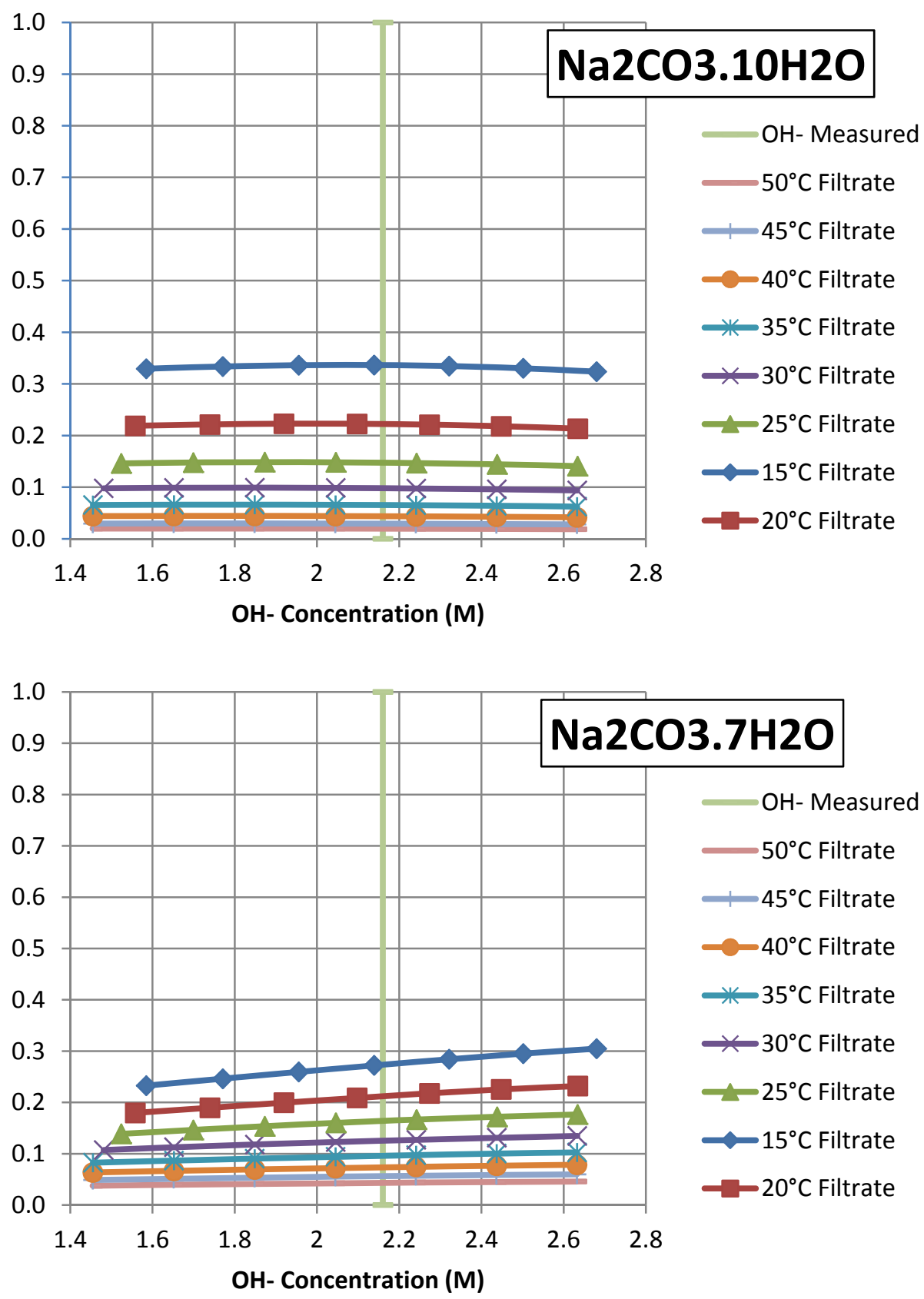

Figure 3-15. Scaling Tendencies for Carbonate Compounds above 0.10 in Sample LWPT-2 


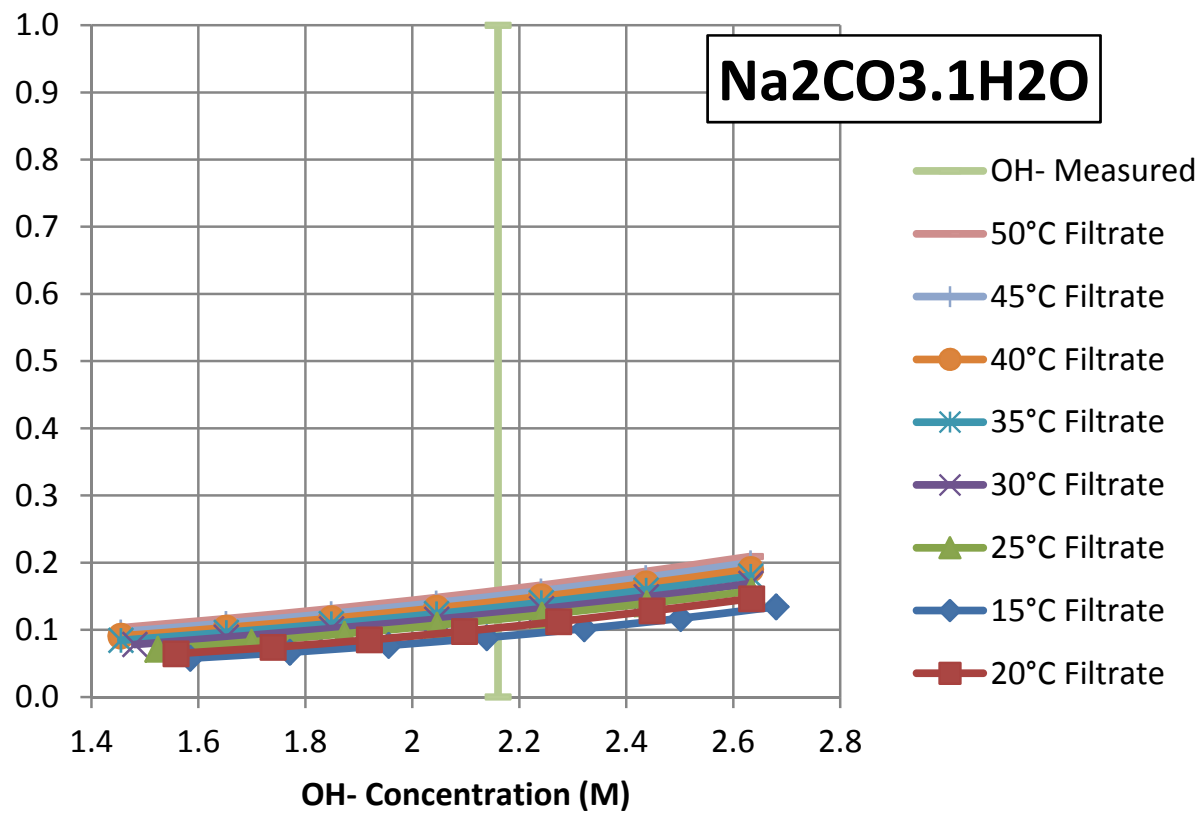

Figure 3-15. Scaling Tendencies for Carbonate Compounds above 0.10 in Sample LWPT-2 (continued)

Sodium aluminosilicates, specifically $\mathrm{Na}_{8} \mathrm{Al}_{6} \mathrm{Si}_{6} \mathrm{O}_{24} \mathrm{CO}_{3} \cdot 1 \mathrm{H}_{2} \mathrm{O}$, are calculated to be above saturation in the Tank $49 \mathrm{H}$ sample, but are not determined in the other 512-S samples as there are no liquid phase concentration results for silicon above the detection limits in the other samples. Past experience in the laboratory and in the HLW waste tanks demonstrate that the precipitation reaction requires temperatures approaching boiling for the reaction formation of solids to occur quickly. Supersaturating conditions have persisted for months at nominal waste tank temperatures, thus, it is reasonable to assume that the silicon in the feed remains approximately at this concentration through filtration and feed to MCU as minimal dilution or heating occurs in this part of the process.

The OLI simulation calculates saturation levels for a total of 3 relevant sodium aluminosilicates. In addition to the two carbonate forms of sodium aluminosilicate already identified, $\mathrm{Na}_{8} \mathrm{Al}_{6} \mathrm{Si}_{6} \mathrm{O}_{24} \mathrm{CO}_{3} \cdot 1 \mathrm{H}_{2} \mathrm{O}$ and $\mathrm{Na}_{8} \mathrm{Al}_{6} \mathrm{Si}_{6} \mathrm{O}_{24} \mathrm{CO}_{3} \cdot 2 \mathrm{H}_{2} \mathrm{O}$, the simulation includes the equivalent hydroxide form, $\mathrm{Na}_{8} \mathrm{Al}_{6} \mathrm{Si}_{6} \mathrm{O}_{24}(\mathrm{OH})_{2} .2 \mathrm{H}_{2} \mathrm{O}$.

The XRD confirmed the presence of sodium oxalate amongst the solids in the LWPT-1 and LWPT-2 and potentially also in LWPT-3. Sodium oxalate measurements in the soluble portions of Tank 49H samples indicate higher concentration than indicated in liquid phase of LWPT-1, LWPT-2, and LWPT-3. This decrease from feed to process samples suggests that sodium oxalate is precipitating in the process. Modelling results show that the LWPT-1, LWPT-2, and LWPT3 samples are still supersaturated with respect to sodium oxalate. As will be seen in Section 3.4.8.5, oxalate solids have been formed previously in the ARP system due to an oxalic acid leak and have correlated with a negative impact on the filter flux. 


\subsubsection{Process Simulation of ARP}

This section describes the inputs and results of the step-by-step thermodynamic equilibrium simulation of the ARP process using OLI ESPTM version 9.1.2. This simulation calculates the chemical equilibrium at each point in the process that causes a change in chemistry for a given feed solution.

\subsubsection{ARP Simulation Input Component List Description}

The chemistry model used for this simulation included the public database for the Mixed Solvent Electrolyte (MSE) model with default redox chemistry active. The molecular component list, Table 3-17, is based on the molecular components identified in the data reconciliation computation for the Tank 49H sample analysis contained in Table 3-15. 
Table 3-17. Molecular Component List for the ARP Simulation

\begin{tabular}{|c|c|}
\hline OLI ESP Name & Component \\
\hline $\mathrm{H} 2 \mathrm{O}$ & $\mathrm{H}_{2} \mathrm{O}$ \\
\hline NA2SIO3 & $\mathrm{Na}_{2} \mathrm{SiO}_{3}$ \\
\hline NABR & $\mathrm{NaBr}$ \\
\hline AL2O3 & $\mathrm{Al}_{2} \mathrm{O}_{3}$ \\
\hline $\mathrm{B} 2 \mathrm{O} 3$ & $\mathrm{~B}_{2} \mathrm{O}_{3}$ \\
\hline $\mathrm{BAO}$ & $\mathrm{BaO}$ \\
\hline $\mathrm{CAO}$ & $\mathrm{CaO}$ \\
\hline $\mathrm{CDOH} 2$ & $\mathrm{CdOH}_{2}$ \\
\hline $\mathrm{CO} 2$ & $\mathrm{CO}_{2}$ \\
\hline CRO3 & $\mathrm{CrO}_{3}$ \\
\hline OXALAC & $\mathrm{H}_{2} \mathrm{C}_{2} \mathrm{O}_{4}$ \\
\hline $\mathrm{CU} 2 \mathrm{O}$ & $\mathrm{Cu}_{2} \mathrm{O}$ \\
\hline CUO & $\mathrm{CuO}$ \\
\hline FEIII2O3 & $\mathrm{Fe}_{2} \mathrm{O}_{3}$ \\
\hline $\mathrm{K} 2 \mathrm{O}$ & $\mathrm{K}_{2} \mathrm{O}$ \\
\hline $\mathrm{LICOOH}$ & $\mathrm{LiCOOH}$ \\
\hline MGO & $\mathrm{MgO}$ \\
\hline $\mathrm{MNC} 2 \mathrm{O} 4$ & $\mathrm{MnC}_{2} \mathrm{O}_{4}$ \\
\hline MNO2 & $\mathrm{MnO}_{2}$ \\
\hline MOO3 & $\mathrm{MoO}_{3}$ \\
\hline $\mathrm{N} 2 \mathrm{O} 5$ & $\mathrm{~N}_{2} \mathrm{O}_{5}$ \\
\hline NA2C2O4 & $\mathrm{Na}_{2} \mathrm{C}_{2} \mathrm{O}_{4}$ \\
\hline $\mathrm{NA} 2 \mathrm{O}$ & $\mathrm{Na}_{2} \mathrm{O}$ \\
\hline NACL & $\mathrm{NaCL}$ \\
\hline $\mathrm{NACOOH}$ & $\mathrm{NaCOOH}$ \\
\hline NANO2 & $\mathrm{NaNO}_{2}$ \\
\hline $\mathrm{P} 2 \mathrm{O} 5$ & $\mathrm{P}_{2} \mathrm{O}_{5}$ \\
\hline PF5 & $\mathrm{PF}_{5}$ \\
\hline $\mathrm{SO} 3$ & $\mathrm{SO}_{3}$ \\
\hline SRO & $\mathrm{SrO}$ \\
\hline UO3 & $\mathrm{UO}_{3}$ \\
\hline V2O5 & $\mathrm{V}_{2} \mathrm{O}_{5}$ \\
\hline $\mathrm{ZNO}$ & $\mathrm{ZnO}$ \\
\hline ZRO2 & $\mathrm{ZrO}_{2}$ \\
\hline CANC. $1 \mathrm{H} 2 \mathrm{O}$ & $\mathrm{Na}_{8} \mathrm{Al}_{6} \mathrm{Si}_{6} \mathrm{O}_{24} \mathrm{CO}_{3} .1 \mathrm{H}_{2} \mathrm{O}$ \\
\hline
\end{tabular}

\subsubsection{ARP Simulation Input}

All simulation input streams are specified by total flow by volume $(\mathrm{gal})$, temperature $\left({ }^{\circ} \mathrm{C}\right)$, pressure $(\mathrm{Pa})$, and composition (mole fraction). In all cases, the temperature is nominally set to $25^{\circ} \mathrm{C}$ and pressure to $100280 \mathrm{~Pa}$. The pressure is a nominal ambient atmospheric pressure in $\mathrm{H}$ Area which happened to be the atmospheric pressure reported in H-Area on the day the input was created. 
Composition for each input is determined by converting molar concentration information to mole fraction using OLI Stream Analyzer ${ }^{\mathrm{TM}}$. Most input streams consist of a few components except for the Tank 49 input stream. The results of the Tank 49 sample reconciliation from Section 2.2 is copied into the Tank 49 composition input for the ARP simulation. Table 3-18 shows the composition values for input streams by each stream type.

\section{Table 3-18. Molecular Component Composition of Chemical Input Streams for the ARP Simulation}

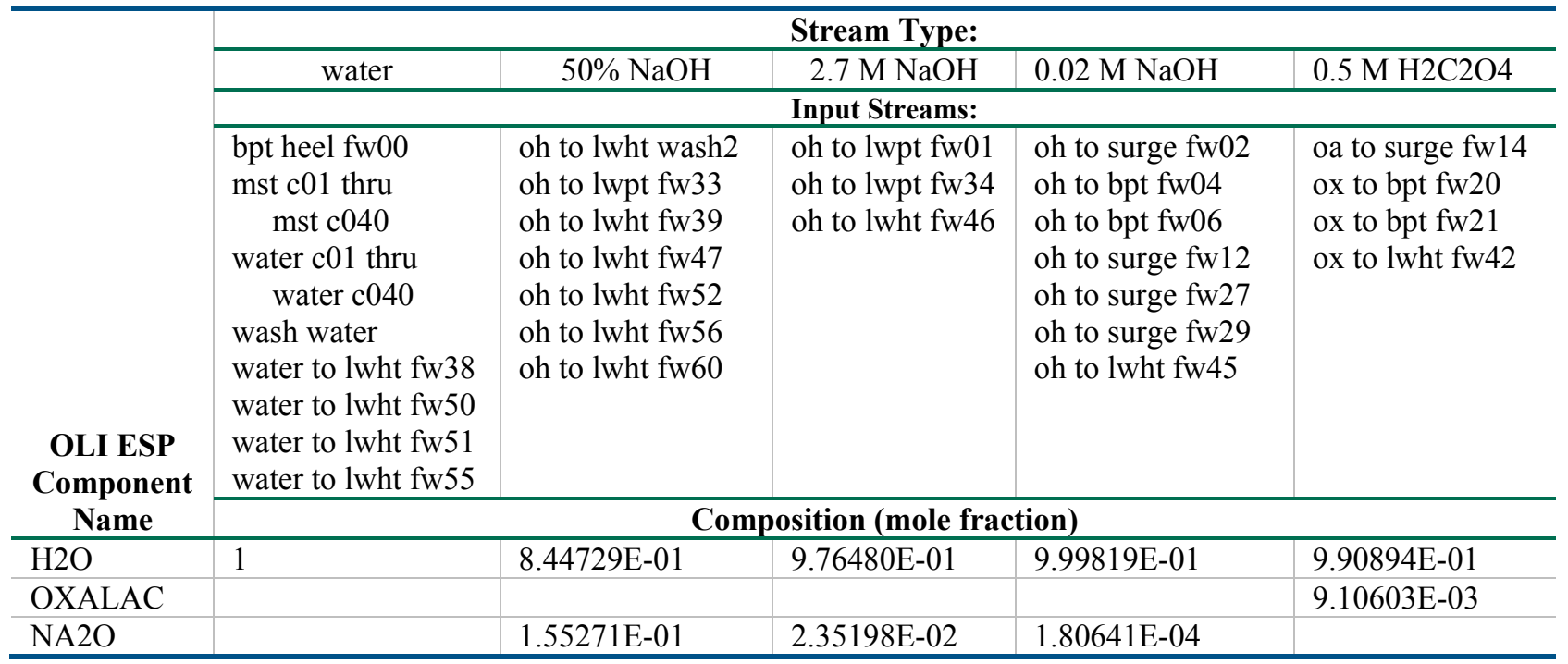

The entire ARP simulation is constructed from 4 OLI ESPTM model blocks: Mix, Split, Filter, and Settler. The Split block requires specification of either a split fraction or amount of each stream. Alternatively, split may be specified by component. In all cases, the parameters selected preserve the volume of the heel in each of the tanks. The Filter block requires split fractions for the solid and liquid phases independently. The Settler is similar to the Filter block with additional options to control the solid components retained in the slurry. In all blocks, no solids were assumed to pass the filter or settler such that all predicted solids accumulated with the solids slurry. The Mixer combines all input streams into one stream. No parameters are required as all mixing blocks are assumed adiabatic. In addition, no heating or cooling is assumed in any of the blocks, i.e., all reactions are adiabatic. The input streams include specification for temperature and the simulation calculates resulting temperatures.

In one instance, the continuous feed and bleed operation during solids washing, no single model block can adequately represent this process. In effect, the chemistry in this unit operation dynamically changes through a spectrum of conditions that cannot be simulated with a steady state flowsheet model. However, the beginning and end point are simulated by using a mixing block to batch add water until the liquid phase is approximately $0.5 \mathrm{M}$ sodium ion, the washing target end point. This step is followed by a settler block to separate a portion of the liquid phase, leaving a specific quantity of liquid with the solids. The excess water is removed from liquid phase decanted from the solids using a split block such that the total water addition is consistent with the quantity of water used in the facility for solids washing. The resulting stream contains all the dissolved solids and only the amount of water actually used in the process. This method to 
simulate the washing step requires a review of the resulting spent wash water to verify that no precipitated solids are present in the stream.

The entire model listing is provided in a separate document. ${ }^{14}$

\subsubsection{Evaluation of ARP Simulation Results}

The simulation produces a large amount of calculated data which is not reproduced here. Select results illustrating the predicted precipitation of solids is extracted from the results and summarized here.

Solids are expected in the LWPT although the solids are expected to be predominately MST. Most of the predicted solids that precipitate are sodium oxalate as shown in Table 3-19. The predicted copper oxide results from the copper measured in the Tank 49 sample. Since copper is not detected in the liquid or solids of the other samples, the analytical result may be somewhat higher than the actual concentration. $\mathrm{Al}(\mathrm{OH})_{3}$ is predicted to be near saturation in the Tank $49 \mathrm{H}$ feed solution as shown in Section 3.1, but is not predicted to precipitate in the LWPT at an operating temperature of $25^{\circ} \mathrm{C}$. MST is not included in the simulation and needs to be manually added to the results.

At each step in the process, the amount of MST in the LWPT is calculated using the following method. At 241-96H, $2858 \mathrm{~g}$ of MST is added to each 3714 gallon batch of feed from Tank $49 \mathrm{H}$ in order to achieve the target $0.2 \mathrm{~g}$ of MST per liter of feed. The MST accumulates in the LWPT so the total amount of MST at any point in the accumulation during the 40 cycles is:

$$
\mathrm{MST}_{\text {LWPT-total }}=\mathrm{MST}_{\text {LWPT-heel }}+\mathrm{MST}_{\text {batch }} * \mathrm{~N}_{\text {batch }}
$$

where

$\mathrm{MST}_{\mathrm{LWPT} \text {-total }}=$ the mass of MST in the LWPT during the 40 batch cycle, $\mathrm{g}$,

$\mathrm{MST}_{\text {LWPT-heel }}=$ the mass of MST in the LWPT before the first batch of the cycle, $\mathrm{g}$,

$\mathrm{MST}_{\text {batch }}=$ the mass of MST added in each batch, $2858 \mathrm{~g}$, and

$\mathrm{N}_{\text {batch }}=$ the batch number.

For the remainder of the process, the MST in LWPT remains constant until it is transferred to the LPPP after washing and after filter cleaning. The MST removed from the LWPT for these transfers is in prorated to the same mass fraction of solids transferred as follows:

$$
\begin{aligned}
& \mathrm{MST}_{\text {trans }}=\mathrm{MST}_{\mathrm{LWPT}_{\text {-total }}} * \operatorname{Solids}_{\text {trans }} / \text { Solids }_{\mathrm{LWPT}} \\
& \mathrm{MST}_{\mathrm{LWPT} \text {-heel }}=\mathrm{MST}_{\mathrm{LWPT}_{\text {-total }}}-\mathrm{MST}_{\text {trans }}
\end{aligned}
$$

where

$\mathrm{MST}_{\text {LWPT-total }}=$ the mass of MST in the LWPT, $\mathrm{g}$,

$\mathrm{MST}_{\mathrm{LWPT} \text {-heel }}=$ the mass of MST in the LWPT after the transfer, $\mathrm{g}$,

$\mathrm{MST}_{\text {trans }}=$ the mass of MST transferred to the LPPP, $\mathrm{g}$,

Solids $_{\mathrm{LWPT}}=$ total solids predicted by the simulation to be in the LWPT, $\mathrm{g}$, and

Solids $_{\text {trans }}=$ solids predicted by the simulation to be in the transfer stream to the LPPP, $g$. 
SRNL-STI-2013-00700

Revision 0

The MST heel after the second transfer to the LPPP becomes the heel for the initial batch, so the calculation is recursive and requires iteration to reach a solution.

\section{Table 3-19. Molecular Composition of Predicted Solids in LWPT at the End of 40 Batches}

\begin{tabular}{l|c}
\hline $\begin{array}{l}\text { OLI ESP } \\
\text { Component Name }\end{array}$ & $\begin{array}{l}\text { Concentration } \\
\text { (mass fraction) }\end{array}$ \\
\hline CUO & 0.030 \\
\hline FEIII2O3 & 0.009 \\
\hline NA2C2O4 & 0.442 \\
\hline CANC.1H2O & 0.260 \\
\hline MST & 0.258 \\
\hline
\end{tabular}

Figure 3-16 illustrates the accumulation of predicted solids and MST solids in the LWPT through the course of an entire ARP cycle for a 40 batch cycle. The figure also shows the effect of batch washing and crossflow filter cleaning after the $40^{\text {th }}$ batch. Predicted total solids loading in LWPT is approximately 4 times the loading that would be calculated based on MST solids alone. The filtration rate is estimated based on a permeate flux model fitted to test data. ${ }^{15}$ The flux model is a function of transmembrane pressure, axial velocity and solids concentration. In this case, the axial velocity is assumed to be constant at $10 \mathrm{ft} / \mathrm{sec}$ and transmembrane pressure at $30 \mathrm{psi}$. Of course, the impact of particle size and morphology of these precipitated solids on filter flux projections are not accounted for in this estimate.

The process simulation recycles the LWPT heel to start of the cycle such that the initial solids concentration and heel composition are at steady-state. This approximates the conditions after a few cycles into a salt batch and does not simulate the transition. Figure 3-16 shows that the solids concentration at the start of the cycle matches the solids concentration at the end of the cycle.

It may be useful to identify where in the sequence and what additional solids are predicted to form or substantially dissolve. Solids washing in the LWPT reduces the sodium concentration to approximately $0.5 \mathrm{M}$ and reduces the overall predicted solids concentration from $4.3 \mathrm{wt} \%$ to 2.3 wt $\%$. While the precipitated sodium oxalate is predicted to dissolve, aluminum hydroxide precipitates. Also, additional NAS and most of the copper will precipitate. After the addition of 400 gallons of $2.7 \mathrm{M} \mathrm{NaOH}$ to the LWPT, aluminum hydroxide dissolves, leaving approximately $1.4 \mathrm{wt} \%$ predicted solids. The amount of predicted solids remain exactly the same through the cross-flow filter washing, reaching $0.51 \mathrm{wt} \%$ at the end before caustic addition due to progressive dilution of the slurry. After the caustic addition, sodium oxalate is predicted to form again whilst the NAS reduces, maintaining about $0.46 \mathrm{wt} \%$ predicted solids in the heel. 


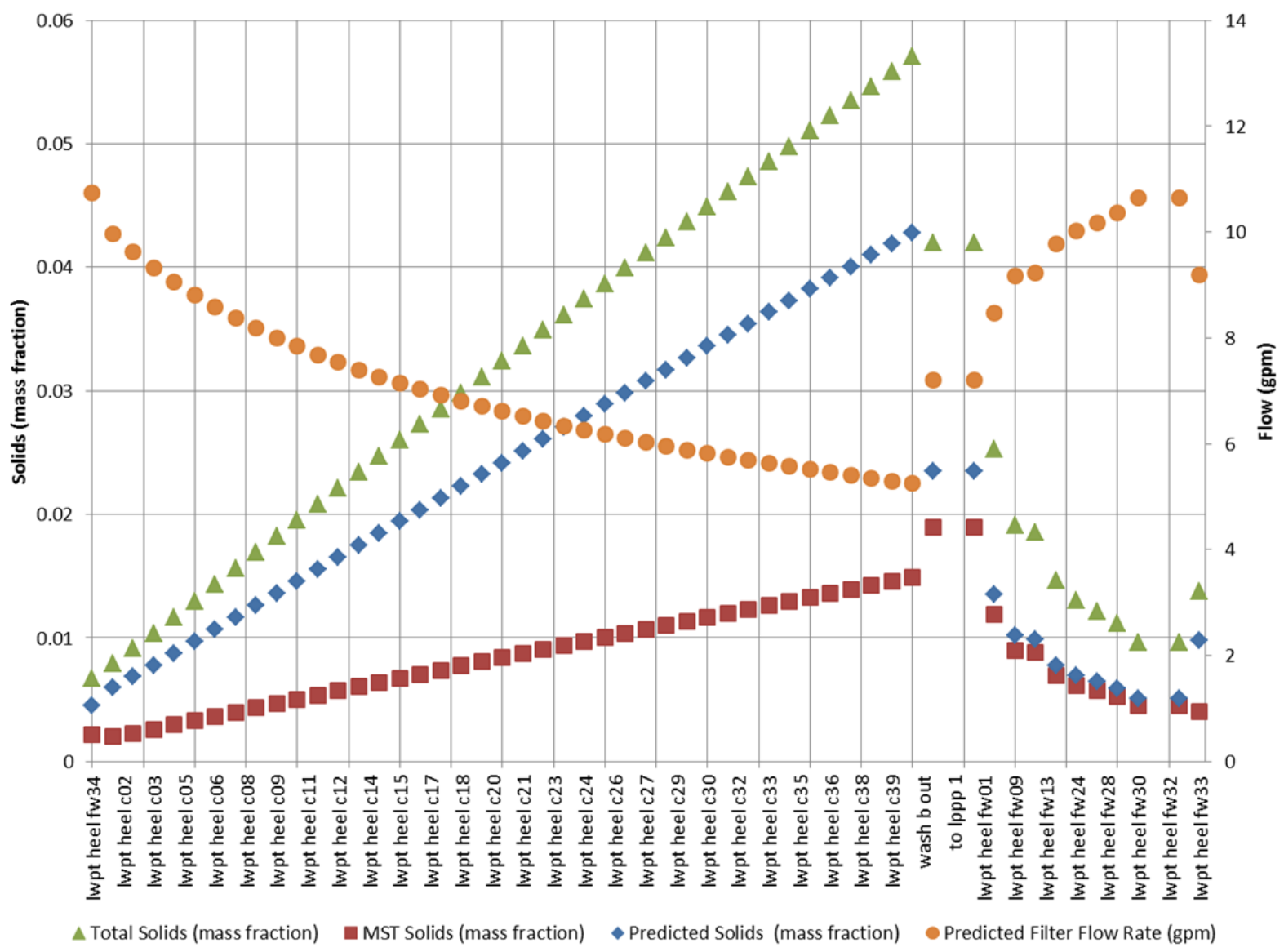

Figure 3-16. Predicted Solids Concentration in LWPT during One Complete ARP Cycle with Predicted Effect on Filtration Rate

Examination of the liquid phase composition of the LWPT heel after each batch indicates that steady state operation is achieved after the $4^{\text {th }}$ batch of each cycle. The composition of the LWPT shows no practical difference if the cycle stops at Batch 5 or Batch 40 except for the amount of accumulated solids in the heel. LWPT-3 sample was taken after processing 16 batches, filter washing, and subsequent caustic additions which is equivalent to the simulated stream "lwpt heel fw34". Table 3-20 shows the ionic or true composition of this stream calculated by the OLI ESP simulation for all components above 1E-10 M. Compared with sample LWPT-3, the simulation of the post filter cleaning and $\mathrm{pH}$ adjustment solution shows the same total sodium, but $33 \%$ higher concentration of hydroxide and about $1 / 5$ th the concentration of other salt components except for carbonate which is about $1 / 12^{\text {th }}$. The simulation assumes perfect mixing and exact heels. The higher salt relative to hydroxide concentration in the actual (LWPT-3) sample suggests that mixing in the tank is not always homogeneous, or that the volume of the heels relative to the batch size are actually larger than simulated. 
Table 3-20. OLI ESP Simulation of LWPT at the End of Filter Cleaning and Adjustment, Compared with LWPT-3 Sample Results from Table 3-7

\begin{tabular}{|c|c|c|c|}
\hline \multirow{2}{*}{$\begin{array}{r}\text { Stream } \\
\text { Phase }\end{array}$} & \multicolumn{2}{|c|}{ lwpt heel fw34 } & \multirow{2}{*}{$\begin{array}{l}\text { LWPT-3 } \\
\text { sample }\end{array}$} \\
\hline & Liquid & Solid & \\
\hline Units & M & mass fraction & M \\
\hline $\mathrm{OH}^{-1}$ & $2.26 \mathrm{E}+00$ & & $1.70 \mathrm{E}+00$ \\
\hline $\mathrm{NO}_{3}^{-1}$ & $2.54 \mathrm{E}-02$ & & $1.25 \mathrm{E}-01$ \\
\hline $\mathrm{NO}_{2}^{-1}$ & $5.55 \mathrm{E}-03$ & & $2.90 \mathrm{E}-02$ \\
\hline $\mathrm{CO}_{3}^{-2}$ & $4.05 \mathrm{E}-03$ & & $4.90 \mathrm{E}-02$ \\
\hline $\mathrm{SO}_{4}^{-2}$ & $6.74 \mathrm{E}-04$ & & $3.30 \mathrm{E}-03$ \\
\hline $\mathrm{C}_{2} \mathrm{O}_{4}^{-2}$ & $1.12 \mathrm{E}-02$ & & $3.34 \mathrm{E}-02$ \\
\hline $\mathrm{PO}_{4}^{-3}$ & 4.24E-05 & & $<5.47 E-04$ \\
\hline $\mathrm{HCOO}^{-1}$ & $7.47 \mathrm{E}-05$ & & $<1.15 E-02$ \\
\hline $\mathrm{Cl}^{-1}$ & $2.93 \mathrm{E}-05$ & & $<1.47 E-02$ \\
\hline $\mathrm{Al}(\mathrm{OH})_{4}{ }^{-1}$ & $1.05 \mathrm{E}-02$ & & $<9.07 E-03$ \\
\hline $\mathrm{Na}^{+1}$ & $2.35 \mathrm{E}+00$ & & $2.24 \mathrm{E}+00$ \\
\hline \multicolumn{4}{|l|}{ Other: } \\
\hline $\mathrm{H}_{2} \mathrm{O}$ & $5.51 \mathrm{E}+01$ & & \\
\hline $\mathrm{NaOH}$ & $2.85 \mathrm{E}-06$ & & \\
\hline $\mathrm{HCO}_{3}^{-1}$ & $1.23 \mathrm{E}-07$ & & \\
\hline $\mathrm{NaOHCO}_{3}^{-2}$ & 2.77E-04 & & \\
\hline $\mathrm{Na}_{3} \mathrm{OHSO}_{4}$ & 4.82E-07 & & \\
\hline $\mathrm{B}(\mathrm{OH})_{3}$ & $1.70 \mathrm{E}-09$ & & \\
\hline $\mathrm{NaB}(\mathrm{OH})_{4}$ & $4.37 \mathrm{E}-05$ & & \\
\hline $\mathrm{B}(\mathrm{OH})_{4}^{-1}$ & $1.68 \mathrm{E}-06$ & & \\
\hline $\mathrm{LiB}(\mathrm{OH})_{4}$ & $1.11 \mathrm{E}-10$ & & \\
\hline $\mathrm{Li}^{+1}$ & $3.06 \mathrm{E}-05$ & & \\
\hline $\mathrm{LiOH}$ & $1.10 \mathrm{E}-07$ & & \\
\hline $\mathrm{SiO}_{2}$ & 3.91E-09 & & \\
\hline $\mathrm{HSiO}_{3}^{-1}$ & $1.29 \mathrm{E}-03$ & & \\
\hline $\mathrm{H}_{2} \mathrm{SiO}_{4}^{-2}$ & $5.03 \mathrm{E}-03$ & & \\
\hline $\mathrm{AlSiO}_{3}(\mathrm{OH})_{4}^{-3}$ & $6.57 \mathrm{E}-04$ & & \\
\hline $\mathrm{Al}(\mathrm{OH})_{3}$ & $2.23 \mathrm{E}-10$ & & \\
\hline $\mathrm{CrO}_{4}^{-2}$ & $8.38 \mathrm{E}-06$ & & \\
\hline $\mathrm{Cu}(\mathrm{OH})_{2}$ & $2.57 \mathrm{E}-10$ & & \\
\hline $\mathrm{Cu}(\mathrm{OH})_{3}^{-1}$ & $1.34 \mathrm{E}-05$ & & \\
\hline $\mathrm{Cu}(\mathrm{OH})_{4}^{-2}$ & $3.10 \mathrm{E}-04$ & & \\
\hline $\mathrm{FeO}_{2}^{-1}$ & $9.20 \mathrm{E}-07$ & & \\
\hline $\mathrm{K}^{+1}$ & $9.43 \mathrm{E}-05$ & & \\
\hline $\mathrm{HPO}_{4}^{-2}$ & $9.29 \mathrm{E}-09$ & & \\
\hline $\mathrm{ZnO}_{2}^{-2}$ & $7.57 \mathrm{E}-07$ & & \\
\hline $\mathrm{HZnO}_{2}^{-1}$ & $3.91 \mathrm{E}-09$ & & \\
\hline $\mathrm{CuO}$ & & 0.033 & \\
\hline $\mathrm{Fe}_{2} \mathrm{O}_{3}$ & & 0.011 & \\
\hline $\mathrm{Na}_{2} \mathrm{C}_{2} \mathrm{O}_{4}$ & & 0.478 & \\
\hline $\mathrm{Na}_{8} \mathrm{Al}_{6} \mathrm{Si}_{6} \mathrm{O}_{24} \mathrm{CO}_{3} .1 \mathrm{H}_{2} \mathrm{O}$ & & 0.159 & \\
\hline MST & & 0.319 & \\
\hline \multicolumn{2}{|c|}{ Mass fraction solids in total stream } & 0.0067 & $\sim 0.0007$ \\
\hline
\end{tabular}


An evaluation of solid precipitates in the simulated LWHT shows solids, primarily sodium oxalate, present throughout the ARP cycle. The source of most of the sodium oxalate comes from the LWPT during solids washing. The material balance resulting from the steady-state simulation of the solids washing operation shows a substantial fraction of the precipitated solids in the LWPT transfer with the wash solution. As noted earlier, the steady-state approximation adds enough water to approximate the sodium concentration endpoint and then removes the excess water from the spent wash water that enters the LWHT. Precipitating solids in the simulated spent wash solution suggests that the steady-state simulation may not be adequate because the solids should be retained in the LWPT and not passed to the spent wash solution. Figure 3-17 shows the amount of solids predicted in the LWHT through an entire ARP cycle. At the start of the cycle, about $600 \mathrm{ppm}$ precipitated sodium oxalate is progressively diluted and reduced with each successive batch. Note that at the end of the secondary filter cleaning, no solids are present at the time of the last transfer to Tank $50 \mathrm{H}$, but form at the time of the last caustic addition that adjusts the hydroxide concentration back to operating levels. An extra rinse and transfer of the LWHT would eliminate the risk of sodium oxalate solids at the start of the cycle. The simulation also predicts a very small amount of sodium aluminosilicate and iron oxide solids starting in batch 11 and continuing through batch 40 .

Examination of the secondary filter cleaning process shows significant sodium oxalate solids are predicted to form at the caustic neutralization steps, step "lwht heel fw 45 " - "lwht heel fw47" on the x-axis. Sodium oxalate is predicted to precipitate to form $2.7 \mathrm{wt} \%$ solids slurry. Subsequent water flushing is expected to reduce the slurry to zero, but the final caustic addition causes additional solids formation. Secondary filter cleaning is no longer routinely performed.

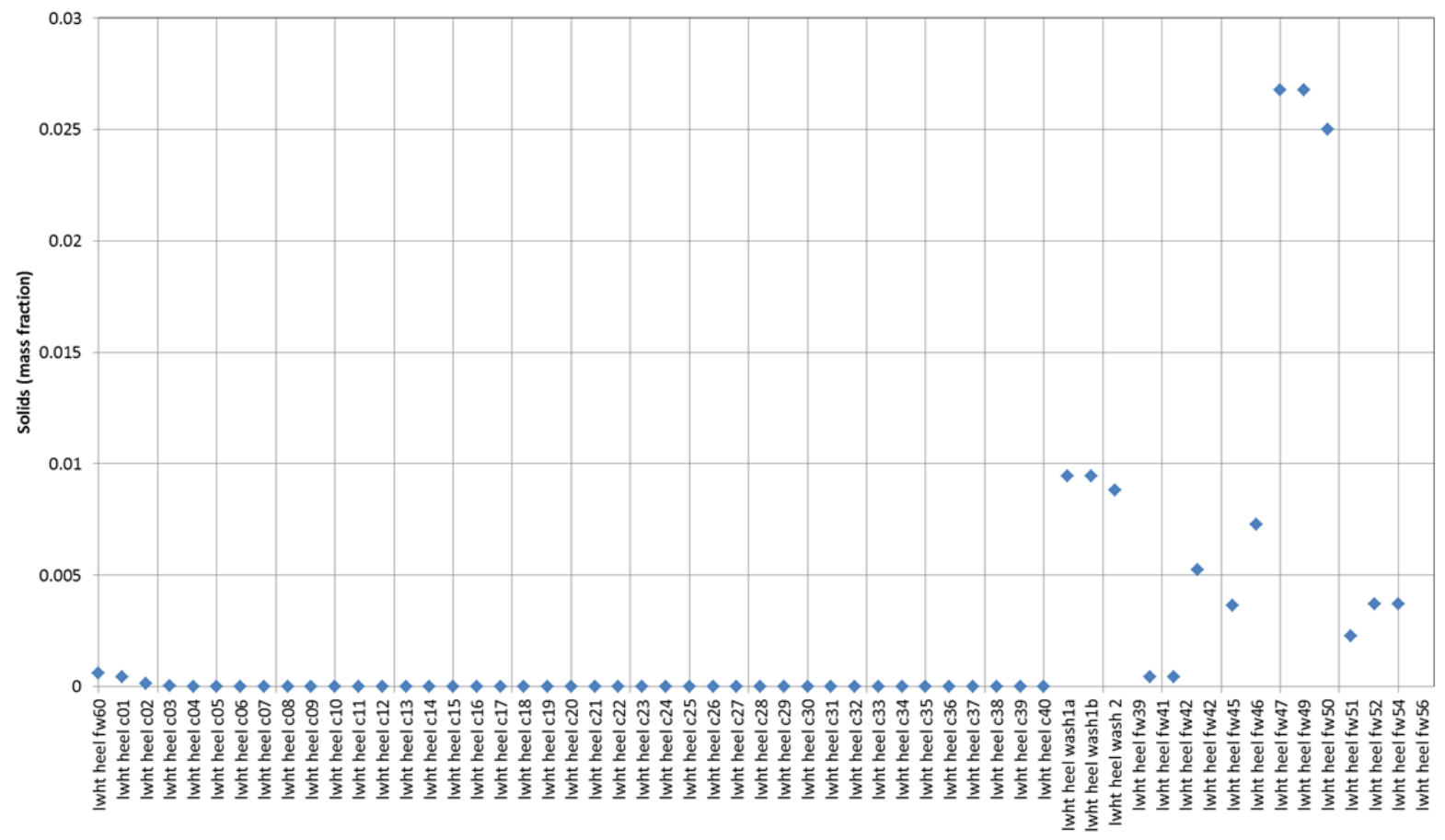

Figure 3-17. Predicted Solids Concentration in LWHT during One Complete ARP Cycle with Secondary Filter Cleaning 
One should note that OLI software simulates equilibrium conditions. Solids precipitation rates vary widely and some common solids in waste such as aluminum hydroxides, once formed, have very slow dissolution rates at operating temperatures in ARP. Furthermore, some supersaturated solutions may remain supersaturated in metastable states until a triggering event causes initiation of the precipitation. As a consequence, the simulation results may be biased toward over predicting actual behavior in the facility. Adding dynamic reaction/precipitation kinetics to the simulation would create more accurate results, but substantially increase the complexity of the simulation, and is not really practical since triggering events are difficult to simulate.

Table 3-21 contains the OLI ESP simulation results for the LWHT for ionic component concentrations above 1e-10 M, compared with the LWHT-1 results in Table 3-7. The MCU feed looks very much like "lwht heel c16" for batches 5 through 40 since the heel has identical composition as the stream transferred to MCU. The model stream corresponding to samples LWPT-1 is "lwpt out c16" and to LWPT-2 is "lwpt heel c16". Both streams are identical to the corresponding simulation stream for LWHT-1, which is "lwht heel c16" as shown in Table 3-21. In this case, the simulation and sample results match relatively well.

At the end of a cycle (40 batches in this ESP model), the accumulated solids undergo washing and are transferred out of the 512-S facility to the LPPP. A second transfer to the LPPP is made when filter cleaning material is dispositioned. In Table 3-22, the modeling results for these two transfers to LPPP are labeled "to lppp1" and "to lppp2", respectively. Only ionic component concentrations greater than $1 \mathrm{E}-10 \mathrm{M}$ are shown. Ultimately, these LPPP materials blended in the proper ratios reflect the composition in the PRFT. 
Table 3-21. Simulation of LWHT at the end of batch 16, compared with LWHT-1 sample results.

\begin{tabular}{|c|c|c|c|}
\hline & \multicolumn{2}{|c|}{ lwht heel c16 } & \multirow{2}{*}{$\begin{array}{l}\text { LWHT-1 } \\
\text { sample }\end{array}$} \\
\hline Phase & Liquid & Solid & \\
\hline Units & M & mass frac. & M \\
\hline $\mathrm{OH}^{-1}$ & $2.27 \mathrm{E}+00$ & & $2.23 \mathrm{E}+00$ \\
\hline $\mathrm{NO}_{3}^{-1}$ & $2.61 \mathrm{E}+00$ & & $2.57 \mathrm{E}+00$ \\
\hline $\mathrm{NO}_{2}^{-1}$ & $5.68 \mathrm{E}-01$ & & $6.10 \mathrm{E}-01$ \\
\hline $\mathrm{CO}_{3}^{-2}$ & $2.89 \mathrm{E}-01$ & & $2.84 \mathrm{E}-01$ \\
\hline $\mathrm{SO}_{4}^{-2}$ & $6.91 \mathrm{E}-02$ & & $6.57 \mathrm{E}-02$ \\
\hline $\mathrm{C}_{2} \mathrm{O}_{4}^{-2}$ & $4.36 \mathrm{E}-04$ & & $1.17 \mathrm{E}-03$ \\
\hline $\mathrm{PO}_{4}^{-3}$ & $4.34 \mathrm{E}-03$ & & $2.49 \mathrm{E}-03$ \\
\hline $\mathrm{HCOO}^{-1}$ & $7.65 \mathrm{E}-03$ & & $<1.16 E-02$ \\
\hline $\mathrm{Cl}^{-1}$ & $3.00 \mathrm{E}-03$ & & $<1.47 E-02$ \\
\hline $\mathrm{Al}(\mathrm{OH})_{4}{ }^{-1}$ & $1.91 \mathrm{E}-01$ & & $1.98 \mathrm{E}-01$ \\
\hline $\mathrm{Na}^{+1}$ & $6.44 \mathrm{E}+00$ & & $6.57 \mathrm{E}+00$ \\
\hline \multicolumn{4}{|l|}{ Other } \\
\hline $\mathrm{H}_{2} \mathrm{O}$ & $4.78 \mathrm{E}+01$ & & \\
\hline $\mathrm{NaOH}$ & 7.76E-06 & & \\
\hline $\mathrm{HCO}_{3}^{-1}$ & $2.53 \mathrm{E}-06$ & & \\
\hline $\mathrm{NaOHCO}_{3}^{-2}$ & $3.53 \mathrm{E}-02$ & & \\
\hline $\mathrm{Na}_{3} \mathrm{OHSO}_{4}$ & $5.06 \mathrm{E}-05$ & & \\
\hline $\mathrm{B}(\mathrm{OH})_{3}$ & $1.98 \mathrm{E}-07$ & & \\
\hline $\mathrm{NaB}(\mathrm{OH})_{4}$ & $4.65 \mathrm{E}-03$ & & \\
\hline $\mathrm{B}(\mathrm{OH})_{4}^{-1}$ & $9.19 \mathrm{E}-08$ & & \\
\hline $\mathrm{B}(\mathrm{OH})_{3} \mathrm{COOH}^{-1}$ & $1.51 \mathrm{E}-09$ & & \\
\hline $\mathrm{HBO}_{2}$ & $4.27 \mathrm{E}-10$ & & \\
\hline $\mathrm{LiB}(\mathrm{OH})_{4}$ & $6.92 \mathrm{E}-07$ & & \\
\hline $\mathrm{Li}^{+1}$ & $3.07 \mathrm{E}-03$ & & \\
\hline $\mathrm{LiOH}$ & $6.98 \mathrm{E}-05$ & & \\
\hline $\mathrm{HSiO}_{3}^{-1}$ & $1.45 \mathrm{E}-05$ & & \\
\hline $\mathrm{H}_{2} \mathrm{SiO}_{4}^{-2}$ & $9.01 \mathrm{E}-05$ & & \\
\hline $\mathrm{AlSiO}_{3}(\mathrm{OH})_{4}^{-3}$ & $8.15 \mathrm{E}-10$ & & \\
\hline $\mathrm{Al}(\mathrm{OH})_{3}$ & $2.88 \mathrm{E}-09$ & & \\
\hline $\mathrm{CrO}_{4}^{-2}$ & $8.59 \mathrm{E}-04$ & & \\
\hline $\mathrm{Cu}(\mathrm{OH})_{2}$ & $1.72 \mathrm{E}-10$ & & \\
\hline $\mathrm{Cu}(\mathrm{OH})_{3}^{-1}$ & $1.69 \mathrm{E}-05$ & & \\
\hline $\mathrm{Cu}(\mathrm{OH})_{4}{ }^{-2}$ & $8.49 \mathrm{E}-08$ & & \\
\hline $\mathrm{FeO}_{2}^{-1}$ & $1.12 \mathrm{E}-06$ & & \\
\hline $\mathrm{K}^{+1}$ & $9.66 \mathrm{E}-03$ & & \\
\hline $\mathrm{HPO}_{4}^{-2}$ & $3.31 \mathrm{E}-07$ & & \\
\hline $\mathrm{ZnO}_{2}^{-2}$ & $7.68 \mathrm{E}-05$ & & \\
\hline $\mathrm{ZnO}$ & $1.62 \mathrm{E}-09$ & & \\
\hline $\mathrm{ZnOCl}^{-1}$ & $3.80 \mathrm{E}-07$ & & \\
\hline $\mathrm{HZnO}_{2}^{-1}$ & $8.41 \mathrm{E}-07$ & & \\
\hline $\mathrm{Fe}_{2} \mathrm{O}_{3}$ & & 0.001 & \\
\hline $\mathrm{Na}_{2} \mathrm{C}_{2} \mathrm{O}_{4}$ & & 0.796 & \\
\hline $\mathrm{Na}_{8} \mathrm{Al}_{6} \mathrm{Si}_{6} \mathrm{O}_{24} \mathrm{CO}_{3} .1 \mathrm{H}_{2} \mathrm{O}$ & & 0.203 & \\
\hline \multicolumn{2}{|c|}{ Mass fraction solids in total stream } & $1.03 \mathrm{E}-10$ & \\
\hline
\end{tabular}


Table 3-22. OLI ESP Model Prediction of Composition

\begin{tabular}{|c|c|c|c|c|}
\hline \multirow{2}{*}{$\begin{array}{r}\text { Stream } \\
\text { Phase }\end{array}$} & \multicolumn{2}{|c|}{ to $\operatorname{lppp} 1$} & \multicolumn{2}{|c|}{ to $1 \mathrm{ppp} 2$} \\
\hline & Liquid & Solid & Liquid & Solid \\
\hline Flow Units & M & mass frac. & $\mathrm{M}$ & mass frac. \\
\hline $\mathrm{OH}^{-1}$ & $1.97 \mathrm{E}-01$ & & $2.70 \mathrm{E}-01$ & \\
\hline $\mathrm{NO}_{3}^{-1}$ & $2.20 \mathrm{E}-01$ & & $5.09 \mathrm{E}-02$ & \\
\hline $\mathrm{NO}_{2}^{-1}$ & $4.81 \mathrm{E}-02$ & & $1.11 \mathrm{E}-02$ & \\
\hline $\mathrm{CO}_{3}^{-2}$ & $2.73 \mathrm{E}-02$ & & $6.37 \mathrm{E}-03$ & \\
\hline $\mathrm{SO}_{4}^{-2}$ & $5.85 \mathrm{E}-03$ & & $1.35 \mathrm{E}-03$ & \\
\hline $\mathrm{C}_{2} \mathrm{O}_{4}^{-2}$ & $2.16 \mathrm{E}-02$ & & $7.48 \mathrm{E}-02$ & \\
\hline $\mathrm{PO}_{4}^{-3}$ & $3.62 \mathrm{E}-04$ & & $8.39 \mathrm{E}-05$ & \\
\hline $\mathrm{HCOO}^{-1}$ & $6.47 \mathrm{E}-04$ & & $1.49 \mathrm{E}-04$ & \\
\hline $\mathrm{Cl}^{-1}$ & $2.53 \mathrm{E}-04$ & & $5.86 \mathrm{E}-05$ & \\
\hline $\mathrm{Al}(\mathrm{OH})_{4}^{-1}$ & $1.44 \mathrm{E}-02$ & & 8.87E-03 & \\
\hline $\mathrm{Na}^{+1}$ & 5.91E-01 & & $5.07 \mathrm{E}-01$ & \\
\hline \multicolumn{5}{|l|}{ Other } \\
\hline $\mathrm{H}_{2} \mathrm{O}$ & $5.49 \mathrm{E}+01$ & & $5.51 \mathrm{E}+01$ & \\
\hline $\mathrm{NaOH}$ & $3.91 \mathrm{E}-08$ & & $5.99 \mathrm{E}-08$ & \\
\hline $\mathrm{HCO}_{3}^{-1}$ & $1.06 \mathrm{E}-05$ & & $2.13 \mathrm{E}-06$ & \\
\hline $\mathrm{NaOHCO}_{3}^{-2}$ & $1.07 \mathrm{E}-04$ & & $3.26 \mathrm{E}-05$ & \\
\hline $\mathrm{Na}_{3} \mathrm{OHSO}_{4}$ & $1.88 \mathrm{E}-07$ & & $4.14 \mathrm{E}-08$ & \\
\hline $\mathrm{B}(\mathrm{OH})_{3}$ & $6.82 \mathrm{E}-08$ & & 1.17E-08 & \\
\hline $\mathrm{NaB}(\mathrm{OH})_{4}$ & $2.02 \mathrm{E}-04$ & & $4.02 \mathrm{E}-05$ & \\
\hline $\mathrm{B}(\mathrm{OH})_{4}^{-1}$ & $1.91 \mathrm{E}-04$ & & $5.06 \mathrm{E}-05$ & \\
\hline $\mathrm{B}(\mathrm{OH})_{3} \mathrm{COOH}^{-1}$ & 1.04E-09 & & $3.77 \mathrm{E}-11$ & \\
\hline $\mathrm{HBO}_{2}$ & $5.90 \mathrm{E}-10$ & & $1.06 \mathrm{E}-10$ & \\
\hline $\mathrm{LiB}(\mathrm{OH})_{4}$ & 8.32E-09 & & $4.59 \mathrm{E}-10$ & \\
\hline $\mathrm{Li}^{+1}$ & $2.66 \mathrm{E}-04$ & & $6.14 \mathrm{E}-05$ & \\
\hline $\mathrm{LiOH}$ & $5.12 \mathrm{E}-08$ & & $1.68 \mathrm{E}-08$ & \\
\hline $\mathrm{SiO}_{2}$ & $8.48 \mathrm{E}-09$ & & $2.22 \mathrm{E}-08$ & \\
\hline $\mathrm{HSiO}_{3}{ }^{-1}$ & $3.83 \mathrm{E}-05$ & & $1.27 \mathrm{E}-04$ & \\
\hline $\mathrm{H}_{2} \mathrm{SiO}_{4}^{-2}$ & $7.36 \mathrm{E}-05$ & & 3.34E-04 & \\
\hline $\mathrm{AlSiO}_{3}(\mathrm{OH})_{4}^{-3}$ & $4.00 \mathrm{E}-06$ & & $1.61 \mathrm{E}-05$ & \\
\hline $\mathrm{Al}(\mathrm{OH})_{3}$ & $3.03 \mathrm{E}-09$ & 0.039 & $1.57 \mathrm{E}-09$ & 0.054 \\
\hline $\mathrm{CrO}_{4}^{-2}$ & $7.26 \mathrm{E}-05$ & & $1.68 \mathrm{E}-05$ & \\
\hline $\mathrm{Cu}(\mathrm{OH})_{2}$ & $1.92 \mathrm{E}-10$ & & $2.17 \mathrm{E}-10$ & \\
\hline $\mathrm{Cu}(\mathrm{OH})_{3}{ }^{-1}$ & $1.45 \mathrm{E}-06$ & & $1.99 \mathrm{E}-06$ & \\
\hline $\mathrm{Cu}(\mathrm{OH})_{4}^{-2}$ & $6.76 \mathrm{E}-07$ & & $1.95 \mathrm{E}-06$ & \\
\hline $\mathrm{FeO}_{2}^{-1}$ & $6.23 \mathrm{E}-08$ & & $9.86 \mathrm{E}-08$ & \\
\hline $\mathrm{K}^{+1}$ & $8.17 \mathrm{E}-04$ & & $1.89 \mathrm{E}-04$ & \\
\hline $\mathrm{HPO}_{4}^{-2}$ & 4.73E-06 & & $9.04 \mathrm{E}-07$ & \\
\hline $\mathrm{ZnO}_{2}^{-2}$ & $5.55 \mathrm{E}-06$ & & $1.40 \mathrm{E}-06$ & \\
\hline $\mathrm{ZnO}$ & $1.65 \mathrm{E}-08$ & & $1.95 \mathrm{E}-09$ & \\
\hline $\mathrm{ZnOCl}^{-1}$ & $3.96 \mathrm{E}-07$ & & $9.71 \mathrm{E}-09$ & \\
\hline $\mathrm{HZnO}_{2}^{-1}$ & $6.33 \mathrm{E}-07$ & & $1.12 \mathrm{E}-07$ & \\
\hline $\mathrm{CuO}$ & & 0.052 & & \\
\hline $\mathrm{Fe}_{2} \mathrm{O}_{3}$ & & 0.016 & & 0.016 \\
\hline $\mathrm{Na}_{8} \mathrm{Al}_{6} \mathrm{Si}_{6} \mathrm{O}_{24} \mathrm{CO}_{3} .1 \mathrm{H}_{2} \mathrm{O}$ & & 0.447 & & 0.458 \\
\hline MST & & 0.446 & & 0.471 \\
\hline mass MST g & & 73,000 & & 41,300 \\
\hline mass fraction solids & & 0.0419 & & 0.0096 \\
\hline
\end{tabular}


Examination of the composition changes in the surge tank indicates that the surge tank is acidic at the end filter washing. Figure 3-18 shows the change in $\mathrm{pH}$ in the surge tank throughout the filter washing process. There are several factors to consider before concluding that the surge tank is always acidic at the end of filter washing. The filter wash simulation assumed no residual heel in the filter though there will be some amount of caustic residual material. The simulation also does not account for acid consumption by reaction of residual solids in the filter. Though the potential consumption should be small compared to the total oxalic acid added to the system, only a small difference would change the $\mathrm{pH}$ above 10 . The inhibited water is made up to be a nominal 0.01 $\mathrm{M}$ such that slightly higher concentrations are reasonably expected in practice. This may also be adequate to bring the surge tank above $\mathrm{pH} \mathrm{10,} \mathrm{but} \mathrm{is} \mathrm{not} \mathrm{controlled} \mathrm{to} \mathrm{guarantee} \mathrm{that} \mathrm{it} \mathrm{does.} \mathrm{The}$ implication is that the residual liquid in the filter after filter washing is acidic and not caustic as is desired. As such, there is a risk that oxalates will precipitate in the filter, perhaps in the filter pores, at the moment of introduction of the first batch from the subsequent filter cycle. This phenomena was also noted in an earlier evaluation. ${ }^{1}$

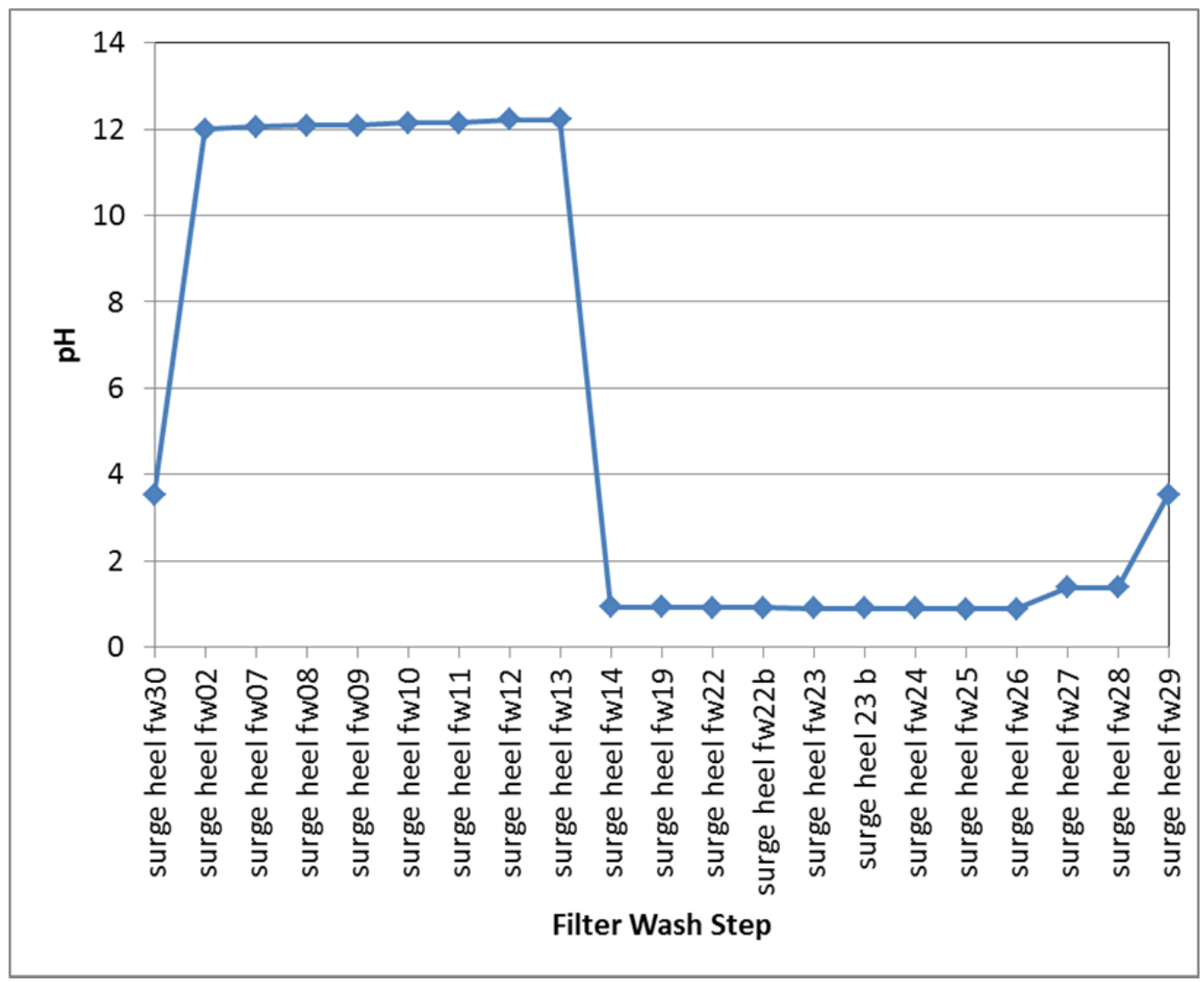

Figure 3-18. The pH in the Surge Tank Throughout the Filter Cleaning Process 
SRNL-STI-2013-00700

Revision 0

\subsection{Filtration Evaluation}

\subsubsection{Description of 512-S Filtration}

The primary filter is a crossflow filter that contains 144 Mott $^{\circledR}$ sintered metal filter tube elements with nominal pore size of $0.1 \mu \mathrm{m}$ and a total filter area of $230 \mathrm{ft}^{2}$. The filter tubes are made of 316 stainless steel with an inner diameter of $0.625^{\prime \prime}$ and are $120 "$ long.

The system includes an in-line secondary filter on the filtrate stream produced by the primary filter. The secondary filter is a dead-end filter constructed of 21 sintered metal filter tubes with a $0.5 \mu \mathrm{m}$ nominal rating, with a total surface area of $16.5 \mathrm{ft}^{2}$. The tubes as made from 316 stainless steel and are also manufactured by Mott ${ }^{\circledR}$. The filter elements sit inside the LWHT. In ARP, the filtrate from the crossflow filter is passed through a secondary filter prior to entering the LWHT. The secondary filter has a history of becoming fouled even though it has larger pore size than the primary filter. ${ }^{10}$

The particle capture efficiency for the $0.1 \mu \mathrm{m}$ and $0.5 \mu \mathrm{m}$ Mott ${ }^{\circledR}$ filter media are shown in Table 3-23. As can be seen in the table, a very small fraction of particles as large as $0.8 \mu \mathrm{m}$ can pass the $0.1 \mu \mathrm{m}$ media.

\section{Table 3-23. Filter Particle Capture Efficiency for Mott ${ }^{\circledR}$ Filter Media}

\begin{tabular}{|c|c|c|c|c|}
\hline \multirow{2}{*}{$\begin{array}{c}\text { Media } \\
\text { Grade }\end{array}$} & & \multicolumn{4}{|c|}{ Particle Size - $\mu \mathrm{m}$} \\
\cline { 3 - 5 } & Thickness & \multicolumn{3}{|c|}{ Initial Collection Efficiency } \\
$90 \%$ & $99 \%$ & $99.9 \%$ \\
\hline 0.1 & $0.039^{\prime \prime}$ & 0.15 & 0.4 & 0.8 \\
\hline 0.2 & $0.039^{\prime \prime}$ & 0.5 & 0.9 & 1.4 \\
\hline 0.5 & $0.047^{\prime \prime}$ & 1 & 1.7 & 2.2 \\
\hline 1 & $0.047^{\prime \prime}$ & 1.5 & 2.2 & 3.3 \\
\hline 2 & $0.062^{\prime \prime}$ & 4 & 5.5 & 9 \\
\hline 5 & $0.062^{\prime \prime}$ & 5 & 8 & 13 \\
\hline 10 & $0.062^{\prime \prime}$ & 10 & 15 & 20 \\
\hline 20 & $0.062^{\prime \prime}$ & 20 & 25 & 35 \\
\hline 40 & $0.078^{\prime \prime}$ & 25 & 35 & 45 \\
\hline 100 & $0.093^{\prime \prime}$ & 50 & 100 & 150 \\
\hline
\end{tabular}

Testing performed per ASTM F795

Tested at $1 \mathrm{gpm} / \mathrm{ft}^{2}$

ISO A2 or A3 test dust suspended in water

\subsubsection{MST}

Batches of MST used by 512-S undergo qualification versus the procurement specification prior to use. Amongst the items measured during qualification is the particle size distribution, specifically to determine the amount of fines $<0.8 \mu \mathrm{m}$ and the geometric standard deviation of the particle size. The measured volume percent of particles less than $0.8 \mu \mathrm{m}$ and greater than 37 $\mu \mathrm{m}$ are shown in Table 3-24 for various MST batches. 
Table 3-24. Measured Fines from MST Batches

\begin{tabular}{|c|c|c|c|}
\hline \multirow[b]{2}{*}{ MST Lot \# } & \multicolumn{2}{|c|}{ Vol \% } & \multirow[b]{2}{*}{$\begin{array}{c}\text { Geometric Standard } \\
\text { Deviation }\end{array}$} \\
\hline & $<0.8 \mu \mathrm{m}$ & $>37 \mu \mathrm{m}$ & \\
\hline 012808 & 7.64 & 0 & 2.55 \\
\hline 040108 & 3.40 & 0.32 & 2.77 \\
\hline MST-2753 & 7.83 & 0 & 1.60 \\
\hline 08-QABP-0192 & 5.86 & 0 & 3.36 \\
\hline 091008 & 2.59 & 0 & 2.20 \\
\hline 081309 & 4.37 & 0 & 2.39 \\
\hline 082709 & 1.68 & 0 & 1.94 \\
\hline 102209 & 3.28 & 0 & 2.48 \\
\hline 120209 & 1.87 & 0 & 2.24 \\
\hline 100910 & 4.89 & 0 & 2.53 \\
\hline 101910 & 4.37 & 0 & 2.18 \\
\hline 110410 & 5.04 & 0 & 2.50 \\
\hline 111510 & 6.29 & 0.33 & 2.73 \\
\hline 121010 & 3.79 & 0 & 2.36 \\
\hline 010611 & 5.84 & 0 & 2.69 \\
\hline 012811 & 2.47 & 0 & 2.23 \\
\hline 030311 & 4.93 & 0 & 2.43 \\
\hline 050411 & 4.98 & 0 & 3.48 \\
\hline 052511 & 6.04 & 0 & 1.87 \\
\hline 071311 & 4.81 & 0 & 2.35 \\
\hline 081811 & $5.39,4.83$ & 0,0 & $3.82,3.28$ \\
\hline 120111 & 3.54 & 0 & 2.91 \\
\hline 46000417120 & 4.77 & 0 & 3.24 \\
\hline 46000524120 & 5.55 & 0.03 & 2.68 \\
\hline 46000619120 & 5.33 & 0.15 & 3.13 \\
\hline 46000706120 & 7.61 & 0.13 & 3.42 \\
\hline 46000722120 & 5.19 & 0 & 3.34 \\
\hline 46000808120 & 5.53 & 0 & 3.45 \\
\hline 46000824120 & 4.60 & 0 & 3.22 \\
\hline 46000908120 & 4.51 & 0 & 2.98 \\
\hline
\end{tabular}

\subsubsection{Crossflow Filtration Theory}

In crossflow filtration, filtrate flux will tend to reduce rapidly at the start of filtration with smaller particle sizes. The rapid degradation between subsequent salt batches is similar to this behavior. During processing in ARP, MST is added to salt solution to sorb soluble strontium and actinides. In 512-S, that material is filtered through the Mott ${ }^{\circledR} 0.1 \mu \mathrm{m}$ crossflow filter to remove the MST. The filtrate is then passed on to MCU for processing. MST is a relatively durable particle with a known, narrow particle size distribution. Most research in support of this process looked at filtering MST with significant amounts of entrained sludge. As evidenced by the samples analyzed for this study, no significant amount of sludge was found in the slurry for filtration. 
The expected behavior during the filtering of MST was an initial high filtration rate with an exponential decay as a filter cake formed on the membrane restricting flow. The filtration rate is expected to reach a quasi-steady state as the formation of the filter cake becomes limited by shear due to the fluid velocity. An increase in the solids concentration as the filtrate is removed will continue the filtration rate decline.

Several methods should increase filtration rate. These include the increase in feed velocity resulting in additional shear at the membrane, increasing TMP providing a greater driving force for filtration, increasing temperature which results in lower viscosity, lowering solids content of the feed, and reducing the amount of fines. During operation, several changes were made to the filtration process in attempts to improve performance. Among these were the increase in transmembrane pressure, the reduction of MST solids, and the increase in feed velocity. All of the changes that were made did not result in sustained improvement to filtration rate. According to filtration theory, any of these changes should have resulted in measurable changes to the filtration rate. However, it is possible that these changes resulted in other impacts which counteracted the expected improvements. For example, the sustained increase in TMP generally coincided with a reduction in axial velocity. In other cases, the change in a parameter was done at the same time as a change to a separate parameter, where both parameters would have potential impact on filtration. An example of this is the reduction in MST from $0.4 \mathrm{~g} / \mathrm{L}$ to $0.2 \mathrm{~g} / \mathrm{L}$, which occurred at the same time as the transition to continuous operation.

\subsubsection{Operational Evaluation}

Performance of the filtration system was investigated in the context of the batch samples analyzed as well as performance of previous batches from the data provided. Throughout operation of ARP, there has been little indication of sludge material in the salt batches. The formulation of MST has been consistent, though with various amounts of fines per batch; thus the solids that are expected to be filtered are consistent. The largest change in the process has been a variety of events and parameter changes and their resulting impacts on filtration, as well as the variation in the chemistry of the salt batches. A plot of filter performance and impacting events over the data reviewed is shown in Figure 3-19.

Noted in the data provided by SRR were several operational events that have the potential to impact filter performance. These events include the batch washing or chemical cleaning of the crossflow filter. During processing, procedures were altered to routinely close the back pressure valve. This results in an increase TMP but reduces feed flow through the filter and thus reducing the axial velocity across the membranes. The amount of MST added to the strike tank was reduced from $0.4 \mathrm{~g} / \mathrm{L}$ to $0.2 \mathrm{~g} / \mathrm{L}$. The intent was to reduce the amount of insoluble solids that are sent to the filter. At the same time the MST was reduced, the filter was transitioned to continuous operation. Continuous operation meant that at the completion of a batch, the feed tank was refilled as the filter continued to operate.

In August of 2012 an oxalic acid leak was discovered. The leak was from the oxalic acid storage tank into the precipitation tank. The oxalic acid leak required $\mathrm{pH}$ adjustment in the LWPT. The contents of the tank were transferred directly to the LPPP. A portion of the solids remained in the tank as part of the tank heel and added a burden on the filter. This material was processed as part of SB5 Cycle 1. 


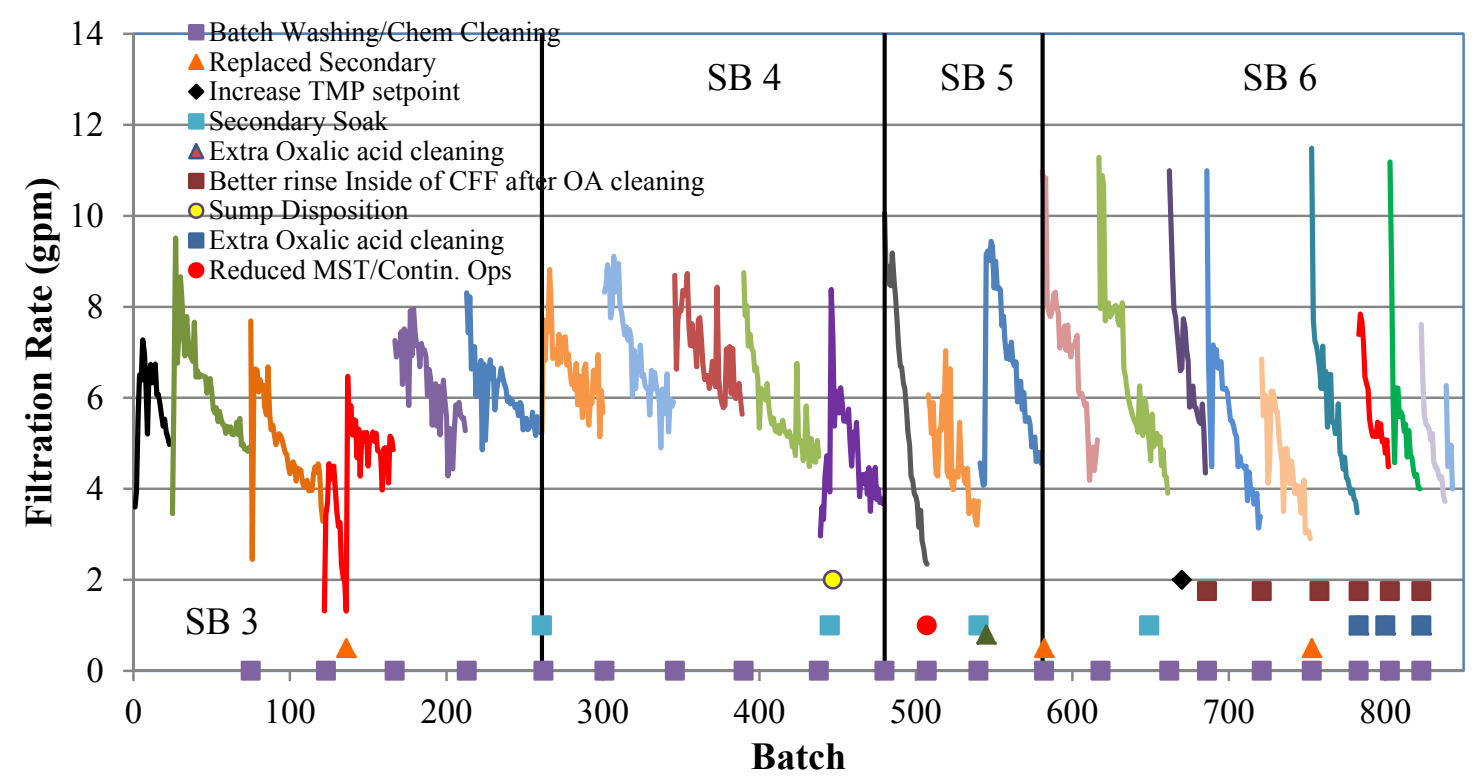

Figure 3-19. Filtration Rate and Significant Events during Processing

In December of 2012 (SB5 cycle 2) the backpressure control valve was manipulated with the net result of increasing the TMP. This was later changed procedurally in April of 2013 (SB6C). The sump disposition in January 2012 (SB4B Cycle 5) involved the removal of material from the cell sump and addition of the material to the LWPT, which included the potential for the addition of foreign substances to the LWPT.

Other events that were noted were additional rinsing of the crossflow filter with inhibited water after cleaning with oxalic acid to reduce the $\mathrm{pH}$ change as salt feed was reintroduced, soaking the secondary filter in an attempt to clean and replacement of the secondary filter after it was determined to be fouled.

\subsubsection{Evaluation of Operational Filtrate Production}

During SB6, the number of batches per cycle decreased before cleaning of the filter was required. SRR provided detailed filter data since the start of SB3 in June of 2010 through current operations for evaluation to determine the cause of the decrease in filter performance. Though the data provided started with SB3, a short review of SB1 and SB2 is included below for completeness.

\subsubsection{SB1 though SB4}

In general, SB1 was started with filtration rates in the 5 to $6 \mathrm{gpm}$ range though there was some variability. Low filtration rate appeared to correlate with facility outages of greater than 5 days with recovery once routine operation was resumed. At the end of SB1, filtration rates had dropped to less than $4 \mathrm{gpm}$. SB2 started with low filtration rates of less than $3 \mathrm{gpm}$. 
Initial startup of SB2 was slow. Caustic was added as a method of keeping aluminate in solution. This was done to improve the performance of the MCU decontaminated salt solution coalescer. Filtration improved during the caustic flush. Waste treatment resumed and performance degraded rapidly.

After the SB2 batch 8, the secondary filter was redesigned and replaced after it was determined the secondary filter was limiting flow. The secondary filter was not expected to see significant solids accumulation and there were no straightforward methods for cleaning or replacement. The original design was a "wagon wheel" consisting of 16 tubes that were 2 " diameter, 1' long with $0.5 \mu \mathrm{m}$ pore size. The removed filter was destructively analyzed. ${ }^{10}$ The current design has been described previously in this report, and processing has continued in the same configuration to the present SB6. In addition to the redesigned secondary filter, procedure changes were implemented to further raise $\mathrm{OH}^{-}$concentration and flush the filter shell after each batch.

SB2 was restarted in March of 2008 and showed dramatic improvement (6 to 7 gpm, output throttled). Process data from 512-S and MCU suggested solids generation was greatly reduced.

SB3 was generally regarded as processing well. Filtration rate showed considerable variability, though. With a few exceptions (primarily in SB3 cycle 4), the filtration rate was maintained above $4 \mathrm{gpm}$ and 45 to 50 batches were completed per cycle prior to cleaning.

SB4 also processed well. Filtration rate was the most consistent through this Salt Batch. The number of batches per cycle ranged from 41 to 49 and filtration rates were generally around 6 gpm until cycle 5, when the secondary filter impacted performance.

\subsubsection{SB5}

SB5 contained only 3 cycles and several events occurred. These events included the oxalic acid leak and subsequent disposition, reduction in the amount of MST, transition to continuous operation, soaking of the secondary filter (previously soaked in SB4 C5) and change in positioning of the backpressure control valve resulting in higher TMP with a reduced axial velocity. The number of batches in the three cycles ranged from 28 to 40 . SB5 cycle 1, after the oxalic acid leak, was run for only 28 batches with the filtration rate of the last 8 batches ending under $4 \mathrm{gpm}$. It was noted that the filtration rate at the start of each of all batches in the cycle were very good, about $7 \mathrm{gpm}$. The final 4 batches of the cycle started about $7 \mathrm{gpm}$ and decayed to less than $3 \mathrm{gpm}$ by the end of the batch. This cycle was unusual in that there was such a large drop in filtration rate in the individual batches at the end of the cycle.

SB5 cycle 2 started continuous operation and the reduced MST loading. The first continuous operation was the transition from batch 2 to batch 3. Filtration rate ranged from 8 to $6 \mathrm{gpm}$ with a slight recovery to $7 \mathrm{gpm}$ as the feed tank was refilled and MST solids diluted. Batch 3 ended at approximately $5.9 \mathrm{gpm}$. There was a brief stoppage between batch 3 and batch 4 . Batches 4,5 and 6 were run without interruption but less filtration recovery was noted as the feed tank was refilled, diluting the MST. Batch 7 was run after a short stoppage and showed a starting filtration rate slightly higher than the Batch 6 ending filtration rate (5.2 gpm versus $4.6 \mathrm{gpm})$. Batch 8 was processed approximately 3 days later with a significantly higher starting filtration rate of approximately 8.6 and ended at approximately $5.8 \mathrm{gpm}$. The next 5 batches were run as individual batches with various filtration rates ranging from $8 \mathrm{gpm}$ down to end-of-batch rates of 4 gpm. 
The next 19 batches of SB5 cycle 2 were run relatively similarly, but with non-continuous operation (there was a stoppage between each batch). Filtration rates showed a steady decline between batches starting at 6-7 gpm and ending at approximately $5 \mathrm{gpm}$. The last 8 batches started around $5 \mathrm{gpm}$ and ended at less than $4 \mathrm{gpm}$. It should be noted that during the processing of this string of batches, the data shows an initial spike in filtration rates, up to $16 \mathrm{gpm}$, before being throttled back. This initial spike in filtration may have contributed to increase in filtration rate decline between batches by pushing particles deeper into the filter pores.

The first 4 batches of SB5 cycle 3 started with low filtration rates, approximately 5 . Note that these rates were relatively flat and did not have the high start rates as the previous cycle. These batches were run individually and not in continuous mode. The $4^{\text {th }}$ batch had a large filtration spike of almost 20 gpm during restart after a short stoppage. The next 5 batches were run with a higher TMP which resulted in filtration rates around $9 \mathrm{gpm}$. The following 25 batches were run in continuous mode and starting at approximately $9 \mathrm{gpm}$ for the first several batches and slowly dropping to less than $5 \mathrm{gpm}$ by the end of the cycle.

\subsubsection{SB6}

The start of SB6A went well based on operating at a low TMP and high filtration rate. Batches 3 through 6 were run continuously. Filtration rate began to decline in batch 24 to approximately $8 \mathrm{gpm}$. The filtration rate continued a slow decline and the final batch ended at approximately $5 \mathrm{gpm}$. A total of 36 batches processed in this cycle.

SB6B started continuous operation with the fourth batch. Each of the first four batches started with a spike in filtration rate of up to $16 \mathrm{gpm}$. Batch 17 started to see a reduction in filtration rate from approximately $8.5 \mathrm{gpm}$. Filtration rate slowly dropped and there were very few processing interruptions. Thirty-two batches were completed; ending with a filtration rate of approximately $6 \mathrm{gpm}$. There was a several day interruption prior to processing batch 33 and another multiday interruption after the start of batch 34. Processing remained around $6 \mathrm{gpm}$. Forty-five batches were completed with filtration rate slowly declining and ending below $5 \mathrm{gpm}$. It should also be noted that the batches from 32 through 45 were not continuous operation, with short interruptions starting after batch 34 .

SB6C started within a day of SB6B completion. SB6C started with high filtration rates, 12 gpm for the first two batches. Both batches started filtration spikes with maximum filtration rates of $18 \mathrm{gpm}$. The next seven batches were processed with in rapid succession ending with filtration rates of $7.5 \mathrm{gpm}$. Batches were restarted approximately 7 days later with filtration rates starting at approximately $9 \mathrm{gpm}$ and dropping to just under $5 \mathrm{gpm}$.

SB6D was started with a high filtration rate, approximately $12 \mathrm{gpm}$. The second batch also started with a high filtration rate but the TMP was reduced half way through the batch dropping the filtration rate to approximately $7 \mathrm{gpm}$. The filter feed flow was noticeably lower $(\sim 1100 \mathrm{gpm})$ for the first 7 batches in this cycle. The next batches, through batch 10, were processed with a filtration rate between 7.5 and $8 \mathrm{gpm}$. Filtration rate continued to decline with the $34^{\text {th }}$ batch ending under 4 gpm.

The first batch for SB6D cycle 2 started at a filtration rate of 13 gpm but dropped off dramatically throughout the batch ending at around $6 \mathrm{gpm}$. Thirty-three batches were completed in this cycle 
but none were processed above $6.5 \mathrm{gpm}$. Batch 1 from this cycle was noticeably different from other initial batches in the dramatic drop in filtration rate and lack of recovery on following batches.

SB6D cycle 3 started significantly better than cycle 2 . Batch 1 was processed at $12 \mathrm{gpm}$, though with low axial velocity and a significant increase in TMP required to maintain the filtration rate. Batch 2 had a large drop in filtration rate starting over $11 \mathrm{gpm}$ but ending at approximately $8 \mathrm{gpm}$. Batch 3 started at $10 \mathrm{gpm}$ and also completed around $8 \mathrm{gpm}$, the same as the previous batch. Over the next 15 cycles filtration rate dropped to approximately $6 \mathrm{gpm}$. Filtration rate continued to drop steadily with the cycle ending with 39 batches processed with an ending filtration rate of $3.7 \mathrm{gpm}$.

SB6D cycle 4 batch 1 was started at 12 gpm but filtration was dropped to approximately 8 gpm $1 / 3^{\text {rd }}$ of the way through. The next three batches were run at $8 \mathrm{gpm}$ and then the filtration rate could not be sustained. 18 batches were completed for the cycle with the filtration rate ending under 5 gpm.

SB6D cycle 5 batch 1 was run at $12 \mathrm{gpm}$. Batch 2 started at $8 \mathrm{gpm}$, dropped to $6 \mathrm{gpm}$ and then brought back to $9.7 \mathrm{gpm}$. The next batches were started around $6.5 \mathrm{gpm}$ with filtration rate declining as the batches progressed until ending under $4 \mathrm{gpm}$ with a total of 20 batches processed.

SB6D cycle 6 batch 1 was run at approximately 8 gpm. TMP increases were required to maintain the filtration rate. As with most of the SB 6 cycles, filter feed rate and therefore axial velocity were low. Filtration steadily declined and 16 batches were processed with filtration rate dropping under 4 gpm.

As seen in Figure 3-19, with the exception of SB6D-C2, SB6D-C4 and SB6D-C6, the initial batches from all of the SB6 cycles show excellent performance. This implies that the cleaning of the crossflow filter between these cycles was effective. The cleaning process restored filter flux to a very high level repeatedly, at least for the first batch of the cycle. However, the high filtration rate from the first batch typically could not be sustained. Filtration rates declined rapidly or were intentionally dropped following these high filtration rate batches.

Examination of the filtration data provided does not indicate a single factor responsible for variations in filter performance. It is likely that the inconsistency in filtration performance is a result of several different factors. Several batches show a negative impact due to the secondary filter. High pressure drops are seen in several instances across the secondary filter that restricted filtrate production.

\subsubsection{Decline in the Number of Batches per Cycle}

The primary issue for recent filtration performance was that fewer batches per cycle were being completed before filter cleaning was deemed necessary. A plot of the end-of-batch filtration rate for the SB4 Cycles, shown as Figure 3-20, illustrate the batch-to-batch change. Linear trend lines show a consistent drop in batch filtration rates as the cycle progresses. It should also be noted that the contents of the sump were dispositioned during SB4B cycle 5 Batch 9, two batches after the secondary filter was soaked. 
SRNL-STI-2013-00700

Revision 0

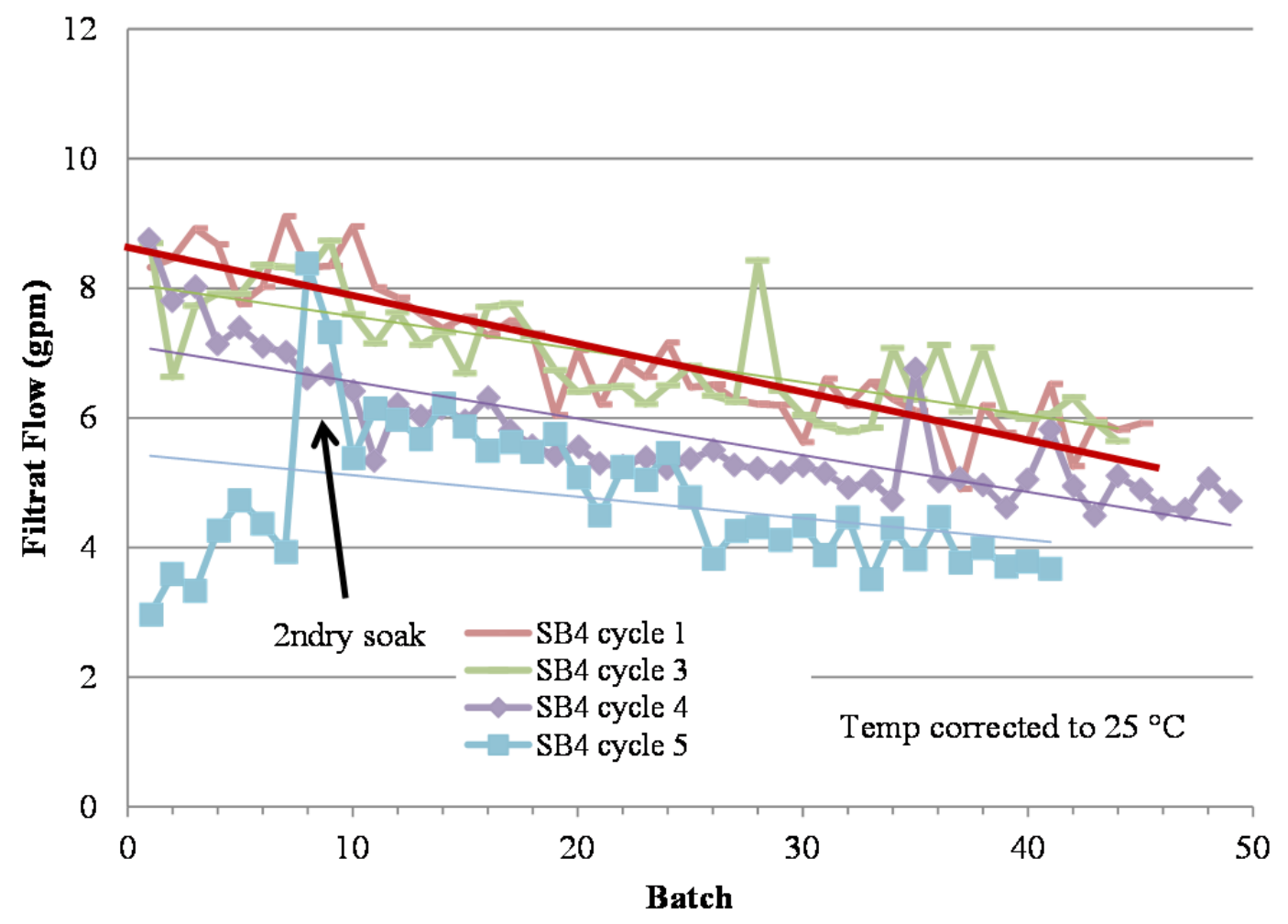

Figure 3-20. Filtration Rate as a Function of Batch for Salt Batch 4 Cycles

Examining a similar plot for SB5 (Figure 3-21), shows a change in the slope for the first cycle.

The oxalic acid leak occurred prior to SB5 cycle 1. A previously discussed, the $\mathrm{pH}$ adjustment of the oxalic acid was expected to result in the precipitation of significant solids. It is expected that the change in the batch-to-batch performance was due to those additional solids.

The rate of batch-to-batch decline in filtration rate for SB5 cycle 2 appears similar to the SB 4 cycles. SB5 cycle 2 was also the beginning of the reduction in MST from $0.4 \mathrm{~g} / \mathrm{L}$ to $0.2 \mathrm{~g} / \mathrm{L}$ and the start of continuous operations. The largest difference in performance for this cycle was the low initial filtration rate. The noticable increases in filtration rate at batches 12,15 and 21 corresponded to increases in pressure drop across the filtration system. 


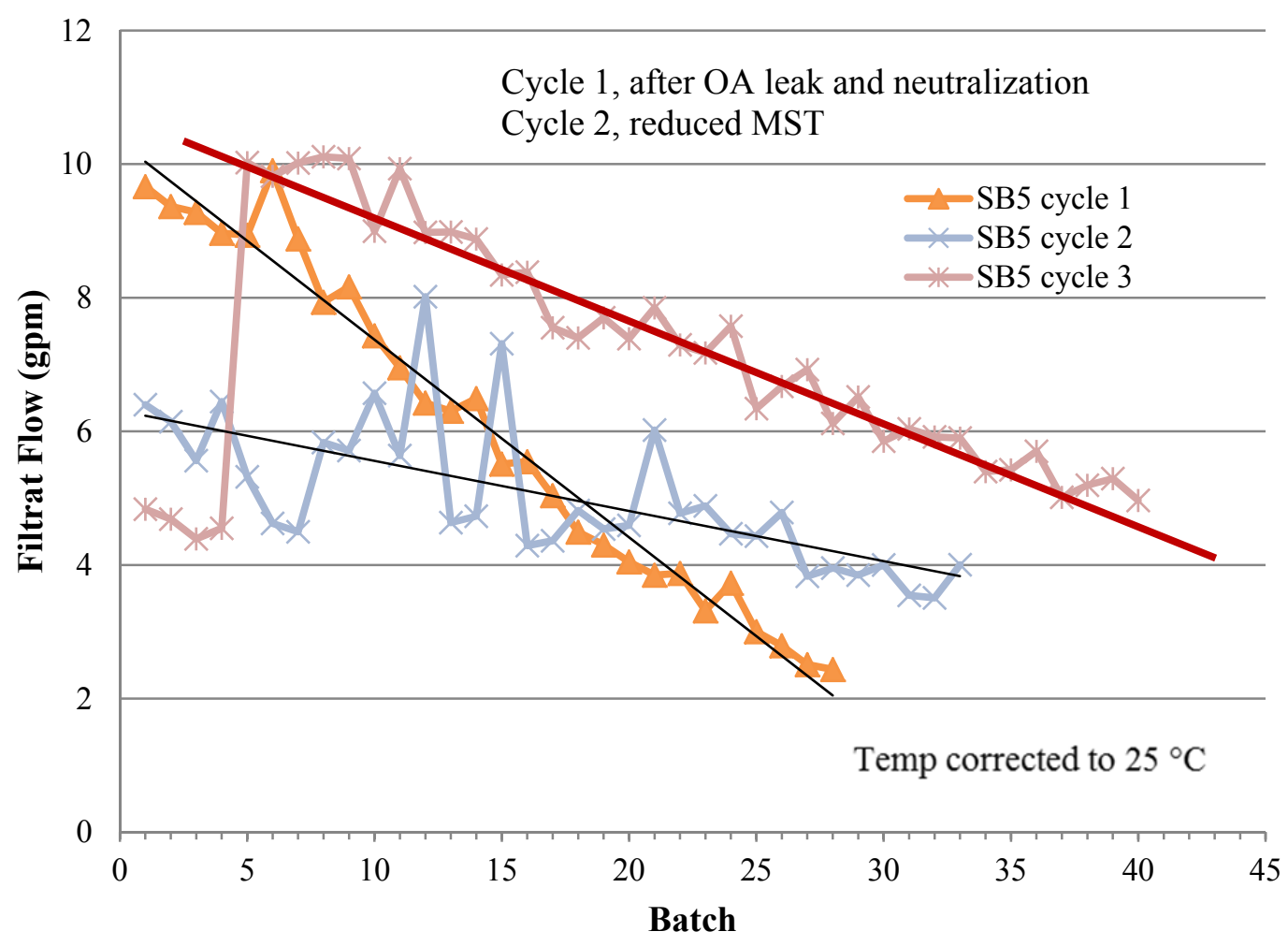

Figure 3-21. Filtration Rate as a Function of Batch for Salt Batch 5 Cycles

The filtration rate for the initial batches of SB5 cycle 3 were low compared to the first batches from previous cycles. Starting with the fifth batch, filtration rates were significantly better. The data shows this was due to a significant improvement in the secondary filter's performance. The batch-to-batch decline in filtration rate for the rest of the cycle was not as great as in SB5 cycle 1, but still higher than for the previous cycles (SB3 and SB4). The operational change during this cycle was the increase in the TMP setting and the resulting drop in axial velocity. 


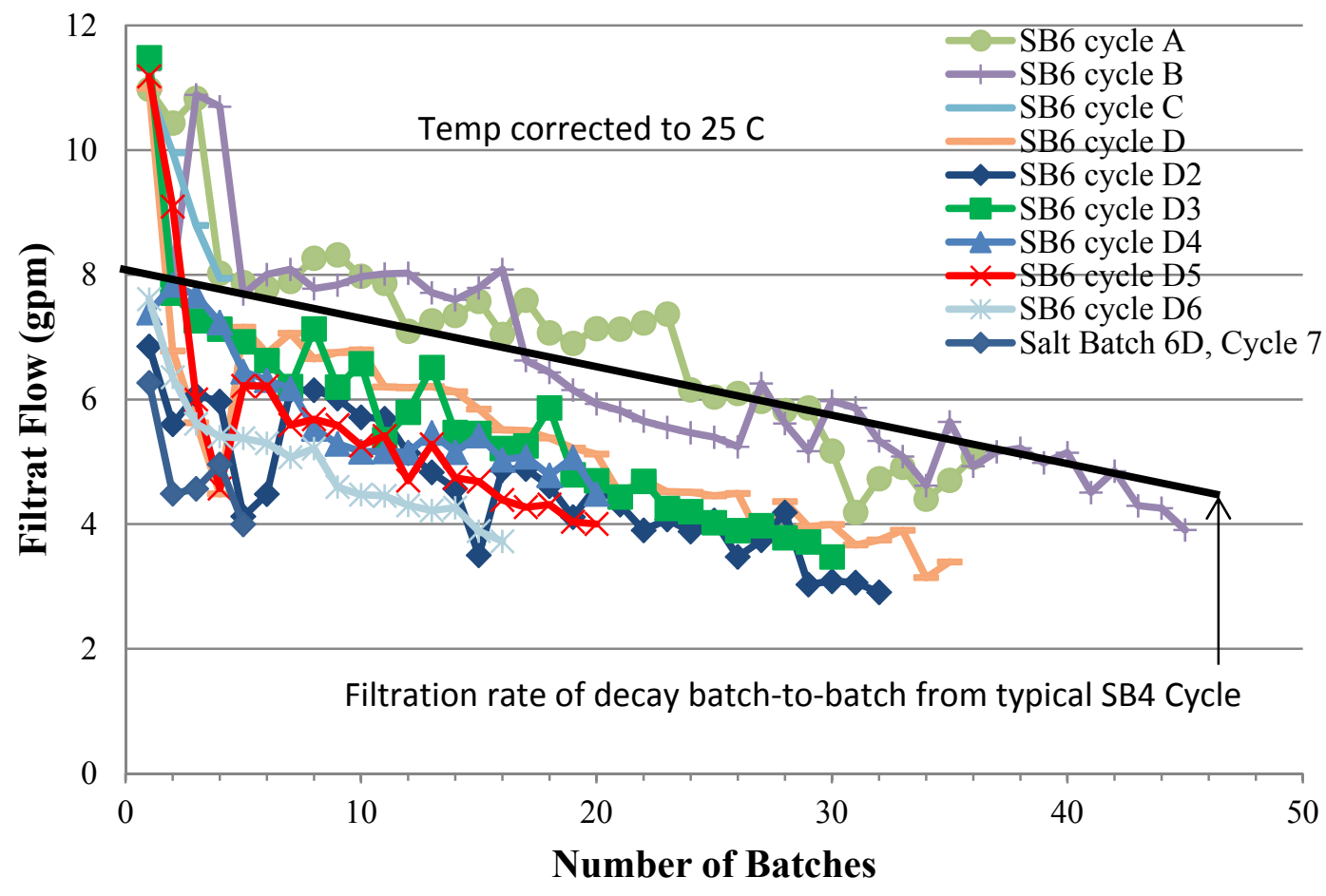

Figure 3-22. Filtration Rate as a Function of Batch for Salt Batch 6 Cycles

Figure 3-22 shows the filtration rate as a function of the individual batches for each of the SB6 cycles. The initial two-to-four batches in several cycles had very high filtration rates. There was a significant drop for the and then a fairly consistent decline. For comparison, a typical trend line from SB4 is overlaid on the chart. Note that the batch-to-batch decline for the SB6 cycles is greater than it was for the SB4 cycles.

\subsubsection{Washing of MST Solids}

At the end of processing of a cycle, the MST solids are washed to a target sodium concentration of $0.5 \mathrm{M}$. This is performed by starting the filtration process with the addition of enough inhibited water (IW) to prevent pump cavitation and continually adding IW as filtrate is removed. Due to the dilution of soluble components, this washing step improves filtration through the reduction of liquid viscosity. The viscosity has a linear inverse relation with filtration rate; therefore, halving the viscosity should double the filtration rate. The washing process for SB6D cycle 5 is shown as Figure 3-23. The performance is measured by permeability (i.e., filtrate flow per psi per square foot of membrane) to factor in the change in TMP and filtration flow rate. 
SRNL-STI-2013-00700

Revision 0

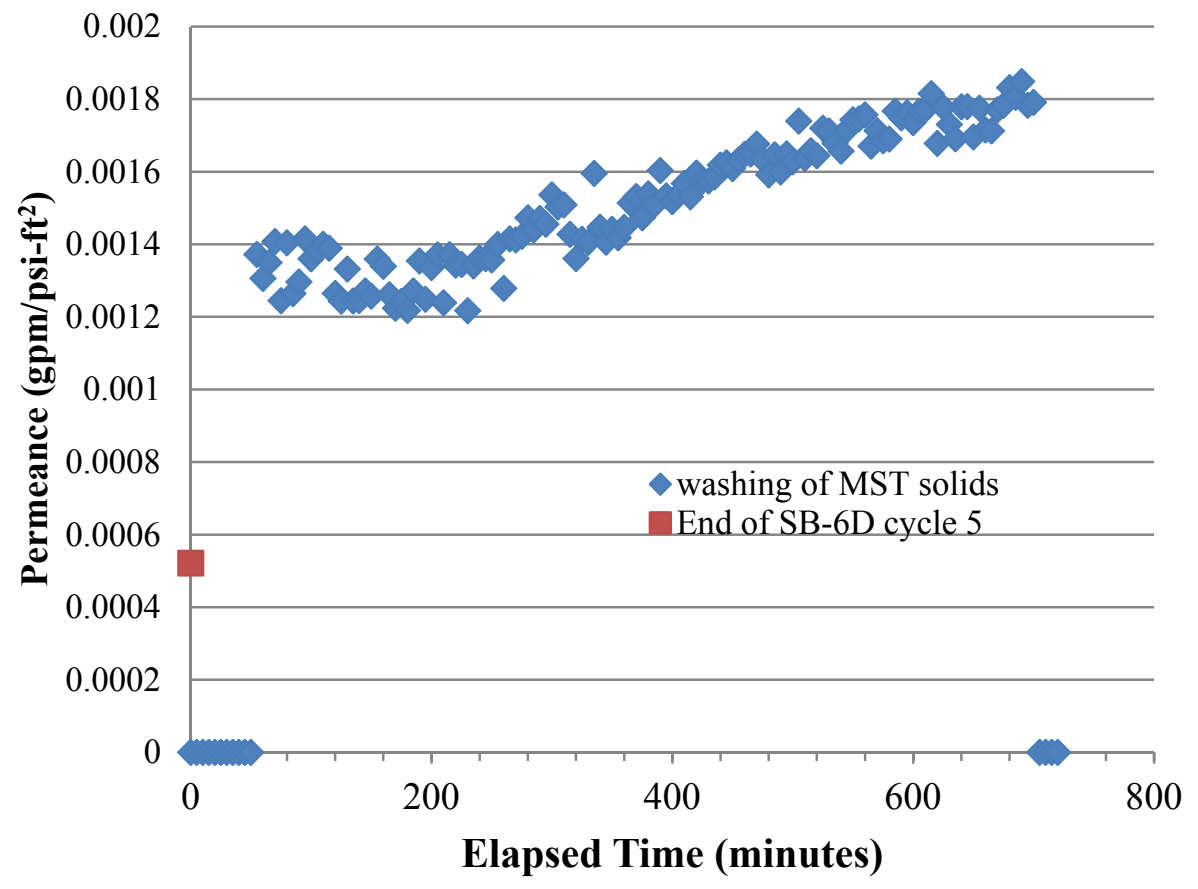

Figure 3-23. Batch Washing of MST at the End of SB6D Cycle 5

The measured viscosity of the filtrate was 2 to $3 \mathrm{cP}$ (sample LWHT-1). The wash water-diluted liquid viscosity is expected to be greater than 1 . Therefore the jump in filtration performance as measured by permeability through the membrane of approximately 2.5 -times is consistent with the change in viscosity. The continued improvement in permeability is also consistent with the continued dilution with wash water. The correlated performance indicates that the material restricting flow through the filter is not being dissolved by the IW.

\subsubsection{Evaluation of Parameters Impacting Filter Performance}

To see the impact of several factors, the crossflow TMP, secondary filter TMP, feed flow rate and filtrate flow rate were normalized to their largest value throughout the entire data set. Therefore a value of 1 indicates the highest value from the data set. In this manner, the relative changes to the parameters can be compared and are displayed in Figure 3-24. 


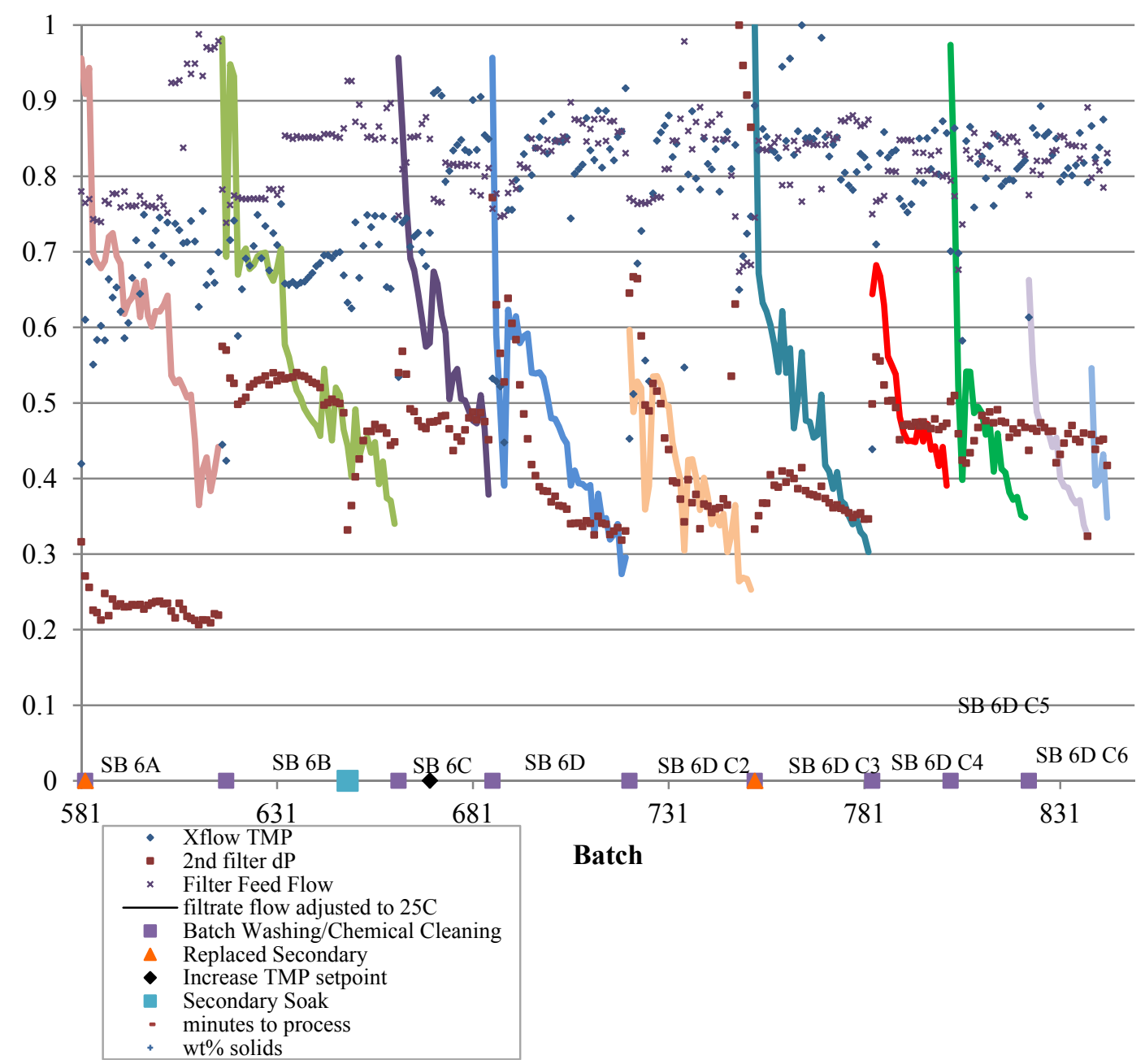

\section{Figure 3-24. Relative Change in Pressure Drop, Filter Feed Flow, and Filtrate Flow for} SB-6 Cycles

The different color solid lines indicate the filter flow rate for the individual cycles. Inspection of the chart shows significant variation in parameters between not only cycles but individual batches within cycles. It also shows that a single parameter is not driving filter performance. Throughout the SB6 cycles, changes to the pressure drop across the secondary filter show an impact to the individual batch performance. However, the step change in secondary pressure drop between SB6A and SB6B did not result in significant change to filtration between the two cycles. SB6A had a large variation in the pressure drop across the crossflow filter. But the pressure drop across the crossflow filter was essentially the same between the two batches. This shows that the rapid drop in performance in this batch was not due to the pressure drop across the secondary filter.

\subsubsection{Contribution of Fines to Filter Performance Degradation}

The lack of sustained filtrate production from increased TMP shown in Figure 3-25 may indicate a couple of factors. Traditionally, a lack of production with increased TMP may indicate a compressible cake. In this condition the filter cake is compressed resulting in decreased porosity 
and thus results in the same or lower flow. The transition to continuous mode may also indicate a compressible cake. While operating in batch mode, a compressible cake may have had the opportunity to "spring back" during the time the batch was being prepared and thus opening filtration area in the filter cake.

Lack of production from increased TMP may indicate pore plugging by fines. ${ }^{16}$ The increased pressure would result in the fines migrating deeper into the pores and thus restricting flow area. This would require a thorough chemical cleaning to restore filtration rate. Inspection of MST acceptance reports (Table 3-24) shows a wide variation in the amount of fines $(<0.8 \mu \mathrm{m})$ between MST batches (1.68 to 7.83 volume percent).

As evident in Table 3-24, the quantity of in fines in MST batches has been variable since initial operation. It is recommended to investigate if there is a correlation between the amount of MST batch fines and filter performance. During 512-S operation, the batches of MST are not necessarily used in order of receipt, adding uncertainty to the trend in quantity of fines with time. Based on this historical MST batch information, however, it is unlikely that an increase in the quantity of fines during processing of SB5 and SB6 processed significantly more fines than the previous salt batches.

\subsubsection{Impact of Transmembrane Pressure on Filtration Rate}

The parameter that was changed the most dramatically and provides the best indication of the behavior of the filter system is the pressure drops across both filters. Figure 3-25 shows the filtrate production, pressure drop across the crossflow filter, secondary filter and total pressure drop across both filters for the individual batches. Note that the filtrate rate has been mathematically adjusted to account for the variation in temperature. Thus the filtrate rate shown has been adjusted to $25{ }^{\circ} \mathrm{C}$. By doing so, the impact of temperature on viscosity has been removed.

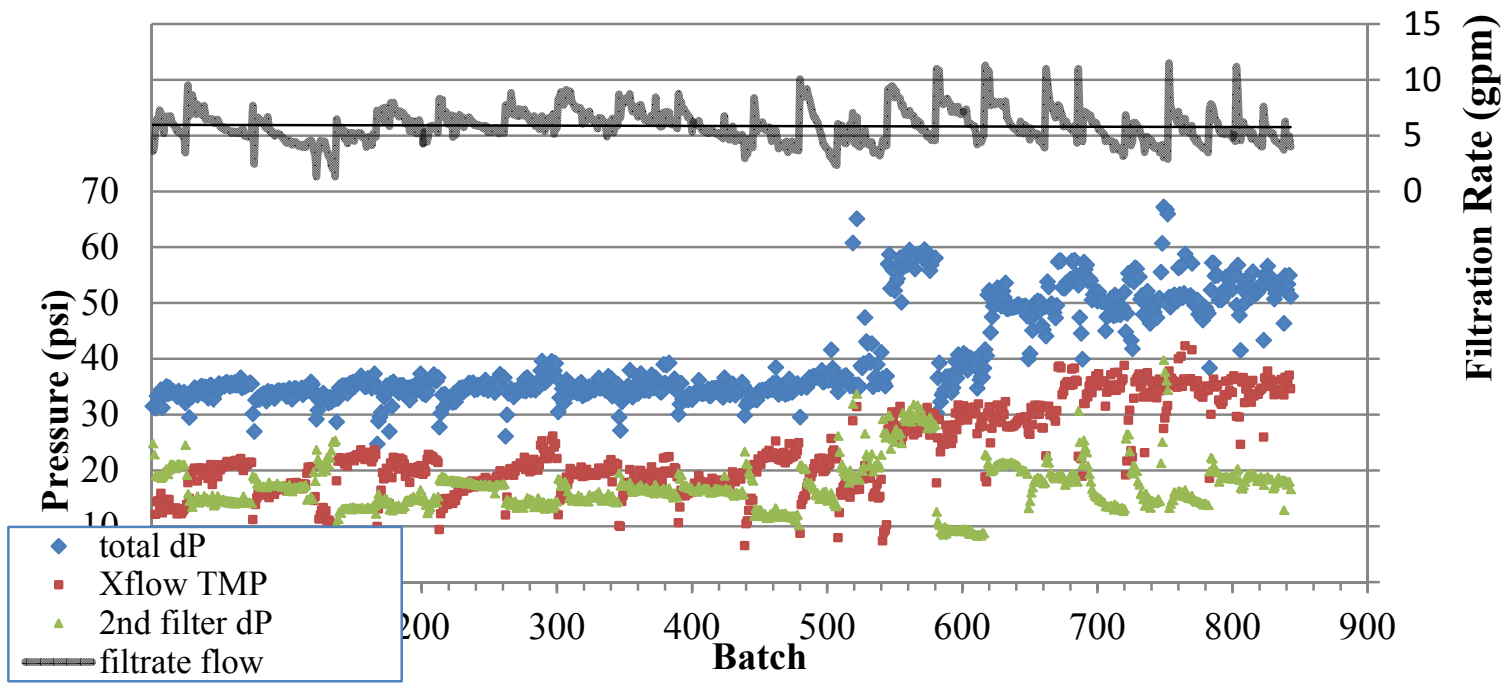

Figure 3-25. Filtration Flow Rate and Filter Pressures as a Function of Batch 
Figure 3-26 shows the filter flow rate as a function of the pressure drop across both the crossflow and secondary filters for SB3 through SB6D. A linear trend line shows that over the total data set there is no increase in filtration as a result of increasing the TMP. This is counter to the expected behavior if all other parameters are held constant. Also note that as described in the data evaluation, the increased TMP also resulted in numerous spikes in filtration rate at the start of multiple batches. It is expected that these spikes in filtration rate will result in particulates being forced deeper into the membrane pores making cleaning more difficult.

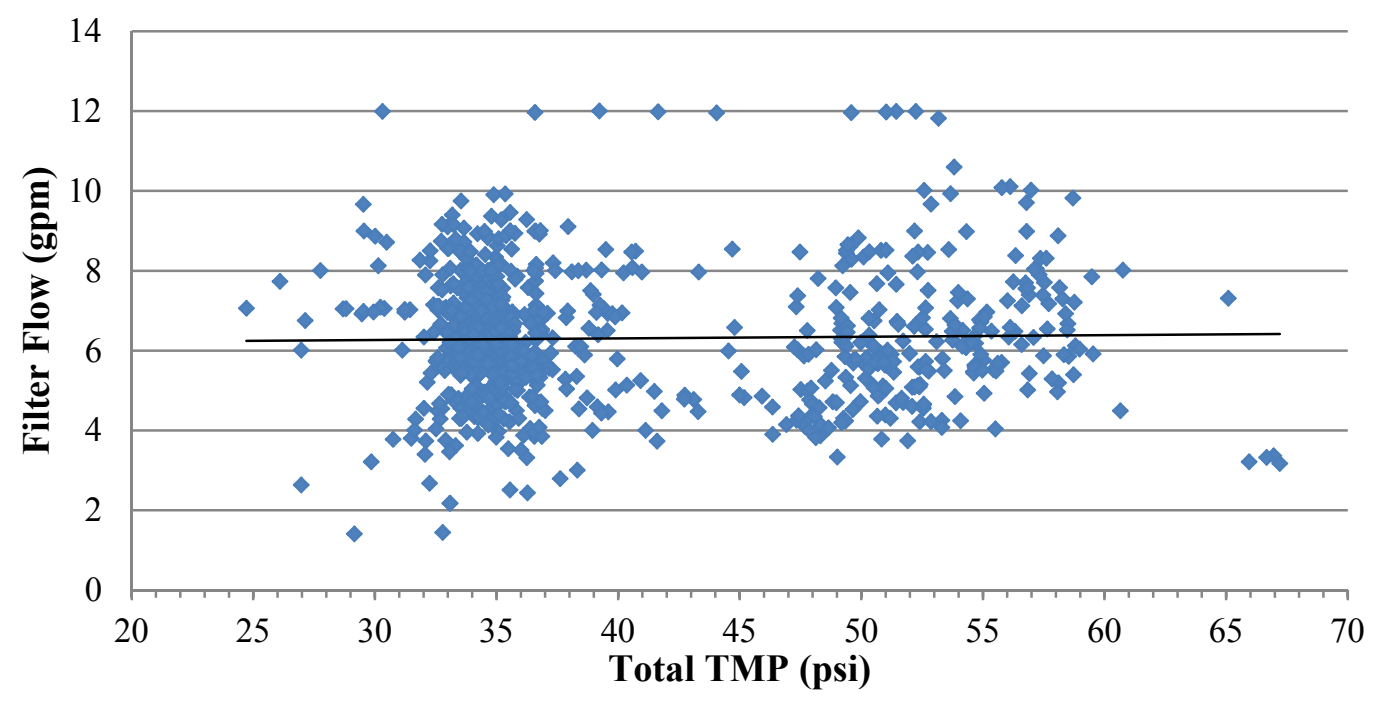

Figure 3-26. Filtration Rate as a Function of Transmembrane Pressure

As previously discussed, the increase in TMP was accomplished by partially closing the back pressure control valve. This also resulted in a drop in feed axial velocity. The axial velocity is generally steady at approximately $9 \mathrm{ft} / \mathrm{s}$ through SB5 cycle 2 . As the TMP setpoint was increased by closing the backpressure valve, the axial velocity dropped to between 7 to $8 \mathrm{ft} / \mathrm{s}$.

\subsubsection{Contribution of Axial Velocity to Filter Performance Degradation}

There was a drop in the axial velocity in the filter tubes corresponding to the higher TMP starting in SB5 Cycle 3. Since the TMP increase and axial velocity decrease, there appears to be a continued decrease in filtration rate after the first few batches of a cycle. The axial velocity and filtration rate are shown in Figure 3-27. 
SRNL-STI-2013-00700

Revision 0

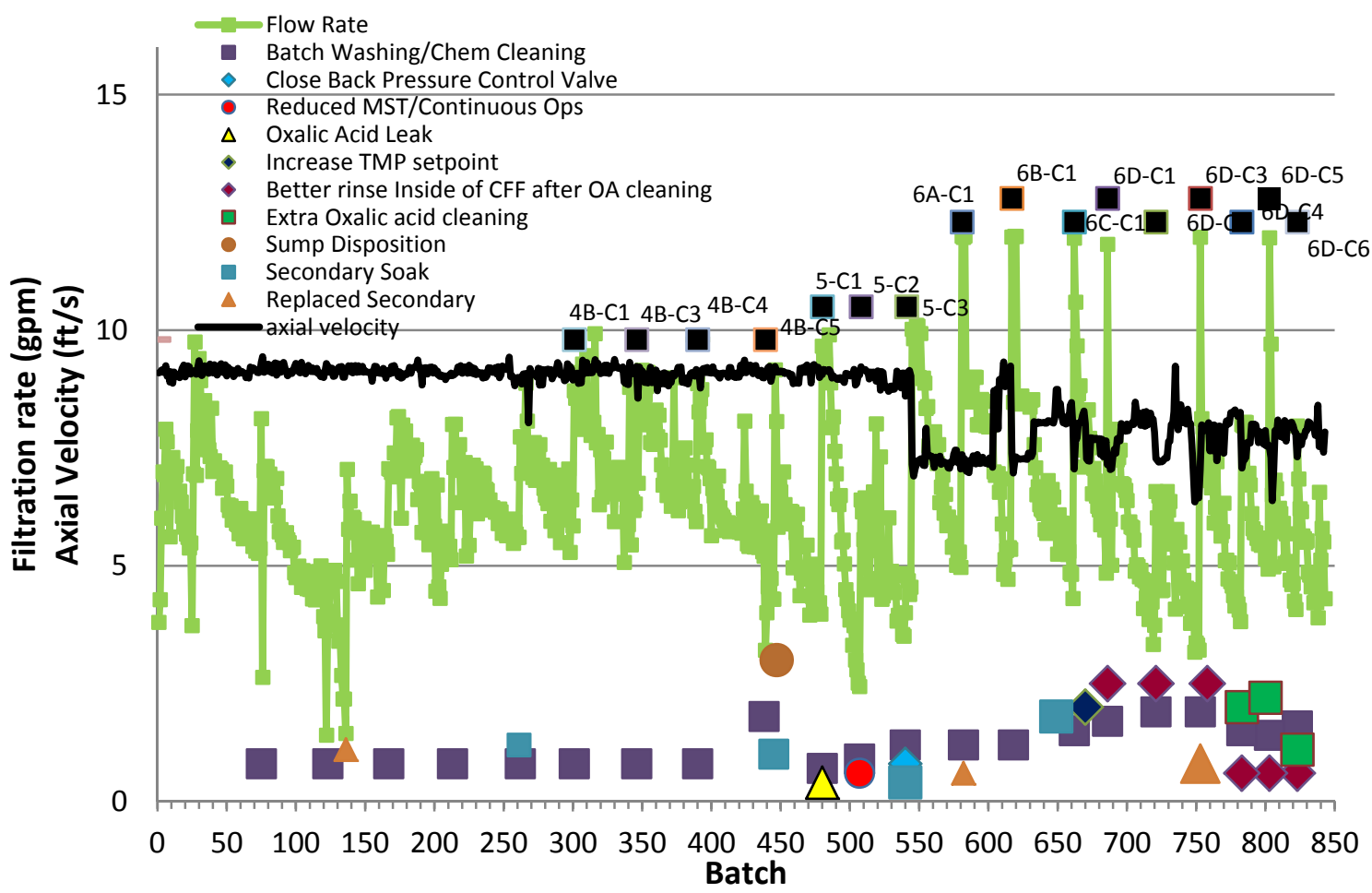

Figure 3-27. Axial Velocity and Filtration Rate

The initial batches have very high filtration rates most likely due to the increased TMP but are unable to sustain filtration rates from batch to batch. This is likely due in part to the low axial velocity. Testing completed by Parsons showed that the axial velocity had a large impact on filtration rate. ${ }^{17}$ Since the increase in TMP showed little positive impact in this system, it is recommended that the axial velocity be maintained as high as practical.

\subsubsection{Contribution of Secondary Filter Fouling to Filter Performance Degradation}

The secondary filter should ideally be transparent to the filtration rate. The secondary filter is constructed with a larger pore size $(0.5 \mu \mathrm{m}$ nominal versus $0.1 \mu \mathrm{m}$ nominal for the crossflow $)$ that is intended to allow any solids that passed the crossflow filter to pass the secondary filter. However, since the Mott ${ }^{\mathbb{R}}$ filters are rated nominally instead of as an absolute, some particles can pass the $0.1 \mu \mathrm{m}$ filter and be rejected by the $0.5 \mu \mathrm{m}$ filter.

Repeated high pressure drops across the secondary filter indicates repeated plugging. The plugging is likely due to three potential causes; passing of fines through the crossflow filter, precipitation of solids between the crossflow filter and the secondary filter, or passing of soft particles that deform through the pores of the crossflow filter. The secondary filter is a dead end filter that operates differently from a crossflow filter. Any material that is collected by the dead end filter has no opportunity to be removed and thus continues to collect on the filter media.

Note in Figure 3-25 that the total pressure drop across the system (i.e., the crossflow and secondary filter) is relatively constant for the first 500 batches, though the higher pressure drop changes between the two filters. The impact of the secondary filter is confirmed with the 
restoration of filtration rate or the drop in pressure across the crossflow filter required to sustain filtration when the secondary filter is either cleaned or replaced.

The performance of the crossflow filter, the secondary filter and the combined filter system was evaluated by comparing the permeability for each. Looking at the data in this way may give insight in filter performance if it is limited by the permeability, it will not indicate if other factors such as tangential velocity are limiting filter performance. By comparing permeability, the effect of TMP and filtration performance are tied together. Note that the permeability for the filter system used the media area of just the crossflow filter. While this is not exact, the intent is to see the impact of the individual filters across the whole filtration system. The plot is shown as Figure 3-28.
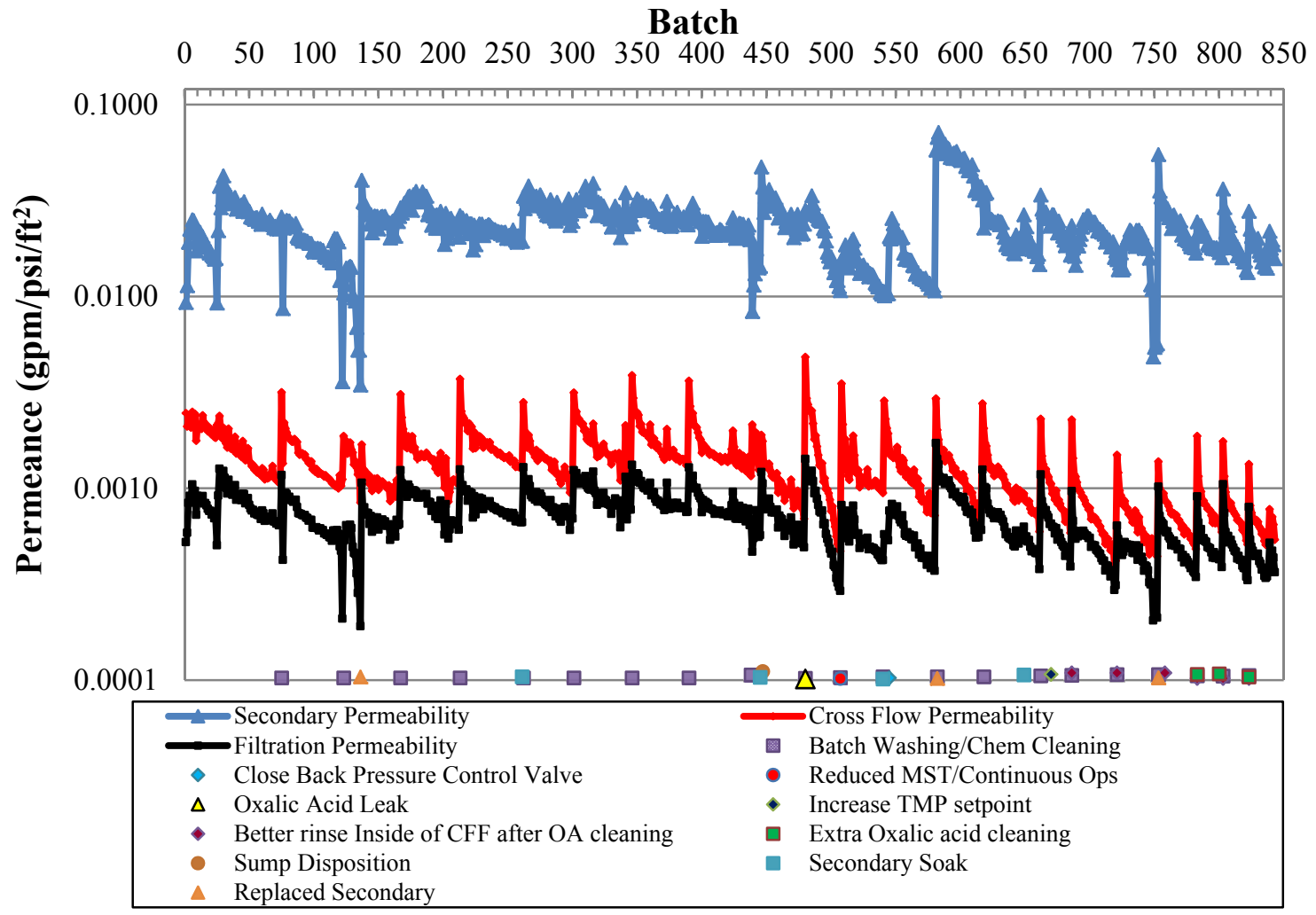

Figure 3-28. Permeability of the Crossflow Filter, Secondary Filter and Total Filter System

For the majority of the data, the crossflow filter drives the filter system performance. Several exceptions can be seen where the drop in permeability across the system corresponds to significant drops in the secondary filter permeability (batch numbers 25, 76, 122, 133-136, 439, and 749-752). Note system performance drops substantially but the drop corresponds to a drop secondary filter performance. The performance of the crossflow filter is relatively unchanged.

The filtration of SB5 cycle 1, where the oxalic acid leak occurred, resulted in an unrecovered decline in secondary filter perfomance (see yellow trangle at batch 480 [SB5 cycle 1] in Figure 3-28). The permeability did not recover after cleaning for the next two cycles. 
After the secondary filter replacement at SB6A batch 2, the system performance as measured by permeability was restored to historical levels performance such in SB4. There then appears to be a continuous decline in performance until a slight improvement is seen after the next secondary filter replacement at SB6D cycle 3. However, the improvement does not restore the overall system performance to historical performance such as the cycles of SB4.

In summary, the data clearly shows that in some instances the fouling of the secondary filter limited the system performance. Fouling of the secondary filter continues to be an issue but is not the primary reason for the decline in overall system performance.

\subsubsection{Contribution of Abnormal Operational Events to Filter Performance Degradation}

In August of 2012 approximately 520 gallons of oxalic acid leaked into the Surge Tank. This acid was transferred into the LWPT and neutralized with 50\% caustic. The surge tank was then flushed twice with 500 gallons of water. All of that water was transferred into the LWPT. An additional 2600 gallons of water were added to the LWPT and then it was transferred to the LPPP Pump Tank. An 870 gallon heel was left in the LWPT. Finally, 650 gallons of dilute caustic and 90 gallons of $50 \mathrm{wt} \%$ caustic were added to the LWPT heel to adjust the $\mathrm{OH}$ and $\mathrm{Na}$ concentrations.

It was expected that the majority of the solids that were formed as a result of the neutralization of oxalic acid were transferred out of the LWPT. The solids that remained behind in the 870 gallon heel processed with SB5 cycle 1. The caustic additions at the end could have played a role as well.

As mentioned previously, the filtration of SB5 cycle 1, where the oxalic acid leak occurred, resulted in an unrecovered decline in secondary filter perfomance.

In January of 2012 the sump level was above its maximum capacity. The contents of the sump were evaluated per the Tank Farm Waste Acceptance Criteria (WAC) and inspected for compatibility with process chemistry and equipment. ${ }^{18}$ A visual inspection was performed to confirm that lubricating oils or other foreign contaminants were not being transferred back into the tanks. The sump contained a small amount of oxalic acid, $\sim 200$ gallons of salt solution, and water. The sump contents were transferred to the surge tank. The volume of the sump before it was transferred was 253 gallons, the majority being salt solution that leaked out at the beginning of a previous batch.

The material was then pumped from the surge tank to the LWPT, and then the surge tank was flushed twice with dilute caustic. The flush water was also sent to the LWPT. Wash water $(0.01$ $\mathrm{M} \mathrm{OH}$ ) was added to the LWPT to make sure there would be enough level in the LWHT after filtration to start the LWHT transfer pump.

\subsubsection{Summary of Operational Evaluation}

The operational data provided was reviewed to determine if the cause of the drop in filter performance could be identified or isolated to a change in the method of filter operation or system event. Inspection of the data does not reveal a clear initiation in decline of filter. SB3 cycle 5 
through SB4 cycle 4 shows the most consistent performance. During that time period the only events noted with filter cleaning and a soak of the secondary filter. Multiple events occurred starting in SB4 cycle 5 and throughout SB5 and SB6 and have probably contributed to the inconsistent filter performance.

In some instances the secondary filter limited the performance of the filter system. Once the situation was remedied by either cleaning or replacement, system performance improved but the improvements were not sustained.

The parameter the appears to correspond with the drop in batch-to-batch performance is the drop in axial velocity. Due to system limitations, reduced axial velocity is encountered when the TMP is raised. This reduced axial velocity may couteract the desired effect of increasing the TMP on filter performance. The reduction in axial velocity appears to coincide with the drop in batch-tobatch performance. Secondary filter issues and operational events have contributed to reduced system performance in several instances, but does not explain the consistent drop in filter performance.

Evaluation of some of the individual batch data revealed different methods for starting and operating the filter. In some instances, the initial filtration flow rates were significantly higher than the typical performance for the filter. Filtration rate spikes were recorded in excess of 20 gpm. These high flow/high pressure spikes during start up have the potential to drive particulate deeper into the pores of the filter membrane where they are difficult to clean.

\subsection{Conclusions}

The following are the key results for sample analysis from the ARP process tanks and the salt feed tank, and from the subsequent modelling effort.

- At the time of sampling, the slurries in the ARP 512-S LWPT and LWHT are $6.6 \mathrm{M} \mathrm{Na}^{+}$, $2.2 \mathrm{M} \mathrm{OH}^{-}$, and $2.7 \mathrm{M} \mathrm{NO}_{3}^{-}$salt solutions with less than $1 \mathrm{wt} \%$ of insoluble solids. The soluble content in the pre-filtration slurry sample (LWPT-1), the post-filtration slurry sample (LWPT-2), the filtrate sample (LWHT-1), and the Salt Bach feed tank (Tank $49 \mathrm{H})$ matched for most analytes with the exception of oxalate.

- The insoluble solids contain primarily titanium and are consistent with the MST added during processing. Based on slurry analysis, the LWPT-1 and LWPT-2 samples have $0.19 \mathrm{wt} \%$ and $0.65 \mathrm{wt} \% \mathrm{MST}$, respectively.

- Sample analysis showed a reduction in the amount of soluble oxalate between Tank $49 \mathrm{H}$ and the ARP 512-S tanks. Sodium oxalate solids were identified in the precipitate tank samples LWPT-1 and LWPT-2. OLI modelling confirmed that sodium oxalate is significantly supersaturated in Tank $49 \mathrm{H}$ and throughout the ARP. There is a risk of precipitating sodium oxalate within ARP and in the downstream MCU process.

- Based on the quantity of iron in the solids, High-Level Waste sludge also appears to be present as a minor fraction of the solids in the ARP slurries, with sludge present at roughly $1 / 24^{\text {th }}$ the mass of MST present. 
- Due to a high concentration of soluble aluminum content of the samples causing analytical interference, there is no direct evidence of precipitated aluminum compounds from sample analysis. OLI modeling showed that aluminum is practically at saturation in Tank $49 \mathrm{H}$ and in ARP during filtration. With minor fluctuations in temperature or hydroxide concentration, there is a risk of precipitating aluminum hydroxide (gibbsite) solids during processing.

- A small quantity of sodium aluminosilicate may also be present in the insoluble solids. OLI modeling showed that silicon is supersaturated in Tank $49 \mathrm{H}$ relative to sodium aluminosilicate (cancrinite). Silicon was present in the unwashed solids isolated from all LWPT samples.

- There is little difference between the chemical results for the samples taken at three different levels in Tank $49 \mathrm{H}$. This good agreement in composition confirms the homogeneity of the soluble components within the feed to the ARP.

- Sample LWPT-3, pH adjusted material from after cleaning of the crossflow filter with oxalic acid, differed significantly from the other ARP 512-S samples. Hydroxide concentration remained high, but most other salt components were diluted approximately 20 -times from the process values. The total salt content of LWPT-3 is consistent with the corresponding simulation stream results, but the sample salt to hydroxide ratio is several times higher than the simulation results. This suggests that more salt is retained in the cross-flow filter/tanks than expected.

- The ARP 512-S slurries exhibited Newtonian flow behavior, with a filtrate viscosity of $3.9 \mathrm{cP}$ and a post-filtration slurry viscosity of $5.5 \mathrm{cP}$ at $25{ }^{\circ} \mathrm{C}$. Flow behavior observed for the samples would not appear to challenge the filtration system outside of the expected salt feeds.

Filter performance over the last several Salt Batches has been relatively constant, producing an average of approximately 6.1 gpm over the last 4 Salt Batches. However, starting in Salt Batch 5 and continuing through the most recent batch (Salt Batch 6D), filter performance has shown a more rapid decline and more frequent cleaning of the filters was performed. A review of the filtration performance data resulted in the following observations.

- There have been multiple changes to the operation of the filtration system. Many of these changes occurred at the same time or in close succession, making it difficult to determine the impact to the filtration system of the individual events. Most of the changes that were expected to increase filtration performance did not have the desired impact. Many of the parameters are interdependent and may have counteracting results.

- It is important to maintain a high axial velocity. A drop in the axial velocity appears to corellate with the inability to sustain an acceptable filtration rate through at least 40 batches. Due to system limitations, reduced axial velocity is encountered when the TMP is raised. This reduced axial velocity may counteract the short-term beneficial effect on filter performance of increasing the TMP.

- The current behavior of the filtration system is consistent with the behavior expected while filtering fines. The amount of fines in the MST varies batch to batch, ranging from 
$1.7 \mathrm{wt} \%$ to $7.8 \mathrm{wt} \%$. No data has been found to correlate the amount of fines per batch of MST with the filtration performance of the 512-S system.

- The secondary filter has limited the performance of the overall filtration system on many occasions. Ideally, the secondary filter would be transparent to the system. However, data has shown that the secondary filter has often become fouled and limits the overall filtration system performance, requiring either cleaning or replacement of the secondary filter. While the secondary filter has limited performance, it has not typically been the cause of the decline in the number of filter batches per cycle.

\subsection{Recommendations}

The analysis of the filtration data, in concert with sample analysis, indicates multiple factors impacting filtration. Several steps can be taken that may provide a consistent improvement to filtration rate.

Limit the amount of fines sent to the crossflow filter. Use the previous specification for MST, with less than $1 \mathrm{vol} \%$ of fines less than $1 \mu \mathrm{m}$. Minimization of fines would reduce the amount of deep pore fouling. The definition of what would be considered as fines is a function of the pore size. ${ }^{19}$ Collect data on the MST batches to determine if there is a relationship between the amount of fines in the MST and the filter performance.

Investigate the removal, redesign, or relocation of the secondary filter. The secondary filter should act as a guard filter and should ideally be transparent to the process (i.e., have small to no pressure drop across secondary filter). Filtration within ARP has had periods where the secondary filter limited the overall filtration performance. In absence of removal of the secondary filter, consider redesign of the filter, including potential changes to configuration (pleated filter instead of tubes), media pore size, and media area.

Given the shift in the salt processing flowsheet (e.g., increased free hydroxide, more concentrated salt solutions, and lower MST concentrations), lab scale tests are needed to define a reliable baseline for filter performance expectations. Tests should be performed with small scale filters (such as the cells unit filter, CUF) to duplicate the current method of operation and to understand filter performance more fully. This testing should show relative effect of changes in parameters, including the following:

- MST (percent fines, solids concentration, inclusion of sludge, etc.)

- Sludge (presence and absence)

- Filter pore size $(0.1 \mu \mathrm{m}$ and $0.5 \mu \mathrm{m})$

- Soluble phase composition (sodium concentration, hydroxide concentration)

- Start-up process filtration impacts (TMP, axial velocity, etc. during filter start-up)

- Methods for restoring filter performance during processing (scouring and backpulsing)

- Agitation in the feed tank (with and without)

- Filter cleaning optimization (acid, time, heel mixing, returning to feed)

- Investigate impact of precipitates (sodium oxalate)

- Other operational parameters

Filtration rates should be limited at the startup to 8 or $9 \mathrm{gpm}$ at the lowest required TMP. The process of running initial batches at very high filtration rates may have a significant impact on sustained filter production. 
Recent testing has demonstrated axial velocity can have a significant impact on filtering MST. ${ }^{17}$ From the ARP data, the axial velocity appears to have a greater impact on extending the number of batches processed per cycle than the short-term benefit obtained in filtration rate by increasing the TMP. Test and develop a redesigned system to increase routine operations at axial velocities up to $15 \mathrm{ft} / \mathrm{s}$.

Additional benefit may be realized by scouring the filter membranes through maximizing the axial velocity with minimal TMP. This may best be applied by scouring the filter at the end of the batch to prepare the filter for the following batch.

Adjustments to the filter cleaning process should be investigated. Assure that the filter is adequately flushed after cleaning with oxalic acid to avoid precipitation of sodium oxalate. Nitric acid cleaning should be considered as a replacement cleaning method if testing shows significant advantages.

Currently, no testing is performed during qualification of a salt batch that evaluates operation of the feed during filtration. Since 512-S filtering often limits salt processing, filtration testing should be performed in the salt batch preparation process. Filtration testing may provide indications of potential filtration issues before they are experienced in the 512-S facility. The testing may also assist in developing more effective cleaning strategies.

\subsection{Quality Assurance}

Data are recorded in the SRNL electronic laboratory notebook system as experiments A658300032-34, A6583-00032-36, A6583-00032-38, A6583-00032-41 and A4571-00084-01. This report received a technical review by means of Design Check. Requirements for performing reviews of technical reports and the extent of review are established in manual E7 2.60. SRNL documents the extent and type of review using the SRNL Technical Report Design Checklist contained in WSRC-IM-2002-00011, Rev. 2.

\subsection{References}

${ }^{1}$ W.R. Wilmarth, S.R. Bush, S.E. Campbell, H.D. Harmon, D.T. Hobbs, V. Jain, C.A. Nash, Q.L. Nguyen, J.A. Pike, C.B. Sherburne, S.C. Smith and K.M.L. Taylor-Pashow, "Salt Integrated Project Chemistry Team Report," SRNL-STI-2013-00354/SRR-STI-2013-00375, Rev. 0, June 2013.

2 T.L. Fellinger, "Sample Analysis for the LWPT and LWHT at 512-S," X-TTR-S-00007, Rev. 0, August 20, 2013.

${ }^{3}$ Q.L. Nguyen, "Provide Analysis for Tank 49 Variable Depth Samples,” X-TTR-H-00029, Rev. 0, August 22, 2013.

${ }^{4}$ C.J. Martino, "Task Technical and Quality Assurance Plan for Analysis of Late Wash Precipitate Tank (LWPT) and Late Wash Hold Tank (LWHT) Samples," SRNL-RP-201300525, Rev. 0, September 5, 2013. 
${ }^{5}$ T.B. Peters, A.L. Washington, II, and F.F. Fondeur, "Task Technical and Quality Assurance Plan for Routine Samples in Support of ARP and MCU," SRNL-RP-2013-00536, Rev. 0, September 12, 2013.

${ }^{6}$ e-mail communication from Stephen Smith, November 13, 2013.

${ }^{7}$ C.L. Crawford and C.J. Bannochie, "Initial Characterization of the PRFT Sample from DWPF," SRNL-L3100-2013-00144, Rev. 1, August 21, 2013.

${ }^{8}$ C.A. Nash, M.R. Duignan, and M. R. Poirier, "Operational Consideration for the 512-S Crossflow Filter used for ARP," SRNL-L3100-2013-00065, Rev.0, May 2013.

${ }^{9}$ M.R. Poirier and S.D. Fink, "Alpha Removal Process Filter Cleaning Recommendations," WSRC-TR-2003-00299, July 2003.

${ }^{10}$ T.B. Peters, F.F. Fondeur, and S.D. Fink, "Results from analysis of Actinide Removal Process Guard Filter," SRNL-STI-2009-00456, Rev. 1, January 27, 2010.

${ }^{11}$ D.C. Koopman, "Rheology Protocols for DWPF Samples," WSRC-RP-2004-00470, Rev. 0, October 4, 2004.

${ }^{12}$ T.B. Peters and S.D. Fink, "Sample Results from the Interim Salt Disposition Program Macrobatch 6 Tank 21H Qualification Samples", SRNL-STI-2012-00707, Rev. 0, December 2012.

${ }^{13}$ H.H. Saito, M.R. Poirier, and J.L. Siler, "Effect of Sludge Solids to Mono-sodium Titanate (MST) Ratio on MST-Treated Sludge Slurry Cross-Flow Filtration Rates," WSRC-TR-9900342, Rev. 0, September 15, 1999.

14 J.A. Pike, "OLI ESPTM V.9.1.2 Simulation Listing for ARP Process Cycle," SRNL-L42202014-00007, May 21, 2014.

${ }^{15}$ D.T. Hobbs, D.T. Herman, M.R. Poirier, "Decontamination Factors and Filtration Flux Impact to ARP at Reduced MST Concentration", SRNL-STI-2012-00299, Rev. 0, June 2012.

${ }^{16}$ R.J. Wakeman, "Fouling in Crossflow Ultra- and Micro-Filtration," Membrane Technology, Vol: 1996, Issue: 70, pp. 5-8, 1996.

${ }^{17}$ Salt Waste Processing Facility Project, Test Report: Cross-flow Filtration System Full-Scale Test, P-RPT-J-00007, Rev. 0, December 21, 2007.

${ }^{18}$ A. R. Shafer, C. K. Chiu, J. W. Ray, J. E. Occhipinti, "Engineering Position: Acceptability of 512-S Sump Disposition for Transfer to Tank 50," SRR-WSE-2012-00010, January 9, 2012.

${ }^{19}$ E.S. Tarleton and R.J. Wakeman, "Understanding Flux Decline in Crossflow Microfiltration: Part I - Effects of Particle and Pore Size," Trans IChemE, v71, part A, July 1993, pp. 399-410. 
Appendix A. Rheology Measurements of 512-S Samples
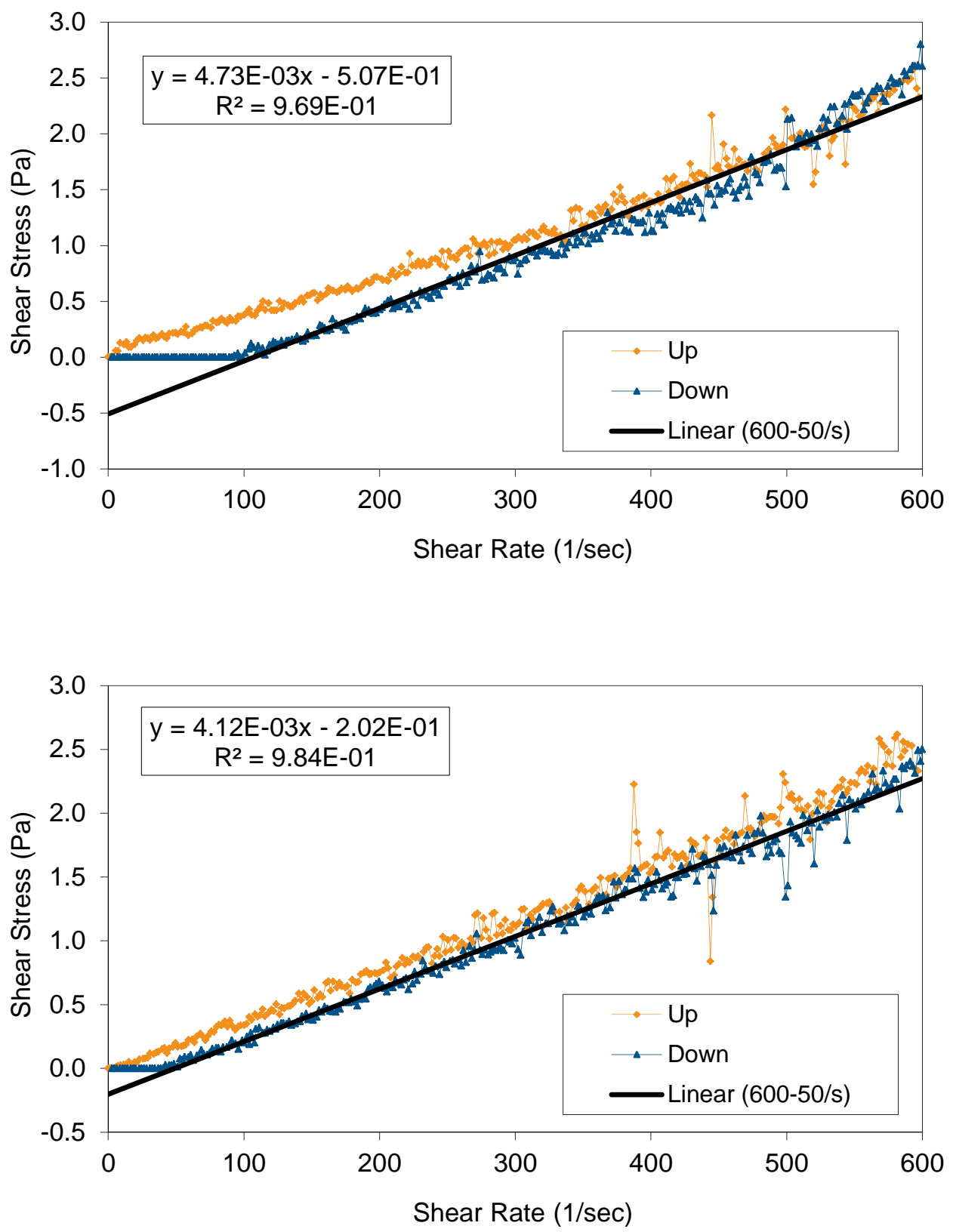

Figure A-1. Flow curves for successive measurements of LWPT-1 

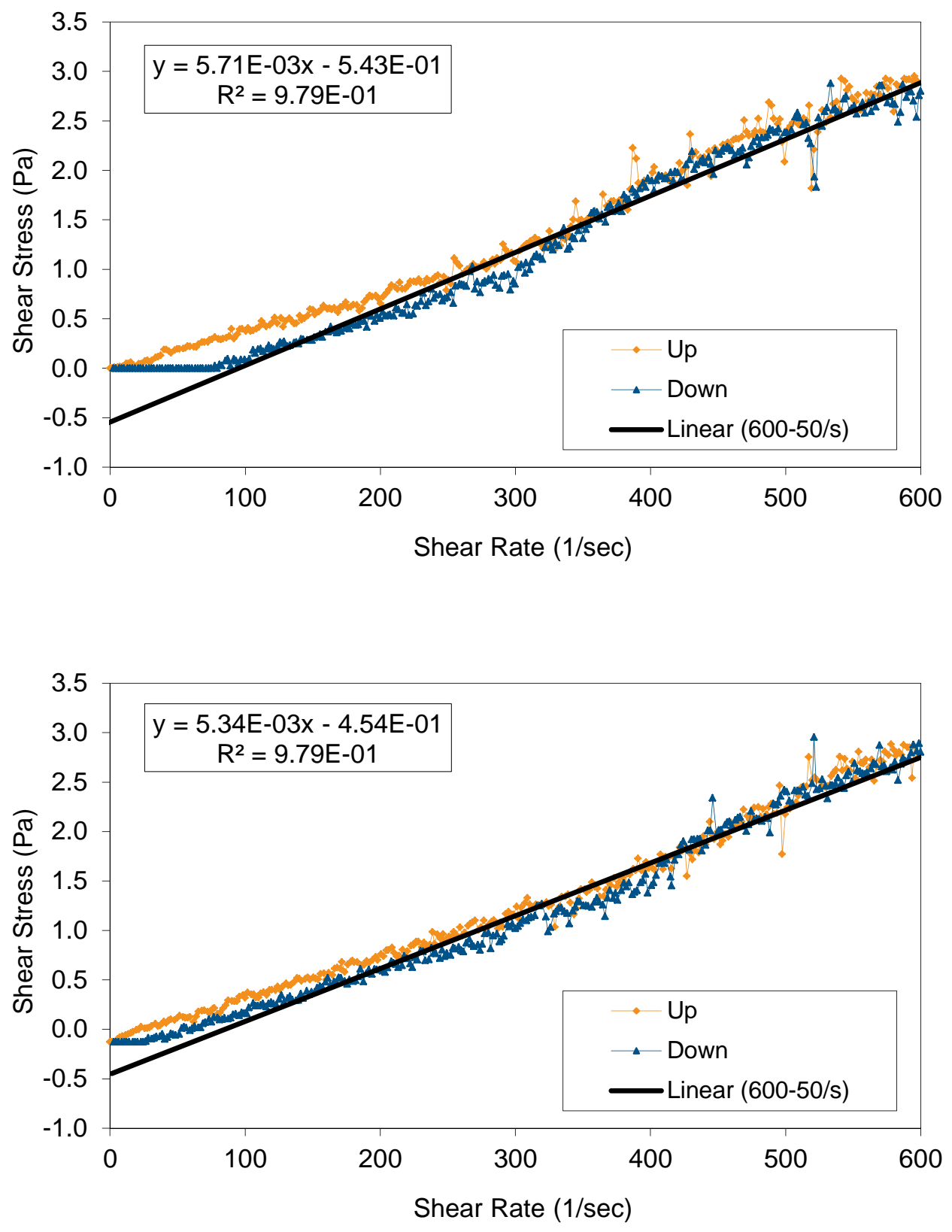

Figure A-2. Flow curves for successive measurements of LWPT-2 

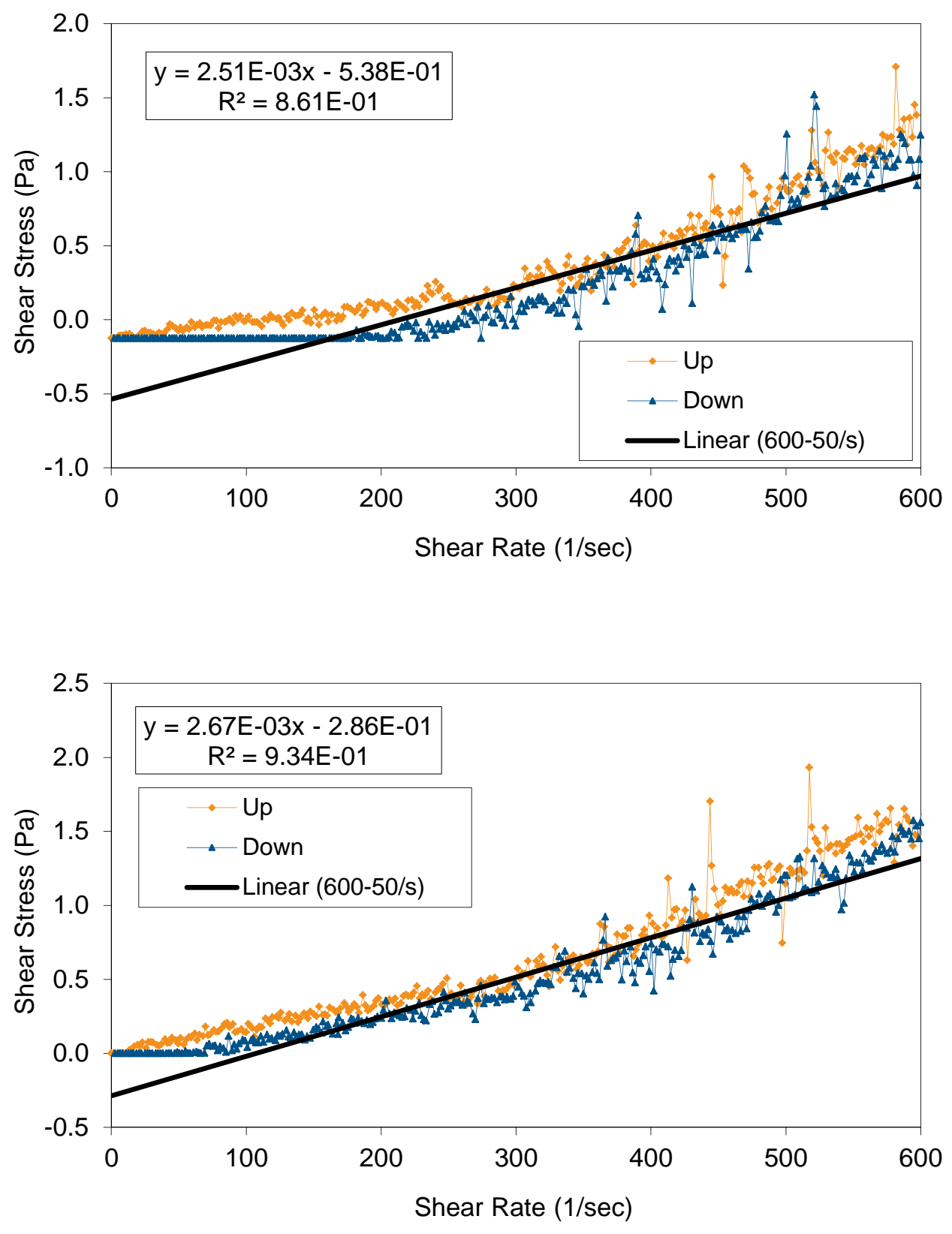

Figure A-3. Flow curves for successive measurements of LWPT-3 

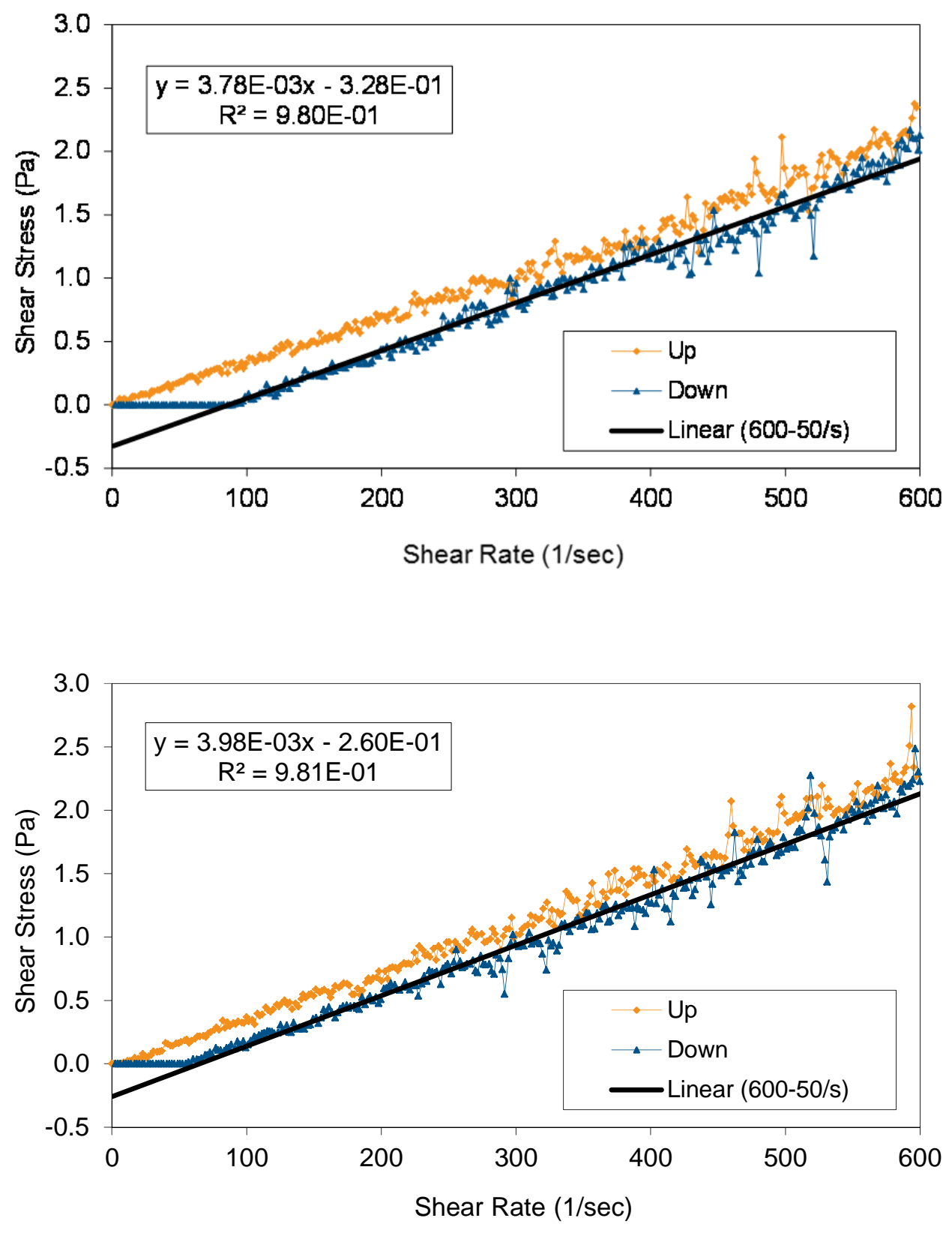

Figure A-4. Flow curves for successive measurements of LWHT-1 
SRNL-STI-2013-00700

Revision 0

Appendix B. Particle Size Distribution Measurements of LWPT Samples

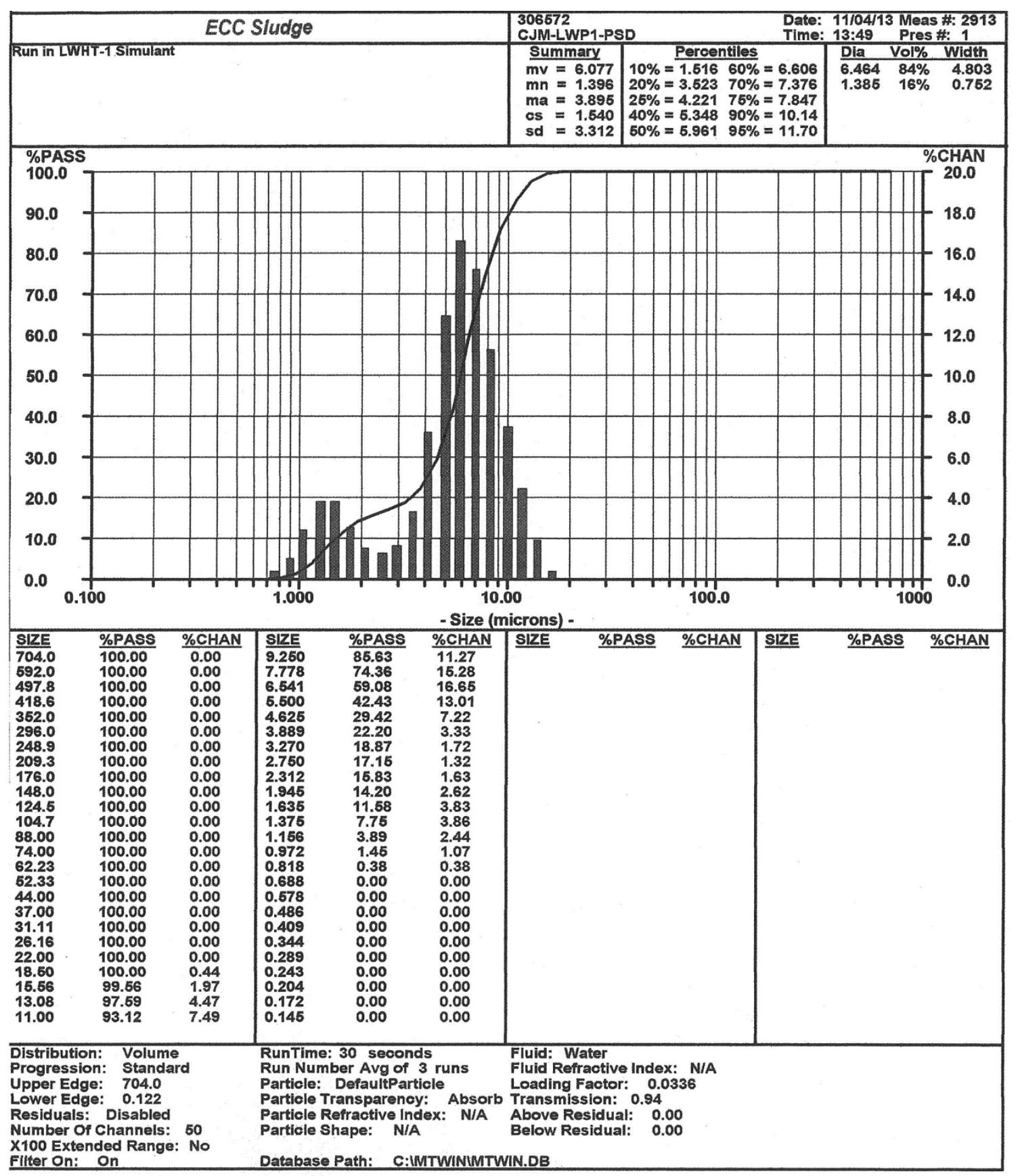

Figure B-1. LWPT-1 particle size volume distribution measured in salt simulant 
SRNL-STI-2013-00700

Revision 0

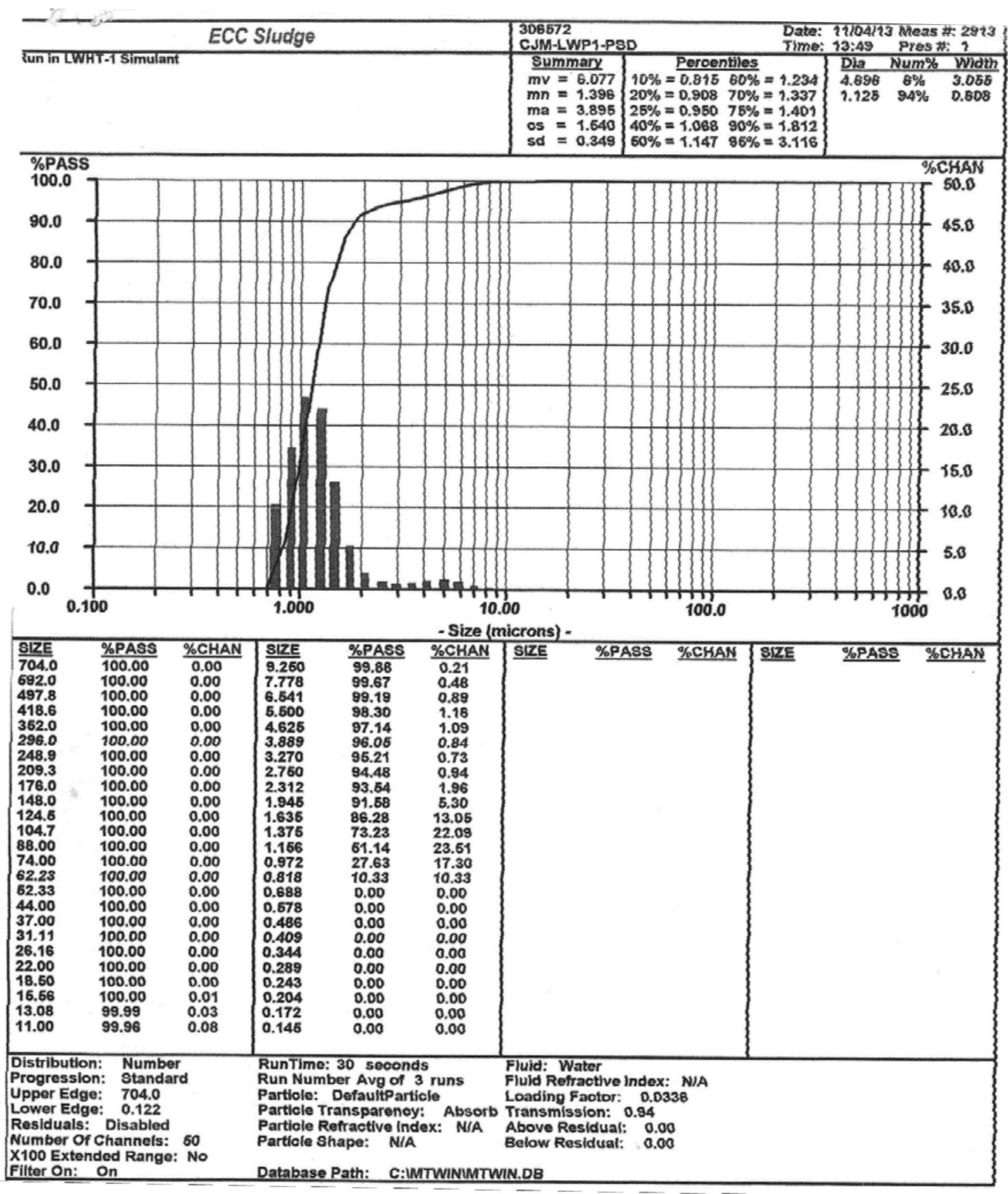

Figure B-2. LWPT-1 particle size number distribution measured in salt simulant 


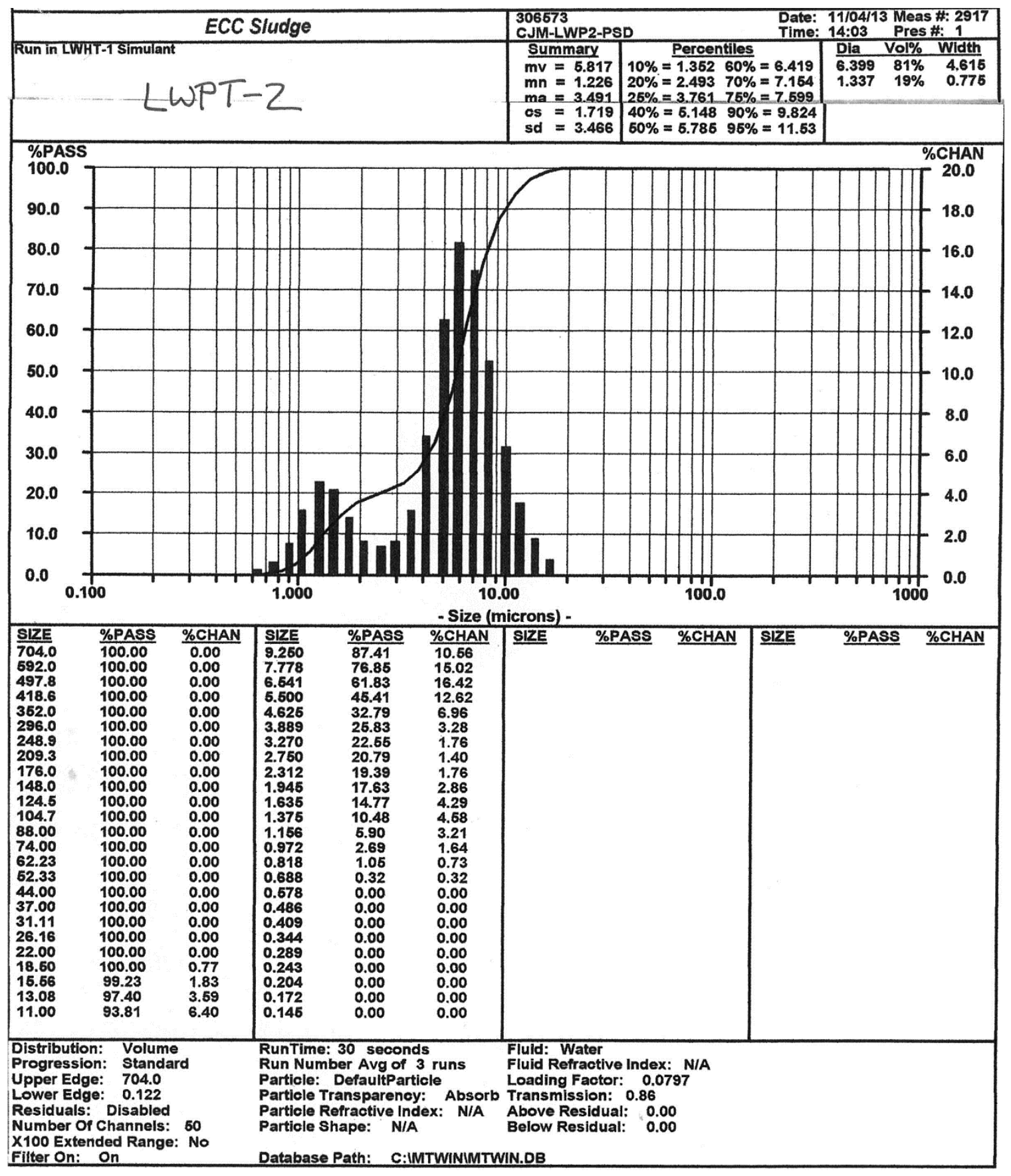

Figure B-3. LWPT-2 particle size volume distribution measured in salt simulant 
SRNL-STI-2013-00700

Revision 0

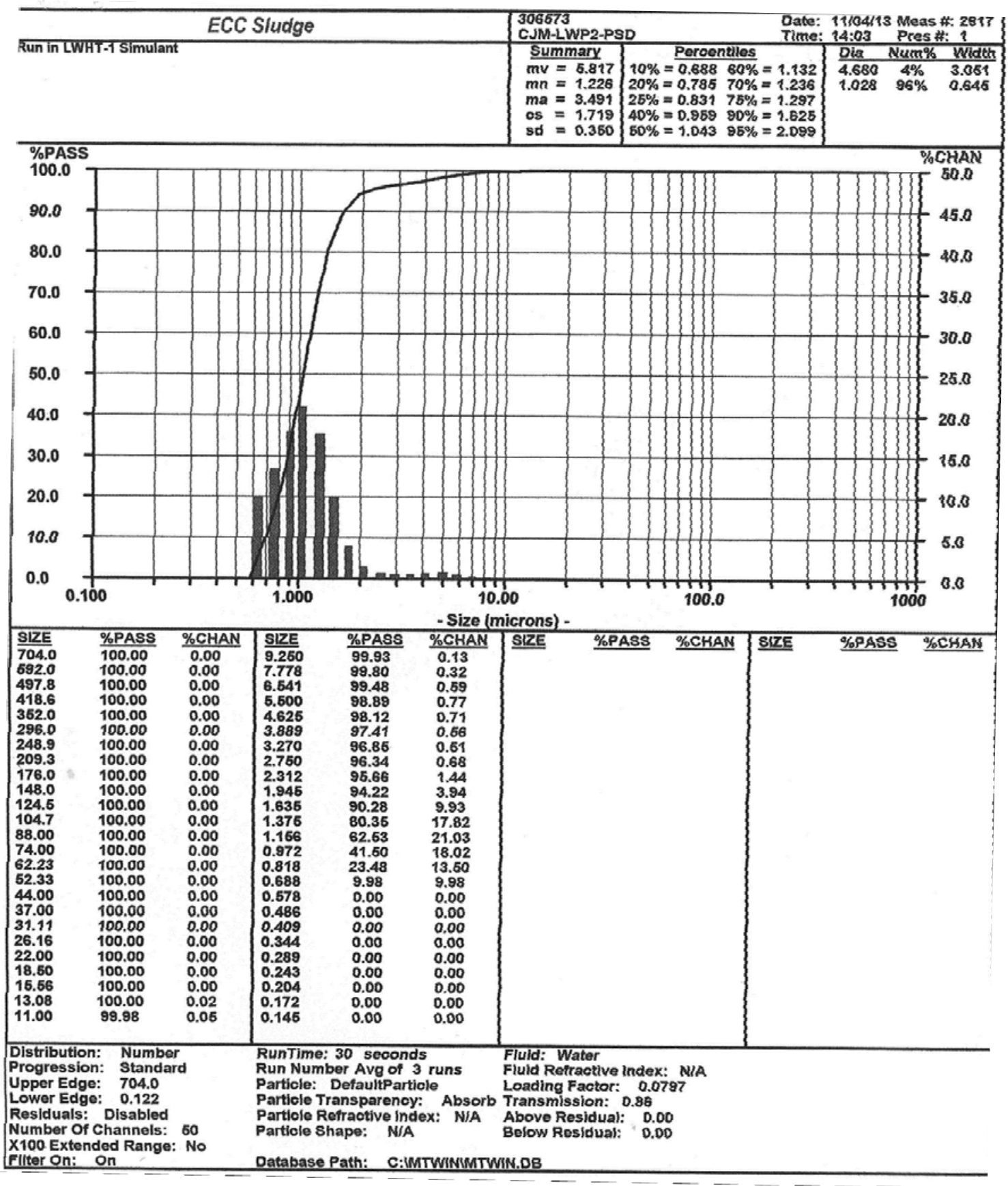

Figure B-4. LWPT-2 particle size number distribution measured in salt simulant 
SRNL-STI-2013-00700

Revision 0

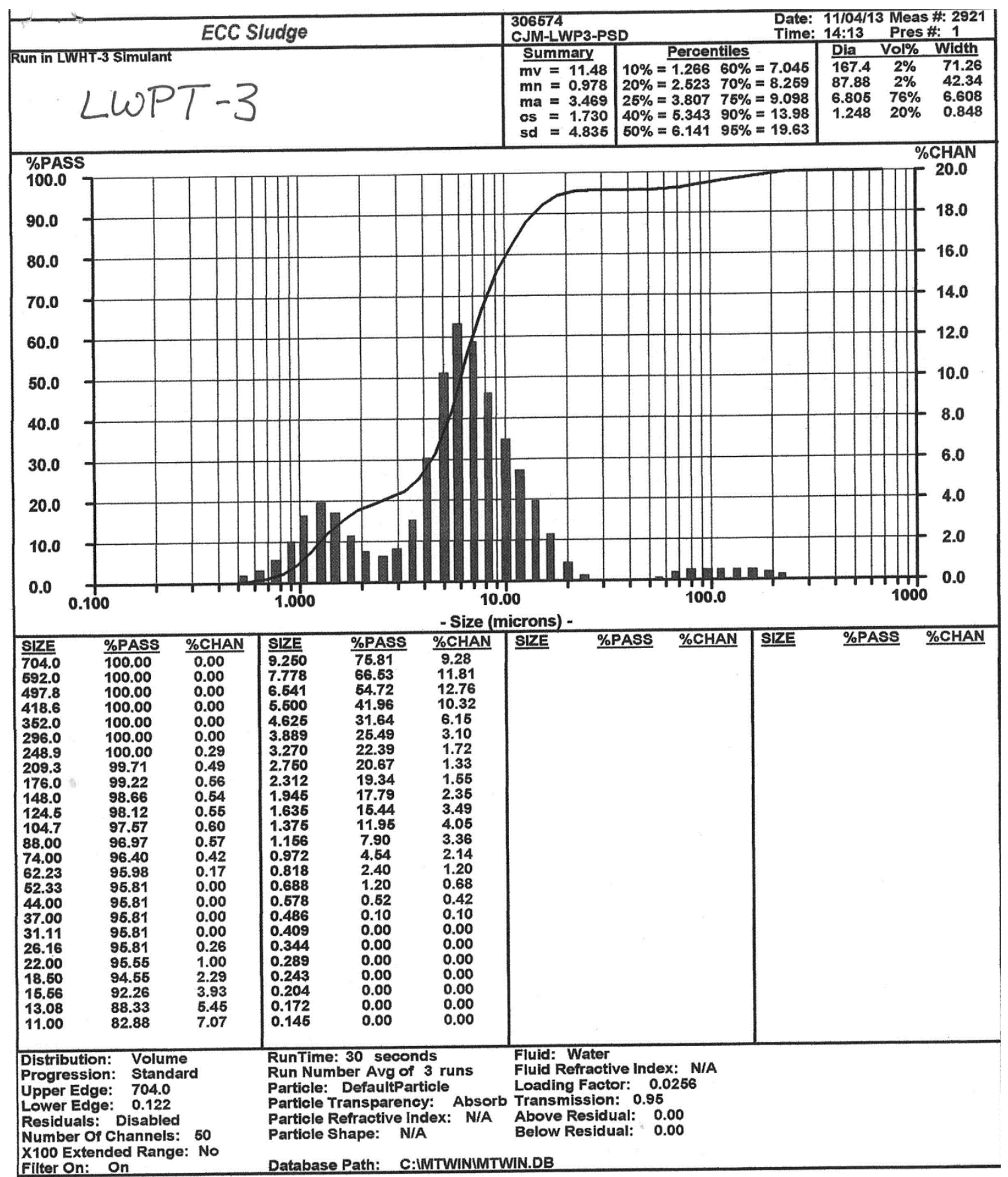

Figure B-5. LWPT-3 particle size volume distribution measured in salt simulant 
SRNL-STI-2013-00700

Revision 0

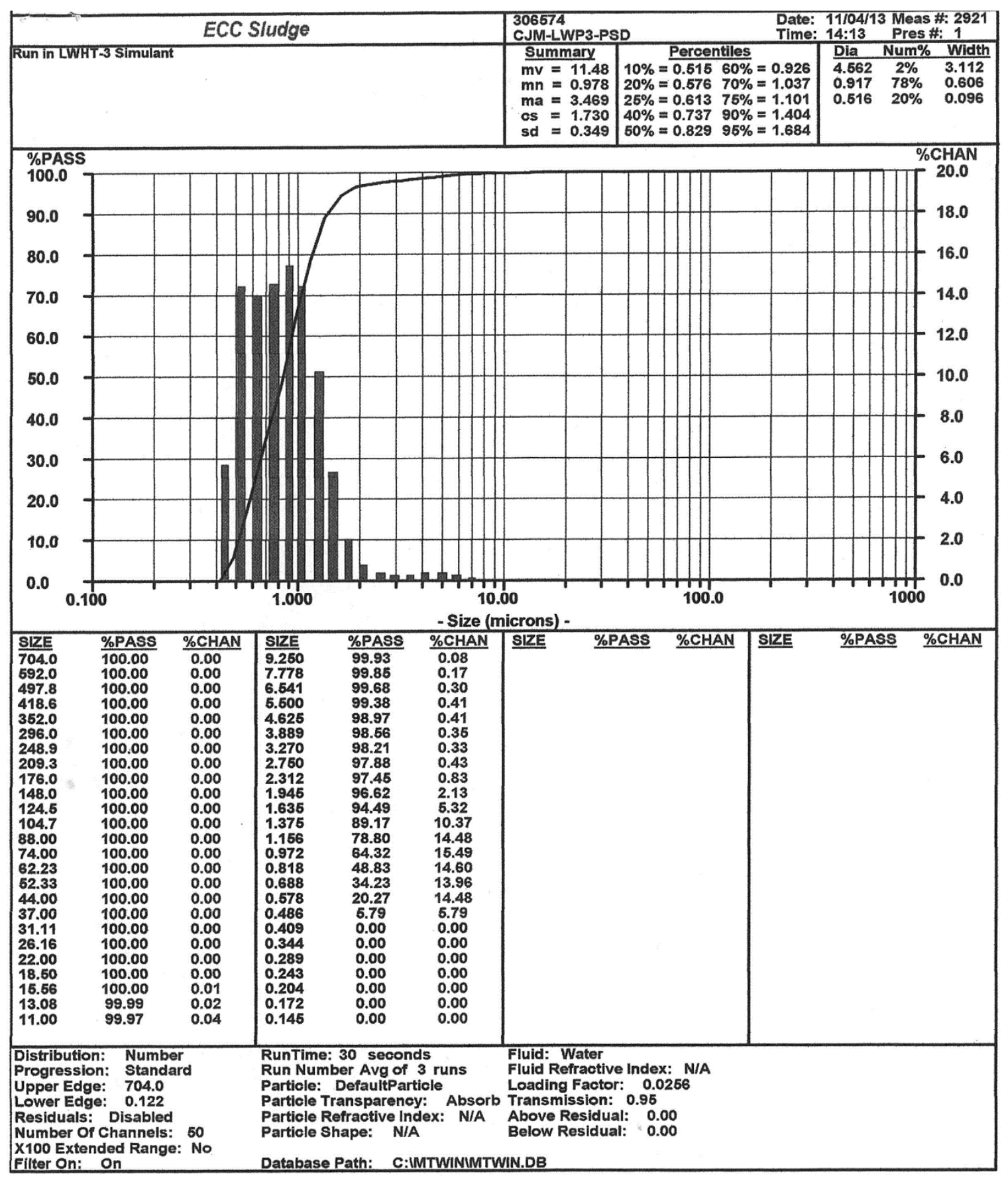

Figure B-6. LWPT-3 particle size number distribution measured in salt simulant 


\section{Appendix C. SEM of Solids Isolated from LWPT Samples}
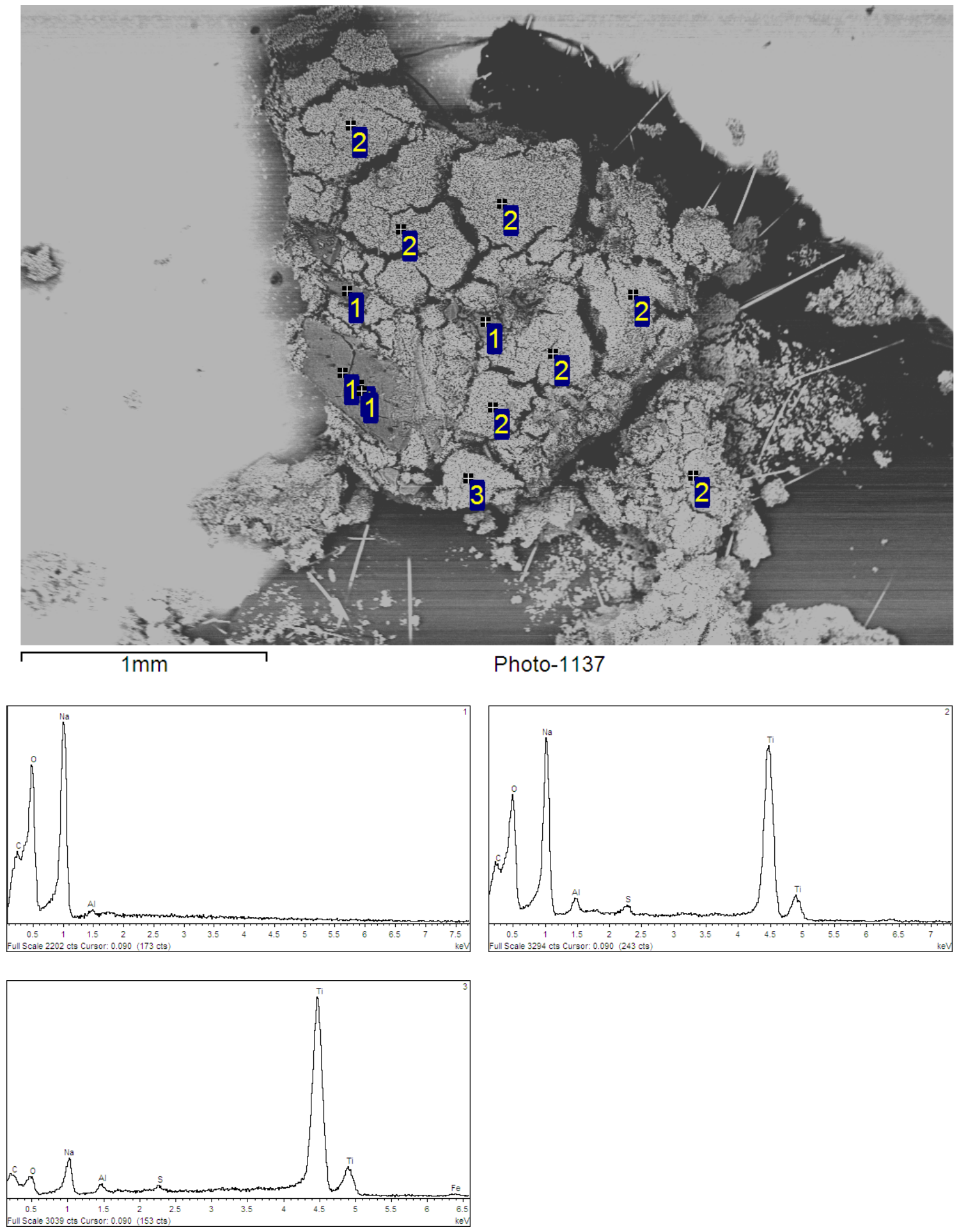

Figure C-1. SEM and EDS for LWPT-1 unwashed solids 

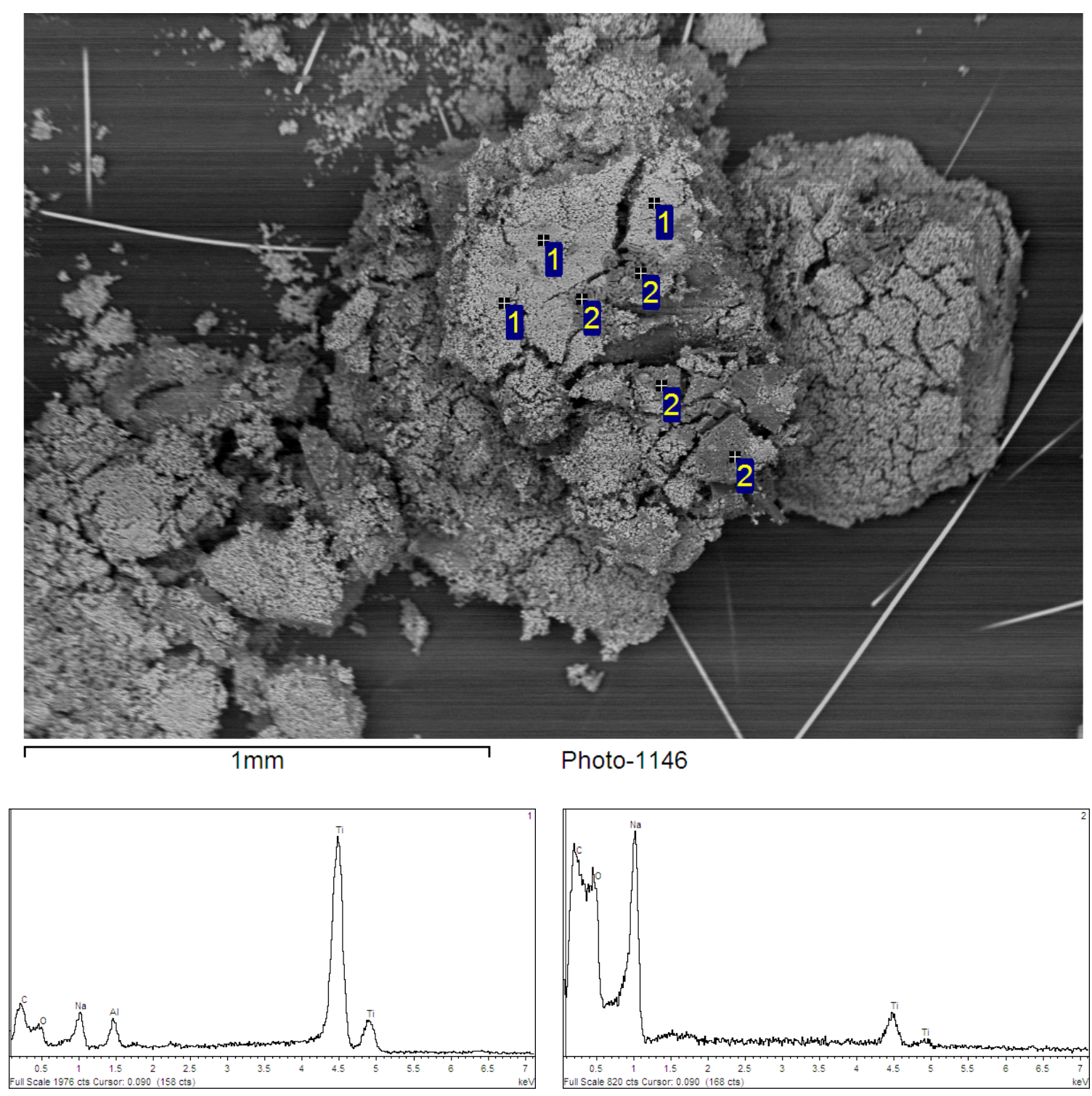

Figure C-2. SEM and EDS for LWPT-1 unwashed solids 

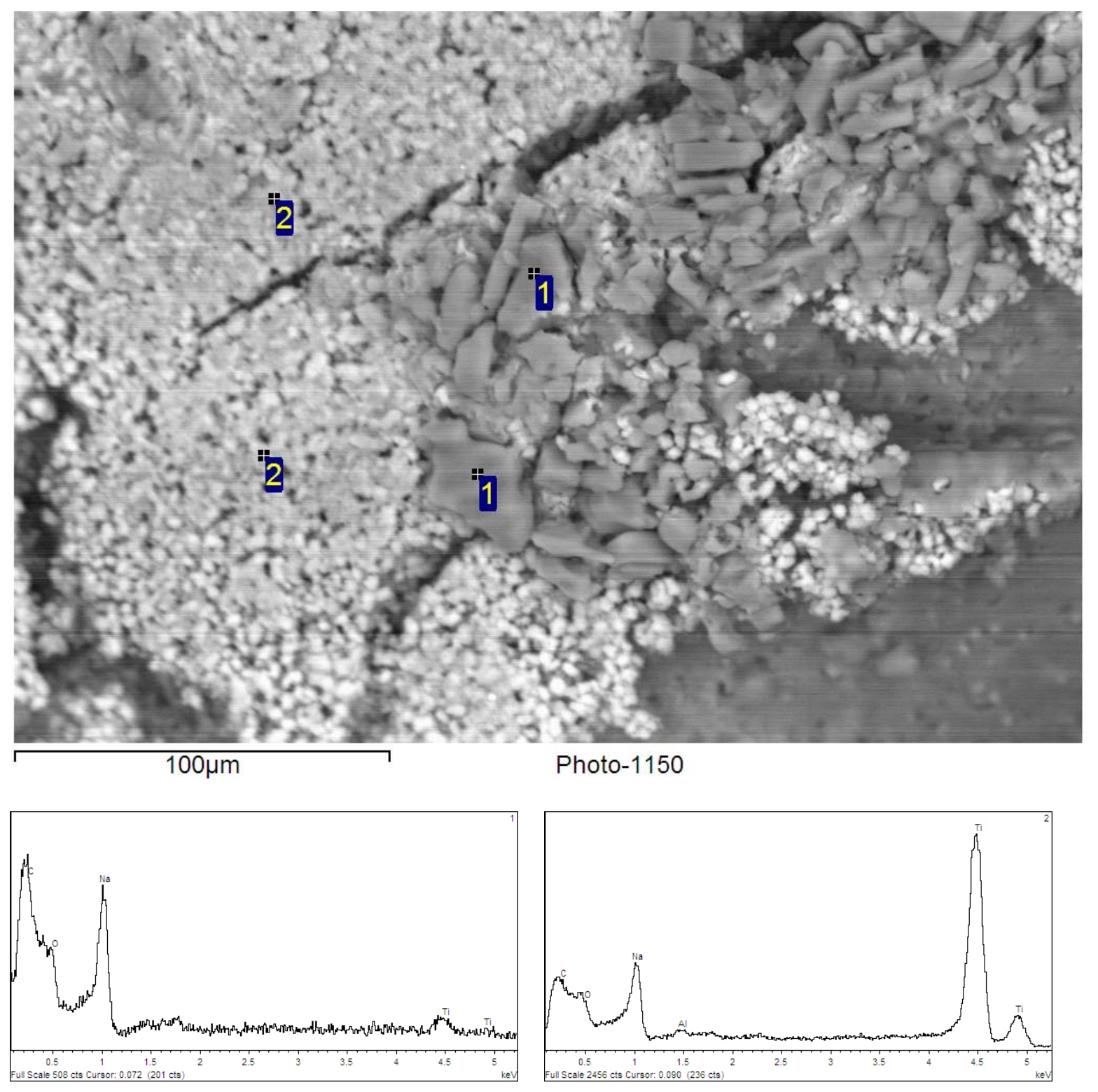

Figure C-3. SEM and EDS for LWPT-1 unwashed solids 

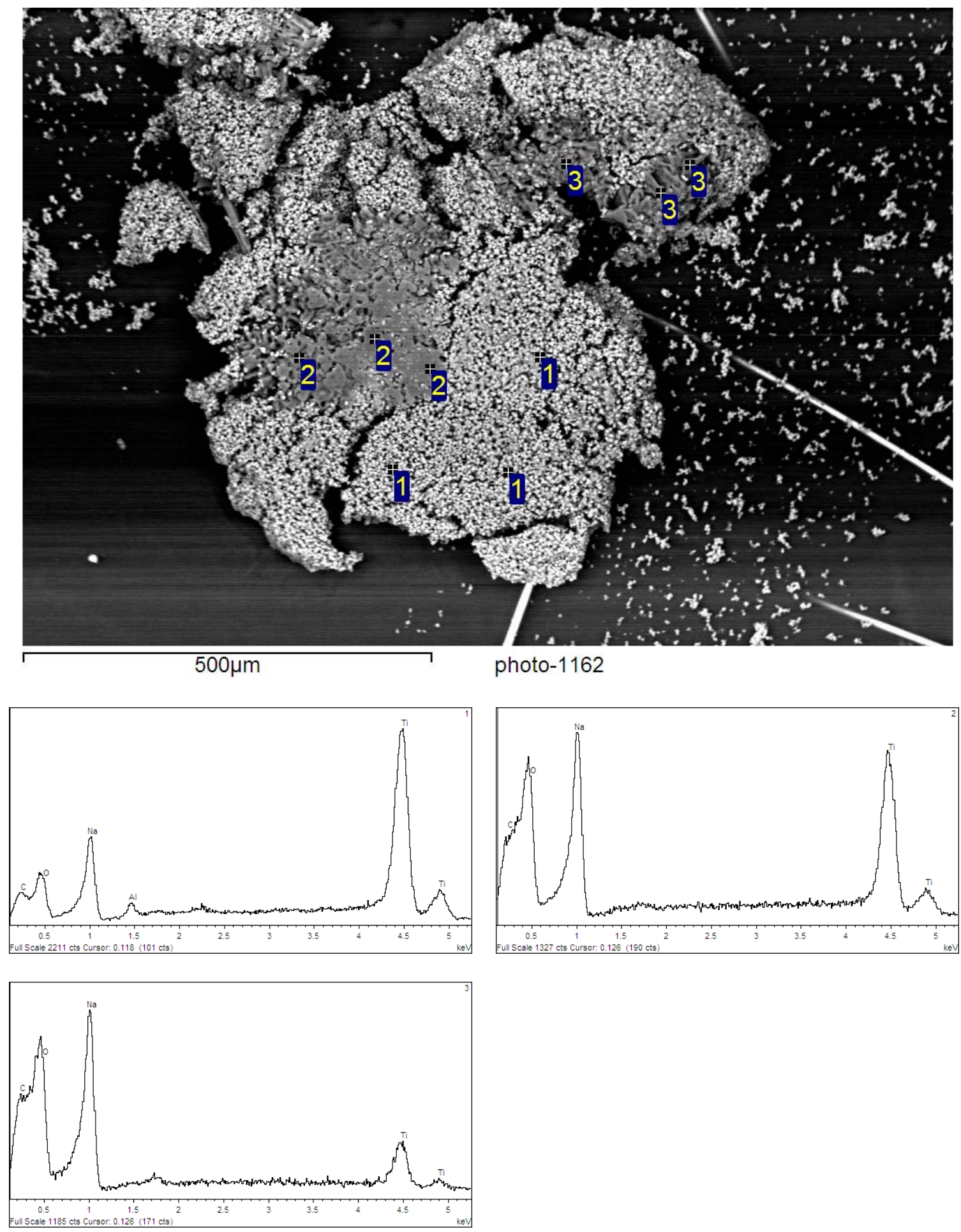

Figure C-4. SEM and EDS for LWPT-2 unwashed solids 

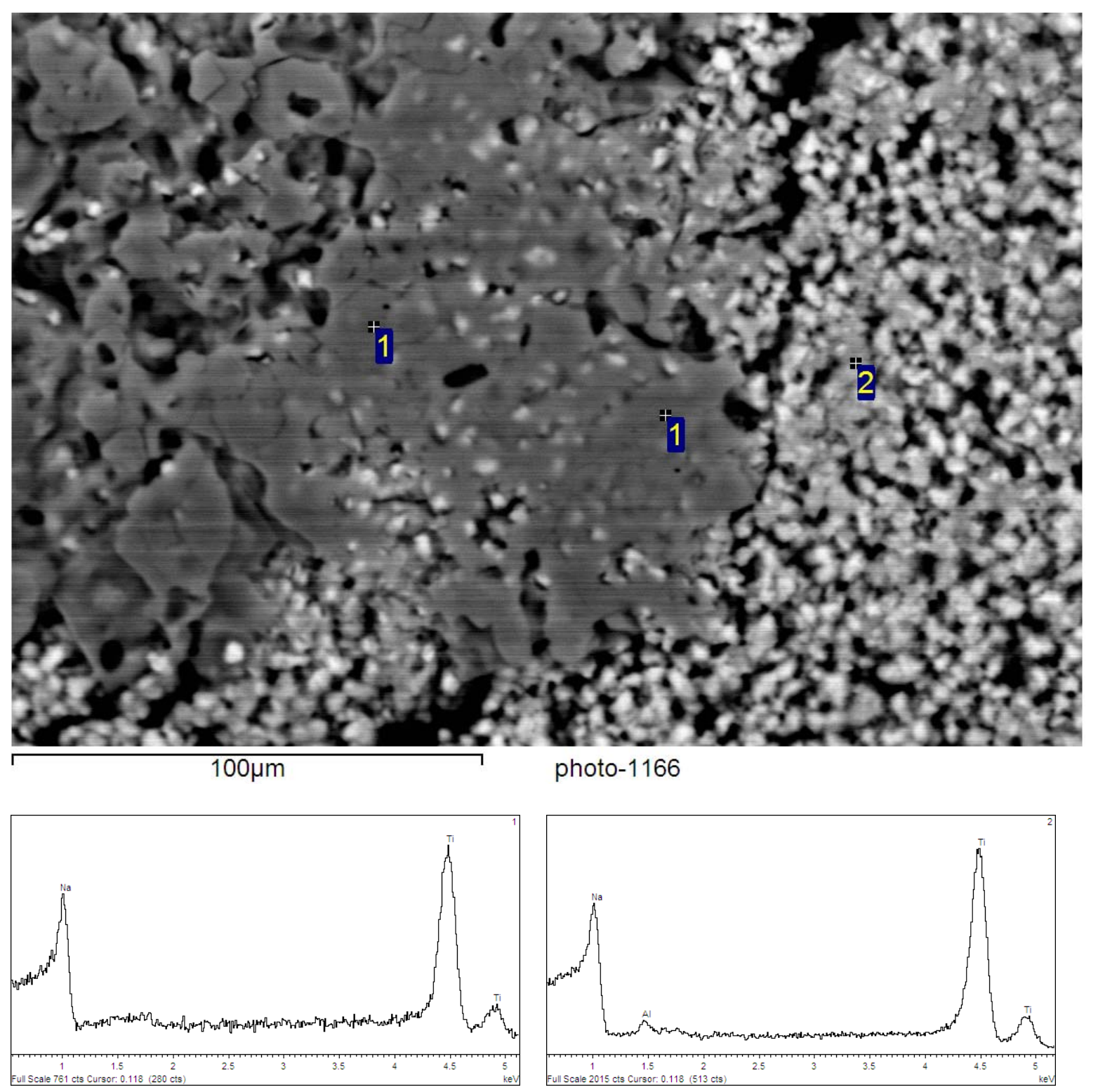

Figure C-5. SEM and EDS for LWPT-2 unwashed solids 

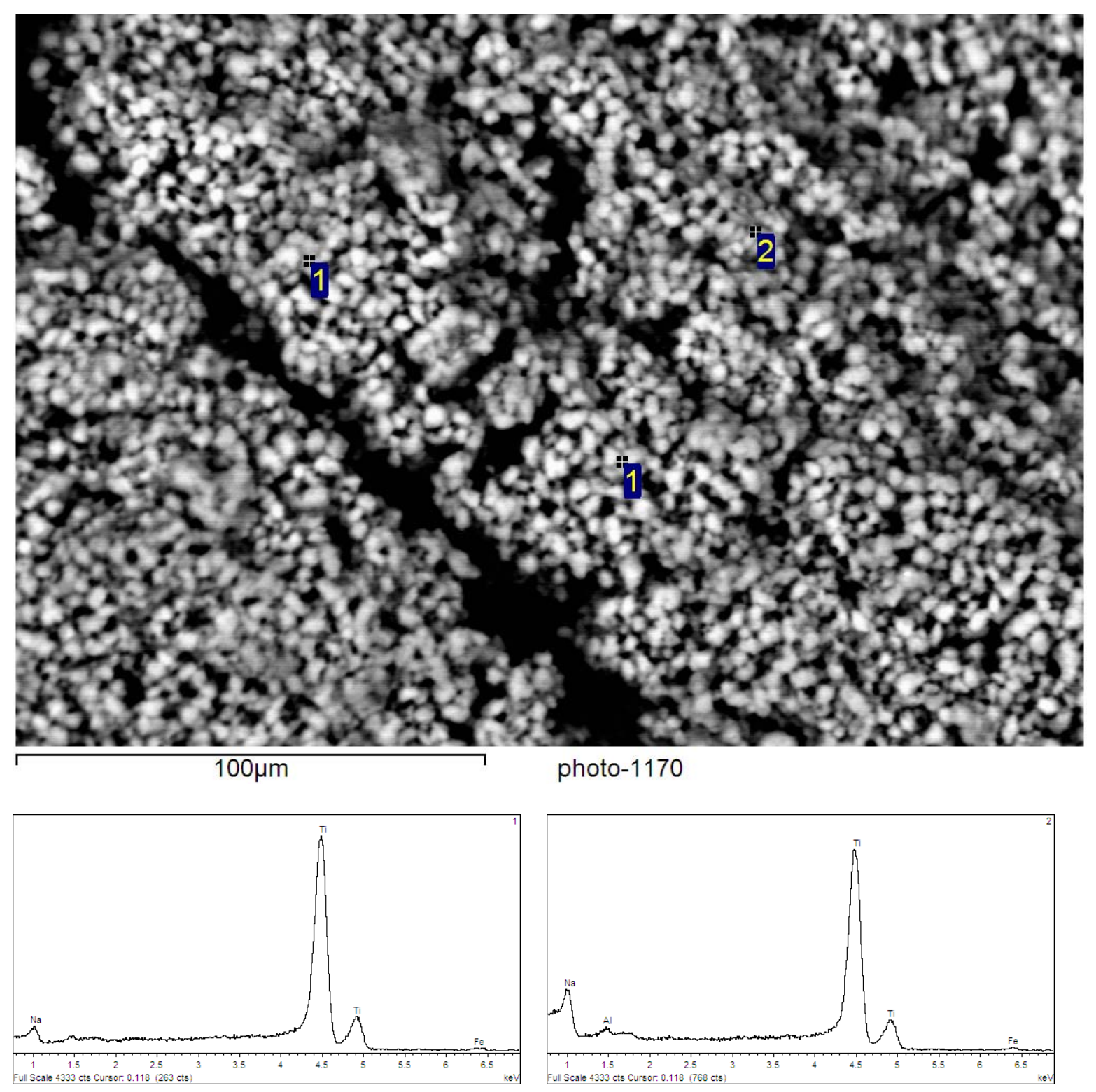

Figure C-6. SEM and EDS for LWPT-2 unwashed solids 

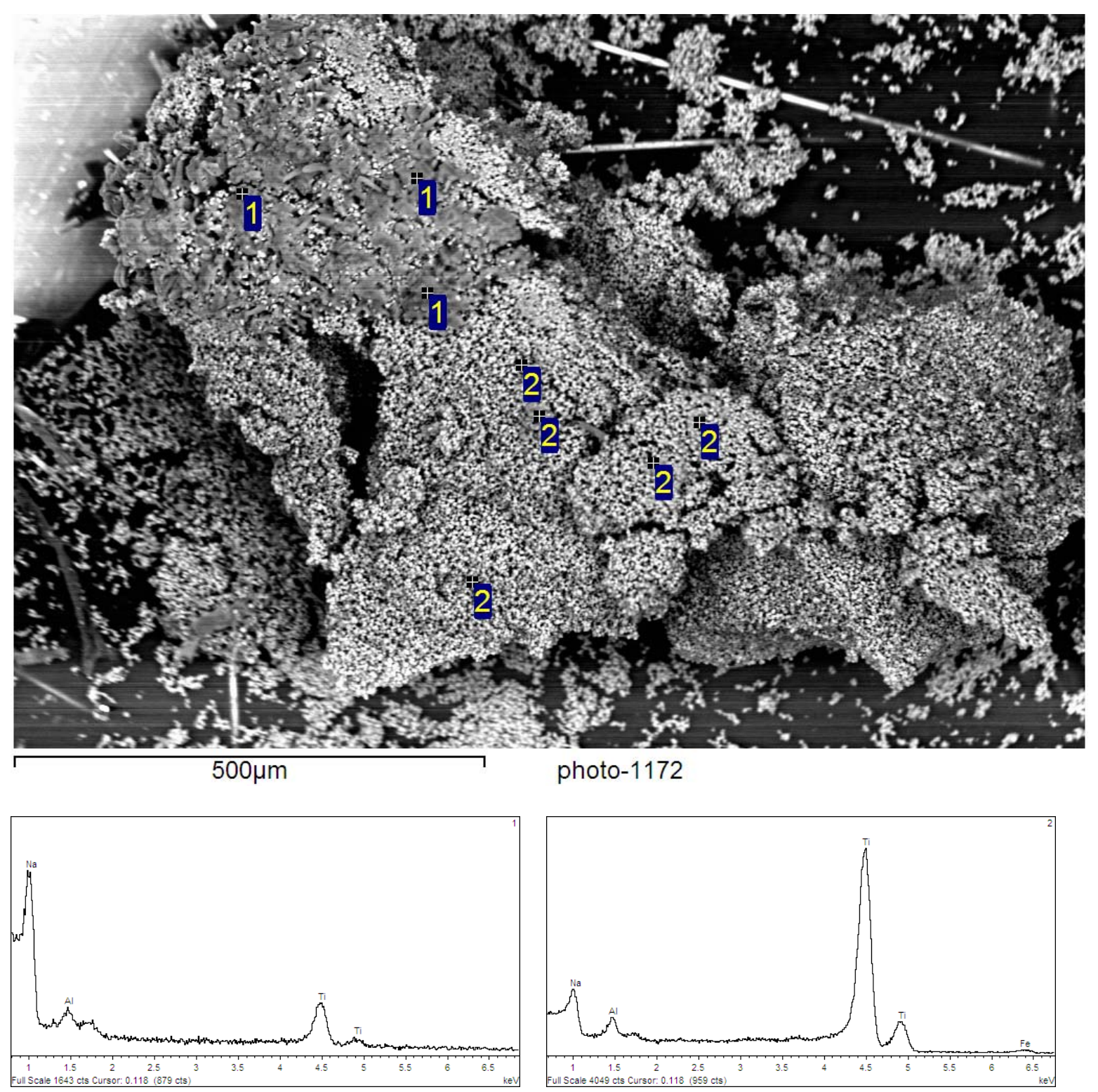

Figure C-7. SEM and EDS for LWPT-2 unwashed solids 

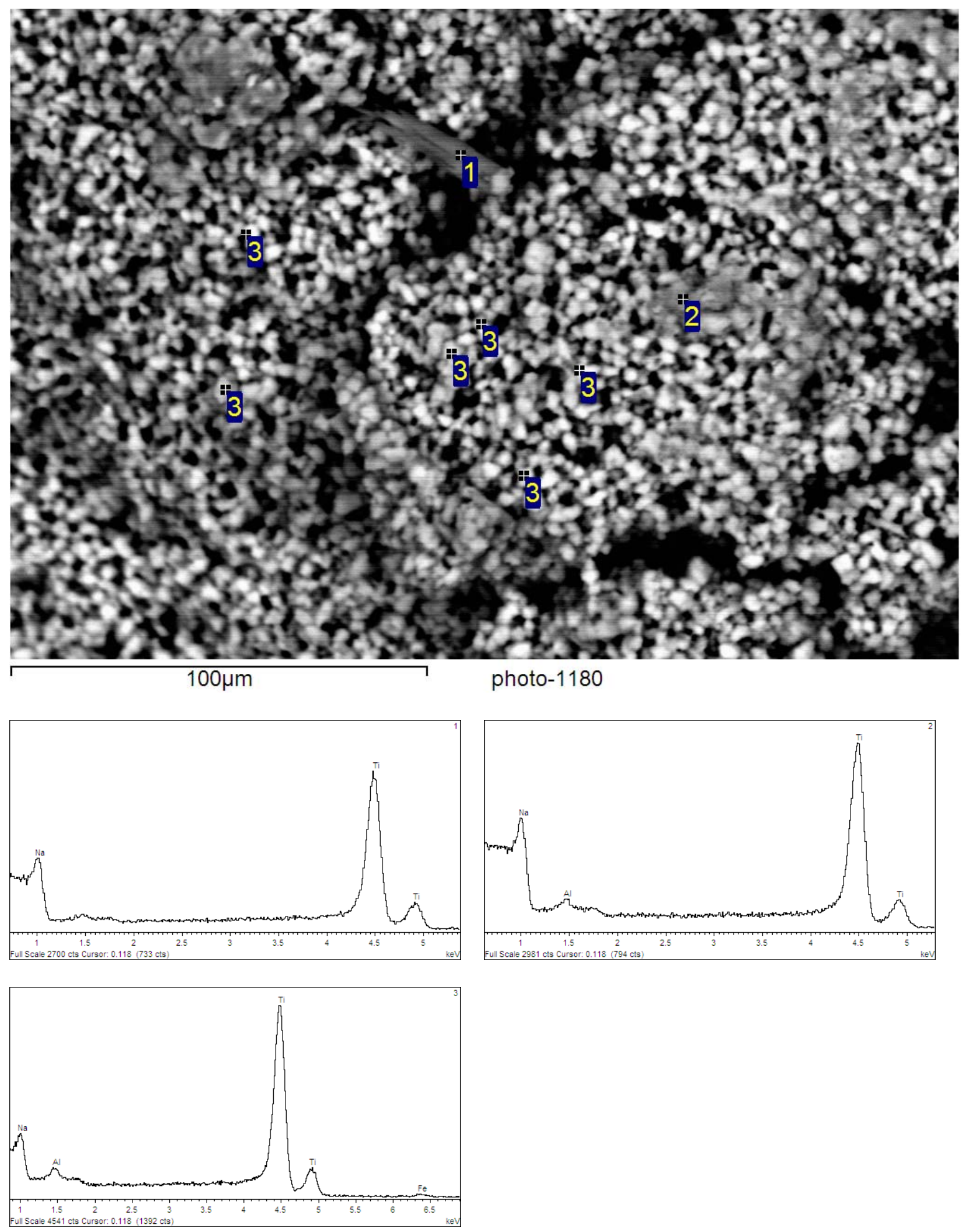

Figure C-8. SEM and EDS for LWPT-2 unwashed solids 
SRNL-STI-2013-00700

Revision 0

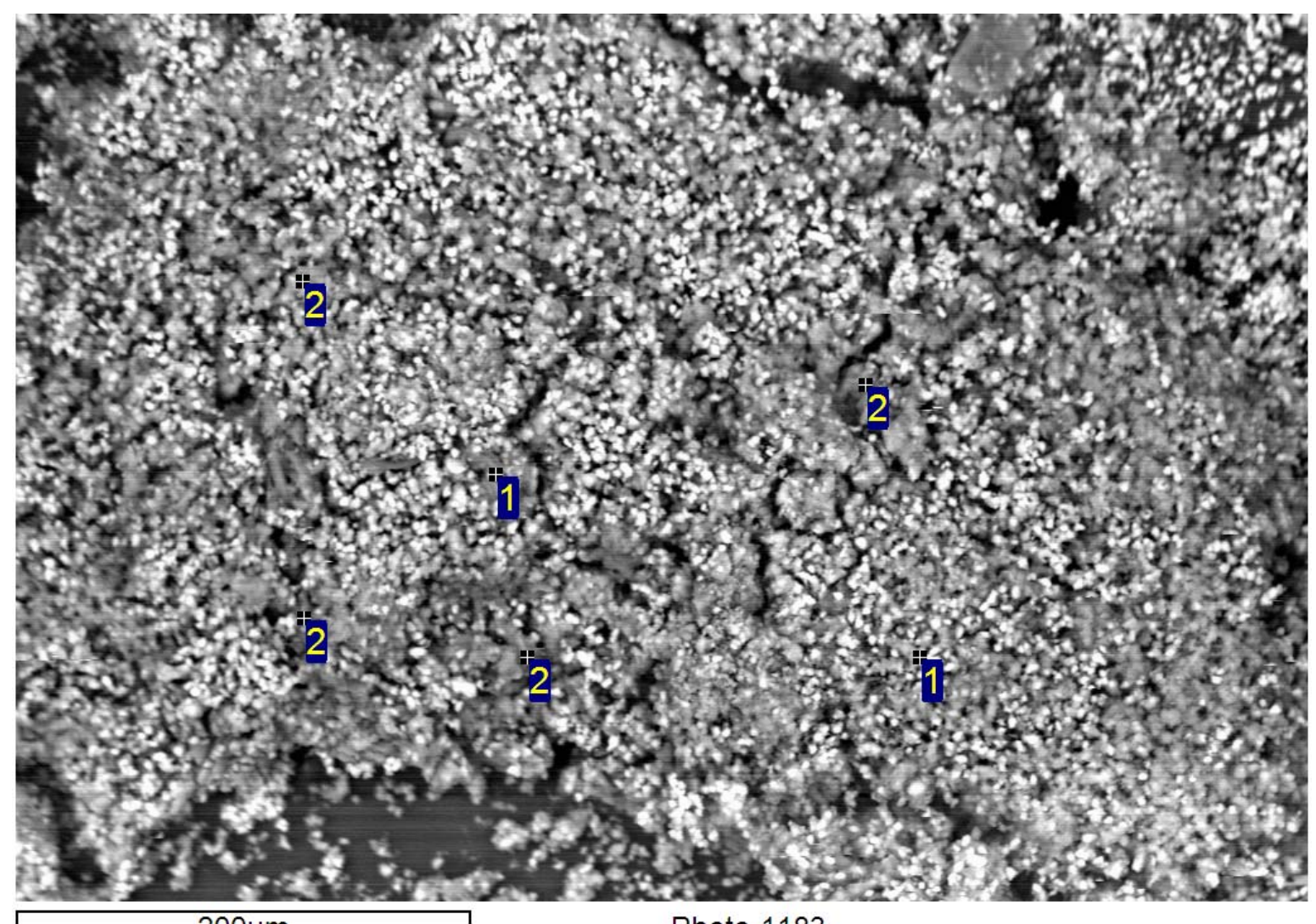

$200 \mu \mathrm{m}$

Photo-1183
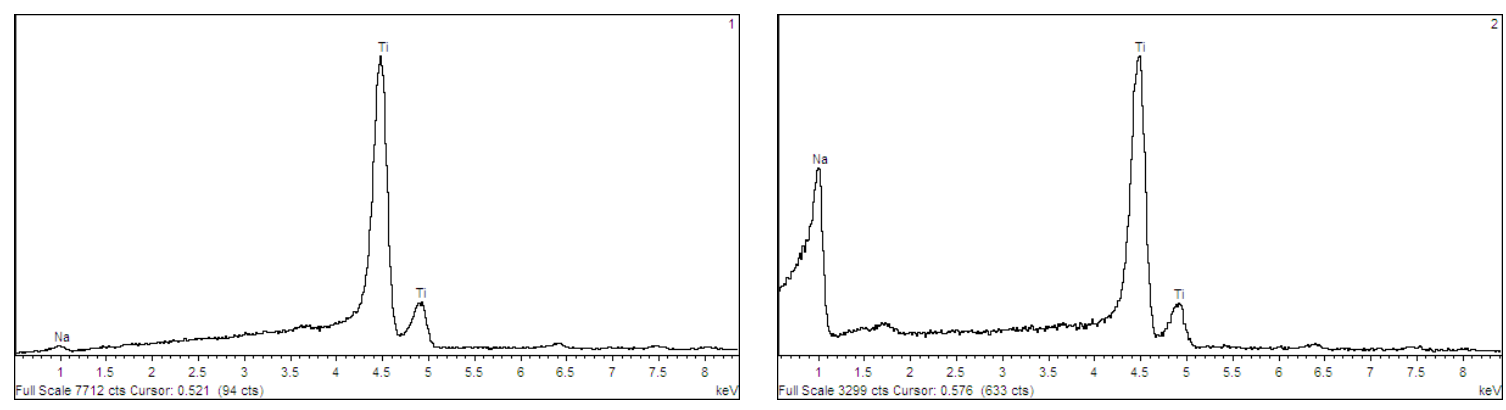

Figure C-9. SEM and EDS for LWPT-3 unwashed solids 
SRNL-STI-2013-00700

Revision 0
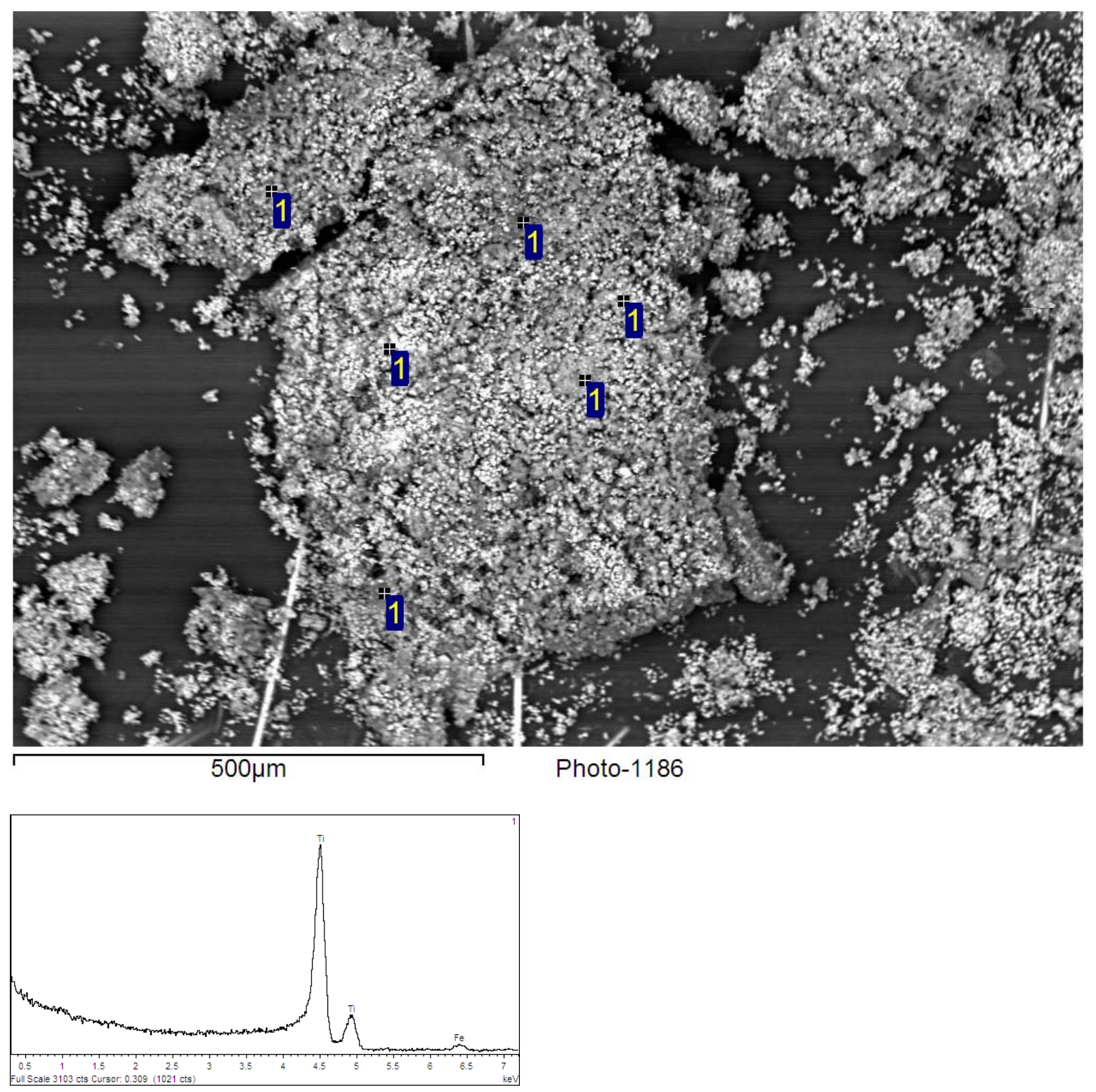

Figure C-10. SEM and EDS for LWPT-3 unwashed solids 
SRNL-STI-2013-00700

Revision 0
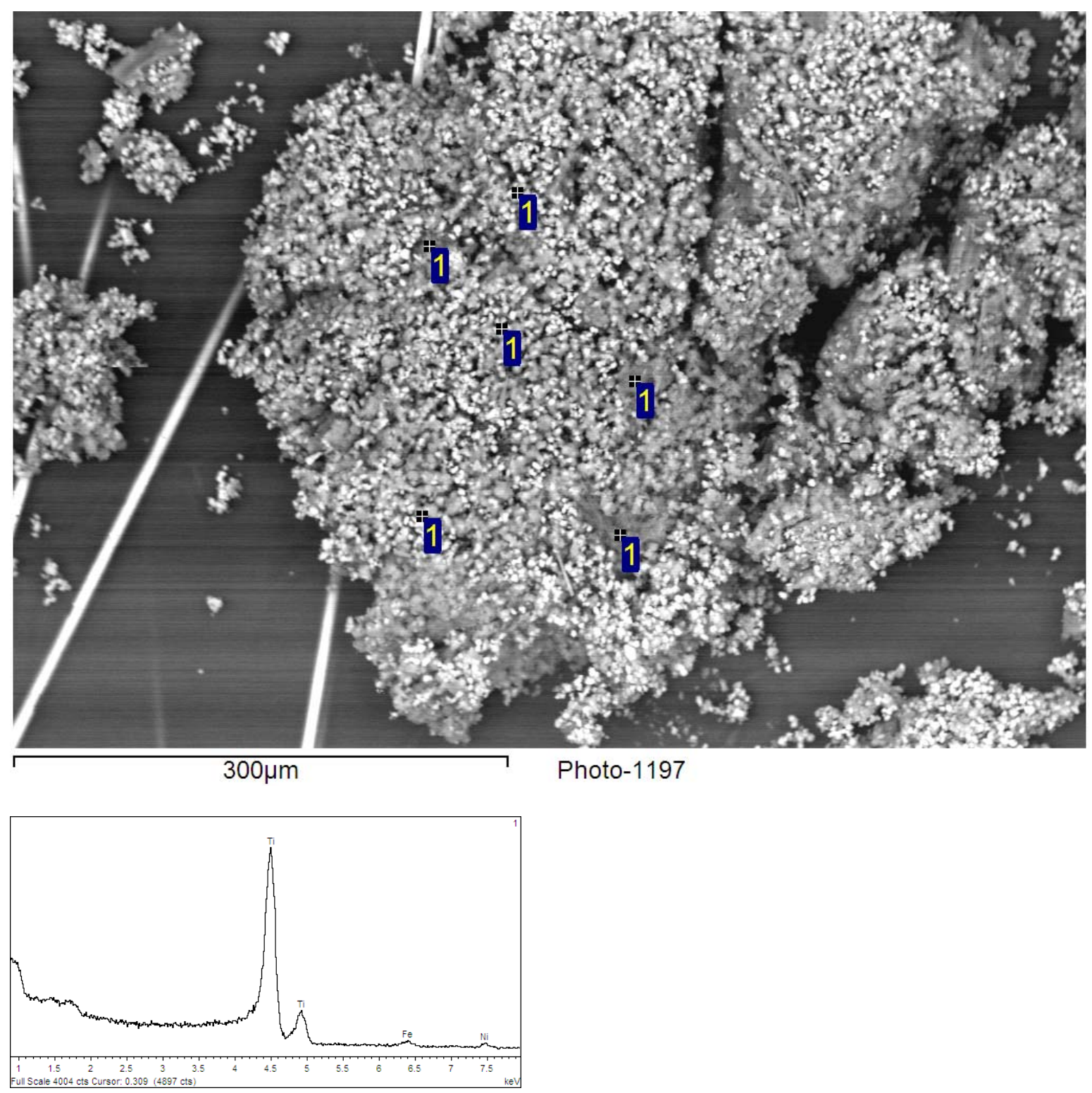

Figure C-11. SEM and EDS for LWPT-3 unwashed solids 

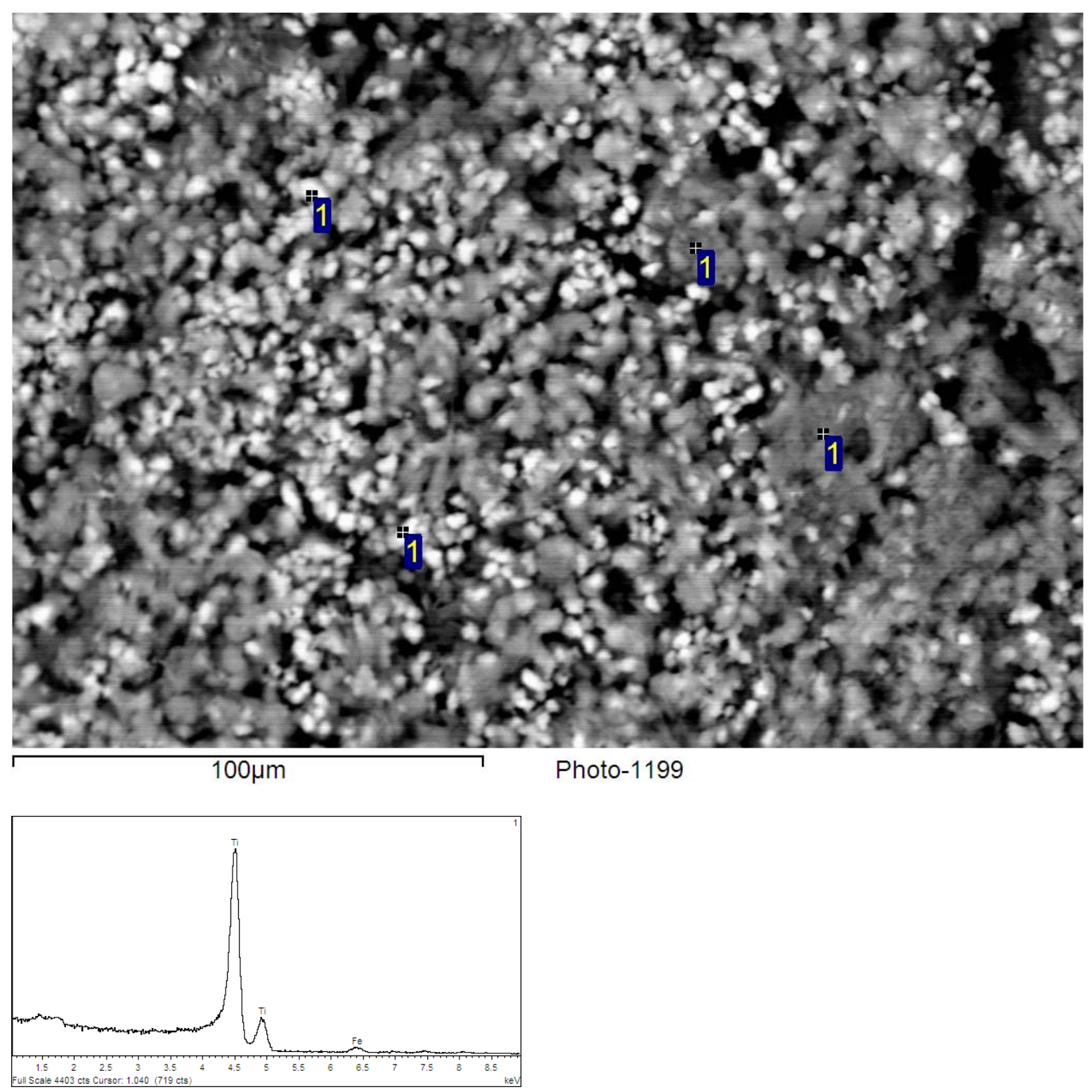

Figure C-12. SEM and EDS for LWPT-3 unwashed solids 
SRNL-STI-2013-00700

Revision 0

\section{Appendix D. Detailed Step-by-Step Process Description of ARP Process Cycle}

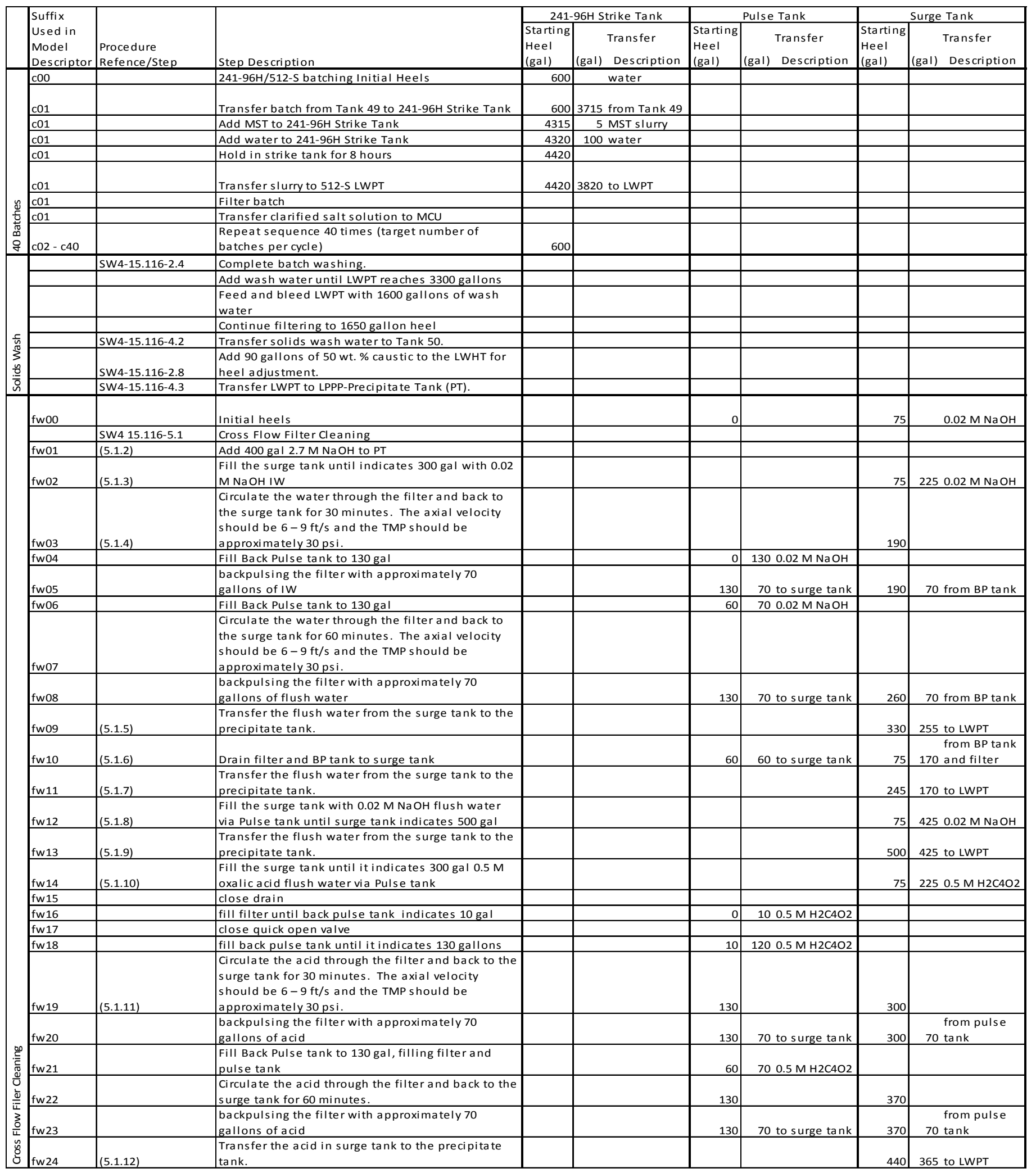


SRNL-STI-2013-00700

Revision 0

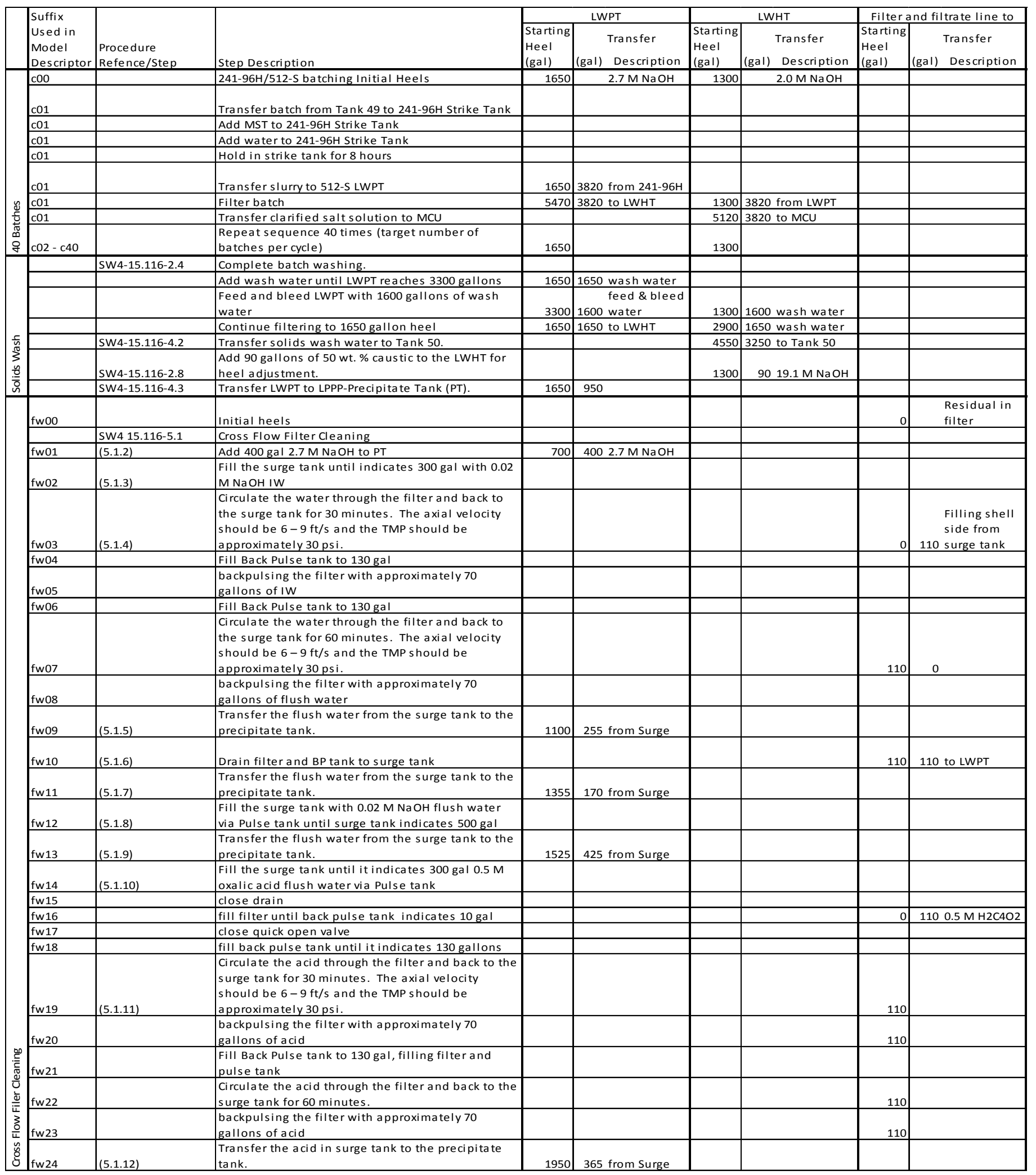


SRNL-STI-2013-00700

Revision 0

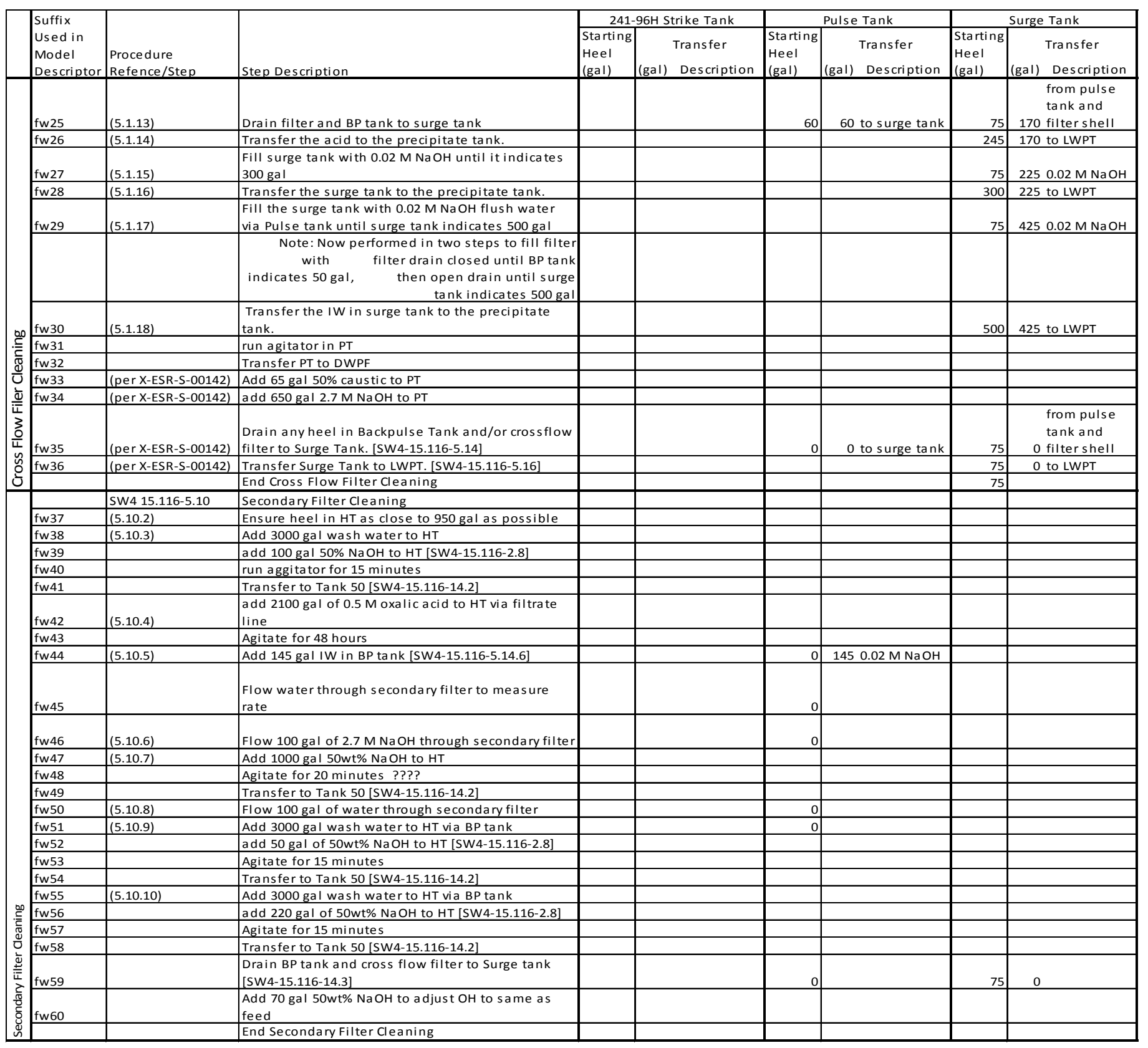


SRNL-STI-2013-00700

Revision 0

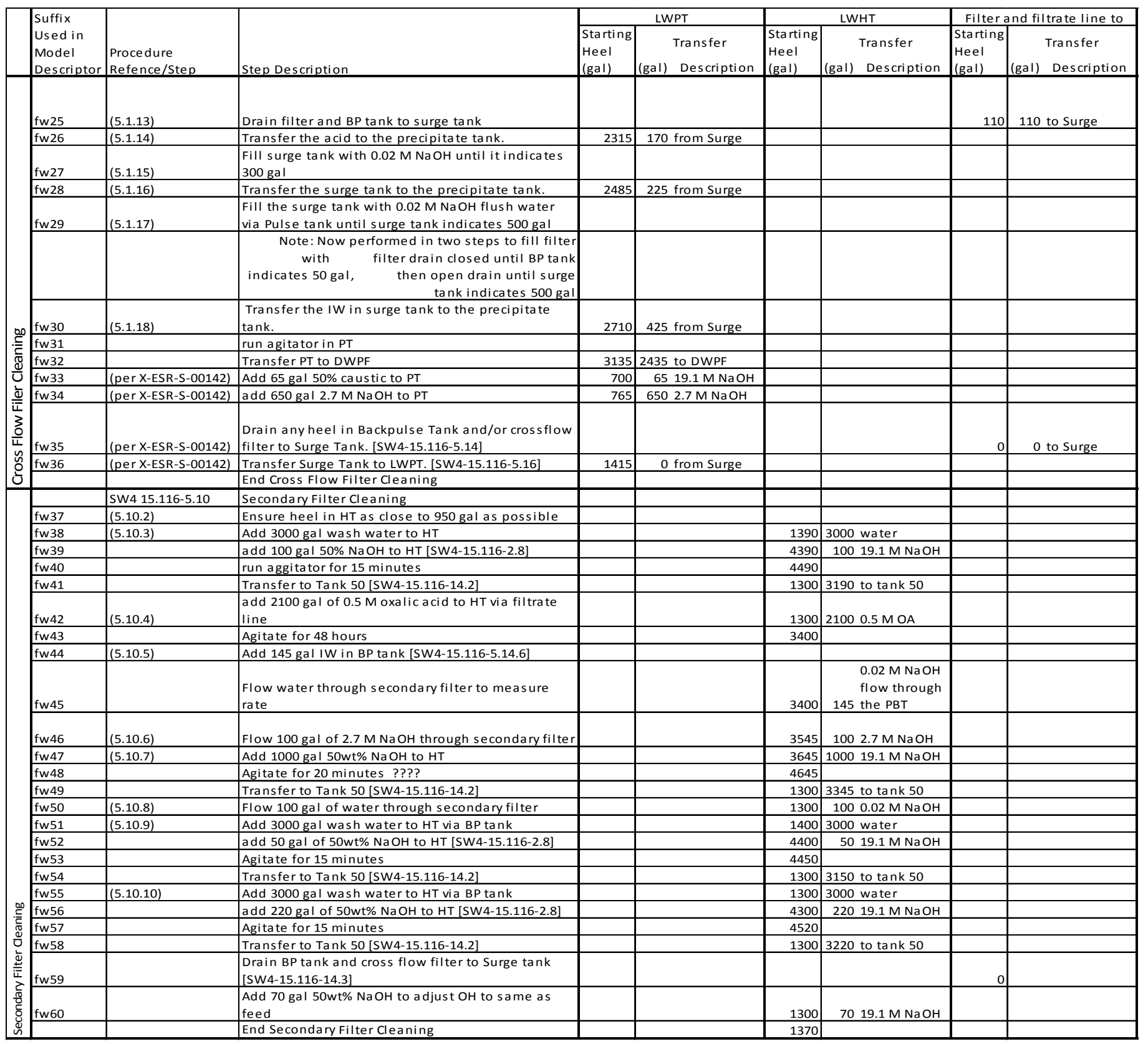


Appendix E. Diagram OLI ESPTM Simulation

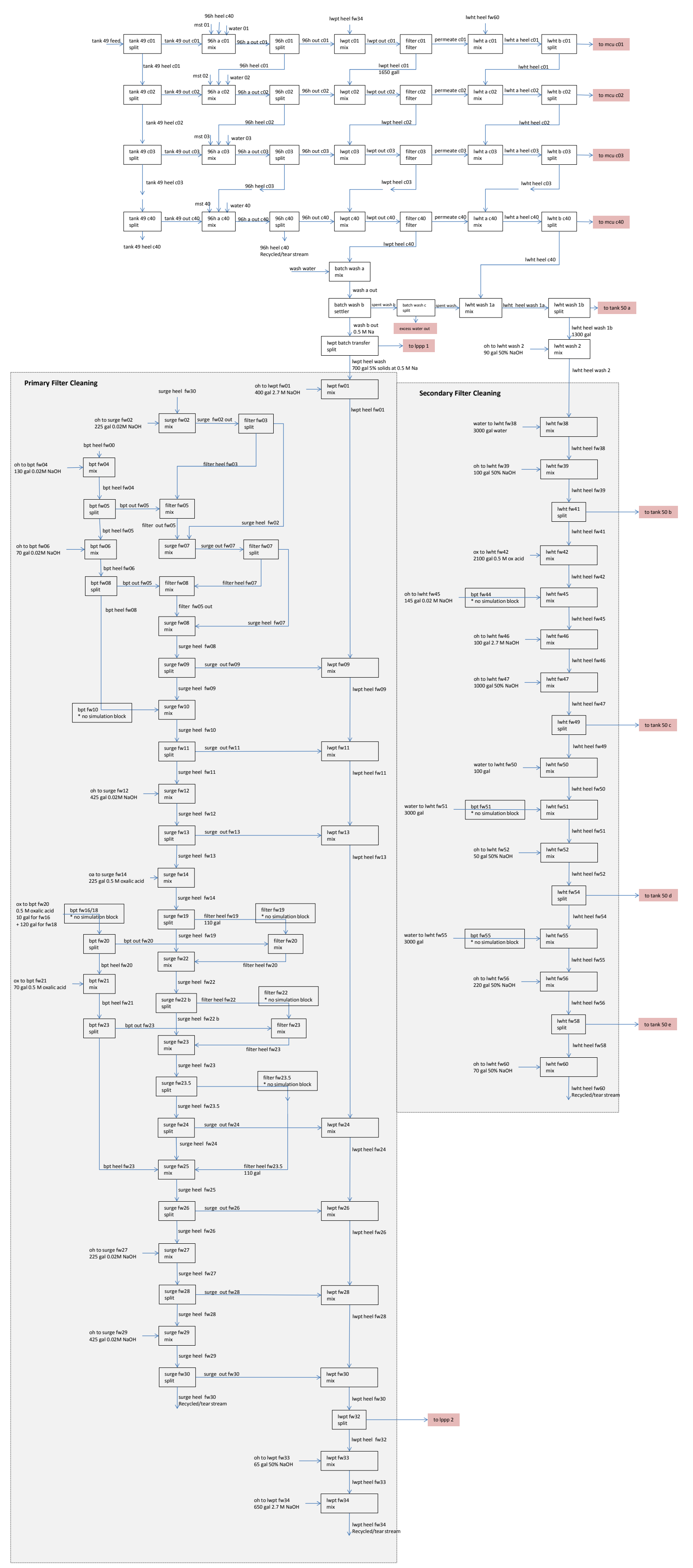

